University of Louisville

ThinkIR: The University of Louisville's Institutional Repository

Electronic Theses and Dissertations

$12-2005$

\title{
All-boy mathematics classes in middle school.
}

Amanda Neel Davis

University of Louisville

Follow this and additional works at: https://ir.library.louisville.edu/etd

\section{Recommended Citation}

Davis, Amanda Neel, "All-boy mathematics classes in middle school." (2005). Electronic Theses and Dissertations. Paper 317.

https://doi.org/10.18297/etd/317

This Doctoral Dissertation is brought to you for free and open access by ThinkIR: The University of Louisville's Institutional Repository. It has been accepted for inclusion in Electronic Theses and Dissertations by an authorized administrator of ThinkIR: The University of Louisville's Institutional Repository. This title appears here courtesy of the author, who has retained all other copyrights. For more information, please contact thinkir@louisville.edu. 


\title{
ALL-BOY MATHEMATICS CLASSES IN MIDDLE SCHOOL
}

\author{
By \\ Amanda Neel Davis \\ B.A., Hollins College \\ M.S., University of Alabama in Birmingham
}

\begin{abstract}
A Dissertation
Submitted to the Faculty of the Graduate School of the University of Louisville in Partial Fulfillment of the Requirements for the Degree of

Doctor of Philosophy

Department of Teaching and Learning College of Education and Human Development University of Louisville

Louisville, Kentucky
\end{abstract}

December 2005

Copyright 2005 by Amanda N. Davis

All rights reserved 


\title{
ALL-BOY MATHEMATICS CLASSES IN MIDDLE SCHOOL \\ By
}

\author{
Amanda Neel Davis \\ B.A., Hollins College \\ M.S., University of Alabama in Birmingham
}

A Dissertation Approved on

November 15, 2005

by the following dissertation committee

Dr. William S. Bush, Dissertation Director

Dissertation Committee:

Dr. Robert Felner

Dr. Joseph M. Petrosko

Dr. Robert N. Ronau

Dr. Charles S. Thompson 


\section{ACKNOWLEDGEMENTS}

I would like to thank my dissertation chair, Dr. William S. Bush, for his guidance and patience. I would like to thank the other committee members, Dr. Robert Felner, Dr. Joe Petrosko, Dr. Bob Ronau, and Dr. Chuck Thompson, for their comments and assistance. I would also like to thank my professor, Dr. Namok Choi, who taught me my first courses in educational research methodology. She introduced me to the engaging field of educational research and taught me well. Furthermore, she supported me and encouraged me in my first opportunities for my own work in the field. Lastly, I would like to thank my husband, Lant. B. Davis, for his understanding and patience, throughout my doctoral course work and the lengthy dissertation process. He was always there to encourage and listen. His comments were invaluable - those of a skilled, thoughtful, and self-effacing expert. His ears should have been “listened-out” long ago, but they never were, and he made me stick with it to the end. 
ABSTRACT

\section{ALL-BOY MATHEMATICS CLASSES IN MIDDLE SCHOOL}

Amanda N. Davis

December 15, 2005

A comparative case study focused on six mathematics teachers of all-boy classes in three middle schools. Each school chose to experiment with gendered classes to improve specific, yet somewhat different, outcomes. A purpose of this study was not to compare single-gender schooling with coeducation, but rather, to focus on each school's implementation process and to identify school and classroom factors that seemed to contribute to success of the single-gender program.

Another purpose was to examine mathematics teaching. Observational analysis used as a framework the Five Strands of Mathematics Proficiency. Related areas of inquiry were classroom time allocation, textbook selection and use, and mathematics beliefs. Results indicated many differences in the nature of the mathematics teaching for the six teachers of the study. Additionally, teacher use of a non-traditional textbook did not relate to non- traditional teacher practices.

Overall findings suggested one school to be more successful than the other two in implementing a single-gender program and in using the all-boy mathematics classes to improve student outcomes. Four school-level phenomena that seemed particularly important were as follows: the faculty "bought-in” to the belief that a single-gender 
program could improve learning for their students; teacher retention was high; teachers possessed a high sense of collective teacher efficacy; and the principal served effectively as an instructional leader. Additionally, the teacher participants at this school most frequently implemented strategies for boys and exhibited the most characteristics of teaching for mathematics proficiency.

In teaching all-boy mathematics classes, classroom management was a first priority. Secondly, teachers of the study found they could engage and motivate boys by using teaching strategies that work for boys and by building relationships with their students. Strategies identified in this study as being successful with boys included games and competition; drama and jokes; the scaffolding of lessons and tasks; and assistance in developing organizational skills. Once, classroom management structures were operational and boys were engaged, teachers reported that boys sustained their engagement in mathematics activities and problems. Thirty-one middle school boys were interviewed, and all reported that they enjoyed mathematics and perceived it as useful for current and future pursuits. 


\section{TABLE OF CONTENTS}

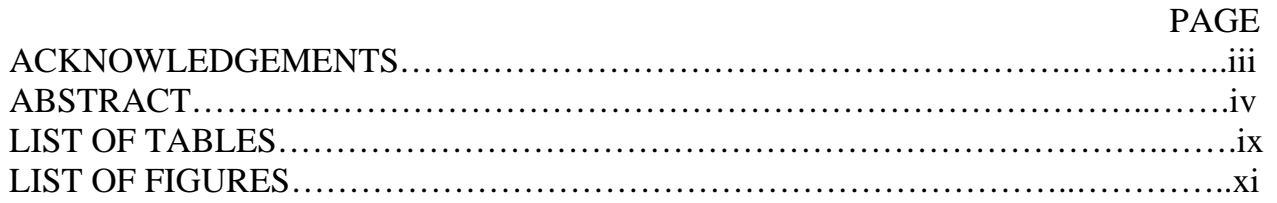

\section{CHAPTER}

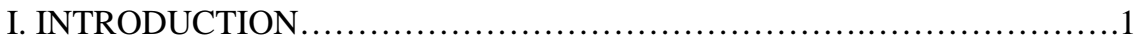

Educators Experiment with Single-Gender Schooling....................1

Mathematics, Middle School, and Boys..............................2

Purpose of the Study...............................................

Significance of the Study ........................................ 6

II. REVIEW OF LITERATURE.......................................... 8

Single-Gender Education.......................................... 8

Middle School Structures and Strategies.............................14

Effective Schools................................................26

Teaching and Learning Mathematics.................................41

Teaching and Learning of Boys...................................67

Conclusions and Implications.................................... 83 


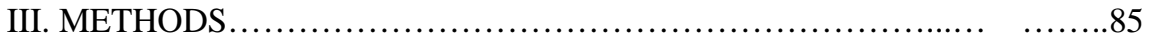

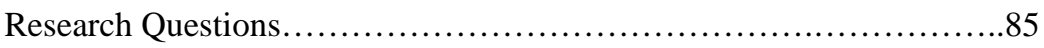

Design.........................................................93

Data Collection: Surveys..........................................97

Data Collection: Observations..........................................102

Data Collection: Interviews........................................106

Data Collection: Test Scores.....................................111

Data Analysis......................................................112

Summary: Collection and Analysis of Data.............................126

\section{RESULTS}

Terre Rouge, Greenville, and Bluefield.............................127

School Factors............................................................142

Middle School Structures and Strategies ..............................159

Strategies for Teaching Boys......................................184

Teacher Characteristics..............................................217

Mathematics Teaching and Learning.................................228

School Achievement Data.......................................267

V. SUMMARIES AND IMPLICATIONS.................................279

An Abbreviated Review of Literature...................................280

Research Questions..............................................285

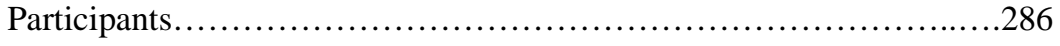

Question 1: School and District Factors.............................287

Question 2: Classroom Structures and Strategies....................292

Question 3: Teacher Characteristics................................303 
Question 4: Mathematics Teaching..............................308

Overall Findings.............................................316

Suggestions for Implementation of a Single-Gender Program...........326

Implications for Further Research..............................338

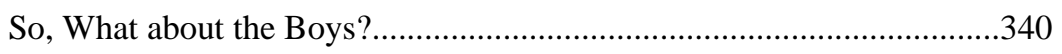

REFERENCES.........................................................

APPENDICES....................................................... 357

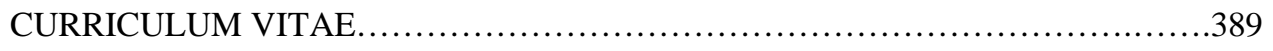




\section{LIST OF TABLES}

TABLE

PAGE

3-1. Timeline for the All-Boy Mathematics Class Study ..............................96

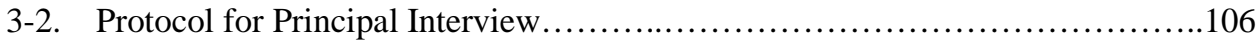

3-3. Protocol for the Mathematics Teacher Interview................................108

3-4. Protocol for Interview of Other Teachers.......................................109

3-5. Protocol for Student Interviews..........................................111

3-6. Mathematics Proficiency Framework for Observational Analysis..................124

4-1. Comparative Demographic Information .......................................138

4-2. Standardized Ratings for School Health.....................................144

4-3. Descriptive Statistics for School Health Factors..................................146

4-4. Descriptive Statistics for Collective Teacher Efficacy............................152

4-5. Comparative Effective School Ratings for the Schools of the Study..............153

4-6. Teacher/School Ratings on Middle School Reform Principles...................161

4-7. Summary of Classroom Management Characteristics............................170

4-8. Characteristics of Classroom Management by Teacher...........................181

4-9. Coded Instances for Boy Structures and Strategies............................186

4-10. Mathematics Teacher Efficacy: Total Scores..................................221

4-11. Mathematics Teacher Beliefs................................................224

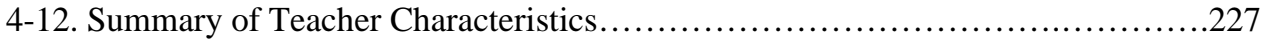

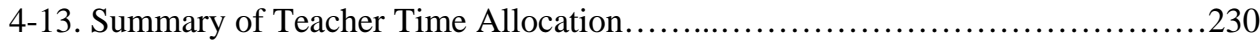

ix 
4-14. Framework of Mathematics Proficiency for Observation Analysis...............235

4-15. Teacher Total for Five Strands of Mathematics Proficiency.....................236

4-16. Beliefs and Practices for Mathematics Teachers............................238

4-17. Mathematics Teachers’ Beliefs, Practices, and Textbook Uses..................242

4-18. School Comparisons: $8^{\text {th }}$ Graders Testing at the Proficient (Passing) Level in Mathematics......................................................278

5-1. Overview of Schools...............................................287

5-2. Summary of School Factors with Descriptive Statistics......................289

5-3. Summary Information by Teacher of Structures and Strategies for Boys..........293

5-4. Coded Instances for Boy Structures and Strategies.........................301

5-5. Time Spent on Management vs. Boy Strategies.............................303

5-6. Summary of Teacher Characteristics...................................304

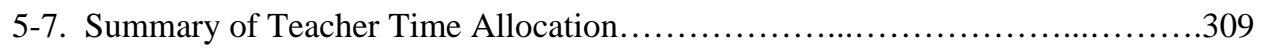

5-8 Framework of Mathematics Proficiency for Observational Analysis...............311

5-9. Teacher Totals for the Five Strands of Mathematics Proficiency.................312

5-10. Mathematics Teachers’ Practices, Beliefs, and Textbook Uses..................315 


\section{LIST OF FIGURES}

FIGURE

PAGE

2-1. The instructional triangle.................................................48

3-1. Diagram of Levels for Data Collection and Analysis...........................126

4-1. School Comparisons for Organizational Health Factors...........................145

4-2. Terre Rouge: Percent of Students Scoring Apprentice or Above...................269

4-3. Terre Rouge: Percent of Students Scoring Proficient or Above...................270

4-4. Terre Rouge: Comparative Scores for Boys on Dreambuilders Team..............271

4-5. Terre Rouge: $6^{\text {th }}$-Grade Scores on Norm-Referenced Test .....................272

4-6. Greenville: Percent of Students Passing All Classes (current $8^{\text {th }}$ grade)............273

4-7. Greenville: Percent of Students Passing All Classes (current $7^{\text {th }}$ grade)..........273

4-8. Greenville: Pass Rates for State Accountability Assessment....................274

4-9. Bluefield: Percent of Students Scoring Apprentice or Above.......................276

4-10. Bluefield: Percent of Students Scoring Proficient or Above.....................276

4-11. Bluefield: Percentile Ranks on the Norm-Referenced Test.......................277

4-12. School Comparisons: $8^{\text {th }}$ Graders at Proficient (or Passing) Level.................277

5-1. Scatterplot for Time on Management vs. Boy Strategies.........................303

5-2. All-Boy Mathematics Classes in Middle School: Diagram of Study Results.......318

5-3. Rashad McCants hugs Roy Williams after the 2005 NCAA Championship.........343 


\section{CHAPTER I}

\section{INTRODUCTION}

Educators Experiment with Single-Gender Schooling

In recent years, standardized testing has increased the visibility of achievement gaps by socioeconomic status, gender, and race in public education. To address low achievement and other issues among particular groups, public school educators began to reconsider single-gender education and to experiment with single-gender classes and other forms of single-gender schooling. In 1991, the Detroit School Board, motivated by concern about dropout, failure, and retention rates for African-American males, approved the establishment of three all-male academies. These academies were to offer special programs, including an Afro-centric curriculum, community mentors, and "rites of passage” units. In 1996, The Young Women’s Leadership School of East Harlem (TYWLS) was founded in New York City for minority and poor girls who were not being well-served by the school system. Groups such as the American Civil Liberties Union (ACLU) and the National Organization for Women obstructed these first single-gender experiments with legal challenges, basing claims on Title IX, the 1972 landmark law banning gender-based discrimination in education. Nevertheless, interest in singlegender education in the public sector has continued to grow. There are now over 100 public schools in the U.S. which offer single-gender options, up from four schools in 1996 (Murray, 2003). 
Single-gender education in public schools is still a new area of inquiry in educational research. A study of single-gender science and mathematics classes in an Arizona middle school reported that the single-gender classes were beneficial only for girls and that disruptive and off-task behavior made all-boy classes difficult for teachers (Baker, 2002). Another team of researchers studied a California middle school and also found benefits only for the girls (Herr \& Arms, 2002). Furthermore, in both studies teachers reported that their schools provided little preparation and no time for faculty collaboration. In both cases, investigators suggested that educators missed opportunities to improve education for both genders (Baker, 2002; Herr \& Arms, 2002).

Mathematics, Middle School, and Boys

\section{Mathematics as a "Gatekeeper"}

Mathematics achievement in middle school is a strong predictor for a student's academic future. A U.S. Department of Education report (Riley, 1997) recommended an advanced mathematics curriculum in secondary school as a "gateway" for future academic success and suggested that the study of high school algebra in $8^{\text {th }}$ grade frequently served as a "gatekeeper" for advanced courses in mathematics and science in high school. Students who take advanced mathematics courses in middle school are more likely to enroll in advanced mathematics and science courses in high school. Despite the importance of advanced mathematics courses for low-income students, they are much less likely to take these courses (Riley, 1997).

\section{Mathematics Reform}

According to the Third International Mathematics and Science Study (TIMSS, 1995), our nation's $7^{\text {th }}$ and $8^{\text {th }}$ graders perform well below average in mathematics achievement when compared with students from other industrialized nations (Silver, 
1998). Even before TIMSS, a U.S. reform movement resulted from the widespread belief that students were not learning the mathematics they needed to know or were expected to learn (NCTM, 1989; NCTM 2000; Ball, Lubienski, \& Mewborn, 2001). To adapt to a rapidly changing and high-tech world, educators and business leaders agreed that American students needed to understand and do mathematics for real life situations, as well as the workplace. Additional reform recommendations from researchers and mathematics educators included adoption of national standards about what students need to know; replacement of superficial curriculum with materials that teach challenging concepts; and continuing efforts to deepen teacher knowledge of mathematics and of how to teach it effectively (Bandlow, 2001).

Related research indicated that this lack of knowledge may have resulted from the ways mathematics was taught - not as a body of knowledge that was to be understood, but as a set of procedures and skills to be learned by rote. To address concerns, the National Council for the Teachers of Mathematics (NCTM) published Curriculum and Evaluation Standards for School Mathematics (1989), which marked beginnings of a standards-based reform movement. Subsequent research suggested that when standardsbased reform was fully and correctly implemented and possessed all of its intended characteristics, student learning was enhanced (Ross, McDougall, \& Hogaboam-Gray, 2002).

Middle School Reform

Middle school reform movements of the 1990's grew out of a belief among educators, researchers, and psychologists that middle schools should not be "junior" high schools but should employ significantly different models more appropriate for early adolescents’ stages of development. Middle school reform principles recommended 
structures such as interdisciplinary teaming, organized teacher mentoring, and heterogeneous groupings (Hoy \& Hannum, 1997; Beane \& Brodhagen, 2001). Because a strong relationship exists between classroom behavior and academic performance in middle school, research suggests that proactive strategies in management be implemented: predictable daily routines; rules that are clear, specific, and consistently enforced; affirmation of positive behaviors; and the provision of appropriate choices to replace negative behaviors (Hester, Gable, \& Manning, 2003). Classroom structure and behavior management seemed to be particularly important for middle school boys (Hudley, 1998; Woody, 2002; Davis, et al., 2004).

What about the Boys?

Before the late 1990's, efforts in education focused on the issues of girls, and educators and parents overlooked boys’ academic problems (Pollack, 1998). However, more current achievement data has revealed a widening gap in favor of girls in the United Kingdom, Australia, and the U. S., most particularly among working class, poor, and minority youth (Foster, Kimmel, \& Skelton, 2001). A robust accumulation of U. S. data indicated that the K-12 public education system might not be meeting the needs of many boys. Girls made $60 \%$ of the A's in secondary school, whereas boys made $70 \%$ of the F's. Boys were suspended more than girls by a ratio of almost 3 to 1, and by high school, two-thirds of all the students placed in special education were boys. Boys were diagnosed with Attention Deficit Disorder(ADD) and Attention Deficit Hyperactivity Disorder (ADHD) and dropped out of high school at much higher rates than girls (Pollack, 1998). Twenty years ago, more boys than girls attended college, whereas today, not only do fewer boys than girls attend college but fewer boys now graduate as well (Newcomb, 2000; Sommers, 2000). 


\section{Purpose of the Study}

The purpose of this dissertation study was to conduct investigations of middle schools experimenting with single-gender classes to improve outcomes, focusing on allboy mathematics classes. Examinations of relationships among school factors, teacher factors, observed structures and strategies, and the teaching and learning of mathematics provided details as well as overarching findings and conclusions. Before conducting the current study, I concluded, as had other researchers (AAUW, 1998; Mael, 1998), that general comparisons between single-gender and coeducation were problematic. The myriad of educational contexts, purposes, and venues (public, private, religious, preparatory, elementary, or secondary) produced confounding background factors and conflicting results. Thus, for my dissertation, I decided against forms of the question, "Is single-gender education more effective than coeducation?” and focused on factors that might affect implementation of a single-gender class program, most particularly the allboy mathematics classes.

School factors can have a significant effect on the quality of education therein; research indicates that two schools with similar demographics can have disparate outcomes (Good \& Brophy, 1986; Marzano, 2003). Other studies suggest that a teacher’s gender and ethnicity may be a key factor in all-boy classes (Hudley; 1998; Hansen, 2002; Weaver-Hightower, 2003). Research studies of single-gender experiments have found that the "how" matters greatly - that the structures and strategies that teachers use may be particularly relevant for males (Hudley, 1997; Noble \& Bradford, 2000; Herr\& Arms, 2002; Woody, 2002). Effective teaching has significant impact on student outcomes (Marzano, 2003), and research in mathematics education reveals that that conceptual and contextual teaching strategies - engaging students in mathematical discourse; connecting 
with prior knowledge; using a variety of representations (e.g. concrete materials, words, pictures, symbols); considering multiple problem solving strategies - relate to better student learning of mathematics ( NCTM, 1989; NCTM, 2000; Cohen \& Ball, 2000; Kilpatrick, Swafford, \& Findell, 2001).

Significance of the Study

New information is needed in the areas of single-gender education, middle schools, mathematics teaching and learning, and schooling for boys and the need to provide assistance to school leaders and teachers in their efforts to improve student outcomes. A study of single-gender education is timely and because of 2004 legislation relaxing Title IX restrictions on separating males and females for educational purposes. The lifting of certain restrictions provided educators the most freedom they've had in 30 years to teach boys and girls separately. Proponents of the change envisioned this move as a means for schools and school systems to respond to the unique needs of their students.

A study focusing on boys is significant for two main reasons. First of all, previous research on gender issues in education has centered itself almost exclusively on girls (AAUW, 1998; Mael, 1998). Research frequently has tended to overlook the needs of boys(Pollack, 1999), and until recently, there have been very few studies about schooling from a boys' perspective. Secondly, there is a need to study boys because of recent information provided by schools and outcome statistics indicating that U.S. public schools may not be meeting needs for large segments of the male population. In his 2003 article in Review of Educational Research, Marcus Weaver-Hightower includes this dearth of knowledge, as well as the emergent awareness of boys' needs, among reasons for a researchers' shift of focus that he refers to as the "boy turn.” Predictors of the "boy 
turn” include popular books about boys by psychologists such as Gurian and Pollack; changes in gender roles and changes in the work force; and claims that girls were surpassing boys academically (Weaver-Hightower, 2003).

This "thrill of the new" is engaging to educational researchers, and investigators studying boys and girls found that boys' responses to their questions were unexpected, whereas they could find very little new to say about those of girls (Yates, 2000). My interest in an all-boy mathematics study arose from findings of a previous study that were "novel” and "unexpected.” In contrast with previous studies that suggested benefits of single-gender classes only for girls (Baker, 2002; Herr \& Arms, 2002), I investigated teachers who felt that single-gender classes were improving outcomes in their all-boy classes. A team of teachers leading a team of $7^{\text {th }}$-grade boys in a low-scoring, urban middle school attributed realized achievement gains among their students to cohesive team leadership, and increased support for individual learners (Davis, Choi, Ronau, \& Muñoz, 2004). This current study probes deeply into details of all-boys mathematics classes and demonstrates that single-gender classes may offer middle school boys increased opportunities for learning mathematics if teachers and schools do things differently. Perhaps all-boy classes can serve as nurturing educational environments; and perhaps these environments can improve educational outcomes for boys now at risk of failing, dropping out of school, or of encountering closed doors in higher education and beyond. 


\section{CHAPTER II}

\section{REVIEW OF LITERATURE}

The purpose of this dissertation study was to conduct investigations of middle schools experimenting with single-gender classes to improve outcomes, focusing on allboy mathematics classes. A broad range of factors present in a school can affect implementation of an educational change, such as the change to single-gender classes: school and district factors; teacher and classroom factors; and the way mathematics is taught. Hence, the following review of the research literature examines a broad range of topics, such as single-gender education, middle school reform, effective schools, strategies for teaching boys, and mathematics education research. Study results then demonstrate how these seemingly distinct topics connect as they affect the complex processes of teaching early adolescents in public schools.

Single-Gender Education

\section{History of Single-gender Education}

In his book, Girls and Boys in School: Together or Separate? (1990), Cornelius Riordan makes the point that, in public education, coeducation may have been chosen over single-gender for convenience and economic reasons and not because of its superior quality. As “mass-education” began, in the early part of the $20^{\text {th }}$ Century, adolescents in cities were no longer used as workers and the main work location shifted from the home to the office or factory, and there were few single-gender schools in the public sector. Three exceptions to this rule in urban education were Philadelphia’s Central High School 
for Boys, its High School for Girls and Baltimore’s Western High School for Girls. All three schools have survived academic and cultural change and remain high-quality academic institutions today. The two girls' schools boast alumnae who were "first women” or “first African-American women” in many fields (Salomone, 2003).

With 1972 passage of Title IX legislation, which banned gender discrimination in federally funded education, single-gender schooling in both the public and private sector became problematic resulting in a decline in the number of single-gender schools began to decline (Salomone, 2003). However, in the early nineties, evidence emerged suggesting that public schools might be failing girls in issues of fairness and equality of learning opportunities, most particularly in science and mathematics. In 1992, the American Association of University Women (AAUW) published a report indicating girls began to fall behind in achievement test scores and to show less interest in mathematics and science in the middle grades. Another study (Sadker \& Sadker, 1994) found that teachers called on boys more frequently and that boys received more of the teacher's attention. Furthermore, boys tended to monopolize classroom educational technology (Sadker \& Sadker, 1994). These concerns raised questions about whether equity of programming always produced equitable outcomes and whether single-gender schooling should be an option in public education.

Single-gender Experiments in the Public Schools

In addition to concerns about equity issues, widespread standardized testing in public education raised concerns of low performance for the urban poor and achievement gaps by gender and ethnicity. These two concerns, along with others, renewed interest in single-gender education and prompted inquiries into the benefits of teaching boys and girls separately. 
In 1997, the AAUW sponsored a conference "Separated by Sex” to take a critical look at single-gender education for girls. A report from that conference (AAUW, 1998) presented a review of the literature with inconclusive results. Whereas girls may develop more self-confidence, academic achievement had not shown statistically significant gains in the single-gender classroom (AAUW, 1998). The report further suggested that single-gender education is not always better or worse than coeducation. Success of single-gender education depends on the group of students, the setting, as well as the institution's academic and social objectives. Results were also confounded by the majority of the studies reviewed concerned single-gender education in the private sector (AAUW, 1998)

Single-gender experiments for the urban poor. Beginning in the early 1990’s, educators began to contemplate single-gender academies to improve outcomes for poor and minority youth who were not being well-served by their school systems. In 1991, the Detroit School Board, motivated by concern about dropout, failure, and retention rates for African-American males, approved the establishment of three all-male academies. These academies were to offer special programs, including an Afro-centric curriculum, community mentors, "rites of passage” units, and uniforms, and a similar program was also proposed for Milwaukee. Basing claims on Title IX, the 1972 landmark law banning gender-based discrimination in education, opposing groups such as the American Civil Liberties Union (ACLU) and the National Organization for Women encouraged parents of urban girls to file lawsuits contesting the all-male requirement and demanding that the proposed academies in both Detroit and Milwaukee admit a certain portion of female students (Salomone, 2003). 
In New York City, philanthropist and journalist Ann Tisch joined with the public schools to found the Young Women's Leadership School of East Harlem (TYWLS). TWYLS faced similar legal challenges, but when no law suits to admit males arose, the school opened the in the fall of 1996 with an all-girl student body of $7^{\text {th }}$ and $8^{\text {th }}$ grade students. In subsequent years, TYWLS added grades and the first class of 32 young women, including 31 college attendees, graduated from high school in 2001. Girls from the surrounding neighborhood receive priority treatment for admission, and the school's population is approximately 5\% Caucasian, 40\% African-American, 54\% Hispanic, and 1\% Asian. A website for information about New York City schools reports that TYWLS has gained a reputation as a serious, academically challenging school for girls who feel that they can achieve more without distraction and competition from boys.

California experiments. In 1996, California governor Pete Wilson, as a means of broadening educational choices in the public school system, promoted and implemented legislation which offered grants of $\$ 500,000$ per year to school districts for the establishment of single-gender academies. In 1997, 12 academies were funded, six for girls and six for boys. In a study that included participants from these California academies (Datnow, Hubbard, and Conchas, 2001), researchers interviewed over 200 teachers and students and found that the great majority of teachers did not tailor instruction to particular groups. Although several teachers reported selecting different reading materials for boys and girls, few curricular and teaching modifications resulted from the separation of girls and boys.

For the girls' classes, things went smoothly, but many teachers said, "What are we going to do about the boys?" A few teachers used an authoritarian "boot camp” type discipline structure, with physical punishments such as doing push-ups and running laps 
(Woody, 2002). Gender equity issues, stated as the original purpose for the establishment of the academies, received little or no inquiry. In the end, the politics surrounding the legislation and the lack of district support caused five of the six pairs of California singlegender academies to close by the fall of 2000 (Datnow, Hubbard, and Conchas, 2001). Students at the remaining San Francisco 49ers academies in East Palo Alto have not only improved their grades and behavior but were also reported less likely to drop out of high school (Ritsch, 2002).

Other researchers (Herr and Arms, 2002) studied an urban middle school in which both boys and girls were in the same building but separated for all of the core classes.

The school of this study was not one of the six pairs of single-gender academies receiving extra funding from the state. Researchers reported that the single-gender classes worked better for the girls and that discipline and classroom behavior were problems with allmale classrooms. Although there were some achievement gains, researchers reflected on educators' missed opportunities in that teachers were not changing their pedagogy in terms of gender equity nor meeting specific needs of both genders (Herr \& Arms, 2002).

A recent newspaper article spoke of successes at Jefferson Leadership Academy in Long Beach, California (Ritsch, 2002) Jefferson was a public middle school which split into single-gender academies soon after the state funded the other academies. Following the change to single-gender academies, the school's test scores have improved $16 \%$, whereas pinpointing particular reasons for the gains has been difficult. The student scores still fall below the state average, yet the academies rank higher than other urban schools with similar demographics (Ritsch, 2002). Teachers at Jefferson make small adjustments for the differences they perceive in boys' and girls' development, learning styles, and interests. 
Middle school experiments. In an urban middle school with a high minority population, researchers studied, through interviews and observation, single-gender mathematics and science classes of $7^{\text {th }}$ graders and reported positive findings only for the girls (Baker, 2002). Teachers found the girls more enjoyable to teach, recalled fewer discipline problems, and reported that students in the all-girl classes worked together well in groups and exhibited better participation in all-class discussions. Just as in the studies of the California state-funded academies, the teachers confused equality with equity, not recognizing that equity is often best achieved by customizing instruction to meet the learning needs of different students (Baker, 2002).

In contrast, two investigations found single-gender classes to be beneficial for boys. Hudley (1998) studied a self-contained classroom of African-American male adolescents, taught by an African-American male teacher. Results suggested strict adherence to classroom discipline policies, strong positive relationships among students and teachers, high levels of teacher support, positive academic, and better task orientation (Hudley, 1998). In the second study of a single-gender experiment in a traditionally lowscoring middle school, researchers noted test score increases in all subject areas for a team of $7^{\text {th }}$ grade boys, taught by an interdisciplinary team of teachers. Interviews of the teachers and students suggested that cooperative leadership, the all-boy team environment, a well-implemented behavior management system, teacher mentoring, and strategies addressing specific learning needs of young adolescent males may have contributed to test score increases (Davis, Choi, Ronau, \& Munoz, 2004).

Middle School Structures and Strategies

Junior high schools arose in the early part of the $20^{\text {th }}$ Century, when elementary schools became overcrowded. The popularity of middle-level schools increased in the 
1960’s as the baby-boomer children began to reach early adolescence (Beane \& Brodhagen, 2001). Junior high schools, however were generally structured as high schools causing a misalignment with the elementary school environment and making transitions difficult. Junior high schools were perceived by parents, educators, and psychologists as alienating and impersonal places, and reports calling for the reform of schooling for young adolescents began to appear in the mid-1970’s (Anfara \& Brown, 2000).

Two reports, the Carnegie Council’s Turning Points: Preparing American Youth for the $21^{\text {st }}$ Century (1989) and the National Middle School Association's, This We Believe (1995) initiated prominent and widespread efforts for middle school reform. Both documents recommended heterogeneous grouping and better communications between school and the larger school community. The following educator expectations of the middle school reform movement are common to both reports: knowledge of adolescent development; participation in collegial teaming; advising and mentorship of students; a variety of teaching and learning activities; and use of curriculum approaches beyond the traditional separate subject approach (Beane \& Brodhagen, 2001).

\section{Teaching Young Adolescents}

Many middle school teachers are either trained as elementary school or high school teachers and possess misunderstandings about middle school students’ learning characteristics (Beane \& Brodhagen, 2001). Teachers may observe, in their middle school students, a lack of motivation, disengagement from school and school activities, a loss of self-esteem, and a sense of boredom. Teachers frequently misinterpret these characteristics as signifying a lack of ability (Gentry, Gable, \& Rizza, 2002) Young adolescents seek more independence in making choices, but also need closer relationships 
with adults other than parents. They become more concerned with peer relationships, and more frequently engage in self-assessments based on social comparisons. Most psychologists agree that the use of higher level cognitive strategies begins to develop in early adolescence, and yet, test data show that student achievement frequently declines as students make the transition from elementary to middle school (Pajares, 1996; Midgley, 2001; Beane \& Brodhagen, 2001;Gentry \& Gable, 2001). Middle school boys frequently show less interest and motivation for school activities than do girls (Gentry \& Gable, 2002). If provided with relevant professional development, middle school educators can use the structures and beliefs of the middle school reform movement to address developmental needs and to improve motivation among middle school students (Beane \& Brodhagen, 2001).

\section{Teaming}

The practice of grouping smaller numbers of middle school students into teams creates a sense of community, enhances bonding between students and teachers, and promotes curriculum integration (Beane \& Brodhagen, 2001). Led by an interdisciplinary team of teachers, the team model's main characteristics include a small (less than 125) number of students on a team; common teacher planning periods; a low student/teacher ratio; student advising; and pedagogical changes consistent with developmental issues of adolescents (Felner \& Jackson, 1997). Benefits of teaming reported by teachers include more planning time, more autonomy, and increased feelings of efficacy (Beane \& Brodhagen, 2001). If the level of implementation for the team model is high, then academic achievement may increase. In a study including 31 schools and over 15,000 students of the Illinois Middle Grades Network (IMGN), researchers evaluated the success of the Turning Points (Carnegie Council, 1989) reform model. 
Results reported significant positive correlations between a school's achievement scores and its level of implementation of the model (Felner \& Jackson, 1997). In a study of an urban middle school employing a team model for an all-boy team of students, investigators found that achievement scores increased. Teachers primarily attributed this increase in test scores to their "cohesive leadership”, as they implemented teaming principles with the all-boy team (Davis, et al., 2004).

\section{Mentoring}

The reform movement's emphasis on psychosocial development shifts counseling, advising, and mentoring responsibilities to the teachers leading a team of students. Some studies indicate that advisory programs increase student self-esteem and decrease drop-out rates, but a in a 1993 study, only 54\% of middle schools investigated found that advisory programs contributed to effectiveness (George \& Shewey, 1994; Beane \& Brodhagen, 2001). Other studies reported that mentorship and advising were especially important for urban and minority students (Manning, Lucking, \& MacDonald, 1995). Teacher support for advisory programs is frequently lacking. Reasons given include lack of time and training and de-emphasis of academics (Anfara \& Brown, 2000). Conversely, teachers leading an all-boys team in an urban middle school reported that close relationships with their students were important for successful guidance and mentoring. “These boys are like my family,” one teacher said. She also reported that she had "no idea" why a certain boy might choose her as confidante (Davis, et al., 2004). Another teacher recalled that, in other instances, they, as team leaders, had made deliberate attempts to gain the friendship and trust of a needy student. "If you build that bond," she said, "the boy will respond differently to you, and you can even 'get on his case’ successfully” (Davis, et al., 2004). 
In a case study of advisory programs in 6 urban middle schools, 14 out of 18 teachers interviewed related dissatisfaction with their advisory programs to gender issues. The female teachers reported that the entire burden for running the program fell on the female teachers (Anfara \& Brown, 2000). Male teachers failed to accept the importance of knowing students on a personal level and perceived advisory programs as a waste of instructional time. These findings disagreed with a previous quantitative study (SillsBriegel \& Bell, 1998) reporting that no significant gender differences were found in teacher perceptions about advisories (Anfara \& Brown, 2000). Researchers for the case study made the following recommendations for advisory programs: develop both long and short range goals; recognize needs and concerns of students, teachers, and parents; provide continuing staff development and support; provide orientation for all involved (parents included); maintain low student-teacher ratios; relate advising to school climate and culture; respect students’ and teachers’ rights of privacy; and ensure shared responsibility of male and female teachers for the advisory program (Anfara \& Brown, 2000).

Learning

Learning goals. In making the transition from elementary to middle school, students frequently experience increased emphasis on performance goals rather than mastery goals for learning (Midgley, 2001). Performance goals focus on the self and how ability is judged relative to others. Empirical studies associate these goals with different cognitive, affective, and behavioral outcomes. Mastery goals relate more directly to learning for understanding, and middle school students should not be moving away from mastery goals just as they are developing the cognitive ability to grapple with more complex and abstract tasks. Midgley (2001) suggests that learning goals in middle school 
focus on developing competency, as well as gaining understanding and insight. Many studies confirm relationship between mastery goals and patterns of learning. Performance goals, in the absence of mastery goals are associated with less adaptive patterns of learning. A cross-sectional study of middle school students found them to be more focused on performance goals and less focused on mastery goals than elementary students (Midgley, 2001).

Varied teaching and learning strategies. Teachers hold great influence over the students they encounter each day, and classroom activities play a significant role in the attitudes adopted by students in middle school. Research indicates that there are negative changes in attitude and motivation as students progress from elementary to middle school, and this decline in motivation seems to be more pronounced in males (Gentry, et al., 2002). By using a variety of teaching and learning strategies, teachers may overcome some of these negative attitudes in early adolescents. Examples of alternative teaching strategies that are successful with middle school students include hand-on experiences, group work, and activities of choice. The work becomes less teacherfocused, and teachers serve as facilitators while students have increased opportunity for peer interaction (Beane \& Brodhagen, 2001).

However, research indicates that middle school teachers are not using a wide variety of strategies and suggests a multifactor rather than a single factor explanation, one that recognizes the complexities involved in expecting teachers to change the way they teach (Beane \& Brodhagen, 2001). Lack of use may relate to emphasis on ability and low teacher expectations, and teachers may also fail to use a variety of strategies because of the additional preparation required or the need to address additional social skills as students work with each other (Beane \& Broadhagen, 2001). 


\section{Classroom Management}

As researchers and practitioners devote increasing amounts of time and attention to educating poor minority children, surveys of research literature about high achievement and opinions of researchers identify classroom management and motivation among the top quartile of variables having the strongest effect on student achievement outcomes (Hudley, 1997). Among the main identifiers of the climate of a school are management issues such as clarity of rules and expectations and classroom organization (Brand, et al, 2003).

Psychological theory and classroom management. The work of psychological theorists B.F. Skinner, Fritz Redl, William Wattenberg, and William Glasser, Thomas Gordon, laid the ground work for contemporary classroom management and can provide Middle school educators with effective ways to encourage and teach appropriate student behavior(Bucher \& Manning, 2001). B.F. Skinner proposed the use of rewards and punishmentsto shape and modify behavior. Many teachers also believe that students will repeat "rewarded behaviors" and stop unrewarded or ignored behaviors. Ways that middle school educators may use Skinner's theories of behavior include ignoring inappropriate behaviors, using only positive comments, and developing behavior contracts and point systems (Bucher \& Manning, 2001).

Glaser is known for his "quality school" and "choice” theories. Choice theory points to young adolescents' need to accept responsibility for managing their own behavior. He believes that students think rationally, yet still rely on teachers to make and enforce rules. He opposes coercion and calls for educators to transform schools into caring places. The "quality school” is one that helps students satisfy their psychological needs and adds quality to their lives. According to Glasser, four basic psychological 
needs drive students: the need to belong; the need for power; the need for freedom; and the need for fun. He reminds educators that students must freely choose to change their behavior and do not do so because of rewards or punishment. Teachers who encourage caring for the community, allow students the freedom to make choices, and foster an enjoyment of school activities are using Glasser's theories of behavior (Bucher \& Manning, 2001).

Redl and Wattenberg's strategies include group dynamics, peer pressure, selfcontrol, and appraising reality. Many negative adolescent behaviors result from a temporary lapse of an individual's control system, rather than from a desire to be disagreeable. A teacher's purpose should be to help students retain or regain their control. To mold students' behavior, teachers may use a pleasure-pain principle and provide a range of experiences to produce a range of pleasant or unpleasant feelings, and then, explain the connection between conduct and consequences. Middle school educators may use Redl and Wattenberg's theories of behavior by seeking to understand group dynamics and how misbehaviors can be contagious with middle school students. Additionally, teachers may support self-control by establishing eye contact and moving close to the student, as well as encouraging them to appraise reality by looking at the effect of their behaviors on the other students in the class (Bucher \& Manning, 2001). Gordon views discipline as self-control, the use of "I-messages", and active listening, as ways of improving the behavior of young adolescents. Effective teachers need the skills to identify student problems and needs, and with that knowledge, they can change the class environment. Contributions from Gordon's theories include a belief that students must accept responsibility for actions, as well as beliefs in the importance of active listening and empathetic understanding. Replace "you statements" with "I 
messages". Instead of "You stop that, say "I'm frustrated by all this noise." Gordon also proposes a six-step problem solving process to resolve conflicts. Ways that middle school educators may use Gordon's theories of behavior include demonstrating empathetic understanding, promoting active listening; and avoiding "you statements" (Bucher \& Manning, 2001).

CHAMPs program. Teachers of an all-boys team in an urban middle school partially attributed test score increases to implementation of the CHAMPs Program for classroom and behavior management (Davis, et al, 2004). CHAMPs is an acronym for Conversation, Help, Activity, Movement, Participation, Success, and provides a way teachers to convey expectations to students in a positive and proactive manner (Sprick, Garrison, \& Howard, 1998). CHAMPs also intertwines reinforcement, modeling, and self-analysis of behavior into the school program (Sprick, et al.,1998). CHAMPs includes curriculum materials and a training component and focuses on the modeling of appropriate behaviors for specific class activities. This research-based program proscribes appropriate voice levels and acceptable actions for a variety of classroom situations and guides teachers in establishing efficient classroom routines. Detailed suggestions are provided for interacting with students in positive ways; developing incentives and recognition schemes to promote excellence; and applying clear standards of behavior fairly and consistently (Sprick, et al., 1998). Teachers learn to implement the program through participation in continuing professional development sessions (Davis, et al, 2004). The CHAMPs Program also emphasizes students’ individual responsibilities (Sprick, et al., 1998). 


\section{Middle School Reform and Urban Students}

There is evidence that middle school reform initiatives can be successful in urban settings and with disadvantaged populations. One study (Lee \& Smith, 1993) suggested that teaming equalized achievement over social class, and Arhar and Kromrey (1995) found that the social bonding accompanying implementation of a team structure made a significant difference in achievement in urban settings but not in suburban ones (Beane \& Brodhagen, 2001). For urban middle school educators, the following practices are recommended: developing an understanding of urban learners; teaching higher-order and critical thinking skills; providing adult mentors; and maintaining high expectations for learning and behavior (Manning, Lucking, \& MacDonald, 1995). Urban educators can benefit from understanding and using middle school concepts such as teaming, positive school climate, comprehensive counseling, and developmentally sensitive teaching. A school and classroom climate that emphasizes cultural pluralism and diversity, as well as teaching that promotes cooperation and equal status among all students, can increase achievement for minority students (Brand, et al, 2003).

Suggestions for implementing effective practices correlate closely with recommendations for middle school reform and include: create smaller groups or communities of learning; provide supportive classroom environments; strengthen teachers' beliefs in their own efficacy and in the competence of their learners; encourage teachers to maintain strong academic focus by providing student with extra direction and support; assign hands-on work as well as adequate practice; place a high priority on overall development; help students understand major concepts, and avoid merely teaching isolated facts; emphasize problem-solving and move beyond worksheets and drill; and give students the opportunity to engage in meaningful dialogue with teachers 
and peers (Manning, et al, 1995). Effective mentors can help urban students catch up, and educators should begin by determining which students are most likely to benefit from mentoring (Manning, et al, 1995)

Middle School Reform and Academic Achievement

Critics of the middle school reform movement propose that its child-centered focus does not direct enough attention to academic achievement (Beane, 1999). Middle school is called the "muddle in the middle” by some (Bradley, 1999) and a "vast educational wasteland” by others (Bandlow, 2001). To engage early adolescents in school and to meet their developmental needs, middle schools may seek to offer a wide variety of topics and student choice, thus failing to provide the depth of knowledge needed to prepare students for high school mathematics (Bandlow, 2001). Although some parent groups call for a return to ability grouping, emphasis on basic skills, and a long and rigid list of topics to be covered (Bandlow, 2001), recent research indicates that new directions are needed (Manning, et al, 1995).

Over the last two decades, middle school reforms have addressed organizational issues and provided environments appropriate for the developmental needs of students. Researchers, educators, and parents now call for attention to be refocused to academic issues (Midgley, 2001). Some studies report improved achievement in schools characterized by high levels of implementation of middle school reform principles (Felner, et al, 1997), whereas others characterize middle school reform as lacking academic emphasis and teaching a large number of topics at superficial levels of understanding (Bradley, 1998). Critics of middle school reform also question whether advocates have overstated the universality and intensity of characteristics perceived in early adolescents. Referring to G. Stanley Hall's 2000-page treatise on adolescence as a 
time of "storm and stress", critics claim that adolescent psychologists have elevated puberty from a life stage to an ideology (Beane, 2000).

Another criticism on middle school reform relates to concerns about achievement in math and science. Dissatisfied stakeholders call for strategies such as going "back to basics", decentralizing governance, creating charter schools, dispensing vouchers, or tracking students as ways to raise achievement in mathematics and science in middle school (Bandlow, 2001). However, unfavorable results for U.S. $8^{\text {th }}$ graders, when compared academically to students of other industrialized countries in the Third International Mathematics and Science Study (TIMMS), do not relate to basic skills. Research indicates that these U.S. deficiencies in mathematics and science result from emphasizing breadth rather than depth in middle school mathematics and not studying algebra until 9th grade (Riley, 1997; Silver, 1998). The rest of the world teaches algebra by 8th grade. U.S. students are developmentally ready, but the curriculum has not prepared them for challenging math. What they lack is not basics; the curriculum repeats these over and over again. U.S. students are deficient in higher level math and science concepts and are unable to apply them to real-life situations (Stigler \& Hiebert, 1999; Bandlow, 2001).

Instead, of adding more drill, memorization, and tracking, mathematics and science educators espouse that real reform will require the following three steps: adopting mandatory national standards that define what children should know and be able to do at every grade level; replacing superficial math and science curriculum with research-based curriculum materials that teach challenging concepts in algebra, geometry, biochemistry, and physics; and ensuring that teachers deepen their backgrounds in content areas and pedagogy to change the way math and science are taught (Bandlow, 2001). 
In the midst of these criticisms, however, Beane (1999) suggests that there is a case to be made for retaining the middle school concept but for increasing academic emphasis within the structures. Middle school advocates should support the best of their ideas, such as teaming and mentoring, both empirically and philosophically (Beane, 1999). A Carnegie Foundation study concluded that substantial and coherent emotional and social support structures are vital to prevent destructive behaviors and promote good health among early adolescents. Middle school practices and social support networks should not be abandoned in the race to raise scores. A middle school should be a personal and intimate place, where teaching is contextual, rather than the traditional, large and impersonal “junior high school model.” Research indicates that this personal and contextual component for education is especially important for disadvantaged and minority students (Shouse, 1996; Phillips, 1997; Beane \& Brodhagen, 2001; Brand, et al, 2003).

An additional perspective on middle school reform points to the need to move away from discussions of hormones and to include principles of equity and democratic ideals as components of the middle school quest for higher achievement. Educators, parents, and policymakers should talk less about standardized testing and more about how our best teachers are being constricted by them; less about competition and tracking and more about learning with depth of understanding and proficiency; and less about “what I want for my child” and more about what we want for all children. We must remember that reform of U.S. public middle schools is an agenda worth fighting for, and yet, reforming a school is a process, and not a linear one, that takes years to accomplish. Resistant forces, limited resources, and old ways of thinking inhibit reform (Beane, 1999). 
Advocates for school reform, specifically the middle school reform movement, have concluded that good schools are always either getting better or falling behind, but never standing still (Erb, 2000). Successful reform is never final and there is always more to be done. Ronald Edmonds was one of the pioneers of the effective schools reform movement and closed his much-cited article, "Effective Schools for the Urban Poor” by saying,

It seems to me, therefore, that what is left of this discussion are three declarative statements: (a) We can, whenever and wherever we choose, successfully teach all children whose schooling is of interest to us; (b) We already know more than we need to do that; and (c) Whether or not we do it must finally depend on how we feel about the fact that we haven't so far (Edmonds, 1979, p. 23).

\section{Effective Schools}

The research on effective schools began as a reaction to the issuance of the Coleman Report (1966), which proposed that schools had little or no effect on academic achievement independent of background and social factors, such as socioeconomic status (SES). Edmonds (1979) was a pioneer in research of climate in effective schools and described effective schools as those having the following characteristics: strong administrative leadership; high expectations for student performance, a safe and orderly environment, an emphasis on basic skills, and a system for monitoring achievement progress (Hoy \& Sabo, 1998). Investigations suggested that the impact of schooling on achievement may be underestimated because of the predictor and outcome variables measured and the extent of the variation (Good \& Brophy, 1982; Marzano, 2003). The Coleman Report (1966) used verbal ability, a measure that is highly correlated with student background variables, as the primary dependent measure of school effectiveness. The school-related variance is much larger when the focus is on subjects actually taught and on subjects that children are not learning at home also (Marzano, 2003). 
Effective schools researchers have frequently asked the question, "Why do some schools with students of similar background factors have better achievement outcomes than others?” Researchers (Brookover, 1979) studied school effectiveness of 68 schools in Michigan. The schools were divided into the two categories of predominately Caucasian or African-American (greater than 50\%). The results of these quantitative analyses indicated that there was only a small proportion of variance in achievement uniquely attributable to input variables (e.g. student SES), whereas strong correlations among the predictor variables clouded specific explanations for high achievement in the complex school social systems. Another finding was that characteristics of highachieving schools differed greatly from school to school (Good \& Brophy, 1986)

Brookover, et al (1979) supplemented their quantitative analyses with a qualitative study of four schools in a low-SES district and examined them on school climate variables such as time spent on instruction, proportion of students who were “written-off”, teacher expectations, reinforcement practices, grouping procedures, motivational strategies, principal's role, and teacher commitment. The four schools were classified as high-achieving or low achieving and as predominately Caucasian or AfricanAmerican. In both of the high-achieving schools, a much higher percentage of the time was spent on instruction. Few students were seen as "destined to fail" in the highachieving schools. In the predominately African-American school, teachers were reported to try other strategies when one did not work. In the two low-achieving schools, teachers had low expectations, most particularly for students on the lowest reading track. Teachers did not view grade-level achievement as a realistic goal, and in the AfricanAmerican school, teachers were unwilling to assume responsibility for student learning. 
In the high-achieving predominately Caucasian school, there was no homogeneous grouping, and in the high-achieving African American school, students were grouped on the basis of pre-test scores, but it was the teacher's purpose to advance students to higher groups. In the low achieving Black school, researchers reported that teachers told students they were doing well when, in fact, they had not (Good \& Brophy, 1986). Although the data collected in this study do not yield results about specific school characteristics that can be generalized, results do suggest that when teachers, principals, and students believe that what they do can make a difference, then the school climate they create is conducive to learning and achievement is higher (Good \& Brophy, 1982).

In a recent compilation of effective schools research of Edmonds, Brookover, and other analyses, Marzano (2003) develops five overarching school-level factors affecting academic achievement: a guaranteed and viable curriculum; challenging goals and effective feedback; parental and community involvement; a safe-and orderly environment; and collegiality and professionalism. Many researchers currently working in the field are investigating how these factors interact with school climate, school culture, and school health, as they affect student outcomes.

\section{School Climate and Culture}

The school as a workplace has engaged long-term interest from researchers and scholars of organizational theory in education. The concepts of school climate or culture arose from Edmonds' original effective schools model for the purpose of distinguishing an effective school from an ineffective one. Initially, the term climate was used to express the enduring quality of organizational life, to describe the characteristics that distinguish one organization from another, and to influence the behavior of people in an 
organization (Hoy \& Sabo, 1998). Due to researchers’ desires to measure a school's climate specifically, “climate” was defined as a set of measurable properties, based on perceptions of educators and students who worked and lived in the environment and demonstrated influences to their behaviors. Some of the more complex workings of a school can be thought of as "the culture." To understand the organizational culture of a school, one must understand the most basic meanings and values in the life of that particular school. To study school culture, qualitative methods of case study and ethnography were frequently used and values and beliefs concerning social integration, loyalty, and commitment were important areas of inquiry (Hoy \& Sabo, 1998).

\section{School Health}

Using quantitative methods, researchers developed the construct of organizational health as an attempt to create a set of measurable properties of school work environments that might guide principals and teachers to make schools more effective (Hoy \& Hannum, 1997). Developers of the instrument defined a healthy organization as one that "survives its environment and prospers over the long term.” Organizational health also depends on how successfully leaders can deal with disruptions from outside forces, while at the same time, directing energies toward its mission and objectives (Hoy \& Sabo, 1998). The six identified dimensions of school health were: academic emphasis, teacher affiliation, collegial leadership, principal influence, resource support, and institutional integrity.

According the framework of Parsons (1967) these six dimensions can be grouped into categories as effects taking place at the technical, managerial, and institutional level. Technical level effects relate to the chief mission of the school - teaching and learning. Both teachers and supervisors have responsibilities of solving problems associated with teaching and learning. Dimensions of a school's health affecting it at the technical level 
are teacher affiliation and academic emphasis (Hoy \& Hannum, 1997; Hoy \& Sabo, 1998). The managerial level controls allocation of resources and coordinates work effort. To manage successfully, administrators must find ways to motivate teachers and to develop teacher loyalty, trust, and commitment. Dimensions of school health affecting the it at the managerial level are collegial leadership, principal influence, and resource support teacher affiliation and academic emphasis (Hoy \& Hannum, 1997; Hoy \& Sabo, 1998). It is at the institutional level that a school connects with its community, including its district and parents. Both teachers and administrators need backing and support from the larger communities and need to work in a harmonious fashion with forces outside the school. Institutional integrity is the dimension of school health affecting the school at the institutional level (Hoy \& Hannum, 1997; Hoy \& Sabo, 1998).

Academic emphasis. Academic emphasis is the extent to which the school is driven by the pursuit of academic achievement. If a school possesses a strong academic emphasis, high but achievable goals are set for students and teachers. Supervisors and administrators create a learning environment that is orderly, purposeful, and respectful of all.

Teacher affiliation. In a school exhibiting positive teacher affiliation, teachers support each other, have positive feelings about their teacher associates, and like their jobs and students. A general friendliness and collegiality among teachers permeates the atmosphere.

Collegial leadership. Collegial leadership refers to principal behavior that is supportive, open, and friendly. A principal must give teachers a sense of empowerment, not a sense of domination. At the same time the principal must set a tone of high performance by letting teachers know what is expected of them (Hoy \& Hannum, 1997). 
Principal influence. Principal influence is the prinicpal's ability to absorb and control district-based influences. Influential principals are persuasive with superiors and can use this persuasion to implement the school's mission. Principals who exert influence over district personnel on behalf of teachers are valued by them.

Resource support. Resource support refers to the availability of classroom materials. In a school with a high level of resource support, sufficient materials are readily available, and additional materials that teachers may request are frequently provided.

Institutional Integrity. Institutional integrity is the extent to which the school can cope with its environment and can remain protected from demands of parents and community.

Academic achievement is associated with educators' perceptions of school climate and health. In a 1997 study (Hoy \& Hannum), investigators used the Organizational Health Inventory to measure organizational health in a sample of 86 middle schools by surveying teachers at faculty meetings. Only teacher affiliation, SES, and institutional integrity emerged as significant predictors of mathematics achievement, whereas resource support was a significant predictor of writing achievement (Hoy \& Hannum, 1997). Two surprising results of this study were that institutional integrity was a negative predictor of mathematics, reading, and writing achievement. Although school personnel frequently prefer having a buffer against parental demands, pressure from parents and the community facilitated rather than hindered academic achievement.

A second surprising finding was that neither collegial leadership nor the influence of the principal with superiors had an independent effect on student achievement. These factors only related to achievement when they are related directly to teaching and 
learning in the classroom (Hoy \& Hannum, 1997). Additional research using a similar instrument confirmed that an environment that emphasized academics contributed to higher student achievement (Hoy \& Sabo, 1998). In another study of 5,659 students in 23 schools only academic factors such as teacher expectations, percent of students taking algebra in $8^{\text {th }}$ grade, and amount of homework related positively to mathematics achievement. Affective considerations such as teachers' caring for students and democratic governance had negative effects and no effect, respectively (Phillips, 1997).

In some investigations, teacher affiliation was significantly and positively related to higher academic achievement (Hoy \& Hannum, 1997; Hoy \& Sabo, 1998), whereas in other studies, teacher affiliation, described as friendliness and harmonious relationships, assumed a more affective role and did not relate positively to academic achievement (Phillips, 1997). More recent investigations distinguish between different types of collegial behavior among teachers. Interactions commonly interpreted as collegial behavior are social interactions and friendships. A more professionally oriented form of collegiality not only involves planning together or engaging in peer coaching, but also involves openly sharing failures or mistakes, demonstrating respect for each other, and constructively analyzing and criticizing practices (Marzano, 2003).

Friedkin and Slater (1994) found that discussion and advice interactions among teachers were positively correlated with student achievement, whereas friendship interactions were negatively correlated. Examples of these professionally-oriented, collegial interactions among Japanese teachers were described in detail in The Teaching Gap (Stigler \& Hiebert, 1999). In this video study of $8^{\text {th }}$ grade mathematics teachers in the United States, Germany, and Japan, mathematics teaching in Japan was observed to be significantly different than mathematics teaching in the United States. One difference 
may be explained by the way that Japenese teachers developed and prepared individual lessons. Researchers observed and videotaped Japanese teachers as they engaged in “lesson study,” a collegial activity in which teachers met in multiple sessions and worked together on student lessons that emphasized student thinking, problem solving and multiple solution strategies (Stigler \& Hiebert, 1999).

Academic achievement and adjustment are associated with students’ perceptions of educational climate. These include greater commitment to achievement by peers or teachers, teacher support, student involvement in class activities, rule clarity, classroom and school organization, instructional innovation and student participation in decision making (Brand, Felner, Shim, Seitsinger, \& Dumas, 2003). Minority students display more positive levels of academic efficacy when a school environment is more supportive of cultural diversity. Students must also perceive the educational environment as safe, not fear-laden (Brand, et al., 2003; Marzano, 2003). In a sample including over 105,000 schools, researchers found that school climate factors such as structure, teacher support, student commitment, and instructional innovation accounted for a substantial portion of the variance among schools of the study in achievement and also found a substantial portion of variance in achievement to be accounted for by other school factors, such as safety, student outcomes. Findings were also consistent with the view that school outcomes are not just a product of differential levels of SES between schools, and there are more improvements in outcomes when reform efforts are comprehensive (Brand, et al., 2003).

Teacher Efficacy

This section explores relevant research on the two related constructs of "teacher efficacy” and "collective teacher efficacy.” Teacher efficacy measures beliefs of 
individual teachers about their own capabilities. Collective teacher efficacy combines the beliefs of educators in a school about their ability as a faculty unit to educate their students well. These two constructs descend from Albert Bandura's construct of selfefficacy, which serves as a major component of his social cognitive theory and has enriched and broadened the study of self-regulatory behavior and motivation (Pajares, 1996). According to Bandura, people construct beliefs about their capabilities in performing tasks at certain levels of competence. These "self-efficacy” beliefs affect how much effort people are willing to expend, how long they will persist as difficulties arise, their resilience when they encounter failures, and the amount of stress they experience in coping with highly challenging and demanding situations (Bandura, 1997).

Bandura's original theories presented outcome expectancy as a component of selfefficacy (Riggs \& Enochs, 1990). However, since outcomes so frequently relate to external occurrences as well as personal actions, investigators began to study outcome expectancy using the constructs of internal and external locus of control. The locus of control model was developed by Rotter (1966), and the model supports the principle that the individual's belief about control over outcomes has greater impact on behavior than the actual situation. High confidence in one's own ability to produce desired outcomes is measured as internal locus of control, and the extent to which one believes in the predominance of outside influences is measured as external locus of control (Wenner, 2001). Bandura later clarified the difference between these two concepts; beliefs about one's capabilities to perform actions (self-efficacy) are not the same as the beliefs about whether or not the actions produce certain outcomes (locus of control) (Goddard, Hoy, \& Hoy, 2000). 
Researchers study the constructs of both teacher efficacy and collective teacher efficacy by separating them into two dimensions, usually referred to as "personal teaching efficacy” (PTE) and “general teaching efficacy” (GTE). Personal teaching efficacy measures self-perceptions of teaching competency, based on skills, knowledge, and personal traits. General teaching efficacy measures beliefs about the extent to which student learning can be influenced by effective teaching and about the difficulty of a teaching task.

Efficacy beliefs of the individual teacher. A teacher who is high in efficacy will experiment more with teaching strategies to meet the needs of individual learners, plan more thoroughly and precisely, persist longer to help struggling students, and exhibit less criticism of student errors (Henson, Krogan, \& Vacha-Haase, 2001). Student achievement has also been shown to be significantly related to teacher efficacy beliefs (Ashton \& Webb, 1982). In 1984, Gibson and Dembo created the Teacher Efficacy Scale (TES), the first major attempt to develop a data collection instrument for measuring this potentially powerful teacher variable empirically. Although a variety of instruments measuring teacher efficacy exist, most of them credit their origins to the work of Gibson and Dembo, and many researchers refer to the TES as the standard instrument in the field (Henson, et al, 2001).

Using the TES, researchers have linked teacher efficacy to many variables related to teacher effectiveness and positive student outcomes. Teaching efficacy, most particularly the dimension of general teaching efficacy, is context-specific and is consequently affected by the subject or topic being taught, the students, as well as specific settings or circumstances (Goddard, et al., 2000). A teacher may feel more efficacious for one class or another. These contextual considerations may offer a partial 
explanation for why general teaching efficacy is more difficult to measure than personal teaching efficacy. In previous studies, the PTE dimension has been used to predict teacher behavior more accurately than has the GTE dimension, and measurement experts have questioned reliability of scores (internal validity) and construct validity for the scale (Henson, et al, 2001). To address these concerns, a team of researchers sought articles of studies using TES and noted reliability assessments. Of the 213 articles reviewed, only 86 reliability coefficients (all internal consistency estimates) were available. On these tests, GTE tended to have less reliable scores than PTE (Henson, et al, 2001). According to Bandura (1997), self-efficacy should be measured specifically, by subject area, task, or problem. When assessment of self-efficacy is too global and does not correspond to the task or endeavor being undertaken, its predictive power diminishes (Pajares, 1996). Other scales have been developed to measure self-efficacy for teaching in particular subject areas. Riggs and Enochs (1990) developed an instrument to measure efficacy for teaching science, the Science Teaching Efficacy Beliefs Instrument (STEBI). In earlier versions of the TES, many items of the scale had not loaded clearly on one of the two factors causing interpretations of results to be more difficult. When teachers earn low scores on the TES, it might be due to their belief that they cannot teach; their beliefs that students cannot learn -- even given effective teaching -- or a combination of the two. To develop the STEBI, researchers repeatedly edited and adapted individual items from the PTE and GTE trying to separate beliefs about competence (PTE) in teaching science from beliefs about difficulty of the teaching task (GTE). After a pilot study, researchers undertook a study of practicing elementary teachers $(\mathrm{N}=331)$ and found that, using the STEBI, teaching competence and difficulty of task, were separate dimensions. Results of 
this study indicated that the STEBI was a valid and reliable tool for measuring elementary teachers’ beliefs about teaching science (Riggs \& Enochs, 1990).

Another researcher (Wenner, 2001) used STEBI to measure elementary teachers' efficacy for teaching science and mathematics. He modified the instrument so that the scale could be shifted from a measure of science teaching efficacy to a measure of mathematics teaching efficacy by exchanging the word "science" for the word "mathematics" in the items of the Riggs and Enochs version of the instrument. Instead of a 5-point Likert scale, the adaptation of the STEBI offered respondents a dichotomous choice of either agree or disagree. The PTE results were interpreted as a confidence factor and GTE, an accountability or responsibility factor, and particular attention was directed toward the issues of confidence and accountability. Three studies were conducted over a five-year period to compare efficacy beliefs held by prospective and practicing teachers toward science and mathematics instruction. The general belief that experience leads to higher efficacy was supported by the data(Wenner, 2001).

Findings in Wenner's study (2001) suggested that pre-service teachers were more optimistic in indicating that good teaching could overcome poor student background in mathematics and science. In mathematics, $43 \%$ of the pre-service teachers and $73 \%$ of the in-service teachers believed that teachers' extra efforts could improve student performance. For questions about understanding math concepts, the pre-service teachers responded more positively than the in-service teachers (Wenner, 2001). Less than half of each group, for math and science, attributed poor student achievement to ineffective teaching. This lack of assumption of responsibility concerned investigators, and they suggested that this finding may have resulted from the extreme sensitivity of the issue (Wenner, 2001). 


\section{Collective teacher efficacy. Collective teacher efficacy is an extension of}

individual teacher efficacy and also descends from Bandura's social cognitive theory. Bandura (1997) observed that because schools present teachers with a host of unique challenges involving public accountability and minimal control over work environment, the task of developing high levels of collective teacher efficacy is difficult. However, there is reason to believe that, once developed, collective teacher efficacy will thrive and can help educators to weather adversity and to overcome obstacles (Goddard, et al., 2000). Team structures, advocated by the middle school reform movement and characterized by a shared teacher responsibility for student outcomes, may serve to strengthen perceptions of collective teacher efficacy. The principles of organizational agency and learning are also related to collective teacher efficacy (Goddard, et al, 2004).

Described similarly to the TES, the two factors of the CE scale are analysis of the teaching task and assessment of teaching competence (Goddard, et al, 2000; Goddard, Hoy, \& Hoy, 2004). The analysis of task produces inferences about the challenges of teaching at that particular school, such as the abilities of students, motivation of students, availability of instructional materials, the presence of community resources and constraints, and the appropriateness of school's facilities. Teachers make judgments about the teaching competence of their colleagues based on skills, methods, training, and expertise.

As postulated by Bandura (1997), the following four types of experiences shape efficacy beliefs of educators within a school: mastery experiences, vicarious experiences, social persuasion, and affective states (Goddard, et al. , 2000; Goddard, et al., 2004). Mastery experiences are the most powerful sources of efficacy information. As teachers 
experience successes and failures, they build a belief in the faculty's unified sense of efficacy. If success comes too frequently and too easily, then a failure may lead to premature discouragement. A resilient sense of collective efficacy means learning to overcome obstacles to attain goals. Vicarious experiences provide another source of information about a school's collective teacher efficacy. Teachers hear and respond to success stories of other colleagues who try new and effective strategies and from other schools, challenged with similar school-wide constraints, yet able to achieve their goals. Social persuasion, in the form of talks, workshops, professional development opportunities, and feedback about achievement, can strengthen a faculty's conviction in the ability to achieve group goals. Social persuasion can also take the form of group pressure on individual teachers to "buy-in" to the school's mission and to make extra efforts to ensure its accomplishment. The affective state of an organization is the level of emotion, such as pressure, anxiety, or personal commitment, present in the organization. Affective state can play a key role in influencing the mood of a school. Organizations with strong efficacy beliefs can use their affective state to successfully function through crises without debilitating consequences and rise to the challenge when confronted with disruptive forces (Goddard, et al., 2000; Goddard, et al., 2004).

In developing the Collective Efficacy Scale (CE), researchers began with previous work on efficacy for the individual teacher (Gibson \& Dembo,1984; Riggs and Enochs 1990; Tschannen-Moran, Hoy, and Hoy, 1998). After a preliminary review by a panel of experts, a field test and a pilot study, the CE scale was ready to be tested with a larger sample of 452 teachers from 47 schools. Results demonstrated that collective teacher efficacy had greater affect on achievement than either socioeconomic status or race, and 
that collective teacher efficacy explained one-half to two-thirds of the variance between schools in student achievement for both mathematics and reading (Goddard, et al., 2000).

In addition to the link between collective teacher efficacy and student achievement (Goddard, et al., 2000; Goddard, et al., 2004), there are important links with group goal attainment, school health, and teacher empowerment. Collective efficacy beliefs contribute to goal attainment and can explain how organized capacity for action is tapped to produce results (Goddard, et al., 2004). Two sociological studies demonstrated how the collective efficacy of a group of residents could deter neighborhood violence (Sampson, Raudenbush, \& Earls, 1997) and how collective efficacy must go beyond relational networks to produce successful child advocacy from a group of parents (Sampson, Morenoff, \& Earls, 2000; Goddard, et al., 2004).

Researchers and educators also recognize the importance of collective teacher efficacy for school climate and the health of a school. Teaching efficacy has a positive effect on school health factors such as academic emphasis, teacher affiliation, and principal influence (Hoy \& Woolfolk, 1993). The relationship between teacher empowerment and collective teacher efficacy relates to a faculty’s participation in school-level decisions. The more schools formally delegate to teachers instructionally relevant school decisions, such as curriculum, instructional materials and activities, professional development, communications with parents, student placement, and disciplinary policies, the higher levels of collective efficacy will be present in the faculty (Goddard, 2002). This increased sense of efficacy fosters among teachers a greater commitment to school goals, most particularly goals for gains in student achievement (Goddard, et al., 2004). 
Almost four decades after the Coleman Report presented socioeconomic status as the only variable having any effect on student achievement, continuing inquires about what makes schools effective confirm the importance for the roles of teachers and instruction. Research tells us that middle school students’ perceptions of teacher support, clarity of rules and expectations, student commitment, and instructional innovation relate to their socio-emotional adjustment and achievement (Brand, et al., 2003). Dimensions of school health, such as teacher affiliation, academic emphasis, and resource support, affect academic achievement in both reading and mathematics (Hoy \& Hannum, 1997; Hoy \& Sabo, 1998). A high level of collective teacher efficacy among a faculty enhances school climate and health and is also a significant and positive predictor of academic achievement (Goddard, et al., 2000; Goddard, et al., 2004). What is now needed is research that explores and interprets details about how school climate, teacher efficacy, and reform movements can be used to help struggling schools and to improve student achievement for students who are lagging behind.

\section{Teaching and Learning Mathematics}

\section{Mathematics Achievement}

Mathematics as a "Gatekeeper.” A 1997 analysis by the United States Department of Education indicated that students who take algebra, geometry, and other rigorous mathematics courses in high school are more likely to go on to college, and benefits of rigorous courses in high school are greatest for low-income students (Riley, 1997). Mathematics achievement in middle school is a strong predictor for a student's academic future. Many $8^{\text {th }}$ graders who have not studied algebra or participated in an advanced program may already be behind (Riley, 1997). An advanced mathematics curriculum in middle school, including the study of algebra, is a "gatekeeper" for future 
academic success. Students who take advanced mathematics courses in middle school are much more likely to enroll in advanced mathematics and science courses in high school. Mathematics achievement does not depend on the school attended as much as the courses selected. The Department of Education report (Riley, 1997) also suggests that students whose parents are more involved with their schoolwork are more likely to study algebra in middle school.

The TIMSS Study. Results of the Third International Mathematics and Science Study (TIMSS) of 1995 indicated that U.S. students do not perform well in mathematics when compared with students in the rest of the world, and middle school may be a weak link in the nation's mathematics curriculum (Riley, 1997). TIMSS found mathematics achievement of U. S. students in Grade 4 to be above average when compared to the other major industrialized nations, whereas by Grades 7 and 8, U. S. students’ achievement levels in mathematics dropped well below average when the same comparisons are made (Silver, 1998). To accompany the written assessments of TIMSS, researchers used video cameras to record classes in 231 randomly selected classrooms in the U.S., Germany, and Japan. Findings suggested that U.S. teachers focused on teaching procedures rather than problem solving and that U.S.mathematics curricula did not include as much problem solving and were not as challenging as those of other countries (Stigler \& Hiebert, 1999). As a response to the TIMSS study and to the Riley Report, mathematics educators recommend that middle schools include additional topics such as algebra, geometry, probability, and statistics in their curricula; emphasize problem solving skills; increase teacher knowledge of mathematics; and increase opportunities for teacher professional development guiding them toward more student-centered ways of teaching (Silver, 1998). 


\section{Standards-Based Mathematics Reform}

In the 1980's, a reform movement for mathematics education in the United States developed because of the widespread belief that students were not learning the mathematics they needed to know or were expected to learn (NCTM, 2000; Ball, Lubienski, \& Mewborn, 2001). To adapt to a rapidly changing, high-tech world, Americans need to understand and do mathematics for real-life situations, the workplace, as well for the scientific and technical community. However, U.S. students are behind those of other nations in mathematics (Silver, 1996), and many Americans who are considered well-educated cannot make judgments about magnitudes of fractions and decimals, cannot estimate the likelihood of a particular event, do not understand that a square is also a rectangle, and cannot reason skillfully about quantitative relationships (Ball, et al., 2001).

Research also indicates that this lack of knowledge may result from how mathematics is taught, not as a body of knowledge to be understood, but as a set of procedures and skills to be learned by rote. Throughout the 1980's the National Council for the Teachers of Mathematics (NCTM) worked toward a goal of improving the teaching of mathematics, and in 1989, introduced Curriculum and Evaluation Standards for the purpose of setting forth a comprehensive and coherent set of goals for mathematics educators, of serving as a resource for teachers, of guiding the development of curriculum, and of stimulating discourse among stakeholders about how to improve students' knowledge, interest, and understanding in mathematics (NCTM, 2000). A unifying principle of the standards-based reform movement is that students should understand the mathematics they do. In a review of research on standards-based 
mathematics teaching (Ross, McDougall, \& Hoganboam-Gray, 2002), authors listed nine defining characteristics of the reform movement.

Characteristics of Standards-Based Reform

(Ross, McDougall, \& Hoganboam-Gray, 2002)

1. The mathematics taught is broader in scope; topics such as probability, geometry, and algebra are added to the curriculum well before high school.

2. Student tasks are complex and open ended problems where students are also asked to explain their reasoning.

3. Instruction focuses on constructing ideas through student and teacher discourse rather than through presentation and practice.

4. The teacher's role is co-learner and creator of a mathematical community rather than as the sole keeper of knowledge.

5. Mathematical problems in reform settings are undertaken with access to mathematical tools such as calculators and manipulatives.

6. Student interactions are encouraged rather than discouraged.

7. Tests are not considered the only form of assessments; the teacher considers a wide variety of skills when assessing students and assessment is integrated with daily class activities.

8. The teacher in a reform classroom presents mathematics as an active and dynamic pursuit instead of a fixed body of knowledge.

9. A student's development of confidence to do mathematics is also an important competency in the reformed mathematics classroom.

Research indicates that when standards-based reform is fully and correctly

implemented and possesses all of its intended characteristics, student learning is

enhanced. Students who understand the mathematics they do rather than merely

performing memorized procedures, can apply their knowledge and retain it (Boaler,

1998; Ross, et. al., 2002). In a meta-analysis of studies, investigators concluded that a

main issue is not the effectiveness of reform, but the barriers to implementation.

Reformed pedagogy is harder to learn and is not a part of teachers' mathematics

experiences, and teachers lack knowledge and understanding of mathematics. The

managing of student discourse about mathematical reasoning requires a high level of

knowledge and skill, and standards-based teaching may not be aligned with parental

expectations or standardized testing. Furthermore, more time is needed to cover topics

thoroughly and deeply than school-approved curricula usually allow (Ross, et al., 2002). 
This same analysis also offers suggestions for overcoming obstacles to reform. Thorough and sustained professional development heads almost every suggestion list for implementing standards (Ross, et, al. 2002; Windschitl, 2002; Borsuk, 2004). Reform efforts can benefit from more teacher self-reflection, as well as communication and planning with other teachers. School restructuring strategies, such as single-gender classes, site-based management, and outside partnerships, are frequently accompanied by increases in teacher collaboration, and these factors, acting together, may also contribute to changes in teaching and standards-based reform (Ross, et al. 2002). Research also shows that the appropriate use of technology, such as computer programs and calculators can improve student outcomes (Kilpatrick \& Findell, 2001;Ross, et al.2002)

The 1989 NCTM standards advocated primarily student centered, non-traditional teaching of mathematics, and several years after they were published, educators became concerned that the standards lacked a needed emphasis on basic skills and practice. NCTM’s revised standards, Principles and Standards for School Mathematics (2000), placed more emphasis on skills and practice, including phrases like “compute fluently” and "work flexibily."

In 2000, NCTM issued a set of revised standards (NCTM, 2000) perceived by most in the mathematics education community to be a step back toward a middle ground, and an effort to emphasize skills as well as concepts. Phrases such as “compute fluently”, “apply appropriate techniques and formulas”, and “use symbolic algebra” appear throughout Principles and Standards for School Mathematics (NCTM, 2000). However, students who memorize facts and procedures without understanding are not sure of what they know. They can’t “think outside the box,”succeed with novel problems, or solve problems they’ve never encountered before (Borsuk, 2003). 


\section{Mathematics Proficiency}

About the same time that NCTM published Principles and Standards (2000), the National Research Council, a non-profit organization affiliated with the National Academy of Sciences, selected a committee of mathematics K-16 educators and charged them with the task of gathering research in mathematics education and addressing the concepts vs. skills debate. The result of this investigation was the report, in book form, Adding It Up: Helping Children Learn Mathematics, (Kilpatrick, Swafford, \& Findell, 2001). According to the report, understanding and doing challenging and important mathematics requires an understanding of the concepts, fluency in performing skills - and much more. The two points of argument, concepts and skills, fall far short of capturing the complexity of teaching and learning mathematics (Kilpatrick et, al., 2001). To become proficient in mathematics students must encounter learning experiences that are both constrained and open. Authors of Adding It Up employ the framework of five interconnected strands to build a new model for proficiency in mathematics. Conceptual understanding and procedural fluency represent the first two strands, but these two are intertwined with the equally important strands of strategic competence, adaptive reasoning and productive disposition.

Conceptual understanding. Conceptual understanding is the comprehension of mathematical ideas, operations, and relationships. A student who understands a concept can connect it to other knowledge and can represent it in multiple ways, both abstractly and concretely. Conceptual understanding facilitates alternative problem solving strategies, builds number sense, and guides students in avoiding critical errors.

Procedural Fluency. Knowing how and when to use a procedure, as well as being able to perform it with speed and accuracy characterize procedural fluency. For 
computation, students need a variety of mental strategies, such as knowing basic facts, using powers of 10, using the distributive property, and estimating. To compute fluently students should also have a sense of when it is more efficient to use a calculator and when it is not.

Strategic Competence. Not only do students need to know how to choose the most efficient method or strategy in computation but also need additional strategic abilities in problem solving. Strategic competence is the ability to formulate, represent, and solve mathematical problems. Students encounter real-world situations calling for the formulation of a problem in mathematical terms. Students use essential skills, such as flexible thinking and building mental images to solve problems.

Adaptive Reasoning. Adaptive reasoning is the capacity for logical thought, reflection, explanation, and justification. Adaptive reasoning not only means the ability to write a formal proof but also the ability to reason informally, inductively, and by analogy. Whenever answers disagree, students who reason more adaptively can check their steps to correct errors or establish validity.

Productive Disposition. Productive disposition is the habitual inclination to see mathematics as sensible, useful, and worthwhile. It is also coupled with a belief in diligence and in one's own efficacy, and students, who see themselves as effective learners as a result of solving challenging problems, gain strategic competence as well.

\section{Teaching for Mathematics Proficiency}

After a thorough description of all five strands of mathematics proficiency, Chapter 9 of Adding it Up (Kilpatrick,et al., 2001) presents details about what it means to teach for mathematical proficiency. Mathematics instruction is not just what teachers do but also involves the interaction of teachers and students around content (Kilpatrick, et 
al., 2001). Important issues for teachers include how to use curriculum materials judiciously, how to choose and use representations and tools, how to interpret and respond to student work, and how to design useful homework assignments (Ball, Lubienski, \& Mewborn, 2001). Mathematics instruction can be presented as a threepoint triangle with content, teacher, or student at each vertex (Cohen \& Ball, 2000; Kilpatrick, et al., 2001). The triangle serves as a framework for characteristics of mathematics instruction established by research in mathematics education as characteristics which lead to mathematics proficiency. These characteristics are categorized by identifying them with one side of the Instructional Triangle (see Figure 21): the teacher/content side; the teacher/student side; or the student/content side.

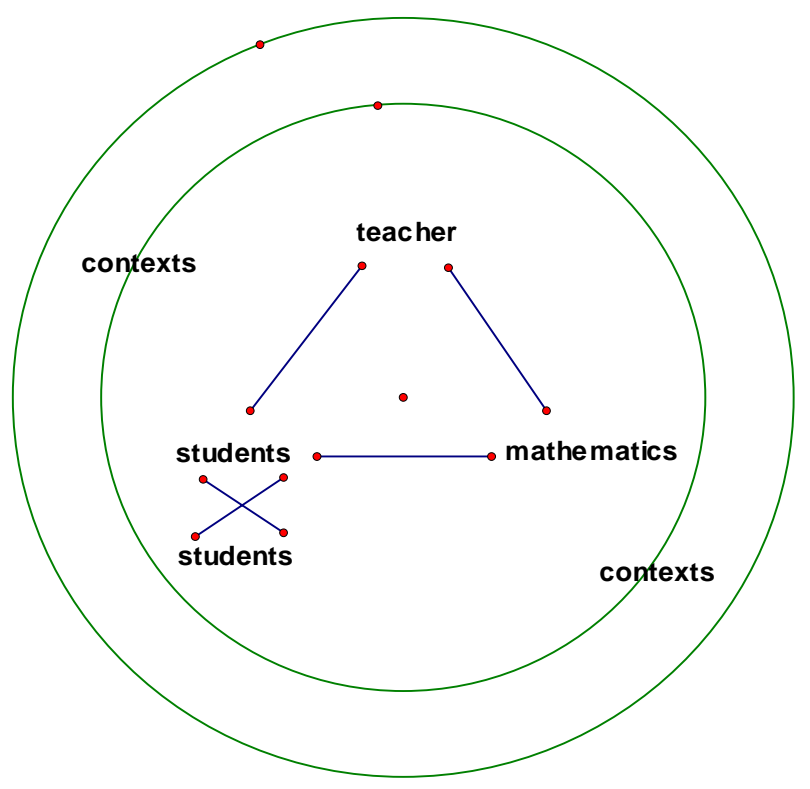

Figure 2-1. The Instructional Triangle: Instruction as the Interaction among Teachers, Students, and Mathematics, in Contexts (Adapted from Cohen and Ball, 2000) 
Teachers and content. Teaching for proficiency requires teachers to have subject-matter knowledge as well as what Lee Shulman (1987) coined as a well-known phrase, “pedagogical content knowledge.” Shulman (1987) defines pedagogical content knowledge as the particular forms of subject-matter knowledge that are most relevant to explanation, edification, and illuminating discourse. Pedagogical content knowledge includes the following: an arsenal of useful forms of representation, which may originate from both the methods of research and the wisdom of practice; knowledge about what makes topics easy or difficult; awareness of preconceptions, including misconceptions, that accompany students into the classroom; and knowledge of students' diverse cultures and stages of cognitive development. For a middle school mathematics teacher, demonstrations of pedagogical content knowledge might involve knowing how well students know basic facts; using circles or other concrete materials to represent $1 \frac{1}{2}+1 / 4$ or $1 / 2 \times 1 / 4$; accepting novel strategies for solving problems; or conducting mathematical discourse to raise students' levels of mathematical thinking.

Factors that relate to the interaction of teachers and content are (1) task selection and use; (2) student opportunity to learn; and (3) plans for daily lessons. Opportunity to learn is the single most important predictor of student achievement. Studies show that when less capable students are given opportunity to learn challenging work, they can do so (Kilpatrick, et al, 2001) Opportunity to learn is affected by school and district level factors such as adopted curriculum and testing program. How teachers manage their instructional time, as well as the structure of class periods also can influence students' opportunity to learn. Students should have opportunities to build knowledge and skill in all strands of mathematical proficiency, but frequently, teachers focus too heavily on one particular strand and ignore others. One teacher may spend the bulk of classroom time on 
drill and practice and not dedicate sufficient time to strategies for problem solving, or vice-versa.

Task selection and use is also an important content concern for teachers. Student tasks should originate with what students already know and move toward more abstract and general versions of this knowledge, thus maximizing possibilities for student progress. Tasks that include multiple representations of important concepts (e.g. manipulatives, pictures, graphs, charts, symbols, words) are particularly beneficial. Research shows that tasks frequently assigned by teachers make minimal cognitive demands on student thinking and emphasize the learning of procedures (Kilpatrick, et al.,2001). Cognitive demand is also lowered when students press teachers to reduce the challenge or when teachers disclose steps. Ways to help students and maintain a high level of cognitive demand are as follows: choose a task that builds on prior knowledge; scaffold the task appropriately; allow the right amount of time for a task; and resist, judiciously, student pressure for explanation (Kilpatrick, et al., 2001).

Planning can be profitably seen as a detailed form of instructional design, used to reduce uncertainties in a daily lesson. Good planning, however, allows for continual adjustment. Studies of how U.S. teachers plan suggest that they organize activities but do not plan for elaboration on content. Various schema for lesson plans in teacher preparation programs do not necessarily reflect what good teachers do (Kilpatrick, et al., 2001). Successful planning is more than just scheduling activities and homework assignments, itemizing content topics, and gathering materials. Planning should include studying the teacher's guides for curriculum materials, working through most of the exercises, and collaborating with other teachers. 
When TIMSS results reported that Japanese students were outperforming U.S. students in mathematics, educational researchers became interested in what Japanese mathematics teachers were doing differently (Stigler \& Hiebert, 1998). A video study comparing $8^{\text {th }}$ grade mathematics classes suggested that U.S. lessons focused on practicing procedures, whereas Japanese lessons were centered around problem solving (Stigler \& Hiebert, 1998). Further study revealed that Japanese teachers spent a great deal of time preparing a single lesson. Before and after teaching trials for the lesson, a group of teachers worked collaboratively to explore different representations and tasks, to investigate student thinking and specific content difficulties, as well as to refine explanations and processes (Stigler \& Hiebert, 1998). This collaborative practice is referred to as "lesson study,” and professional development providers are experimenting with lesson study as a way to enhance the skills of U.S. mathematics teachers.

Teachers and students. Important considerations in the interactions of teachers and students about mathematics are: (1) teacher expectations of students; (2) perceptions of task value and efficacy; (3) the creation of a learning community; (4) group vs. whole class activities; (5) assessment of student work; and (6) mathematical discourse. As previously stated, if students are given an opportunity to learn, they can frequently do so, thus teachers should have high expectations for their students. Low expectations frequently lead teachers to wait less time for a student to answer a question. Teachers with high expectations for students place priority on motivating students to set and reach higher goals. Student motivation to learn mathematics adds additional dimensions to general motivational strategies such as activities that are perceived as fun, grades, or extrinsic rewards and punishments. Students' motivation to learn mathematics depends on both expectation and value (Kilpatrick, et al., 2001). A student who has high 
expectations for success is a student who possesses a sense of self-efficacy and feels that, with sufficient effort, the task can be accomplished. A student values a task if they perceive them to be useful and if they perceive successful completion of the tasks will bring rewards. Teacher strategies that help students to value their work in mathematics class include using tasks that students find interesting and relating what happens in the classroom with student experience and knowledge from the outside. Teachers can motivate students by selecting tasks for which success is possible and by scaffolding tasks, thus helping students to meet high expectations.

Creating classroom environments that function as communities of learners is an important part of teacher/student relationships. Most of the research on classrooms as learning communities has focused on mathematics teaching in elementary rather than middle schools (Kilpatrick, et al., 2001). A learning community functions by using the following four principles: students' ideas and methods of problem solving are valued; students have autonomy in sharing their methods with other students and respect the methods used by others; mistakes are valued learning experiences; and authority for what is correct lies in the logic of the subject. Videos lessons in Japanese classrooms exhibit many of these learning community principles (Stigler \& Hiebert, 1998).

As a means for enhancing social and collaborative skills, as well as learning content, teachers frequently divide students into cooperative groups. Like any practice, the effectiveness of cooperative groups depends on how they are used. Effective use requires teacher skill, planning, and experience. Teachers should present and organize tasks so that they are well-suited to group work and to the curriculum. Students need to be taught how to work in this mode, and teachers should evaluate group work based on both group goals as well as individual accountability. Using cooperative groups as a 
teaching strategy is one of the recommended practices of standards-based reform. As part of their comprehensive view of mathematics proficiency, authors of Adding It Up emphasized that cooperative grouping is one of many instructional strategies that teachers may choose to use some of the time. However, to avoid emphasizing one strand of mathematics proficiency over others, one particular instructional method should not dominate. For example, work in cooperative groups should not be used exclusively; other instructional methods such as whole-class instruction, seatwork, practice, and homework should also be included (Kilpatrick, et al. 2001).

Student progress can be monitored through assessment of student work and questioning. When teachers learn to analyze verbal and written evidence about student learning and use that knowledge to shape instruction, their instruction becomes clearer, more focused, and more effective (Fennema, Carpenter, Franke, Levi, Jacobs, \& Empson, 1997). More formal assessments, for example, grades on projects, homework, and tests, and careful analysis by teachers can also serve as guides for instruction.

Thought-provoking mathematical discourse among teachers and students is a key element for building students' mathematics proficiency. Managing the discourse is both one of the most complex tasks of teaching and the least thoroughly studied (Kilpatrick,et al., 2001). Research needs to make visible teachers' considerations as they handle classroom discourse and the consequences of their moves for student learning. Classroom discourse should include the acceptance of students' multiple solution strategies for problems. Teachers must move the discussion along and help students develop understanding of key items, while at the same time giving students opportunities to make claims and provide explanations (Kilpatrick, et al., 2001). 
Students and Content. Aspects of instruction that relate students to content are (1) the role of practice (2) the role of homework (3) the use of tools, such as manipulatives, computer programs, and calculators. It is through practice that procedures such as computation, factoring, and solving equations become automatic. As procedures become automatic, students have more mental capacity and time for higher level cognition (Kilpatrick, et al., 2001). A main criticism directed at the standards-based reform movement has been the neglect of practice for procedures and basic skills. However, research indicates that the U.S. curricula are often repetitive and students relearn the same topics year after year (Stigler \& Hiebert, 1998). Practice exercises may also be overly repetitive. Textbooks and worksheets are most frequently used for practice, and these focus only on one lesson, thus missing opportunities to review previously learned material. An additional practice opportunity that often remains unrecognized is practice that is embedded in problem solving (Kilpatrick \& Findell, 2001). The research literature includes evidence that students who study in programs focused on conceptual understanding and problem solving perform just as well as other students on computational assessments (Hiebert \& Wearne, 1993; Cramer, Post, \& DelMas, 2002).

Homework can be useful for providing practice, preparing students for the next topic, fostering responsibility and independence, as well as encouraging self-assessment and meta-cognition in learning. Definitions of homework may vary in different schools and different classrooms. Homework practice can increase a student's procedural fluency, can help a student to retain skills, and can provide for teachers a medium and purpose for communicating with parents. If homework is given, teacher should follow- 
up the next day. Students should be able to check work, and teachers should never assign homework for punishment (Kilpatrick \& Findell, 2001).

The use of manipulatives as learning aids is far more complex than many educators understand. A teacher cannot just put them on a student's desk; students must be guided to appreciate their relevance and to connect that meaning with appropriate symbolism and concepts. Research suggests that manipulatives are beneficial for learning when used appropriately, and for older students, particularly when used to introduce new concepts (Fennema, 1972; Suydam \& Higgins, 1977). As fraction, decimal, and percent concepts are introduced in late elementary school and early middle school, comparable concrete representations of three-fourths, 0.75 , and 75\% can enhance conceptual understanding and improve student knowledge retention for the topic of rational numbers (Cremer, et al., 2002; Wearne \& Hiebert, \& Taber, 1991). Even though fractions and rational numbers represent key concepts for middle school students, research indicates that the use of manipulatives declines considerably in the late elementary grades and declines even further in middle school (Gilbert \& Bush, 1988; Hatfield, 1994). Manupulatives can also provide good opportunities for students and teachers to use them as a referential medium in discussions about mathematical ideas (Kilpatrick \& Findell, 2001).

There is much controversy in the mathematics community about the use of calculators, and many educators are concerned that the use of calculators inhibits learning of basic skills. From 1980 to 1996, calculator use in U.S. schools rose from 0 to $80 \%$ for both $4^{\text {th }}$ and $8^{\text {th }}$ graders (Kilpatrick \& Findell, 2001). Studies generally show that use of calculators does not threaten the development of basic skills and can have positive effects. A meta-analysis of 88 studies reported that, except for $4^{\text {th }}$ graders where a small 
negative effect was found, calculators did not have a detrimental effect on skill acquisition (Hembree \& Dessart, 1986; 1992). Positive effects of calculator use include enhancement of problem solving skills and enjoyment of mathematics. In a Swedish study, students who used calculators exhibited increased ability to choose correct operations (Brolin \& Bjork, 1992). In another study, students who used calculators developed better number sense and were better able to solve real-world problems (Groves, 1993; 1994). The benefits of calculators found in these studies suggest that calculator use could shift mathematics teaching from computational procedures to problem solving. However, when the negative $4^{\text {th }}$ grade findings are recalled, important questions arise about the grade level at which calculators should be introduced and how can they be used appropriately and beneficially at each level.

\section{Student Metacognition}

Another important component of understanding proficiency in any subject area relates to understanding how learners connect pieces of knowledge. Metacognition is the knowledge of one's own thinking and the ability to monitor one's own learning, reasoning, and problem solving ability and investigations indicate that the skills of metacognition can be taught (Bransford, Brown, \& Cocking, 2000). Strategies and characteristics of metacognition include predicting outcomes, activating prior knowledge, self-regulation, and apportionment of time and memory. Research has demonstrated that children can be taught these strategies (Bransford, et al. 2000). The strategy of apportioning time and memory relates to how to prepare for performance involving memory and how much time it will take to perform a task. Students can over-estimate their capabilities to remember information or under-estimate the amount of time of a task requires. 


\section{Beliefs of Mathematics Teachers}

Research strongly supports that teachers' beliefs about mathematics as well as beliefs about the teaching and learning of mathematics have a strong effect on their classroom practices (Thompson, 1992; Raymond 1997). There are three dimensions that are common to belief systems. The first principle explains that beliefs are not held independently; they are affected by primary beliefs and derivative beliefs. Secondly, beliefs are characterized by strength of conviction. Central beliefs involve more strongly held convictions and peripheral beliefs are more susceptible to change or examination. Thirdly, beliefs are held in clusters which are isolated from other clusters (Thompson, 1992).

Beliefs and knowledge can be very different. Knowledge more easily classifies as either true or not true, and for knowledge, there is general agreement on procedures for evaluating and judging validity. Unlike knowledge, beliefs about a phenomena and knowledge of that phenomena possess different characteristics, and beliefs, unlike knowledge, are held with varying degrees of conviction from "passionately" to "more probable than not." Belief includes awareness that others may think differently, whereas knowledge does not. If someone believes in a concept, then this belief is independent of proof of validity.

There are many inconsistencies in teachers' beliefs. One explanation for these inconsistencies may be the claim of Kaplan (1991) that teachers hold two kinds of beliefs: deep beliefs and surface beliefs (Raymond, 1997). Surface beliefs may not be an integral part of the teacher's philosophy of teaching and may only be beliefs that the teacher thinks that he/she should hold. Surface beliefs are usually associated with superficial practices, whereas beliefs about the nature of mathematics, which remain from 
early experiences may influence practice more profoundly (Raymond, 1997). This section discusses the following four topics relating to mathematics beliefs and practices: teachers' beliefs about the nature of mathematics; beliefs about teaching and learning mathematics; comparisons of teachers' beliefs and instructional practices; and changing teachers' beliefs and practices.

Beliefs about the nature of mathematics. Even among mathematicians, there is disagreement about the nature of mathematics. Hoffman (1987) defines mathematics as the "science of patterns" and others describe it as problem-driven, fluid, dynamic, or procedural (Raymond, 1997). Ernest (1988) philosophically distinguishes three conceptions of mathematics: a problem-solving view, a Platonist view, and an instrumentalist view (Thompson, 1992). According to the problem-solving view, mathematics is a dynamic, continually expanding field. Through processes of inquiry and validation, patterns and new ideas are generated and then distilled into knowledge. The Platonist concept views mathematics an unchangeable and infallible, but unified body of knowledge bound together by logic - a "Platonic Ideal". According to the Platonist view, mathematics is discovered, not created, by investigation, formation of definitions and conjectured principles, as well as justification and reasoning. Thirdly, instrumentalists perceive mathematics as a collection of tools to be used by a trained or skilled craftsman. The collection contains rules, facts, skills, and procedures, and these are used in the pursuance of some external end (Thompson, 1992).

Based on Earnest's views, Raymond developed a series of rating scales for placing mathematics beliefs, beliefs about mathematics teaching, and beliefs about mathematics learning on a continuum from "traditional” to "non-traditional”. A traditional view of mathematics is an unrelated collection of facts, rules, and skills. 
Mathematics can be described as fixed, predictable, absolute certain, and applicable. The extreme non-traditionalist perceives mathematics as surprising, relative, doubtful, and aesthetic, as well as dynamic, problem-driven, and continually expanding (Raymond, 1997). It is probable that an individual teacher's concept of mathematics will contain aspects of both traditional and non-traditional characteristics. Lerman (1983) identified alternative concepts of the nature of mathematics as either absolutist or fallibilist. In the absolutist view, mathematics rests on universal, unconditional foundations, which are abstract and value-free. From the fallibilist perspective, mathematics is characterized by conjectures and justifications followed by refutations and uncertainties (Thompson, 1992).

Beliefs about teaching and learning mathematics. According to Kuhs and Ball(1986), there are four distinctive views of how mathematics should be taught that dominate the research literature, and these four models can be used in describing and analyzing teacher practices (Thompson, 1992). The first model calls for learner-focused mathematics teaching. Learner focused teaching results from a constructivist philosophy, and the model is characterized by active involvement in doing mathematics and problem solving. A learner-focused teacher views mathematics as a dynamic discipline and serves as facilitator, posing interesting questions, challenging students to think, and helping them to explain or correct their own thinking. Students are responsible for validating their own ideas, and knowledge is assessed through the shared meanings of students' ideas and meanings of those ideas in the discipline. In a second model the teaching is content-focused with an emphasis on conceptual understanding. This view is related to Earnest's Platonist view of mathematics and emphasizes student understanding of ideas 
and processes. Students understand the relationships of the mathematical ideas and the logic underlying the mathematical procedures (Thompson, 1992).

Mathematics teaching that is content-focused with an emphasis on performance presents rules as the building blocks, characterizes mathematical behavior as rulegoverned, and de-emphasizes finding reasons for solutions or for errors. In this third model, mathematical knowledge means that rules are used to get answers and computational procedures should be automatized. Many self-paced instructional programs follow this instrumentalist and performance-oriented model. The teacher demonstrates and explains and the students listen or read, and then work problems. Mathematics educators are critical of this rule-based view of teaching mathematics, because research suggests that students do not retain and cannot apply it. This model misrepresents mathematics and does not permit students to engage in real mathematics (Thompson, 1992). The fourth model, classroom-focused instruction, descends from the process/product approach to teaching effectiveness and represents mathematics teaching that is based solely on knowledge about general classroom methods. Generic classroom methods focus on the structure of lessons and general pedagogical skills. The relationship of teaching to content is not a consideration in this model.

Contrary to this fourth model for teaching mathematics, Shulman (1986) proposed that, in any subject area, it does not make sense to separate pedagogical knowledge from the content taught, and thereby, he defined the term "pedagogical content knowledge” as the blending of subject matter knowledge and a knowledge of how to communicate it and teacher it to others. For mathematics, the alignment of content and pedagogy seems even more critical. Shulman recommends for teachers "an arsenal” of useful and varied forms of representation, powerful analogies, and illuminating and relevant illustrations. 
Possessing pedagogical content knowledge also means knowing what makes learning easy or difficult, as well as knowing something of research-based knowledge of misconceptions (Shulman, 1986).

Raymond (1997) separately characterizes mathematics teaching and mathematics learning, again, along a traditional to non-traditional continuum. In traditional teaching of mathematics, the classroom is teacher-centered. It is the teacher's duty to lecture, to dispense mathematical knowledge, to assign work, to seek correct answers, and to emphasize mastery and memorization of skills and facts. Lessons and activities follow the textbook and follow the same pattern daily, and all assessments take the form of standard quizzes and exams. Non-traditional teaching of mathematics is studentcentered. The teacher guides student learning, poses challenging questions, promotes the sharing of knowledge, promotes student autonomy, provides problem solving and handson activities, and helps students to like and value mathematics. In a non-traditional classroom, students frequently work in cooperative groups, and lesson plans are not rigid or inflexible (Raymond, 1997).

Sample traditional teacher beliefs about learning mathematics are as follows: students passively receive knowledge; students learn mathematics by working individually; students engage in repeated practice for mastery of skills; students learn mathematics solely from the textbook, worksheets, and teacher assignments. A nontraditional belief structure for learning mathematics emphasizes the student's role as autonomous explorer - learning through problem solving activities, work with concrete materials, use of technological tools, or and learning through cooperative group interactions. In the non-traditional view, students are active mathematics learners, all 
students can learn mathematics, and each student learns mathematics in his or her own way (Raymond, 1997).

Skemp (1978), proposed for mathematics learning, a corollary to his theory of instrumental understanding vs. relational understanding. Instrumental knowledge of mathematics can be described as knowledge of a set of fixed plans and step-by-step procedures, or skills. A student with instrumental knowledge can apply a rule or substitute in a formula but does not know why it works. In contrast, a relational understanding emphasizes concepts and relations among concepts, as well as knowing what do and why. Instrumental knowledge can be thought of as resulting from traditional teaching; relational knowledge may result from non-traditional teaching. With relational understandings, students possess conceptual structures which allow them to address a variety of questions with a variety of strategies (Skemp, 1978; Thompson, 1992). These two different conceptions of learning mathematics, relational understanding and instrumental understanding, can account for vast differences in instructional approaches and emphases (Thompson, 1992).

\section{Teacher Beliefs and Instructional Practices}

Researchers report a variety of uncertainties and inconsistencies about the relationships between mathematics teacher beliefs and their practices (Thompson, 1992; Raymond, 1997). Findings stem mainly from teacher self-reports, which may express only surface beliefs, thus leaving uncertainties about deep beliefs (Thompson, 1992). Inconsistencies may be due to pressures to cover material and to maintain classroom control. Furthermore, the political climate of the school, as influenced by testing and standards, may also cause a disconnection with teaching beliefs and practices (Thompson, 1992). As teachers focus solely on performance and preparing students for 
standardized tests, they may forego an emphasis on problem solving or hands-on

activities, even though they believe them to be beneficial. A 1997 study (Raymond)

identified time constraints, scarcity of resources, classroom management, and

standardized testing as principal reasons for inconsistencies between beliefs and practice.

A great deal teacher knowledge is needed to implement less traditional models of mathematics teaching, and less experienced teachers may avoid strategies such as handson learning, group work, or engaging in whole-group mathematical discourse (Ross, et al., 2002; Windschitl, 2002). In a study of a novice teacher who expressed strong beliefs about the value of problem solving and working with manipulatives, the investigator found that the teacher avoided the use of manipulatives because of the number of students in the class and her fear of losing control (Raymond, 1997).

Changing teachers' beliefs and practices. The growing awareness of the role that teacher beliefs play leads researchers to look for ways to influence teacher beliefs and thereby begin to enrich teacher knowledge and to improve practice. Few teachers leave their in-service training and begin to try new things in the classroom (Thompson, 1992). They are frequently more influenced by the social and professional norms at their schools (Raymond, 1998) or the way they were taught (Thompson, 1992). A first step toward changing practice begins when teachers begin to reflect on their own practice. A crucial point for a teacher educator or researcher in developing a collaborative relationship with teachers is when they begin to realize that their current practice may be problematic Teachers learn by doing and reflecting on actions and it is productive for researchers to focus on general teacher conceptions, mental structures, knowledge, beliefs (Cobb, Wood, \& Yackel, 1990). 
Teacher education. Teacher education programs produce mixed results in changing beliefs and guiding practice (Thompson, 1992). Some teacher education programs have been found to shift beliefs slightly, away from traditional views (e.g. teacher demonstration, facts, and procedures) toward non-traditional views (e.g. student discovery, trial and error, and encouragement of original thinking). In a 1988 study, preservice teachers progressed through a series of three innovative mathematics methods courses in concept development, group work, and problem solving. Teachers changed their perceptions of the nature of mathematics, the structure of classes, and the process of learning (Schram, Wilcox, Lanier, and Lappan, 1988).

Other studies found that teacher education programs do not have a strong influence on either teacher beliefs or practice. In one study, a teacher expressed the view that teacher education had not been influential. In a case study of nine in-service high school mathematics teachers, all expressed the view that mathematics content knowledge came from their university experience, whereas learning about teaching was derived principally from on-the-job classroom experiences following teacher education (Cooney \& Stinson, 2003). Research in teacher education at the University of Delaware employed design-based research methods to continually monitor and improve a teacher education course (Hiebert, Glass, \& Morris, 2003). In design-based research experiments, development and research take place through design, enactment, analysis, and redesign. (Design-Based Research Collaborative, 2003).

At the University of Delaware, the research project/teacher education course began with the premise that teacher education programs cannot, in two or three years, provide prospective teachers with all of the knowledge and skills they need to be effective mathematics teachers. Instead, goals for the program were to graduate teachers 
who were proficient in mathematics and teachers who have "learned to learn to teach" (Hiebert, et al., 2003). Using a design-based research methodology, professors used their teacher education classes as experiments, and in a similar manner, prospective teachers were schooled in the concept of using their future lessons with children as experiments. In both instances, the teacher/researcher applies to their lessons intentional, rigorous, and systematic processes for the purpose of growing in teaching expertise by studying one’s own practice (Hiebert, et al., 2003). Noticeably absent from the discussions of learning to teach were endorsements or analyses of theories of teaching and learning, such as behaviorism, constructivism, or social-constructivism. Research questions related, instead, to how the instructional activities will help students achieve learning goals (Hiebert, et al., 2003).

Extended professional development. Two ongoing research projects report a high degree of success in changing teacher beliefs and practices through extended professional development. The Cognitively Based Instruction (CGI) Project and Developing Mathematical Ideas (DMI) are both professional development programs that focus on helping teachers to connect with children's mathematical thinking. A major premise of CGI is that children come to school with informal and intuitive knowledge of mathematics that can be used as a basis for developing more formal mathematical thought and reasoning (Fennema, Carpenter, Franke, Levi, Jacobs, \& Empson, 1996). Teachers construct models for the development of children's thinking and develop their own teaching materials. CGI has been found to contribute to major changes in teachers' instructional practices that have resulted in significant achievement gains (Fennema, Carpenter, Franke, Levi, Jacobs, \& Empson, 1996; Kilpatrick, et al., 2001). In a study of the DMI professional development model, teachers attended a professional development 
program three hours a week for 8 weeks. Observational and interview data showed that DMI helped teachers to enhance their content knowledge, to understand the importance of supporting students' development of mathematical strategies, and to learn how to probe students’ thinking (Neumann, 2003).

\section{Textbook Use}

There is current interest among educational researchers about how teachers use school or district-adopted textbooks and the influence they may have on the nature of their mathematics teaching. The purpose of a meta-analysis of 25 years of research on elementary mathematics teachers' uses of curriculum materials was to examine the theoretical underpinnings of curriculum use and to describe various teacher-curriculum relationships (Remillard, 2005). Curriculum use was conceptualized in four main ways (1) the teacher either follows the curriculum faithfully or subverts its faithful implementation; (2) the teacher draws from the materials as one of many teaching resources; (3) the teacher interprets the curriculum to students, representing tasks and concepts in ways they are most likely to respond to; (4) or the teacher participates and interacts with the curriculum, engaging in a learning experience for both students and teacher (Remillard, 2005).

The investigation found that the process of using a mathematics curriculum guide is complex and dynamic and is mediated by teacher knowledge, beliefs, and dispositions. Because of these considerations, fidelity of implementation may not be a viable concept (Remillard, 2005). Findings relevant for educators and policy makers include the following: a decision to adopt a single curriculum in a school or district will not result in uniform instruction; implementation of a reformed curriculum must be supported by professional development in which teachers have extended opportunities to interact with 
the curriculum guide; and the ways in which designers of curriculum materials frame and support the teacher-curriculum relationship are extremely important (Remillard, 2005).

In a study of the nature and extent of middle school mathematics teachers' use of district-adopted textbooks, preliminary findings suggested that teachers using nontraditional, reformed textbooks are more likely to use standards-based instructional practices (Reys, 2004). However, textbook use and use of standards-based instructional practices vary widely among teachers. Results also suggested to investigators that teachers assigned various levels of authority to their district-adopted textbooks (Reys, 2004). Some teachers use their textbooks as a comprehensive and trusted authority, consulting accompanying teaching guides for what, when, and how to teach. Others use texts as scope and sequence guides, referring to provided materials about what to teach and when to teach it, but then sometimes using lessons and activities from other sources. Some teachers use their textbooks and curriculum materials less frequently, mostly as a resource for homework, tasks, or problems, and then, other teachers do not use it at all (Reys, 2004).

\section{Teaching and Learning of Boys}

\section{Boys and Education: Current Findings}

Previous research about single-gender education has focused on benefits for girls, whereas current educational statistics strongly indicate that the K-12 public education system is not meeting the needs of boys (Pollack, 1998; Weaver-Hightower, 2003). Girls make $60 \%$ of the A's in secondary school, while boys make $70 \%$ of the F's. Boys are suspended more than girls by a ratio of almost 3 to 1 . By the time of high school, twothirds of all the special education students are boys. Boys are diagnosed with ADD (Attention Deficit Disorder) and ADHD (Attention Deficit Hyperactivity Disorder) and 
drop out of high school at much higher rates than girls (Pollack, 1998). Twenty years ago, more boys than girls attended college. However, fewer males now attend college or graduate from college, and post-secondary enrollment for boys is predicted to show future declines. Educational concerns about boys have also arisen in the United Kingdom (UK) and in Australia. A brief look at the state of education for boys in all three countries allows comparisons.

United Kingdom. The underachievement of boys in the UK may not be a recent phenomenon but one that is now being noticed because of the provisions for standardized testing in the Education Act of 1986. Characteristics of the Education Act include increased autonomy and choice among schools; government-controlled funding; a standard curriculum; and standardized testing. Underachievement concerns arose particularly about Caucasian, working-class boys. Public outcry called for changes to the “laddish, anti-learning culture” (Foster, Kimmel, \& Skelton, 2001, p 2 ). Educators explored, among other things, "back to basics” efforts, and a group of educators organized a clearinghouse on effective educational programs for boys and materials for promoting male literacy. Recommended practices included more teacher-led work; a structured environment; high expectations; frequent and thorough homework checks; consistently applied sanctions; greater emphasis on silent work; and single-gender classes (Sommers, 2000). Recent reports indicate increases in reading proficiency for boys in related experimental programs (Sommers, 2000).

Australia. Due to girls’ superior academic performance, many Australians consider boys the "new disadvantaged.” Some Australian educators have expressed concerns that movements to boost boys' achievement may erase realized gains for girls and that males will regain their previous positions of hegemony (Foster, et al., 2001). 
Psychologist and researcher R.W. Connell (1996) reports on studies of varied

masculinities in males, masculinities other than the traditional masculinity of hegemony.

United States. Answers to questions concerning boys and schools in the U.S. appear in books by therapists, who treat mostly middle class boys and make suggestions about boys' difficulties in the form of advice to parents and educators. Michael Gurian takes the "boys will be boys" approach, emphasizing and exaggerating hormonal and brain differences. Psychologist William Pollack (1999), thinking along the same lines as did Mary Pipher in her book on the problems of adolescent girls, Reviving Ophelia, points to the silent, emotional crises that boys face in our oppressive culture. These approaches which come from popular literature can be informative but leave many questions unanswered about helping urban, disadvantaged, and minority boys in the U.S (Sommers, 2000).

The "boy turn." A 2003 issue of Review of Educational Research published an article discussing the educational research community's new interest in studying boys (Weaver-Hightower, 2003). The author abandons the "What about the Boys?” phraseology because of its implications of a conflict with girls' educational interests and describes the new movement in educational research as the "boy turn.” Indicators of a "boy turn” include popularity of psychological books about boys; new discussions amid feminists and others questioning male roles; gaps in test scores and enrollments for boys; educational movements such as school choice, back-to-basics, and standardized testing; claims that girls are passing boys; and changes in the work force (Weaver-Hightower, 2003). The article closes by suggesting, among other areas, research on best practices and programs for boys. Additionally, the author stresses the "imperative need" for research that actually takes place within schools. Consequences of work on gender and 
gender-specific programs in schools should be reexamined constantly (Weaver-

Hightower, 2003).

\section{Brain Research and Gender Differences}

By the beginning of the nineteenth century, scientists, physicians, and scholars recognized that functions of the brain might fall to specific regions. Paul Broca was a surgeon practicing in Paris in the latter part of the nineteenth century and became interested in the study of stroke victims who had suffered loss of speech. When Broca performed post-mortem examinations of persons known to have had loss of speech as a result of a stroke, he found damaged tissue or lesions in the left frontal lobe (Springer \& Deutsch, 1998). Later experiments repeatedly confirmed the importance of the left hemisphere for speech and verbal functions.

Discovery of right hemisphere functioning came later through analysis of psychological tests. Results of tests for over 200 patients indicated that patients with damage to the left hemisphere performed less well on tasks emphasizing verbal ability. Those with damage to the right hemisphere performed less well on non-verbal tasks involving the manipulation of geometric figures, puzzle assembly, missing parts of patterns, as well as other tasks involving form, distance and spatial relationships ( Springer \& Deutsch, 1998). Victims of brain damage to the right hemisphere often display disturbances in orientation. They display, for example, the inability to find their way around a house in which they have lived for many years; difficulties recognizing familiar faces; or perceptual difficulties with distance, depth, or using maps or forms. Other evidence indicates that damage to the right half of the brain may result in the loss of musical ability, whereas speech functions remain unhampered (Springer \& Deutsch, 1998). 
Brain asymmetries and gender. In the past, researchers gained knowledge of how a normal brain functions through the study of the effects of brain injury. New techniques, such as neuroimaging, allow researchers to investigate anatomical and functional differences in the left and right hemispheres (Springer \& Deutsch, 1998). Using these new techniques as well as traditional ones, studies suggest that there are particular problem solving tasks which favor each gender. According to Kimura (1992), women tend to be more proficient when identifying matching items; noticing displacement of items; listing words beginning with the same letter; performing manual tasks that require fine-motor coordination; and producing accurate mathematical calculations. Males perform better on tasks that involve mentally rotating or manipulating an object, finding hidden shapes in complex drawings, as well as tests of mathematical reasoning. Psychologist Diane Halpern proposes that females will show increased performance on tasks that require rapid access retrieval of information from memory and that males will excel in tasks which require the maintenance and manipulation of mental representations. From these results, questions arose about whether these gender differences in cognitive abilities related to gender differences in the organization or functioning of the brain.

Although there are studies which disagree, the majority of studies strongly suggest gender differences in asymmetric functioning. (Springer \& Deutsch,1998). Abilities in males are controlled principally in either one or the other hemisphere of the brain, whereas abilities in females are more bilaterally controlled. In a study using an MRI to measure blood flow changes in the brain, researchers tested 19 women and 19 men on a task of phonological processing. For all 19 men, the increased in blood flow was principally confined to the left hemisphere. With 11 women, blood flow to both 
hemispheres increased almost evenly and with 9 women the flow increased more in the left hemisphere but not to the same extent as for the men. In a meta-analysis of approximately 400 comparisons of laterality effects in males and females and concluded that there is greater lateralization, or separation in brain function, in men (Springer \& Deutsch, 1998). Another group of researchers (Boyle, Benbow, \& Alexander, 1995) obtained EEG data of brain activity for a sample of gifted and average male and female adolescents. The brain patterns for the gifted students of both genders demonstrated higher activity levels in the frontal regions than the average students, whereas a result unique to the gifted boys was a pattern of a higher level activity in the right hemisphere.

Findings from brain research suggest anatomical differences in male and female brains, but these differences appear small. On the average, males have larger brains, consistent with their overall size. Postmortem investigations indicated that more females have a slightly larger right hemisphere than males, and researchers associate this difference with more bi-laterality of brain function (Springer \& Deutsch, 1998). Witelson (1995) and others found gender differences in the shape of corpus callosum region of the brain. In addition, the size of the callosum decreases as age increases in men but not in women (Springer \& Deutsch, 1998). Witelson’s further research on brain anatomy indicated that in certain regions of the brain, women may have a higher density of neurons (Springer \& Deutsch, 1998).

A great deal of evidence indicates that gender hormones, such as testosterone, have an effect on brain development and cognitive functioning (Springer \& Deutsch, 1998). By adulthood, a male's body can have as much as twenty times or as little as six times as much testosterone as a female’s body (Gurian, 2001). Hampson (1995) conducted a study of children with a genetic disorder known as congenital adrenal 
hyperplasia (CAH), in which adrenal glands produce abnormally high quantities of testosterone after the first three months of fetal life. CAH girls demonstrated enhanced spatial ability over their unaffected sisters (Springer \& Deutsch, 1998). In studying this topic further, Kimura(1996) suggested that superior spatial ability may be associated with testosterone levels in the lower male range(Springer \& Deutsch, 1998) Both greater lateralization of function in males and levels of testosterone may account for the fact that boys tend to perform better on spatial tasks.

Brain research and learning. In light of previous discussion of gender differences in brain structure and functioning, it should be noted that, gender differences in brain research should not be used as criterion for educational opportunities or career options. Group differences for males and females are very small, and study findings report differences on the order of one-quarter of a standard deviation from the mean (Springer \& Deutsch, 1998). Information about gender differences in brain functioning should be combined with other knowledge to improve learning for both males and females and to tailor curriculum and methods of instruction to individual abilities (Springer \& Deutsch, 1998).

There is growing evidence that both the developing brain and the more mature brain are structurally altered when learning occurs. A wiring diagram of the brain is created through formation of synapses. At birth, the human brain has only about one-third of the trillions of synapses that it will eventually have (Bransford, Brown, \& Cocking, 2000). Synaptic connections are added to the brain in two basic ways. The first method is overproduction of synapses and then subsequent loss, which is the mechanism for incorporating information into the brain from early experience and then discarding what is not needed. This process of overproduction can persist through eight to ten years of 
life. Some neuroscientists compare the overproduction and subsequent loss process to the work of a stone sculptor who begins with a block of marble and then proceeds to chisel away unnecessary stone (Bransford et al., 2000).

The second method of synapse formation is through the addition of new synapses, a process driven by experience. For this type of a "sculpture", the artist creates the work of art by adding pieces of clay or objects until the artist declares the sculpture complete. The process of synapse addition operates throughout the human life span and is especially important in later life (Bransford, 2000). Instruction in specific areas can influence brain development and create new synapses. An example of an instance when this occurs is the case of a deaf person who learns sign language. Neuroscientists have observed different patterns of language processing in the brain for subject who can hear, for deaf subjects trained in sign language, and for deaf subjects not trained in sign language (Bransford, et al. 2000).

Neuroscientists and cognitive scientists are also studying memory processes and research indicates that the brain does not merely record items to be remembered but records them in sequences that make sense when recalled. Implications for teaching, from this new knowledge of memory, include the importance of an appropriate framework. Teachers have the potential to enhance learning by presenting concepts clearly and relationally and striving to make recall efficient and effective (Bransford, et al., 2000).

Strategies for Teaching Boys

Several experiments in single-gender classes found that teachers did not customize instruction to meet the different learning needs of boys and girls (Baker, 2002; Herr \& Arms, 2002; Woody, 2002). Furthermore, these experiments reported positive 
results only for the girls. When compared to research on girls' learning, there is little research about boys' learning or about teaching strategies for boys, most particularly as it applies to single-gender education (AAUW, 1998; Mael, 1998). This section includes previous findings about boys' learning and successful teaching strategies found for boys in both the single-gender and coeducational contexts. Learning and strategies in the areas of structure; engagement; reading; technology; and groups are considered.

Structure in classroom environment. The fact that boys in all-male classroom present behavioral challenges is well documented in the literature (Hudley, 1997; Baker, 2002; Herr \& Arms, 2002; Woody, 2002; Davis, et al., 2004). A teacher of a selfcontained classroom of African-American adolescents described his students as "kids who try to jump through the windows or throw others out” (Hudley, 1997). He then stressed the importance for a teacher to realize that boys thrive on structure and the importance for students to know who is in control. Studies concerning the teaching of boys frequently attribute classroom success to a rule-based environment. Boys respond to guidelines that are set and then enforced. There should also be rewards for good work and appropriate behavior (Gurian, 2001).

Gurian also suggests the inclusion of a strong authority figure, and that teachers and administrators must work together as a team to provide a fair and consistently applied system for classroom and behavior management (Gurian, 2001). Clearly defined rules and fairly applied consequences discourage male tendencies of obtrusive rule-breaking and risk-taking behavior in the classroom. Australian psychologist R.W. Connell (1996) suggests that when positive means are not available to boys, that rule breaking can become a way for boys to gain recognition. Disadvantaged boys frequently exhibit characteristics of a "protest masculinity" by engaging in disruptive behavior, breaking 
rules, and defying authority. To combat these negative behaviors, the structure of the classroom environment should emphasize group cohesion and individual responsibility (Connell, 1996).

A case study of a Catholic high school in urban Chicago (Hansen, 2002) focused on the importance of strict discipline and moral teaching as reasons for the school's success. Teachers combined elements of preacher, protector, disciplinarian, parent, and educator (Hansen, 2002). The student population was 300 African-American boys, most of whom lived in low-income and crime-ridden neighborhoods. The school day was regimented and students marked for tardiness to school encountered fines $\$ 1$ or 30minute after school detention. Teachers frequently included moral commentaries, informed students about the importance of education, and strictly enforced dress code rules (e.g. tuck shirt in). Graduation rates at the school are $90 \%$ and over $60 \%$ going on to higher education.

Teacher experiences and research indicate that successful teacher interactions with boys may be different than interactions with girls, and sometimes female teachers may not be aware of these differences. A female teacher of boys learned from experience that unlike girls, who want to discuss a problem or issue immediately, males frequently yell and shutdown. Males may sometimes need a place they can go, such as an isolated desk in another teacher's classroom, to help them with their personal behavior management (Gurian, 2001). Another teacher reported use of the "sixty-second rule" with boys (Gurian, 2001). If she told a student to do something she would give him 60 seconds to do it. If he began to question or to complain, she would never enter into an argument with the student but would move on to something or someone else in the class. This teacher had observed that most boys would do as they were asked once the focus of 
the classroom moved elsewhere. Many boys are competing for manhood and don't want peers observing them being controlled by a woman.

Academic structure. A teacher of African-American boys expressed the belief that student motivation increases when students perceive academic expectations as clearly defined and that policies are followed consistently (Hudley, 1997). In 1988, a council of British educators suggested the following practices as being successful with boys: a structured environment; high expectations; and frequent homework checks (Somers, 2000). Boys in all-boy classes were found to do poorly on tasks with low structure and high cognitive demand and need tasks broken into smaller pieces (Baker, 1999). Educators of boys in the United Kingdom advise teachers to avoid vague and “creative” assignments such as “Imagine you're a sock in a dustbin.” Boys have difficulty seeing the intrinsic worth in this kind of work (Sommers, 2000, p 161). Questions asking boys for descriptions or justifications should be explicit and broken down into parts.

Organizational skills. Boys also have difficulty with organizational skills. They are much more likely to fail to complete class work and homework, and more likely to lose assigned work, either before or after completion (Rennie \& Parker, 1997; Baker, 2002; Hansen, 2002). To enhance boys’ organizational skills, a science teacher used a student science binder which included a table of contents, and all assigned student work. At designated intervals the binder would be graded for completeness. She gave them extra worksheets when they lost them allowed the boys to stay after school for assistance in completing their binders (Davis, et al., 2004). Note taking is also an important organizational skill and poses more difficulty for early adolescent boys than for girls in this same age group. A strategy to help boys with note taking was developed during a two-year study conducted in six Missouri school districts (Gurian, 2001). Boys are given 
a skeletal set of notes and teachers go over these orally, step-by-step. There are sections in the notes in which students only fill in a missing word and sections for which a longer answer or explanation is required. Another benefit of all-boy class is that a boy's academic and organizational skills will not be compared with those of girls, and he can get the extra support he needs to prepare his academic work.

Engagement. Psychologists and educators studying the academic issues for boys stress that teachers must begin with boys’ own interests and experiences (Connell, 1996; Hudley, 1997; Pollack, 1999; Gurian, 2001). Teaching methods and curricula in U.S. schools frequently do not reflect the interests of boys (e.g. action, adventure, sports, or video games), and these interests are frequently discouraged in schools (Newkirk, 2002). In a study investigating gender differences in perception of classroom activities among students in grades 3-8, middle school males were found more likely to dislike their school activities, and researchers suggested that educators consider ways to engage male students in more enjoyable learning, so as to counteract negative attitudes and behaviors (Gentry, Gable, \& Rizza, 2002)..

In a study of $7^{\text {th }}$ grade boys, a teacher of African-American males emphasized African-American culture to increase student interest and motivation (Hudley, 1997). In a single-gender class in California, a teacher of boys reported engaging students with activities concerning military battles (Ritsch, 2002). An all-male environment may also encourage boys to engage in activities they might shy away from in a mixed group. In a summer single-gender program, a teacher reported that boys became involved in acting out of Shakespeare’s Othello (Murray, 2003). At another all-boy school, observers reported increased interest in activities such as playing in an orchestra (Ritsch, 2002) or participating in a bell choir (Sommers, 2000). 
Technology. Male preference for activities which emphasize mastery of objects has been frequently documented (Leder, 1990a), and computers and calculators fit in this category. In an all-boys class (Baker, 2001), teachers found that technology motivated boys to remain on task and to cooperate. Boys worked well together on their computer or calculator tasks and even created extensions of the activity (Baker, 1999). Boys are more likely than girls to spend out-of school time using computers. Computer games are generally more appealing to boys' interests, as they frequently involve adventure, sports, and war. Research in coed classes (Sadker \& Sadker, 1994) documented instances in which boys monopolized classroom computers and other classroom technology. Singlegender classes may provide both boys and girls increased opportunities to use computers and calculators in mathematics class. Availabililty of technology is also an issue at some schools (Kenning, 2003).

Groups, teams, and competition. Although research reports that boys work together less successfully in groups and exhibit more off-task behavior in the group setting (Rennie \& Parker, 1997; Baker, 2002), using specific strategies for boys working in groups can be a positive learning experience. Boys work together better in groups when girls are not there (Gurian, 2001; Evans, 1993). The single-gender class gives boys the opportunity to practice working together (Rennie \& Parker, 1997). One successful strategy is to assign boys specific roles in their groups, such as recorder or calculator operator, and then change roles for another iteration of the process (Gurian, 2001).

A teacher in Alexandria, Virginia reported improved attitudes and motivation among boys when he formed competing teams in all-boys classes. The teacher selected his teams carefully and heterogeneously, according to ethnicity, reading skill, and behavior. Students were responsible for their own learning. Teams earned points for 
attitude and behavior, class work, homework, and class preparation. Prizes were awarded to winning teams (Evans, 1993). Over a two-year period, individual achievement scores rose from 7 to $18 \%$ and homework completion rates rose from 30 to $95 \%$. The boys reported that the absence of girls on their teams helped them to focus on their work. One boy allowed that it was good not to be distracted or to "worry about saying things to upset girls” (Evans, 1993).

A teacher of African-American males successfully used cooperative groups which functioned as teams, competing with each other in timed relays to solve mathematics problems (Hudley, 1997). A teacher of a single-gender class in a Baltimore elementary school took advantage of boys' enjoyment of team competition to boost academic achievement. He placed the boys on teams and they competed in classroom activities. To add to the success of the endeavor, he has developed an elaborate point structure, through which students could obtain prizes (Sommers, 2000). Another team of teachers used a point structure effectively to encourage competition for participation on field trips planned by the team leaders. At the end of a term, boys with the highest totals for daily ratings on behavior and academic work were selected for the outing "For the first trip, boys who were not selected complained and protested,” said a team leader. But, after that, they realized it was fair and that everyone had an equal chance to be selected” (Davis, et al., 2004).

\section{Boys and Verbal Skills}

Early adolescent girls lag several points behind boys in assessments of mathematics achievement, but these differences appear only at the $90^{\text {th }}$ percentile and above (Sommers, 2000). Whereas in reading, girls are $1 \frac{1}{2}$ years ahead of boys in all percentile ranks (Sommers, 2000; Gurian, 2001). Literacy programs in coeducational 
classes do not use boys’ interests to guide selection of reading materials, and frequently, teachers consider boys’ selections unacceptable (Newkirk, 2002). In a study of all-boy classes, a teacher reported that focusing on topics of interest was a successful strategy. "I try to use basketball,” she remarked (Davis, et al, 2004). Another teacher in the same study explained a dramatic rise in a boy's reading score through perseverance of on the part of both teacher and parent. As requested by the teacher, the student's mother read with him for at least 15 minutes every day. They read together items of interest to him, such as the sports section of the newspaper and directions for video games (Davis, et al., 2004). In a study of single-gender classes in Australia (Rennie \& Parker, 1997), teachers used single-gender classes to improve the boys’ communication and reading skills. They also reported that these deficiencies had gone unnoticed in the coeducational classes (Rennie \& Parker, 1997). In an all-boy mathematics class in Virginia, a teacher reported integrating reading to increase boys’ interest in mathematics concepts and problem solving (Murray, 2003).

Boys and Mathematics

A question may arise at this point about the common perception that boys far surpass girls in mathematics achievement. Throughout the 1980's and 1990's, progress was made in increasing girls’ mathematics scores (Sommers, 2000; Campbell \& Storo, 1995a). Findings from different areas of research support the belief that there is little difference in the mathematics abilities of males and females. The research of cognitive psychologists and neuro-psychologists suggests that females may perform better on some types of mathematical tasks and males perform better on others. Furthermore, gender differences in all higher mental functions are typically on the order of one-fourth of a standard deviation from the mean (Springer \& Deutsch, 1998). When comparing the 
mathematics performance of boys and girls, researchers in mathematics education advise that a much larger within-group difference than between-group difference, with correlations between gender and quantitative skills of approximately 0.1 (Campbell \& Storo, 1994b).

When comparing boys and girls on high-stakes, standardized test scores, differences do appear. Recent tests show that boys score 35 points (out of 800) higher than girls in mathematics. Boys also score 7 points higher on verbal tests even though other data indicates that boys lag behind girls in verbal abilities (Sommers, 2000). The area of verbal skills is one in which, according to other measures, girls show superiority and some attribute higher scores for boys to test format (Sommers, 2000). There is also a "spread factor" to consider. On most tests of knowledge, the distributions of males' scores and females' scores are different, and standard deviations for males' scores are generally greater (Sommers, 2000). The female scores are more centered, whereas the male scores are usually at the extreme ends of ability and disability. When an equal number of gifted $7^{\text {th }}$ graders, males and females equally represented, took the math Scholastic Achievement Test (SAT), the ratio of males to females with scores 500 or above was 2:1; for scores above 600, 4:1; and for scores above 700, 13:1.

However, the majority of current single-gender experiments in the public sector focus on underachieving students of both genders, hence it is appropriate and timely to investigate the mathematics achievement for boys. The fact that boys are overrepresented in the top echelons of the math SAT is not relevant to the issue of raising mathematics proficiency among low achieving boys. In a study of a middle school recording the lowest achievement test scores in the state, 2002-2003 mathematics scores rated only 2\% of the boys as Proficient or Distinguished, whereas 6\% of the girls rated in top categories. 
The portion of girls rated Apprentice or above in mathematics was $43 \%$ compared with a boys’ rating of 26\% (Davis, et al., 2004).

\section{Conclusions and Implications}

Contents of this review of research literature indicate that the proposed study of all-boy mathematics classes in middle school is timely and has the possibility of providing new and useful information. In recent years, standardized testing has increased the visibility of achievement gaps by socioeconomic status, gender, and race in public education. In an effort to improve outcomes and environments, public school educators have begun to experiment with single-gender schooling. In 1994, there were only four public single-gender schools in the U.S., whereas ten years later there were over one hundred (Murray, 2004). The 2004 lifting of certain Title IX restrictions provided educators the most freedom they've had in 30 years to teach boys and girls separately, thus making single-gender education a viable public school choice (Associated Press, 3 March 2004).

Researchers working in area of middle school reform recommend investigations concerning implementation of these reforms. Critics suggest that too much focus is placed on developmental issues and not enough on academic achievement (Bandlow, 2001). Improvements in mathematics education in middle school are also needed. According to the Third International Mathematics and Science Study (TIMSS, 1995), our nation's $7^{\text {th }}$ and $8^{\text {th }}$ graders perform well below average in mathematics achievement when compared with students from other industrialized nations (Silver, 1998). To measure up internationally, middle school students need to be introduced to challenging concepts in algebra, geometry, statistics, and probability. Additional recommendations from researchers and mathematics educators include adoption of national standards about 
what students need to know; replacement of superficial curriculum with materials that teach challenging concepts; and continuing efforts to deepen teacher knowledge of mathematics and of how to teach it effectively (Bandlow, 2001).

Research is needed in the area of schooling for boys. Previous research on gender issues in education has focused itself almost exclusively on girls (AAUW, 1998; Mael, 1998), and educators have tended to overlook the problems of boys (Pollack, 1998; Sommers, 2000). Furthermore, positive educational outcomes, such as completion of high school and college enrollment, have declined for males in the U.S., the U.K., and in Australia (Foster, et al, 2001; Weaver-Hightower, 2003). Even so, research in schools experimenting with single-gender classes has reported a lack of benefits for boys and found that teachers were missing opportunities to tailor their pedagogy (Baker, 2002; Herr \& Arms, 2002). Hence, a study focusing on single-gender education, middle school structures, the teaching and learning of mathematics, and strategies for teaching middle school boys, may provide additional knowledge, helpful information for educators, and new directions for further research. 


\section{CHAPTER III}

\section{METHODS}

The overriding themes of this study were the education of middle school boys and the teaching of mathematics. Primary goals were to identify, explore, and interpret the following factors for the early adolescent male: organizational structures that nurture them; means of communication that reach them; teaching strategies that engage and challenge their cognitive abilities; and learning aids that support their weaknesses and capitalize on their strengths. Specific areas of inquiry include school factors that affect teaching, learning, and environments in single-gender classes; structures and strategies for teaching middle school boys; teacher characteristics and beliefs, and the teaching and learning of mathematics. Analyses and interpretations considered all types of collected data.

\section{Research Questions}

Readings from the research literature and my own previous investigations suggest that educational benefits do not automatically develop when boys and girls are separated but that benefits depend on other factors such as how a single-gender program is implemented and how teachers adapt instruction for boys and for girls (Datnow, et al., 2001; Baker, 2002; Herr \& Arms, 2002; Davis, et al., 2004). Therefore, I proposed the following four research questions: 
1. What are school and district factors that affect the development and implementation of all-boy mathematics classes in middle school? Do some factors seem stronger than others as they relate to successful implementation?

2. What classroom structures and instructional strategies are used by teachers in allboy mathematics classes? Do some structures and strategies seem more effective than others?

3. What teacher characteristics affect the development and implementation of allboy mathematics classes in middle school? Do some characteristics seem more important than others?

4. What is the nature of the mathematics instruction used by middle school mathematics teachers in all-boy classes? Do some types of instruction seem to be more effective than others?

To answer the four questions for this dissertation study, I sought the participation of teachers, administrators, and students in middle schools experimenting with singlegender education for the purpose of improving school environments and/or student outcomes. Existing research about characteristics of effective schools, middle school reform, and the teaching and learning of mathematics served as a framework for interpretation of the data.

Question 1: School and District Factors

Formatted: Bullets and Numbering

What are school and district factors that affect the development and implementation of all-boy mathematics classes in middle school? Do some factors seem stronger than others as they relate to successful implementation? The "effective schools” Deleted: What are school and district level factors that affect beliefs and practices of middle school mathematics research literature identifies school factors that relate to academic achievement and other 
school outcomes such as organizational health and collective teacher efficacy (Good \&

Brophy, 1986; Marzano, 2003; Goddard, et al., 2004).

School health. School health can be measured by examining six aspects of

organizational functioning: academic emphasis, teacher affiliation, collegial leadership, resource support, principal influence, and institutional integrity. A healthy school is able

to cope with its environment, to succeed in following its mission, and to accomplish its

goals over an extended period of time (Hoy \& Hannum, 1997). Academic emphasis is an

important indicator of school health and the indicator that is the strongest predictor of

student achievement. Schools that set high but achievable goals, establish an orderly and

serious work environment, and require students to work hard and to respect others,

exhibit high academic emphasis. Teacher affiliation is a sense of closeness and

friendliness among teachers and students. In a school characterized by high teacher

affiliation, teachers feel good about each other, are committed to both their colleagues

and students, and work with enthusiasm. Collegial leadership in a school is exemplified

by principals who support teachers’ work, treat subordinates fairly, and practice open

communications among faculty and administrators (Hoy \& Hannum, 1997).

Principal influence describes the principal's ability to absorb and control district-

based interventions. A highly influential principal will persuade superiors, such as

district personnel, of the importance of the school-developed mission and will ensure that

this mission is carried out relatively unimpeded by the hierarchy (Hoy \& Hannum, 1997).

Resource support may relate to both a principal’s relationship inside the school and

outside the school. Perceptions of resource support within a school relate to the

availability of classroom supplies and instructional materials. Teachers experience

increased feelings of resource support if the principal is able to supply additional 
resources when requested. The institutional integrity of a school describes the degree to which the school can cope with its environment in a way that maintains the established programs of the school and resists changes sought by parents and the community.

Teachers and administrators frequently perceive these demands as unreasonable and high institutional integrity indicates the extent to which teachers are protected from these demands (Hannum \& Hoy, 1997).

Collective teacher efficacy. The construct of collective teacher efficacy builds on Bandura's theory of self-efficacy and represents the shared belief among a school's teachers in their joint capabilities to produce positive effects on student outcomes (Goddard, Hoy, \& Hoy, 2000). Measures of collective teacher efficacy assess teacher perceptions of difficulties in teaching students in the school and collective competencies for teaching those students.

Teachers and administrators make judgments of their school's collective teacher efficacy based on their own particular school context and the perceived competence of their colleagues.

Question 2: Structures and Strategies,

What classroom structures and instructional strategies are used by teachers in all-

boy mathematics classes? Do some structures and strategies seem more effective than

others? To answer Question 2, the following were used as frames of reference: middle

school reform structures, developmentally appropriated classroom management structures and strategies; and gender-specific strategies for teaching boys previously identified in the research literature.

Middle school principles . Middle school reform efforts of the 1990's recognized that classrooms of middle schools should not be merely high school classrooms occupied 
by younger students. To create more appropriate environments, this line of research suggests structures and strategies such as interdisciplinary teaming; developmentally appropriate rules, procedures, and instruction; and mentoring relationships among teachers and students (Beane \& Brodhagen, 2001).

Classroom management structures and strategies. Research-based strategies for positive behavior management in the middle school classroom include predictability of daily routines, clear expectations, consistently enforced classroom rules, and the teaching of appropriate behaviors (Hester \& Gable, 2003; Sprick, et al, 1998). Classroom management strategies must create the correct balance of dominance and cooperation, as well as produce support for positive behaviors and terminate negative behaviors. A teacher also uses communication to engage and motivate students and to promote appropriate student communications as they work together in groups.

Strategies for teaching boys. Strategies for teaching middle school boys fall into two categories - strategies for engaging and motivating boys and strategies for adapting to boys' learning needs. Engagement and motivation strategies previously identified in the research literature include relating academic work to boys' topics of interest, including games and competition in instruction, and using educational technology (Noble \& Bradford, 2000; Gurian, 2001; Baker, 2002). Strategies for adapting to boys' learning needs include structuring tasks and improving boys’ organizational skills (Noble \& Bradford, 2000; Gurian, 2001; Davis, et al., 2004). This investigation sought to identify in the classrooms of teacher participants strategies previously identified in the research literature, as well as to identify new gender-specific strategies for teaching boys in singlegender classes. 


\section{Question 3: Teacher Characteristics}

What teacher characteristics affect the development and implementation of allboy mathematics classes in middle school? Do some characteristics seem more important than others? Teacher characteristics analyzed included gender, ethnicity, beliefs, and additional characteristics identified in the investigation.

Gender and ethnicity. Some educators believe that the gender of the teacher influences classroom interactions and structures (Weaver-Hightower, 2003). Ethnicity may also be a factor related to practices and interactions in single-gender classrooms (Hudley, 1998).

Mathematics teacher beliefs. All mathematics teachers hold beliefs about mathematics, the teaching and learning of mathematics, and beliefs about their own efficacy for teaching mathematics. Teacher beliefs about mathematics fall along a continuum from traditional (mathematics as a set of facts, rules, and skills) to nontraditional (mathematics as problem-driven and continually expanding). Traditional beliefs about the teaching and learning favor a teacher-centered environment, one in which the students passively receive knowledge from the teacher. Teachers demonstrate procedures and ask questions for which a particular answer is expected. Non-traditional teaching beliefs favor approaches that are primarily student-centered and include an emphasis on classroom discourse, hands-on activities, and group work (Raymond, 1997). Teacher efficacy beliefs for teaching mathematics relate to the factors of personal competence in teaching mathematics and student outcome expectations based on the difficulty of the task (Riggs \& Enochs, 1990).

Question 4: Mathematics Teaching

Formatted: Bullets and Numbering 
What is the nature of the mathematics instruction used by middle school mathematics teachers in all-boy classes? Do some types of instruction seem to be more effective than others? To evaluate the effectiveness of the mathematics instruction, the following documents served as benchmarks: standards documents of the National Council for the Teachers of Mathematics (NCTM, 1989 \& 2000) and the National Research Council's research document delineating the "five strands of mathematics proficiency” (Kilpatrick, et al., 2001). Other factors considered were textbook use, time allocation, and the use of metacognitive strategies.

NCTM Standards-based teaching. Characteristics of standards-based mathematics teaching include a broader scope, inclusion of topics such as probability; linear alignment of topics and the teaching of complex ideas to all students; use of manipulatives and calculators; a classroom organized to encourage student/student interaction; and instruction focuses on the construction of ideas through mathematical discourse (Ross, et al., 2002). Additional description is needed to identify classroom interactions that are examples of mathematical discourse, and the following types of interactions can be characterized as such: student conjectures about mathematical ideas, explorations of connections within mathematics and connections with daily life, reflections on whether answers are reasonable, explanations of reasoning, and discussions of multiple perspectives and strategies (Reys, 2004).

Teaching for mathematics proficiency. According to Adding It Up: Helping Children Learn Mathematics, mathematics instruction is described as not only as what teachers do but also as the interaction of teachers and students around content (Kilpatrick et al. 2001). As authors describe details of teaching for mathematics proficiency, they present mathematics instruction as a triangle with the labels Content, Teacher, and 
Student anchoring the vertices. Characteristics of mathematics instruction are then grouped into three categories, each representing one side of the triangle: teachers and content; teachers and students; and students and content (See Figure 2-1).

From the teacher/content side of the triangle, factors that impact student learning are teacher knowledge of mathematics, task selection and use, and planning. Teacher considerations from the teacher/student side of the triangle are expectations for student learning, task value and student efficacy, the learning community, and mathematical discourse. Important teacher decisions for the student/content side of the triangle include the roles of practice and homework, as well as when and how to use teaching aids, such as manipulatives and calculators.

Time allocation. The investigation included analysis of how teachers spent their classroom time. Types of activities considered were classroom management, teacher-led activities and discussion, practice, and group work and were classified as traditional (teacher-centered) or non-traditional (student centered).

Textbook use. Research suggests that teachers use curriculum materials and textbooks in a variety of ways (Reys, 2004; Remillard, 2005). Teachers may use textbooks as comprehensive and trusted authorities, scope and sequence guides, or as resources along with other teaching resources (Reys, 2004).

Metacognition. Teaching for mathematics proficiency emphasizes the importance of connecting with each student's thinking, and hence, the skills of metacognition should be important for learning mathematics. Metacognition in mathematics is the knowledge of one's own thinking and the ability to monitor one's own learning, reasoning, and problem solving ability (Kilpatrick, et al., 2001). Metacognitive strategies include predicting outcomes, targeting misunderstandings, activating prior 
knowledge, and considering alternative strategies, and research has demonstrated that children can be taught these strategies (Bransford, et al. 2000).

Design

A comparative case study design was used to interpret and explore factors affecting all-boy classes in middle school. General comparisons between single-gender and coeducation are problematic. The myriad of educational contexts, purposes, and venues (public, private, religious, preparatory, elementary, or secondary) can produce confounding background factors and conflicting results (AAUW, 1998; Mael, 1998). Therefore, points of analysis for the study were not whether single-gender education is more beneficial than coeducation but concerned school factors, extant structures and strategies, and teacher characteristics. Research in single-gender education indicates that benefits do not automatically develop when boys and girls are separated but that benefits depend on how the single-sex education is implemented and how teachers adapt instruction for boys and for girls (Baker, 2002; Herr \& Arms, 2002; Davis, et al., 2004).

The study focused on boys for several reasons. First of all, the teaching and learning of girls has received much more investigation (Weaver-Hightower, 2003). In the early 1990’s, a renewed interest in single-gender education for girls arose in the public sector with reports of ways that schools "shortchange girls" (Sadker \& Sadker, 1990; AAUW, 1992). Multiple investigations also focused on female disadvantages in advanced mathematics and science courses and careers in science and mathematics (Fennema, 1990a; Campbell \& Storo, 1994a). Statistical data indicating poor educational outcomes for certain groups of boys in all subject areas have recently intensified researcher interest in male issues in education (Pollack, 1998; Sommers, 2000; Foster, Kimmel, \& Skelton, 2001; Weaver-Hightower, 2003). 
There is an increasing amount of experimentation with single-gender education for both genders, as educators attempt to improve outcomes for low-achieving and disadvantaged students (Mael, 1998; Davis, et al., 2004). Although there is some evidence that teachers' uses of gender-specific strategies, engagement strategies, and strategies designed to meet boys' learning needs can be beneficial (Rennie \& Parker, 1997; Hudley, 1998; Davis, et al, 2004), the effectiveness of all-boy classes and particular strategies used by teachers in this context has not been widely documented.

Quantitative methods have produced no clear answer to the question about benefits of single-gender education. I have chosen qualitative methods for this study and focused on how teachers can use single-gender classes to improve learning. Data from the United States, the United Kingdom, and Australia report that low achievement among boys from disadvantaged populations is a pervasive problem (Sommers, 2000; Foster, Kimmel, \& Skelton, 2001; Weaver-Hightower, 2003). Qualitative inquiry is needed to find strategies for engaging and motivating boys and to learn more about how boys learn. Quantitative studies of both middle school reform and standards-based mathematics reform suggest that well-implemented interventions and programs improve student achievement, but that low implementation lessens reform effects considerably (Felner \& Jackson, 1997; Ross, McDougall, \& Hogaboam-Gray, 2002). Qualitative research can also inform researchers and practitioners about how teachers implement a variety of strategies and interventions in their classrooms.

\section{Screening of Cases}

Six mathematics teachers in three schools were selected as cases for the study. I sought public middle schools that had adopted single-gender classes for the purpose of improving student outcomes and/or school environment. To identify middle schools 
experimenting with single-gender education, I used newspaper reports, information passed along to me from other educators, and the website for National Association of Single-gender Public Schools (NASSPE). The screening of cases included middle schools in California, Connecticut, Georgia, Kentucky, Indiana, Pennsylvania, and Texas. Some of these schools that were all-boy schools and some were schools that enrolled both boys and girls but had single-gender classes. I also sought schools using single-gender classes for at least one full-school year before the data collection year and recognized that two or more years would be preferable.

I had telephone conversations and written correspondences with principals at all of the targeted schools to gather further information about each school. I asked each principal about the reasons for making the change to single-gender classes and about when the single-gender experiment began. I also asked about whether there were observed or documented changes and about how educators there felt about the changes. All of the administrators with whom I spoke seemed pleased with the single-gender classes and planned to continue them for the current school year. I then asked administrators to recommend mathematics teachers in their schools who were experienced in teaching all-boy classes and who might be qualified study participants.

\section{Timeline for the Study}

From these possibilities, I selected three middle schools in the lower mid-west, and in each school, both a $6^{\text {th }}$-grade and a $7^{\text {th }}$-grade mathematics teacher currently teaching all-boy classes. Both boys and girls attended all of these schools but the teachers selected for study were teaching at least two all-boy classes. The six mathematics teacher participants had varying levels of teaching experience, but all were at least in their second year of teaching all-boys. To investigate the four research 
questions, I collected and analyzed survey data, as well as data from observations, and interviews. The timeline for the study consisted of three main phases: an organization and planning Phase; a data collection phase; and a follow-up phase.

During the organization and planning phase, I screened and selected cases, obtained approval from the university’s Internal Review Board (IRB) for research with human subjects, and scheduled school visits. The data collection phase consisted of school visits for the purposes of observing classrooms, conducting interviews, and administering surveys. Surveys were administered to faculty and students on later school visits and additional interview data was also collected. During the follow-up phase, I made written and telephone contact with participants for the purpose of constant, comparative analysis and verification of the data. Table 3-1 represents a timeline for the study.

Table 3-1

Timeline for the All-Boy Mathematics Class Study

Organization and Planning Phase (May-Sept 2004) Contact schools; recruit cases; obtain IRB approval; schedule visits.

Data Collection Phase (Sept 2004- December 2004)

Collect field data (survey, observation, interview, documents).

Follow-Up and Analysis Phase (December 2004- May 2005)

Follow up with school personnel; collect additional data; comparative analysis of data; verification of data; interpret results.

\section{Participant Consent}

As required by the University of Louisville’s Internal Review Board (IRB) for Research with Human Subjects, disclosure information was distributed and signed consent forms were obtained for all participants. Administrators and teachers who participated by completing surveys or through interviews and observations received 
disclosure information and signed consent forms either at faculty meeting or during individual interviews. For students, consent forms and disclosure information were distributed in classes asked to participate. I explained the study and students’ participation in the study to all classes in which I was observing and interviewing students. My explanation of the study included the purpose of the study, perceived benefits, as well as requirements for participants.

IRB regulations for research with human subjects require that students under the age of 18 must have parent permission to participate in a school research study. Hence, after explaining the study to the students, I asked them to take two copies of the consent letter home to a parent, to keep the white copy and return the green copy with a parent signature. One difficulty in studying middle school boys is getting them to return a parent consent form. I used rewards such as University of Louisville basketball posters and frequent reminders to obtain the required signatures.

\section{Data Collection: Surveys}

Surveys about school-related attitudes and beliefs were completed by teachers and administrators. As required by the IRB, all teachers and administrators who completed surveys received the required disclosure information and signed consent forms.

\section{Faculty Surveys}

I administered, at each of the three schools, two surveys to the school's faculty: the Organizational Health Inventory for Middle Schools (OHI-M) developed by Hoy and Sabo (1998) and the Collective Efficacy Scale (CTE) developed by Goddard, Hoy, and Hoy (2000). In an initial interview with each school principal in which I explained the purposes and methods of my study, I asked for and was granted permission to administer these surveys myself at a scheduled faculty meeting. 
Organizational Health. The Organizational Health Inventory for Middle Schools (OHI-M) is a 45-item scale and measures a school's health on the institutional, administrator, and teacher levels. A healthy school maintains harmony within its community; meets its functional needs; and allows its leaders to direct collective energies toward the mission. The six dimensions of the OHI-M are teacher affiliation, academic emphasis, collegial leadership, resource support, principal influence, and institutional integrity. A school's teachers and administrators are asked to rate items based on occurrence by selecting from “rarely occurs”(RO); "sometimes occurs”(SO); “often occurs" (O); and "very frequently occurs” (VFO). Sample items from the principal influence dimension and the institutional integrity dimension, respectively, include: "The principal gets what he or she asks for from superiors" and "A few vocal parents can change school policy.” (see Appendix A for complete instrument) In a pilot study, each sub-scale was found to have high reliability coefficients with alphas of either .93 or .94 for all six factors. Construct validity was established by comparing the scale with the stable factor structure of Organizational Climate Descriptive Questionnaire (Hoy \& Hannum, 1997).

Collective Teacher Efficacy. The Collective Efficacy Scale (CE-Scale) was originally developed by modifying Gibson and Dembo’s 1984 Teacher Efficacy Scale (TES). To establish content validity, investigators engaged a panel of experts to review the scale, and based on the panel's review, added several new items. The resulting 21item scale has two dimensions: analysis of the teaching task and assessment of teaching competence, and these relate to the dimensions personal and general teaching efficacy the original instrument designed for self-assessment of an individual teacher's capabilities 
(Gibson \& Dembo, 1984). Teachers rate items on a 6-point Likert scale with anchors of Strongly Agree and Strongly Disagree.

The analysis of task factor produces inferences about the challenges of teaching at that school, such as the abilities of students, motivation of students, and the presence of resources and constraints. Sample items include "These students come to school ready to learn,” and “The lack of instructional materials and supplies makes teaching very difficult.” Teachers make judgments about the teaching competence of their colleagues based on skills, methods, training, and expertise. Sample items for this second factor are “Teachers here are confident they will be able to motivate their students," and "Teachers in the school do not have the skill to deal with student disciplinary problems.” (See Appendix B for complete CE-Scale.)

In studying collective teacher efficacy at an elementary school, researchers tested criterion-related validity of the scale by using other instruments to examine the scale's correlations with factors such as sense of powerlessness, trust in colleagues, and individual efficacy. As anticipated, sense of powerless $(\mathrm{r}=-.51, p<.001)$ was significantly but negatively correlated with CE scores, and both trust in colleagues $(\mathrm{r}=$ $.67, p<.001)$ and individual efficacy $(\mathrm{r}=.41, p<.001)$ were positively correlated with CE scores for the pilot study sample of 70 elementary teachers (Goddard, et al., 2000). Researchers also used a pilot study to test internal consistency reliability and criterion validity for the scale. Although the scale has two factors, all of the items loaded on one factor for this elementary school sample, with all but four items loading at .71 or above. These results provide evidence that when elementary school educators evaluate collective efficacy, they unite the concepts of group competence and task analysis (Goddard, et al., 
2000) and for the current study only a total score is analyzed for collective teacher

efficacy.

Mathematics Teacher Questionnaires

To measure mathematics teacher beliefs, I asked the six mathematics teachers selected for the study to complete the Mathematics Teacher Efficacy Beliefs Instrument ( MTEBI; Riggs \& Enochs, 1990) and a questionnaire I developed from a mathematics beliefs schema used in a study of teacher beliefs about mathematics, teaching mathematics, and learning mathematics (Raymond, 1997).

Mathematics Teacher Efficacy Beliefs Instrument. Because self-efficacy is most appropriately measured in specific contexts (Bandura, 1997), Riggs and Enochs (1990) developed a subject-specific instrument to measure teacher efficacy beliefs for science. The Science Teacher Efficacy Beliefs Instrument (STEBI) was developed using Gibson \& Dembo’s (1984) model and later adapted to create the MTEBI (Stevens \& Wenner, 1996; Wenner, 2001). The outcome expectancy dimension relates to the general efficacy construct of the Teacher Efficacy Scale (Gibson \& Dembo, 1984 and also relates to the "difficulty of teaching task" as assessed in the CE instrument. The MTEBI consists of two largely uncorrelated sub-scales of personal teaching efficacy and teaching outcome expectancy for mathematics (Henson, Kogan, \& Vacha-Haase, 2001). An example from the teaching efficacy sub-scale is "If parents comment that their child is showing more interest in math at school, it is probably due to the performance of the child's teacher.” Riggs and Enochs (1990) used factor analysis on the scale and concluded that the instrument was reasonable and valid. In a series of three studies in which the scaled was administered to elementary school teachers, alphas for the entire scale were $.93, .92$, and .86 (see Appendix C for complete instrument). 
Mathematics teacher beliefs. At the initial interview, the six mathematics

teachers of the study received a questionnaire and were asked to respond using a 6-point

Likert scale with anchors of Strongly Agree(1) and Strongly Disagree (6). The

questionnaire consisted of 33 statements about the nature of mathematics, teaching

mathematics, and learning mathematics. Statements were drawn from a schema

developed in a beliefs study for elementary mathematics teachers (Raymond, 1997) and

were classified similarly as traditional, primarily traditional, an even mix of traditional

and non-traditional, primarily non-traditional, or non-traditional. Samples of statements

revealing traditional or non-traditional beliefs were as follows (See Appendix D for the

complete instrument).

Traditional Beliefs

Mathematics is fixed, predictable, absolute, certain, and applicable (nature of

mathematics)

The teacher's role is to assign individual seat work (teaching)

Memorization and mastery of algorithms signify learning (learning)

Primarily Traditional Beliefs

The teacher should emphasize memorization over understanding (teaching)

Students learn mathematics mainly from the textbook and worksheets (learning)

Even Mix of Traditional and Non-Traditional Beliefs

Mathematics is a static but unified body of knowledge with interconnecting

structures (nature)

Primarily Non-Traditional Beliefs

Students learn mathematics primarily as active learners (learning)

Students learn mathematics mainly through problem-solving activities (learning)

Non- Traditional Beliefs

Mathematics is dynamic, problem driven, and continually expanding (nature)

The teacher should promote student autonomy (teaching)

Students learn mathematics through cooperative group interactions (learning).

Of the 33 items on the questionnaire, there were 5 statements relating to beliefs about the nature of mathematics, 13 items relating to beliefs on teaching mathematics, and 15 items relating to the learning of mathematics. To help teachers avoid outside influence on their 
responses, they were instructed not to ponder each question but to answer with their first impression.

\section{Faculty Survey Administration}

I administered the OHI-M and the CE-Scale to the faculties of the three schools at their regular December faculty meetings. I told each principal that, because everyone at the school had been so hospitable to me and willing to help, I would like to bring holiday treats for the faculty meeting. The principal approved and thought it would be appreciated by the faculty. In administering the surveys at the three meetings, I distributed to each faculty member, including administrators, a stapled packet, including a consent form on the top attached to the two surveys, the OHI-M and the CE-Scale. To ensure the confidentiality of faculty responses, participants gave their packets directly to me. As they handed them to me, I detached the consent forms from the responses and placed responses inside a large envelope. This way there was no name associated with responses on the surveys. The two surveys took about 15 minutes for teachers and administrators to complete.

\section{Data Collection: Observations}

\section{Mathematics Class Observations}

During the screening of cases, I decided to study two mathematics teachers at each school, instead of my original plan to focus on only one. This decision provided me with the opportunity to focus on two different grade levels and to compare strategies, management, behavior, and activities. The study of two mathematics teachers in the same school also allowed the possibility of distinguishing between teacher factors and school factors affecting classroom phenomena. I observed at least eight classes taught by each of the six mathematics teachers of the study during my residency period at the 
school. After selecting teachers and holding initial meetings with them, we agreed on one of their all-boy classes for me to observe and study. However, I later decided, at two of the schools, to observe more than one all-boy section taught by that teacher. At one school, the classes in both $6^{\text {th }}$ and $7^{\text {th }}$ grade were rearranged after observations began. In $6^{\text {th }}$ grade, the students on the all-boy teams were rearranged according to reading stanines. In 7th grade, classes were rearranged twice -once due to the reading stanines, and then again, because a new teacher was added to the team, increasing the number of sections from four to five. At another school, I wanted to make some comparisons between classes on the regular class and honors track. For each class observed, I made hand-written notes and recorded an audio-tape of the lesson. Using the hand-written notes for additional information and corroboration, I transcribed these audio recordings. I then used HyperResearch, a program designed for qualitative analysis, to search for themes and categories in the observational data.

For my on-site observation notes and subsequent interpretations, I focused on three dimensions of the lesson: learning environment, tasks, and discourse, which are delineated and explained in Becoming a Reflective Mathematics Teacher (Artzt \& Armour-Thomas, 2002). For learning environment, the authors listed the following noteworthy factors: maintaining a positive rapport and appropriate student behavior, encouraging student involvement, allowing time for students to express themselves mathematically, and managing instruction with effective procedures and routines. Factors worthy of note in the task category included using different modes of representation, engaging students' curiosities and interests, and sequencing tasks for progressive levels of difficulty (Artzt \& Armour-Thomas, 2002). 
In the discourse category, authors recommended tracking teacher/student communications that were non-judgmental and encouraged questions, as well as beneficial student/student discussions (Artzt \& Armour-Thomas, 2002). Managing mathematical discourse is one of the most important, yet complex, tasks of teaching (Kilpatrick, et al., 2001). In studying characteristics of NCTM standards-based teaching, researchers identified nine observable characteristics of standards-based teaching. Those that related to mathematical discourse were as follows: the lesson provided the opportunity to make conjectures about mathematical ideas; the lesson explored connections within mathematics and connections to students' daily lives; students explained their responses and solution strategies; the teacher encouraged and valued multiple perspectives and strategies; the teacher valued students' statements about mathematics and used inquiries as a guide for instructional decisions; and students were encouraged to reflect upon whether or not the answer was reasonable (Reys, 2004)

In my observations, I frequently tried to move around the room and to record notes about what particular students were doing, what they were saying, or what questions they were asking. I also made notes about students who were engaged and students who were off-task. In the all-boy context, I looked for strategies and characteristics reminiscent of reports about boys that appear in the research literature. While classes were engaged in all-class, teacher-led instruction, I sat in a student desk located in different areas of the classroom, but preferably near students. With permission of the teacher, I sometimes involved myself in group discussions and moved the audio cassette recorder near a particular group while they were working on an activity or solving a problem. I also talked with students about strategies, methods, and answers for problems they were working in class and answered their questions. 


\section{Additional Teacher Observations}

All three middle schools of the study used team structures, and for each of the six cases of the study, I identified another teacher on the team with previous experience with all-boy classes and observed an their all-boy class with the same students. Research recommends that rules and procedures for middle school students should be specific, so that the student has a clear idea what type of behavior is expected of him and what range of behaviors are appropriate (Manning, Lucking, and MacDonald, 1995). One advantage of the teaming model is the emphasis on uniformity of rules and procedures across the teachers of the team (Beane \& Brodhagen, 2001). A high level of implementation for the team model is characterized by consistency of rules and structures over all classrooms of the team. By observing a class of another teacher, I was able to gain information about consistency of rules and procedures over the teachers of the team for the boys' classes and to learn about strategies that those teachers were using with the boys.

\section{Field Notes}

Observations that I made in other areas of the school buildings, faculty meeting observations, and informal conversations that I had with teachers, administrators, and students outside the mathematics teachers' classrooms were recorded in field notes. At each school, I asked permission of the principal to observe faculty meetings during my residency periods. I recorded meeting observations in my field notes only, because making an audio-tape of the meeting might have been perceived as intrusive. At faculty meetings, I observed the leadership style of the principal and responses and interactions of faculty to that leadership style. I noted items on the faculty meeting agenda, and also considered the types of issues that they spent the most time discussing. In some instances, 
I noted how much meeting time was spent on particular topics such as student learning, testing, and discipline.

\section{Data Collection: Interviews}

In the three schools of this study, I conducted interviews with principals, mathematics teachers, students, and teachers who taught student participants in other subject areas.

\section{Principal Interviews}

I arranged an interview with the principal during my residency period at the school and again after all of the classroom observations and surveys were completed. To interview principals, I made an appointment at least a week ahead of the scheduled interview at the principal's convenience, and these interviews lasted about thirty minutes. In one of the schools, I used an assistant principal as the interviewee, since she had been at the school for 17 years and the principal was new to the school this year. In order to follow up with future correspondence, I obtained, from the principal, contact information, which enabled me to triangulate interview data with results from the OHI-M and the CE scale and to employ comparative analysis. Principals were interviewed using the following interview protocol (see Table 3-2).

Table 3-2

Protocol for Principal Interview

1. Discuss with me some of the positive effects and negative effects of single-gender education in your school?

2. Do you think that your faculty buys-in to the single-gender (single-gender) strategy?

3. What are some different reactions, attitudes, and beliefs you perceive in teachers about teaching boys and teaching girls?

4. What accommodations or modifications do they make in their classrooms with respect to gender? 
5. Tell me about professional development that you provide for teachers. How often? Over how long a period of time? For teaching single-gender classes? For teaching mathematics?

6. Tell me about your perceptions of working relationships among teachers.

7. What effects are standardized testing, accountability, and curriculum standards having on your school?

8. What are the main goals and objectives you are addressing in your school this year?

9. Are your schools goals and objectives supported by the school district?

10. Does your district provide your school with adequate resources (e.g. instructional materials and professional development)?

11. What are some of your teachers' main challenged with their all-boy classes and how do they cope with those challenges?

\section{Teacher Interviews}

For teacher interviews, I made arrangements to talk with the teachers during a planning period, again giving the teacher about a week's notice. However, for teacher interviews, rescheduling was frequently necessary due to a parent conference, a team meeting, a change in daily schedule, or another event which took precedence. The mathematics teacher interviews usually took two planning periods. I conducted follow-up interviews of both the principals and the mathematics teachers after all of the classroom observations had been conducted and the surveys administered.

Mathematics teacher interviews. I conducted an interview with the mathematics teacher selected for the study once during the residency period and again after all of the classroom observations were completed. I obtained contact information from the mathematics teacher of the studied classrooms, such as Email address or telephone number, for future correspondence, and after the residency period ends. These additional contacts permitted me to triangulate interview and survey data and to employ comparative analysis and member checking. The mathematics teacher was interviewed using the following protocol (See Table 3-3). 
Table 3-3

Protocol for the Mathematics Teacher Interview

General Questions

1. Discuss with me some of the positive and negative effects of the single-gender education that you perceive in your classes and in your school.

2. Tell me about professional development that you have received. How often? Over how long a period of time? For teaching single-gender classes? For teaching mathematics?

3. Do you have the resources you need to teach effectively?

4. Do you feel as if the school's administration is supporting your work in the classroom?

5. Tell me about your perceptions of working relationships among teachers? Plan together? Observe/ critique each other? Work mostly alone?

6. What effects are standardized testing, accountability, and state curriculum standards having on your teaching?

7. Do you practice teaming? Do teachers who teach the same students have approximately the same rules?

8. Do you and other teachers do interdisciplinary activities with students?

9. Do boy students or girl students talk to you about their personal problems?

10. Do you think single-gender classes can improve student outcomes? Which outcomes (e.g. test scores, self-esteem, adjustment, focus, behavior, academic interest, failure rates)?

11. Discuss differences (if any) in teaching strategies for all-boy classes; from coed classes; all-girls classes.

12. Discuss differences in classroom management strategies for all-boy classes; from coed classes; all-girls classes.

13. Please talk about some of the learning strengths of the boys you teach.

14. Please talk about some of the learning needs that you find among the boys in the classroom. Are these different from the learning needs of girls?

15. What has teaching all-boy classes taught you about boys that you didn't know before?

Questions Specific to Mathematics

16. Tell me about professional development that you have received for teaching mathematics. How often? Over how long a period of time?

17. Do you think that boys and girls have different beliefs about and attitudes toward learning mathematics?

18. Do you think that boys and girls have different ways of learning mathematics, of doing mathematics, or of solving mathematics problems?

19. Do you feel that boys and girls are motivated differently in learning mathematics? Relate this to the all-boy environment.

20. Are some strategies for teaching boys more effective? If so, what are they? Would these work with girls, too?

21. What do you see as some of the important factors for improving mathematics learning for your students? Do these relate to gender? 
22. How do you use the mathematics textbook? as a scope and sequence guide? as a resource for specific topics and lessons ? not at all ?

Interviews of other teachers. For each of the six mathematics teachers in the study, I interviewed another teacher on the same team. These teachers taught the same students in different subject areas, and I also observed one class for each of the teachers that I interviewed. The selected teachers were interviewed once during my period of residency, and I obtained contact information from each teacher, such as Email address or telephone number, for future correspondence. These additional contacts permitted me to triangulate interview and survey data and to employ comparative analysis and member checking. The teachers selected for interview responded to the following protocol (see

Table 3-4).

Table 3-4

Protocol for Interview of Other Teachers

1. Discuss with me some of the positive and negative effects of the single-gender education that you perceive in your classes and in your school.

2. Tell me about professional development that you have received. How often? Over how long a period of time? For teaching single-gender classes?

3. Do you have the resources you need to teach effectively?

4. Do you feel as if the school's administration is supporting your work in the classroom?

5. Tell me about your perceptions of working relationships among teachers? Plan together? Observe/ critique each other? Work mostly alone?

6. What effects are standardized testing, accountability, and state curriculum standards having on your teaching?

7. Do you practice teaming? Do teachers who teach the same students have approximately the same rules?

8. Do you and other teachers do interdisciplinary activities with students?

9. Do boy students or girl students talk to you about their personal problems?

10. Do you think single-gender classes can improve student outcomes? Which outcomes (e.g. test scores, self-esteem, adjustment, focus, behavior, academic interest, failure rates)?

11. Discuss differences (if any) in teaching strategies for all-boy classes; from coed classes; all-girls classes.

12. Discuss differences in classroom management strategies for all-boy classes; from coed classes; all-girls classes. 
13. Please talk about some of the learning strengths of the boys you teach.

14. Please talk about some of the learning needs that you find among the boys in the classroom. Are these different from the learning needs of girls?

15. What has teaching all-boy classes taught you about boys that you didn’t know before?

\section{Student Interviews}

For student interviews, twelve focus groups of two or three boys each were selected and 31 boys in all responded to questions from the interview protocol. Each of the mathematics teachers of the study helped me select two groups of three students from the observed classes to be interviewed. Teachers selected boys that they felt would be willing to talk with me and be best at answering questions. To obtain a variety of viewpoints, ethnicity was also considered. I selected the focus group structure to talk to the boys because, in a previous study, I had encountered difficulty getting the boys to talk in a one-on-one interview. The focus group strategy proved to be more successful. With a group of two or three, the boys would sometimes agree with each other and at other times would express their own ideas. Although they would sometimes talk all at once, I chose to encourage this because I felt that this strategy produced more honest and thoughtful answers. However, if one or two boys seemed to be doing all the talking, I would ask the more reticent boy for his response or opinion. All in all, I felt that the group interview provided more information than the individual interviews of the previous study. These interviews were audio-recorded and later transcribed.

The students who were selected for interview responded to the questions on the following interview protocol (see Table 3-5). Questions were designed to lead students in reflecting on the change to single-gender classes and reporting about various aspects of their mathematics class. 
Table 3-5

Protocol for Student Interviews

1. How do you like all-boy classes?

2. Do you think you are learning better?

3. What are some of the pros and cons of (all-boy classes) not having girls in the class?

4. Do you think math is important?

5. Do you sometimes feel that math is too hard? too easy? not understandable?

6. Tell me a little about your math teacher.

7. What are some ways you learn math best?

8. What could your teacher do to help you learn better?

9. Do you think your teacher likes having all-boys?

10. What are some of the things that make you want to learn and to try hard?

11. Do you feel that if you try hard you can learn and make good grades?

12. Do you work in groups much in math class? If so, do you like working in groups?

13. Do you use graphing calculators or computers? How frequently? Once a week? Twice?

14. Do you plan to take advanced math in high school?

15. Is there a more advanced math class at your school than the one you are taking or are all the math classes the same? How is it decided which students will enroll in that class?

\section{Data Collection: Test Scores}

To create a comprehensive overview for the schools of the study, study data included published school results from state-administered achievement tests. The state assessments were criterion-referenced tests focused on the measurement of school improvement and not focused on the measurement of individual student progress. Accordingly, students were not assessed in mathematics each year. Schools also may periodically assess particular groups of students using norm-referenced achievement tests, and those scores were also included in the data collection process. School-wide objectives for student learning of mathematics lead in the direction of proficiency for all students. Because a purpose of the study was to learn about how schools implemented single-gender programs as part of improvement plans, analysis of results for school-wide progress in achievement was appropriate. 


\section{Data Analysis}

As stated previously, the overriding theme of this study was the education of boys, and thus, a primary goal in data analysis was to identify, explore, and interpret the following factors for the early adolescent male: organizational structures that nurture them; means of communication that reach them; teaching strategies that engage and challenge their cognitive abilities; and learning aids that support their weakness and capitalize on their strengths. A secondary area of interest was the examination of relationships of collected data with research in mathematics education and research in middle school reform. A third area of inquiry was the relationship of teacher beliefs about teaching and learning mathematics and classroom practices. Analyses related to boys' learning, standards and research, as well as teacher beliefs will extend over all four research questions and all types of collected data.

\section{Faculty Surveys}

Two surveys were administered to the faculties of the three schools of the study: the Organizational Health Instrument for Middle Schools (OHI-M; Hoy \& Sabo, 1997) and the Collective Teacher Efficacy (CE-Scale;Goddard, Hoy, \& Hoy, 2000). The organizational health of a school relates to how a school copes with its environment and community and with its ability to direct energy toward its mission and objectives. Educational research has recently focused interest on the construct of collective teacher efficacy because of its relationship to positive school goal attainment (Goddard, Hoy, \& Hoy, 2004). The CE-Scale measures teacher beliefs about their collective capabilities for teaching their students. A model of the construct (Goddard, et al, 2000; Goddard, et al. 2004) depicts collective efficacy as a joint analysis of teaching competence and the difficulty of the teaching task. The surveys were first analyzed both using procedures 
recommended by the instrument developers. Then to make additional comparisons of the three schools, they were further analyzed using analysis of variance techniques. Survey instructions and a list of all items for the OHI-M and the CE instruments appear in Appendix A and Appendix B, respectively.

\section{Mathematics Teacher Questionnaires}

In addition to the surveys administered at faculty meetings, the six mathematics teachers of the study were asked to complete two other questionnaires. Research indicates that a teacher's beliefs about mathematics and mathematics teaching can have a significant effect on practice (Thompson, 1992; Raymond, 1997). The six mathematics teachers of the study completed two instruments relating to mathematics beliefs. The first instrument was a 25-item survey measuring mathematics teaching efficacy. The Mathematics Teacher Efficacy Beliefs Instrument (MTEBI) was developed Stevens and Wenner (1996) from the Riggs and Enochs instrument (1990) to measure efficacy beliefs in science teaching. The second was a mathematics beliefs questionnaire, a 6-point Likert-scale survey that I developed from Raymond's (1997) schema of traditional vs. non-traditional teacher beliefs. See Appendix C for items of the MTEBI and Appendix D for a full list of items for the Mathematics Beliefs Questionnaire.

MTEBI survey was a 25-item questionnaire designed to measure how competent teachers feel in teaching mathematics to their students. Developers and subsequent researchers using the MTEBI separated mathematics and science teaching efficacy into two factors. The first factor was called personal teaching efficacy (Riggs \& Enochs, 1990) or confidence in teaching ability (Wenner, 2001). In the researchers' model for collective teaching efficacy this dimension was referred to as "assessment of teaching competence.” The other factor of the MTEBI related to the students being taught. This 
factor was referred to by researchers using the instrument as outcome expectancy (Riggs \& Enochs, 1990) or accountability. In the researchers' model for collective efficacy, a factor related to this factor for individual efficacy was called "assessment of teaching task.”

I developed the mathematics teacher beliefs questionnaire from a schema created by researcher Anne M. Raymond (1997). Responses to the 33-item questionnaire were based on a six-point Likert scale, and teachers indicated their levels of agreement with statements about the nature of mathematics, about teaching mathematics, and about learning mathematics. Each item, both in Raymond's schema and the subsequent questionnaire, described beliefs classified along a traditional to non-traditional continuum. Because the items used for this study's questionnaire had been only used previously for teacher interviews, there were no scoring guidelines available.

I analyzed this mathematics beliefs questionnaire by finding mean scores for teacher beliefs in three categories: the nature of mathematics; the teaching of mathematics; and the learning of mathematics. These scores were then assessed according to where they fell along the continuum from traditional to non-traditional according to Raymond's schema (1997). Then using a schema developed by Raymond (1997) to characterize teacher practice, I analyzed the teaching practice of the six mathematics teachers of the study. Again, their teaching practices were characterized by relating them to a continuum from traditional to non-traditional.

\section{Classroom Observations}

I conducted 9-12 classroom observations of each of the mathematics teachers of the study, and all were audio-recorded and later transcribed. I also took hand-written notes in each observation. For further analysis selected 8 observations from each teacher 
and used HyperResearch software for qualitative data analysis to code these 8

observations for each teacher. Codes used to record and identify classroom occurrences included codes characterizing strategies for teaching boys, classroom structures, management strategies, types of mathematics discourse, and characteristics of teaching for mathematics proficiency. A master list of codes used for classroom observations is given in Appendix E.

Interviews

Interviews with principals, teachers, and students were voice-recorded and later transcribed. Parallel comparisons were made of responses and other interview information among the three principals, the six teachers, and the 12 groups of students who were interviewed. Interview data was also compared and triangulated with data from surveys, questionnaires, and observations.

\section{School and District Factors}

Research Question 1 of the study inquired about school and district factors affecting the all-boy mathematics classes and the teachers who teach them, and to identify them, I used the following: results of the OHI-M and the CE-Scale; interview and observational data; and a list complied through meta-analysis of research (Marzano, 2003). To create his list, Marzano reviewed and consolidated research findings on school factors that affect student achievement. He reviewed a number of studies and used results to develop a list of between 20 and 25 effective school factors. He, then, condensed the list into five, and his compiled list of five school factors included the following: a guaranteed and viable curriculum; challenging goals and effective feedback; parent and community involvement; a safe and orderly environment; and collegiality and professionalism. Marzano’s list of school factors did not coincide exactly with my areas 
of inquiry (e.g. parent and community involvement), but my collected data did provide some relevant information.

Instead of classifying leadership as a school factor, Marzano characterized leadership as an "overarching variable that impacts the effective implementation of the school level factors, teacher-level factors, and student-level factors (p. 20).” Other research on leadership also suggests its complexity, illusive qualities, and difficulty in description (Good \& Brophy, 1986).

To compare the effectiveness of three schools of the study, I used the collected data to rate schools according to Marzano's list of five school factors, and added to those, the additional factors of collective teacher efficacy and leadership, making a total of seven. Using these seven factors as criteria, I rated the schools as high, medium, or low for effectiveness.

\section{Structures and Strategies}

Question 2 asked about structures and strategies used in all-boy mathematics classrooms, and I identified three areas of inquiry in which to describe, interpret, and compare schools in response to this question: structures and strategies recommended by middle school reform research (Carnegie Council, 1989; National Middle School Association, 1995); structures and strategies for classroom management; and strategies teachers were using to teach boys. in middle school, and structures and strategies of the middle school reform movement, such as teaming and teacher mentoring of students, fit in this category. Middle school reform research advocated five common expectations of middle school teachers: a thorough understanding of developmental concerns of young adolescents; participation in a collegial interdisciplinary team arrangement; mentorship for students; provision of a variety of teaching and learning activities; and an approach 
beyond the traditional separate-subject model (Beane \& Brodhagen, 2001). Using observation and interview data, I considered levels of implementation for middle school reform principles by teacher and by school.

Classroom management methods for the six teachers of the study were described, analyzed and compared with each other, with research on classroom management for early adolescents, and with classroom management programs, such as CHAMPs (Sprick, Garrison, \& Howard, 1998). Teacher observations were analyzed to determine how much time each teacher spent on classroom management, and HyperResearch codings were used to track instances in which teachers corrected behavior or modeled appropriate behaviors.

One of the main purposes of the study was to identify new structures and strategies that teachers of the study were using to teach middle school mathematics in allboy classes, and results for Question 2 include details, interpretation, and analysis for these observed strategies. The study investigated both strategies that had been described and identified in other research inquiries and some that had not. The analysis includes a comprehensive list of all strategies observed in the all-boy classes of the study and details of how teachers used the strategies. Also considered were the number of times particular strategies were observed.

\section{Teacher Characteristics}

Question 3 of the study explored teacher characteristics, and these characteristics were also related to strategies teachers used and to how they taught mathematics. Teacher characteristics considered in responding to Question 3 included mathematics teacher beliefs, gender and ethnicity, and career characteristics (e.g. experience and career goals) identified as being relevant to study results. 
The MTEBI and the Mathematics Beliefs Questionnaire, along with interviews were used to analyze mathematics teacher beliefs. Beliefs were compared with teacher practice, experience, and other characteristics. Both mathematics teacher beliefs and practices were considered along a continuum from traditional to non-traditional. A traditional mathematics learning environment is usually thought of as teacher-centered, one in which the students passively receive knowledge from the teacher. Non-traditional teaching approaches are primarily student-centered and include an emphasis on mathematical discourse, hands-on activities, and group work. Analysis of teacher beliefs was also related to textbook use and time allocation. The significance of the gender and race of the mathematics teacher was described, interpreted, and analyzed using classroom observations and interviews.

\section{Teaching Mathematics}

Data related to the characteristics of the mathematics teaching practiced by the teachers of the study were collected from observations, interviews, and teacher questionnaires and were used to respond to Question 4. Aspects of teaching considered for analysis were time allocation; characteristics of teaching, as they related to mathematics education research and the five strands of mathematics proficiency (Kilpatrick, et al., 2001); and textbook use. Analysis and interpretation of results also include summary information for each teacher, presenting detailed overviews and interpretations of practice including classroom management, characteristics of mathematics teaching, time allocation, and textbook use.

Mathematics teaching and learning, when considered broadly, can be characterized as either traditional or non-traditional. A traditional mathematics learning environment is usually thought of as teacher-centered, one in which the students 
passively receive knowledge from the teacher. Teachers demonstrate procedures and teachers ask questions of students for which a particular answer is expected. Practice holds an important position in the traditional mathematics classroom. Non-traditional teaching approaches are primarily student-centered and include an emphasis on classroom discourse in which teachers ask open-ended questions about mathematics; ask students to explain reasoning and problem solving strategies; and lead classroom discussions toward high levels of student thinking. In non-traditional classroom environments, students have opportunities to work in groups, to participate in hands-on activities and to sharing thoughts and ideas with other students.

Allocation of classroom time. To determine how teachers of the study allocated classroom time, I selected eight observations, 50 minutes each, for each of the six teachers of the study. This totaled 400 minutes of class time, and I then reviewed the transcripts for these selected observations and estimated the number of minutes during each class spent on the various activities of the day's mathematic lesson. I then compiled the list of these activities into several categories and then categorized time allocation further into the two categories of traditional (teacher-centered) practices or nontraditional (student-centered) practices. For example, the time spent on discourse, individual activities, and group activities would suggest non-traditional practices and time spent on activities such as note-taking and procedures, as traditional. Decisions about how to characterize teacher-led dialogue as either discourse or teacher-centered activity were difficult, but for discourse, I tried to look for teacher/student discussions that explored students' thinking and encouraged multiple strategies or representations. I also considered the asking of open-ended questions or the requesting of student explanations in the category of mathematical discourse rather than in the category with 
more traditional teacher-led question and answer discussions. The following code list provides detailed descriptions of how teacher time was allocated. The portions of time spent on mathematics (vs. management or free time) and the time spent on preparation for standardized testing were also considered.

\section{$\underline{\text { List of Time Allocation Codes }}$}

M- management (travel from previous class or restroom, behavior, distribution of papers, administrative information)

F- Free time or down time

D- Discourse (open-ended questions and responses, requests for explanations and reasoning, conjectures and generalizations, discourse on mathematics concepts)

$\mathrm{T}$ - Teacher-centered activities such as notes, procedures, vocabulary, spelling test, demonstrating solutions to problems, reading aloud)

P - Practice (seatwork, homework)

IA - Individual Activity (problem solving, making graphs, computer lab, manipulatives, modeling, hands-on, calculators)

GA- Group Activity (work with group or partner; problem solving, collect data, manipulatives, modeling, hands-on)

$\mathrm{Ma}$ - Percent of time spent on mathematics (not included in 100\% tally)

ST - Percent of time spent on preparing for standardized tests (not included in 100\% tally).

Mathematics proficiency and characteristics of teaching. For an overall

framework in looking at mathematics teacher practices of the study, I have adopted the National Research Council’s five interwoven strands of mathematics proficiency

(Kilpatrick, et al., 2001). The five strands are conceptual understanding, procedural fluency, strategic competence, adaptive reasoning, and productive disposition. In the National Research Council (NRC) book, Adding It Up: Helping Children Learn

Mathematics (Kilpatrick,2001), a main point made by the authors was that mathematics proficiency is complex and cannot be characterized as only understanding concepts or competency in performing skills.

In further structuring a framework for the analysis of classroom observations, I used the following four lists to classify observational information: a list of characteristics 
of mathematics reform (Ross, et. al., 2002); a list of nine characteristics of standardsbased instruction (Reys, 2004); a list of characteristics of teaching for mathematics proficiency (Kilpatrick, et al., 2001), further classified according to a teacher/student/content triangle (Cohen \& Ball, 2000); and a list of metacognitive strategies (Bransford, et al., 2000).

I used multiple sources and lists because I thought that each list added important aspects of the five strands for mathematics proficiency that were not included in the other lists. The lists for characteristics for NCTM standards-based reform (Ross, et al., 2002) and the list for characteristics of standards-based classroom instruction are closely aligned with characteristics of non-traditional teaching practice. But neither of these lists included homework and practice of skills, and thus, may underemphasize the strand of procedural fluency. The list of standards-based instruction characteristics provided details needed to distinguish mathematical discourse from other types of discourse in classroom situations. Additionally, if a goal of teaching is to move toward more student-centered classrooms, then metacognitive strategies or skills in monitoring one’s own learning, should be important aspects of proficiency within the various strands.

Characteristics of mathematics reform. This list of characteristics emerged from a meta-analysis of studies about the effects of teaching mathematics based on standards established by the National Council for the Teachers of Mathematics (NCTM, 1989, 2000). The following list was a product of authors' reviews of individual studies and NCTM policy statements.

\section{Characteristics of Mathematics Reform (N1-N10)}

(Ross, McDougall, Hogaboam-Gray, 2002)

1. Broader scope; increased attention to topics less commonly taught like probability. 2. All students have access to all forms of mathematics, including teaching of complex mathematical (like algebra) ideas to less able students. 
3. Student tasks are complex, open-ended problems.

4. Instruction focuses on construction of mathematical ideas through students' talk rather than transmission through presentation, practice, feedback, and remediation.

5. The teacher's role in reform settings is that of co-learner and creator of a mathematical community rather than sole knowledge expert.

6. Mathematical problems are undertaken in reform classes with the aid of manipulatives and ready access to mathematical tools.

7. Student interaction is encouraged rather than discouraged.

8. Assessment is more far-reaching than the unit test at the end of the week. Assessment in a reform classroom includes a wide variety of skills and abilities and is integrated with daily class activities.

9. The conception of mathematics presented by the teacher is that of an active and dynamic pursuit rather than a fixed body of knowledge.

10. Student development of confidence in ability to do mathematics is an important competency in the reformed mathematics classroom.

Standards-based instruction. This list of characteristics of standards-based

instruction was developed by at the University of Wisconsin and later adapted for use in

the University of Missouri’s Middle School Mathematics Study (MS)² (Reys, 2004).

These nine descriptors served as observational guides for studying practices of

mathematics teachers (Reys, 2004).

Characteristics of Standards-Based Instruction (S1-S9)

( adapted from a U of Wisconsin list; Reys, 2004)

1. Lessons provided students opportunities to make conjectures about mathematical ideas.

2. The lesson fostered the development of conceptual understanding.

3. Connections within mathematics were explored in the lesson.

4. Connections between mathematics and students daily lives were apparent in the lesson.

5. Students explained their responses or solution strategies.

6. Multiple perspectives/strategies were encouraged and valued.

7. The teacher valued students' statements about mathematics and used them to build discussion or work toward shared understandings for the class.

8. The teacher used student inquiries as a guide for instructional decisions or as a guide to shape the mathematical content of the lesson.

9. The teacher encouraged students to reflect on reasonableness of their responses.

Teaching for mathematics proficiency. The following classroom and teacher

characteristics are suggested in the chapter "Teaching for Mathematic Proficiency” in the 
NRC book (Kilpatrick, et al. 2001). The chapter provides details to help teachers to learn to teach for mathematics proficiency, characterizing these details as relationships among the teacher, the student, and knowledge of mathematics, three sides of a

“teacher/student/content triangle” (Ball \& Cohen, 2000).

Teaching for Mathematics Proficiency: The Teacher/Student/Content Triangle (T1-T12) (Kilpatrick, Swafford, \& Findell, 2001; Ball \& Cohen, 2000)

Teachers and Content

1. Task selection and use

2. Opportunity to learn

3 Planning

Teachers and Students

4. Teacher expectations

5. Task value and efficacy

6. Learning community

7. Group vs. whole class activities

8. Assessment of student work

9. Mathematics discourse

$\underline{\text { Students and Content }}$

10. Practice

11. Homework

12. Use of tools (manipulatives, computer programs, calculators)

Metacognition. Another important component of understanding proficiency in

any subject area relates to understanding how learners connect pieces of knowledge.

Metacognition in mathematics is the knowledge of one's own thinking and the ability to monitor one’s own learning, reasoning, and problem solving ability (Kilpatrick, et al., 2001).

Characteristics of Metacognition

M1-7 (Bransford, Brown, \& Cocking, 2000)

1. monitor one's own learning

2. predicting outcomes,

3. targeting misunderstandings

4. activating prior knowledge

5. considering alternative strategies

6. self-regulation; apportionment of time and memory.

7. explaining reasoning 
Research has demonstrated that children can be taught these strategies (Bransford, et al.

2000). The strategy of apportioning time and memory relates to how to prepare for

performance involving memory and how much time it will take to perform a task.

Students can over-estimate their capabilities to remember information or under-estimate

the amount of time of a task requires.

Table 3-6

Mathematics Proficiency Framework for Observational Analysis

\begin{tabular}{|c|c|}
\hline $\begin{array}{l}\text { Conceptual } \\
\text { Underst. }\end{array}$ & 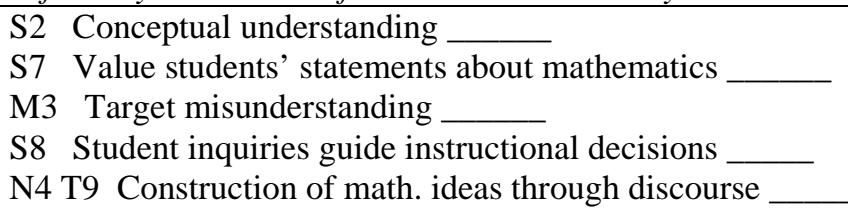 \\
\hline $\begin{array}{l}\text { Procedural } \\
\text { Fluency }\end{array}$ & $\begin{array}{l}\text { T10 Practice } \\
\text { T11 Homework }\end{array}$ \\
\hline $\begin{array}{l}\text { Strategic } \\
\text { Competence }\end{array}$ & $\begin{array}{l}\text { S1 M2 Make conjectures; predict outcomes } \\
\text { S6 M5 Multiple perspectives/strategies } \\
\text { N9 Mathematics is a dynamic, changing discipline } \\
\text { T1 N3 Task selection and use; complex open-ended tasks } \\
\overline{\text { S3, M4 Connections within math; activate prior knowledge }} \\
\text { M1 Metacognition; monitor one’s own learning }\end{array}$ \\
\hline $\begin{array}{l}\text { Adaptive } \\
\text { Reasoning }\end{array}$ & $\begin{array}{l}\text { S5 M7 Explain Reasoning } \\
\text { S9 Reflect on whether answer reasonable } \\
\text { T7 N7 Group activities; student/student interaction }\end{array}$ \\
\hline $\begin{array}{l}\text { Productive } \\
\text { Disposition }\end{array}$ & $\begin{array}{l}\text { S4 T5 Connections w daily life ; task value } \\
\text { N5 T6 math community; learning community __ } \\
\text { N10 student confidence; efficacy; } \\
\text { Math is enjoyable (inc. boy motivators) }\end{array}$ \\
\hline $\begin{array}{l}\text { All Strands } \\
\text { of } \\
\text { Math. } \\
\text { Proficiency }\end{array}$ & $\begin{array}{l}\text { T2 N1 N2 Opp. to learn challenging math; broad scope } \\
\text { T4 High teacher expectations } \\
\text { T3 Teacher planning } \\
\text { N8 T8 An integrated and broad assessment of student work } \\
\text { N6 T12 Use of tools (manipulatives, calculators, computers) } \\
\text { M6 Planning ahead; self-reg; apportion time \& mem. }\end{array}$ \\
\hline
\end{tabular}


A framework for mathematics proficiency. Table 3-6 organizes teaching and learning characteristics from these four lists under the framework of the strands of mathematical proficiency. In reviewing the set of lists used for the framework, I noticed that enjoyment of mathematics, which is referred to in describing the strands of proficiency (Kilpatrick, et al., 2001) but does not appear in a list. Therefore, I added “enjoyment of mathematics" as a sub-topic in the productive disposition section. Study findings revealed that the enjoyment of mathematics is an important factor for middle school boys who lose interest in school (Midgley, 2001; Gentry, et al., 2002). I included strategies teachers used to engage and motivate boys under this category.

Textbook use. There is current interest among educational researchers about how teachers use district-adopted textbooks and the fidelity of their implementations.

Research suggests that there is much variety in teachers' uses of curriculum materials and textbooks (Reys, 2004; Remillard, 2005). The following list, developed by the Middle School Mathematics Project (MS), ${ }^{2}$ categorizes that teachers' uses of textbooks according to five levels of authority.

\section{A List of (MS) $)^{2}$ Textbook Use Codes (Reys, 2004)}

Tx - Use of School/District Adopted Textbook

A - Comprehensive and trusted authority (what, when, and how to teach)

SS - A scope and sequence guide (what and when to teach)

$\mathrm{R}$ - An occasional or regular resource (homework, tasks, exercises, tests)

$\mathrm{N}$ - Textbook plays no role

Teachers may use textbooks daily, a significant amount during the year, or not frequently. Instructional decisions may or may not be influenced significantly by the instructional philosophy of the textbook (Reys, 2004). Preliminary results in (MS) ${ }^{2}$ suggested to investigators that teachers assigned various levels of authority to their district adopted textbooks (Reys, 2004). 


\section{Summary: Collection and Analysis of Data}

For the four research questions of the study data was collected on three different levels (See Figure 3-1). The school and district factors represented the outer level, and on the middle level, were the classroom and teacher factors. Factors identified for consideration on the school and district level were school health and collective teacher efficacy. On the middle level, factors included classroom management; middle school reform; boy strategies; gender/ethnicity; and teacher beliefs. The inner level of data related to the teaching of mathematics.

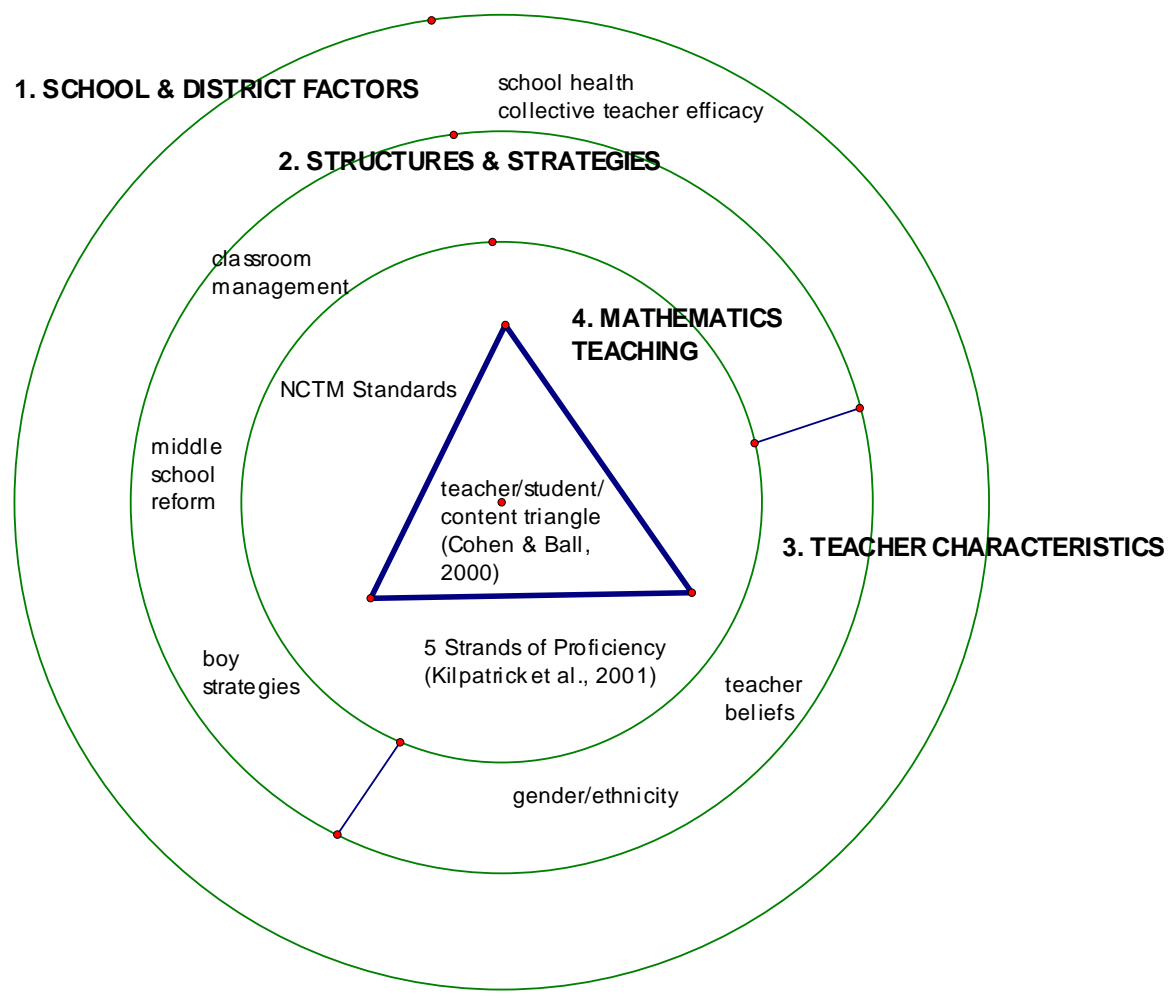

Figure 3-1. Diagram for Levels of Data Collection and Analysis 


\section{CHAPTER IV}

\section{RESULTS}

Terre Rouge, Greenville, and Bluefield

This is a story of three public middle schools that are experimenting with singlegender classes in an effort to improve the outcomes of targeted student populations. The investigation of these schools focuses on pedagogies, management styles and structures used by mathematics teachers of all-boy classes. Both school- and teacher-level factors are considered. On the school level, the study explores factors such as school health and collective teacher efficacy. The school-level findings also are compared with existing research on effective schools. On the classroom level, six mathematics teachers of allboy classes, including one 6th-grade teacher and one 7th-grade teacher from each school, were selected for the study. Two of the six teachers are males and four are female; two are African-American and four are Caucasian. At this level, investigations explore general details of classroom teaching and learning, teacher characteristics, and teacher beliefs. Then, the focus of inquiries shifts to the teaching and learning of mathematics. Areas of interest in the observations and interviews of the six teachers of the study were time allocation, teaching for mathematics proficiency (Kilpatrick, et al.) and textbook selection and use. Findings were compared to research in mathematics education. All names of schools, teachers, and administrators are pseudonyms. 


\section{Terre Rouge Middle School}

Situated in an increasingly transient neighborhood of a large mid-western city, Terre Rouge Middle School has experienced a decade of declining test scores, and in 2002, reported the state's lowest scores for a middle school. The school is part of a large county-wide school district, one of the largest school districts in the United States. The school population is approximately 800 students, the largest of the three schools of the study, with a student body that was almost exactly 50\% African-American and 50\% Caucasian or other. The school also reports that $90 \%$ of its students are eligible for free or reduced lunch programs. The neighborhood surrounding the school contains a declining school-age population and some students living in the neighborhood attend magnet middle schools in other parts of the city.

The current principal Dr. Alice Russell assumed duties in the fall of 1999, and soon after became interested in the prospect of using gender-specific strategies as a means for improving test scores. In the year preceding the change, Dr. Russell gathered information about single-gender education and shared it with her faculty. In the spring of 2002, the faculty and administrators had several discussions and voted unanimously to separate boys and girls in the core subjects (mathematics, language arts, reading, science, and social studies) for the following school year. For the pilot year of the single-gender experiment, Terre Rouge produced modest overall gains in scores, with more significant gains for the 7th grade team of boys (Davis, Choi, Ronau, \& Munoz, 2004). The fall of 2004 brought even better news to the Terre Rouge faculty: a five-point overall gain in test scores, one of the largest for the schools in the area. After learning of these gains, faculty identified preparation for testing, a focus on reading and writing, as well as the single-gender classes as possible reasons for these increases. 
The school building was built in the late 1920’s and was originally a high school. The three-story structure wraps around a courtyard that students are rarely allowed to enter. The open square configuration creates long halls on each of the four sides of the building on the first and second floors, and on the third floor, there is just one long hallway in the front of the building. Two gyms and a lunchroom extend from the firstfloor hall on one side of the building, and an auditorium occupies a center spot next to the courtyard. Staircases are located in the four corners of the building, with the front staircases appearing to be original to the structure. Each front staircase contains a center section that rises to a landing and is divided in half by a rail. Then, two split sections leave the landing on opposite sides and continue to rise to the next floor. The direction "up” is painted on the wall to the right and the left wall is marked "down."

The halls at Terre Rouge are bounded above by high ceilings and below by grey terrazzo floors. They also seem somewhat dark, and in walking through the halls, one experiences a cavernous and impersonal atmosphere, reminiscent of American high schools of past generations. Keeping the halls free of students while teachers are teaching in classrooms appears to be a major challenge. Through announcements at the end of the school day, visits to team meetings, and admonitions at faculty meetings, administrators remind teachers frequently of their responsibilities to keep the halls clear of unsupervised students and to escort students at all times as they move through the halls and to the buses in the afternoons.

To create a more intimate environment for its 800 students, Terre Rouge administrators use a team structure advocated by the middle school reform principles (Carnegie Council, 1989; National Middle School Association, 1995). Interdisciplinary teams of teachers lead single-gender teams of approximately 100 boys or 100 girls. The 
administration attempts to assign classrooms to teachers so that a team's four or five classrooms are adjacent and on the same hall. Almost all of the classrooms at Terre Rouge are large by current standards, and a few are large enough to hold meetings and gatherings for the entire team. The proximity of a team's classrooms enables team leaders to monitor their students closely as they change classes. Common hallways for teams also prevent boys and girls from sharing hall space and locker areas. Although a few classes, such as physical education and band are coeducational, boys and girls eat lunch with their teams and are not scheduled in the lunchroom concurrently.

At Terre Rouge Middle School, I selected Ms. Ellen Alcott and Mr. David Blake for study. Ms. Alcott is team leader for the boys' team in $6^{\text {th }}$ grade, teaching five all-boy mathematics classes, and Mr. Blake teaches mathematics to all boys on the $7^{\text {th }}$-grade boys’ team. Both Ellen Alcott, a Caucasian female, and David Blake, an AfricanAmerican male, are in their third year of teaching. Ms. Alcott has taught all boys here at Terre Rouge since she began teaching, but Mr. Blake taught in a coed classroom one year before coming to Terre Rouge. For the preceding school year at Terre Rouge, both Ms. Alcott and Mr. Blake had taught $6^{\text {th }}$-grade mathematics and used a different team structure. For that year, both teachers were members of three-teacher team. Classes were longer, ninety-minutes each, and there were fewer than 20 students to a class. For the current year, administrators returned to a schedule of 50-minute periods and larger classes so that a 50-minute daily homeroom period could be devoted to reading and literacy.

Both Ms. Alcott and Mr. Blake follow similar schedules with their $6^{\text {th }}$ - and $7^{\text {th }}$ grade teams. They have one 50-minute planning time that coincides with planning time for the other teachers on the team and with the "related arts" period, in which students 
rotate periodically in classes such as practical living, physical education, and art.

Although all classes and planning periods are fifty minutes in length, the actual time in the classroom is only 40-45 minutes as all teachers are required to accompany and monitor students as they travel through the halls from one class to another. Additionally, restroom breaks are taken during the class periods where students, accompanied by the classroom teacher, line up and move to a position just outside the boys' restroom and go into the restroom about five students at a time. After the students exit the rest room, they stand in a different line, usually facing the opposite direction, until all students rotate through the cycle.

Greenville Middle School

Greenville Middle School is serving approximately 400 students who reside in a small suburban town with a high working class population. The school's principal, Ms. Pat Glover, reported that the unemployment rate is high in the area because of factory closings. The school has a significantly lower African-American population than either of the other schools, with 83\% Caucasian, 8\% African-American, 6\% multi-racial, and 3\% Hispanic, and the rate for students receiving free or reduced cost lunches is $56 \%$. It should also be noted that Greenville is in a different state than the other two schools of the study. Accordingly, state testing, reporting, and accountability requirements are different.

Greenville’s town school district is small with only two elementary schools and one middle and high school. However, there are three nearby districts in surrounding counties, and Ms. Glover also reported that student transience from one district to another is a major problem. During the year of the study, their total school enrollment remained about the same but, because of a large number of students leaving and an equal number 
coming into the school throughout the year, only about $50 \%$ of the students ending the school year at Greenville Middle were the same students who began their year there. Ms. Glover suggested that students whose families cannot pay the rent move to and from apartments in different school districts, thus making it difficult for the school to maintain continuity in teaching and learning.

Greenville Middle School was built in the late 1960’s and appears to be a compromise between the "open classroom” design that was then popular and a traditional, closed classroom building plan. The school is a sprawling one-story building with wide halls that are carpeted and well-lighted. The spacious and open central core of the building contains locker areas, a lunchroom, and a play/gathering/assembly area.

Classrooms, library, computer labs, gym, and offices are located around the periphery of the central core. The classrooms are of adequate size and are separated from the open areas of the central core. Teachers report not being bothered by noise when students have lunch or go to their lockers. Even so, the openness of the central core causes visitors to be greeted by lunchroom smells of fried foods.

The halls at Greenville are quiet and orderly, and class changes are monitored by teachers who usually stood in the doors of their classrooms. Students at Greenville do not seem to need close supervision. The halls are usually quiet between classes, and when visiting the school, I saw students working unsupervised out in the halls. They sat quietly on the floor, alone or with one other student and seemed to be talking about school work most of the time. One day, I saw 6 or 8 students taking up a large area of hall space to set up models of villages and forts from a previous era of American history.

Pat Glover has been principal at Greenville Middle School for four years. She previously served as dean of students for a high school in a nearby district and had also 
worked in the area of special education with the Greenville town district. As middle school principal, Ms. Glover frequently serves as a mediator and communicator between the elementary and high schools of her district and advocates within her district for increased communication with the three surrounding districts.

The 2004-2005 year was the second for gendered classes in all grades of Greenville Middle School. In 2002-2003, the $7^{\text {th }}$-grade team of teachers piloted gendered classes for their students, and then in the following year, the $6^{\text {th }}$ - and $8^{\text {th }}$-grade teachers made the change to single-gender classes in core subjects of reading, mathematics, language arts, science and social studies. Boys and girls remained in coed classes for their elective skills classes, as well as for related arts subjects and lunch. Ms. Glover and teachers of the $7^{\text {th }}$-grade team reported that concerns they wanted to address with the single-gender classes were low passing rates for boys both for the state assessments and in core classes, and over the past three years, teachers and administrators tracked these failure rates for both boys and girls. The school also had coeducational honors classes because there were not enough students to have two separate classes.

The 6th-grade mathematics teacher, Mr. Darrell Fisher was a Caucasian male and has been teaching mathematics for seven years. For the last two years, he has taught allboy classes at Greenville Middle. His teaching schedule included the majority of the $6^{\text {th }}$ grade students, leaving out only those who were in special education. In the year of the study, he taught two sections of boys, two sections of girls, and a coeducational honors class. The $7^{\text {th }}$ grade mathematics teacher who participated in the study was Ms. Julia Edwards. She had been teaching for 15 years, and was a member of the team that advocated for the change to the gendered classes several years before. Like Mr. Fisher, she taught two classes of boys, two classes of girls, and a coeducational honors class. 
Ms. Edwards said that she would have preferred to have these honors students in singlegender classes but confirmed that the school is not large enough to warrant two honors classes. Both Mr. Fisher and Ms. Edwards believed that the single-gender environment was lowering failure rates, as well as improving focus and learning. Ms. Edwards also noted improvements in discipline and a reduction of office referrals in her all-boy classes. Bluefield Middle School

Bluefield Middle School serves a population of approximately 600 students, 46\% of whom are Caucasian or other ethnicities (8\% other) and 54\% are African-American. Approximately sixty-five percent of their students qualify, for free or reduced-cost lunch programs. The city of Bluefield has a large central high school which is well-established in the community. Loyal alumni of the high school maintain associations with their alma mater, attend athletic functions, and continue family traditions of sending their children there. The high school also has a well-respected academic program with a wide array of advanced placement and honors courses. The community considers the honors track at Bluefield Middle a feeder program for the high school's honors track, and students sometimes elect to transfer from elementary schools in the county to Bluefield Middle in preparation for high school.

Built in the mid-fifties, the two-story, red-brick school is near the street and has the appearance of a building to which wings and sections have been added over the years. Through this process, a school with classrooms of a variety of sizes has evolved. The corridors are not as wide as those in the other two schools, and although some of the newer stairwells are spacious, one of the school's heaviest traffic areas is a narrow stairway near the school's main entrance and offices. On the second floor, one wing 
contains the 6th-grade hall and classrooms, and the other wing provides spaces for all of the 7th-grade students, both boys and girls. Eighth-grade classes are on the first floor.

Upon entering the school building, visitors arrive at a reception desk that is usually staffed by a parent volunteer. Parents whom I encountered at the desk were interested in my study of the gender-specific classes and generally expressed approval for them. However, the parents spoke mostly about the importance of the all-girl classes for their daughters and about learning benefits for girls. In addition to their work at the reception desk, parents volunteer in other capacities and serve on the school's Site-Based Decision Making committee (SBDM), and the week before the winter break, parents from the PTO organized daily buffet lunches for the teachers. In reviewing conversations with parents who volunteered, I thought it was significant that several mentioned that their children were in the honors program.

The assistant principal, Ms. Cheryl Baxter, has been at the school, in the capacity of either teacher or administrator, for 17 years. The school's principal, Ms. Sandra Warren, is in her first year at the school, so I conducted my interviews with Ms. Baxter who has more history with the single-gender program there. She explained to me, early in the study, that school leaders adopted the single-gender classes in an effort to reduce boy/girl interactions in the classrooms, which were perceived by some administrators, teachers, and parents as "sexual harassment." When I asked her to be more specific, she reported that $6^{\text {th }}$-grade girls had reported to teachers and parents that boys had been touching them inappropriately in the halls and also making comments to them of a sexual nature. "They are growing up too soon,” she said. “They see things in the media and elsewhere and think these things are acceptable.” Ms. Baxter had also shared with me that she was not a strong supporter of the single-gender classes, and it was a previous assistant 
principal who had been the main advocate for the program. At the beginning of the year, however, he left his position to take an administrative position in another county. Ms. Baxter spoke of two negative effects of the single-gender classes. First of all, she felt as if the separation may create a "locker room mentality" in the all-boy classes. She also suggested that having gendered classes makes class placement changes more difficult.

The year of the study, the 2004-2005 school year, was the third year for the single gender classes. Mainly because of the school's traditional emphasis in preparing students for high school, the $8^{\text {th }}$-grade teachers were never willing to support the single-gender experiment, and the their classes remained coed. Over the three years of the gendered classes, the school has tried a variety of structures and schedules for 6th and 7th graders. In the current year, all of the sixth grade students have 90-minute single-gender block classes; however of the three $6^{\text {th }}$ grade teams, one has all-boy homerooms, one has allgirl, and one has mixed homerooms. Each team is led by three teachers, one teaching language arts and mathematics; another teaching science and writing; and the third teaching social studies and reading. Each teacher on the team has a daily planning period equal to one 90-minute block.

For 7th grade in the previous year, there were two four-teacher teams, but for the year of the study, the school superintendent forced the administration to move closer to a junior-high model, and required that the 7th grade students and teachers comprise one large team. The homerooms are coeducational, there are 50-minute periods, and each teacher is responsible for multiple sections of a single subject. Both teachers and administrators reported that this new structure is not operating in the intended way. Teachers are no longer able to know students on a personal level and were no longer able collaborate with each other about needs of individual students. Ms. Baxter attributes a 
significant increase in the number of 7th-grade office referrals to this lack of personal contact between teachers and students, as well as ensuing difficulties in maintaining the uniform rules and policies.

Ms. Christine Ingram participated in the study as the $6^{\text {th }}$-grade mathematics teacher. She has been teaching mathematics for seven years, and this is her third year to teach all-boy classes at Bluefield. Her schedule this year includes three 90-minute blocks, teaching mathematics and language arts to three all-boy classes. Her first block is the honors group, and her other two blocks are regular program. She uses the same curriculum for both honors and regular. Ms. Ingram expressed the opinions that she likes teaching the all-boy and feels that there are advantages to this classroom environment, such as focus and motivation. The $7^{\text {th }}$-grade teacher, Ms. Melanie Jones, is in her eighth year of teaching, her third in the gendered classes. Her first five years of teaching were in high school mathematics in another city. She is African-American and teaches two classes of boys, two classes of girls, and an all-boy honors class. Unlike Ms. Ingram, Ms. Jones finds benefits of the gendered classes mainly for the girls. “I feel as if I’m accomplishing more with the girls," she said, "because there are not the discipline issues there are with the boys.”

\section{Overview of Schools}

In looking broadly and comparatively at the three schools, Terre Rouge, Greenville, and Bluefield, I noted three different sets of school demographics, as well as divergent purposes for experimenting with single-gender education. Terre Rouge is the largest school and Greenville the smallest, with Bluefield half-way in between. District characteristics are also very different and frequently relate to decisions, processes, and results for the schools' experiments. Terre Rouge is part of a large urban district, one of 
the ten largest districts in the United States. The large district provides subject area specialists, coaches, and subject-area professional development opportunities not available in the other districts. Both Bluefield, with four elementary schools; one middle school, and one high school; and Greenville, with two elementary schools, one middle school, and one high school, were significantly smaller than the district that included Terre Rouge. Ms. Glover, Greenville’s principal, expressed the view that the small size is preferable and increases the school's ability to innovate and make their own decisions. Comparative demographic information for the three schools appears in Table 4-1.

Table 4-1

Comparative Demographic Information

\begin{tabular}{|l|c|c|c|c|c|c|}
\hline & District & Locale & $\begin{array}{c}\text { School } \\
\text { Size } \\
\text { (approx.) }\end{array}$ & $\begin{array}{c}\text { Free/Red. } \\
\text { Lunch }\end{array}$ & $\begin{array}{c}\text { African- } \\
\text { American }\end{array}$ & $\begin{array}{c}\text { Caucasian/ } \\
\text { Other }\end{array}$ \\
\hline $\begin{array}{l}\text { Terre } \\
\text { Rouge }\end{array}$ & large & $\begin{array}{c}\text { urban } \\
\text { low SES }\end{array}$ & 800 & $90 \%$ & $50 \%$ & $50 \%$ \\
\hline Greenville & small & $\begin{array}{c}\text { suburban/ } \\
\text { town } \\
\text { low SES }\end{array}$ & 400 & $56 \%$ & $8 \%$ & $92 \%$ \\
\hline Bluefield & small & $\begin{array}{c}\text { town/ rural } \\
\text { mixed SES }\end{array}$ & 600 & $64 \%$ & $54 \%$ & $46 \%$ \\
\hline
\end{tabular}

Terre Rouge and Bluefield have similar proportions of African-American students, whereas Bluefield's African-American population more closely reflects the population of the community. Terre Rouge lies in a large metropolitan area, with countywide school system and government, in which the African-American population is only $19 \%$. The school system contains a variety of magnet schools on the middle and high school level, but no school, whether a neighborhood school or a magnet school, is allowed to be more than 50\% African-American.

My investigations revealed early that the three middle schools had adopted the single-gender classes for different reasons. At Terre Rouge, the clear purpose was to 
improve test scores. Dr. Alice Russell, principal at Terre Rouge, described how the

change came about in the year after she came to the school.

I looked at the scores over the last few years and saw that they were not getting any better. So from my perspective, coming in new, if we did what we had always done, our scores would not improve. I knew we needed to move our students forward. They had the abilities, but a lot of it was the motivation and variables over which we had no control. I went on the internet to find schools that been successful doing some things - schools with like populations, like demographics, like size and I saw this school in Long Beach California, Jefferson Leadership Academy. They were doing some good things. I talked to their principal on the phone, and she told me about decreases in sexual harassment behaviors, the increases in achievement for the boys, the increases for the girls in the areas of science and math. But you know, it's not enough for a principal to have a good idea if everybody doesn't buy into it. So I sent some teachers out to California to look at the school. I didn't go myself because wanted them to form their own opinions and give me a totally objective view about what they saw. They found the populations to be similar, and they all came back so excited and convinced that this could be replicated with some modifications accounting for our school's uniqueness. I had those who went to Long Beach to present it to the rest of the faculty and all were enthusiastic. Since I believe that $90 \%$ of everything you do is the attitude with which you do it, I told them that either everybody goes for it or we don't do it. So using the model in Long Beach, California, we voted unanimously to implement all-boy and all-girl teams and core classes for the following school year.

As was mentioned previously, Greenville Middle School is in a different state from the other two schools, and periodically, the state required schools to use specific guidelines to develop and update improvement plans. About the time Ms. Glover became principal, teachers and administrators were preparing an improvement plan, and had targeted performance of their male students for improvement. For boys, passing rates for the state assessment were lower and percentages of students failing one or more classes were higher. At the same time, a few 7th-grade teachers were taking a graduate education course and read "research" supporting single-gender education as a means for boosting achievement. These teachers saw gendered classes as a possible way to improve outcomes for the boys, and their readings led them to anticipate a variety of benefits for both genders. 
The staff at Greenville, as a whole, was not ready to try the gendered classes at that time, so the 7th-grade teachers went to Ms. Glover and asked if they could pilot the program on their team, and Ms Glover worked it out for them and explained as follows:

When they asked me about the single-gender classes, I told them I wanted to do a little more research and get back to them. What I read about it looked favorable and like something that might help the boys, so I took it to the superintendent, who approved it. We didn't make a formal announcement, but just scheduled the 7th graders in their classes that way. Students and parents questioned a little bit but not very much. Then, we surveyed the other students and 70\% said they didn't want to do it. However, in the following year, after hearing positive reports from the 7 th-grade teachers, both teachers in both $6^{\text {th }}$ and $8^{\text {th }}$ grades decided to implement the gendered classes the following year, and we've done it at all grade levels for two years

Teachers at Greenville explained that they have not actually had professional development specifically for gender-specific teaching, but at the two faculty meetings I attended, time was spent for sharing with the group ideas and strategies they had tried for teaching boys and teaching girls.

At Bluefield, the single-gender concept also arose from teacher interest. Ms. Baxter, the Assistant Principal, reported that, several years ago, teachers had seen favorable reports for single-gender education on a TV news program and began to think of it as a possible solution to current classroom management problems they were experiencing in $6^{\text {th }}$ grade. I questioned Ms. Baxter and the two mathematics teachers about the specific nature of the problems and all three used the term "sexual harassment." When I probed further as to what they meant by this, they said that 6th-grade boys were touching girls furtively and inappropriately or making comments of a sexual nature, most particularly when classes were changing and the halls were crowded with students. The girls reported these events to teachers and parents, and parents became upset and vocal about the situation. "They are growing up too early,” said Ms. Baxter. "They see these things in the media and don't understand that they are inappropriate.” At the end of the 
first semester for this school year, the 6th-grade teachers asked the principal if they could try separating the boys and the girls in their classes, and he agreed to let them try it.

The $6^{\text {th }}$-grade teachers were encouraged by the decreases in discipline problems and in instances of inappropriate sexual behavior from boys. One of the other assistant principals became a supporter of the single-gender intervention and joined with the 6thgrade teachers and parents to present it to the SBDM (Site-Based Decision Making Committee) as an option for the following year. At this point, the single-gender advocates called on "research” claiming that single-gender classes not only physically separated boys and girls but also improved test scores and produced teacher opportunities to tailor instruction for one gender or the other. The $8^{\text {th }}$-grade teachers and parents did not support the single-gender classes and expressed the view that single-gender classes might detract from their traditional and strong focus of preparing their students for high school. However, at that time, the $6^{\text {th }}$ and 7 th grades implemented the single-gender classes, and students who began sixth grade with the first full year of single-gender classes are now eighth-grade students.

\section{Research Questions}

Each school chose to experiment with gendered classes to improve specific, yet somewhat different, outcomes. Research indicates comparisons between single-gender and coeducation to be problematic (AAUW, 1998; Mael, 1998). The myriad of educational contexts, purposes, and venues produce confounding background factors and conflicting results. Accordingly, the purpose of this study was not to compare singlegender schooling with coeducation but to study aspects of each school's implementation process relating to success of the gendered-class experiment, such as school factors, teacher characteristics, structures and strategies, and mathematics teaching, Readings 
from the research literature and my own previous investigations suggest that educational benefits do not automatically develop when boys and girls are separated but that benefits depend on other factors such as how the single-gender program is implemented and how teachers adapt instruction for boys and for girls. Therefore, I proposed the following four research questions:

1. What are school and district factors that affect the development and

Formatted: Bullets and Numbering implementation of all-boy mathematics classes in middle school? Do some factors seem stronger than others as they relate to successful implementation?

2. What classroom structures and instructional strategies are used by teachers in allboy mathematics classes? Do some structures and strategies seem more effective than others?

3. What teacher characteristics affect the development and implementation of allboy mathematics classes in middle school? Do some characteristics seem more important than others?

4. What is the nature of the mathematics instruction used by middle school mathematics teachers in all-boy classes? Do some types of instruction seem to be more effective than others?

\section{School Factors}

Following the publication of the Coleman report (Coleman, et al., 1966), the question of whether schooling could overcome factors of student background and socioeconomic status has haunted educational researchers for forty years. The report suggested that "schools bring little to bear on a child's achievement that is independent of background and general social context (p. 325).” Subsequent research studies and metaanalyses indicated that school and teacher factors can, in fact, have significant effects on 
student achievement and other outcomes (Good \& Brophy, 1986; Marzano, 2003). Over the last four decades researchers have studied a variety of highly-predictive school factors such as academic emphasis, high expectations, and opportunity to learn, and also identified a variety of factors with somewhat weaker statistical relationships to student achievement, such as collegiality and professionalism and parent involvement (Marzano, 2003).

One of the purposes of this study was to look at school characteristics for the three schools and to relate these to classroom activities. Data sources included survey results from the Organizational Health Instrument for Middle Schools (OHI-M) and the Collective Teacher Efficacy (CE) Scale, along with interviews of teachers, students, and administrators.

School Health

The organizational health of a school relates to how a school copes with its environment and community and with its ability to direct energy toward its mission and objectives. In the three schools of this study, faculty completed the OHI-M instrument (Hoy \& Sabo, 1997) in one of their regularly scheduled faculty meetings. A total of 108 responses (39 responses from Terre Rouge faculty members, 29 from Greenville, and 40 from Bluefield) were included in the analysis. I used procedures provided in the instrument developers’ guidebook (Hoy \& Sabo, 1998) to analyze results. First, an average school score, rounded to the nearest hundredth, was calculated for each item. Then, for items composing each of the six factors, means for the item totals by school were computed. These six scores represent a health profile for each school.

Comparisons with normative data. These scores were then standardized using, as a norm, Hoy and Sabo’s current data base of middle schools drawn from a large, diverse 
sample of schools in New Jersey. The sample consisted of responses from 2,777 teachers in urban, suburban, and rural schools from diverse geographical areas. A demographic breakdown of these schools was 28\% low SES, 38\% middle, and 34\% high SES. Raw mean scores and standard deviations from the New Jersey sample were used to convert the subtest scores for Terre Rouge, Greenville, and Bluefield to standardized scores with a mean of 500 and a standard deviation of 100 . A rating scale provided in the developers' guidebook placed these standardized scores in the following categories: very high; high; above average; slightly above average; average; slightly below average; below average; low; and very low (Hoy \& Sabo, 1998). Table 4-2 and Figure 4-1 display standardized results of the OHI-M survey instrument.

Table 4-2

Standardized Ratings for School Health

\begin{tabular}{|c|c|c|c|}
\hline & Terre Rouge & Greenville & Bluefield \\
\hline $\begin{array}{l}\text { institutional } \\
\text { integrity }\end{array}$ & $\begin{array}{c}\text { 609-Very } \\
\text { High }\end{array}$ & 567-High & $\begin{array}{c}346 \\
\text { Very Low }\end{array}$ \\
\hline $\begin{array}{l}\text { collegial } \\
\text { leadership }\end{array}$ & $\begin{array}{c}\text { 609-Very } \\
\text { High }\end{array}$ & $\begin{array}{c}570 \\
\text { High }\end{array}$ & $\begin{array}{l}504 \\
\text { Average }\end{array}$ \\
\hline $\begin{array}{l}\text { principal } \\
\text { influence }\end{array}$ & 559-High & $\begin{array}{c}636 \\
\text { Very High }\end{array}$ & $\begin{array}{c}480 \\
\text { Slightly Below } \\
\text { Avg. }\end{array}$ \\
\hline $\begin{array}{l}\text { resource } \\
\text { support }\end{array}$ & 560-High & $\begin{array}{c}466 \\
\text { Below Average }\end{array}$ & $\begin{array}{l}424 \\
\text { Low }\end{array}$ \\
\hline $\begin{array}{l}\text { teacher } \\
\text { affiliation }\end{array}$ & $\begin{array}{c}279 \\
\text { Very Low }\end{array}$ & $\begin{array}{l}425 \\
\text { Low }\end{array}$ & $\begin{array}{c}297 \\
\text { Very Low }\end{array}$ \\
\hline $\begin{array}{l}\text { academic } \\
\text { emphasis }\end{array}$ & $\begin{array}{l}\text { 549-Above } \\
\text { Avg. }\end{array}$ & $\begin{array}{c}483 \\
\text { Below Avg. }\end{array}$ & $\begin{array}{l}425 \\
\text { Low }\end{array}$ \\
\hline $\begin{array}{l}\text { total school } \\
\text { health }\end{array}$ & $\begin{array}{c}528 \\
\text { Above Avg. }\end{array}$ & $\begin{array}{c}524 \\
\text { Above Avg. }\end{array}$ & $\begin{array}{l}412 \\
\text { Low }\end{array}$ \\
\hline
\end{tabular}

Table 4-2 reports standardized results for each school on the factors of school health. Total school health scores for Terre Rouge and Greenville were slightly above average, and for Bluefield, the score was low. A reading of the graph (see Figure 4-1), 
placed scores for Bluefield Middle School below the mean of 500 for all factors of school health, except collegial leadership, for which the score was just above the average score of 500. All scores for Terre Rouge, except for teacher affiliation were above the 500 mark, whereas for Greenville, three scores were above and three fell below the normative mean score of 500 .

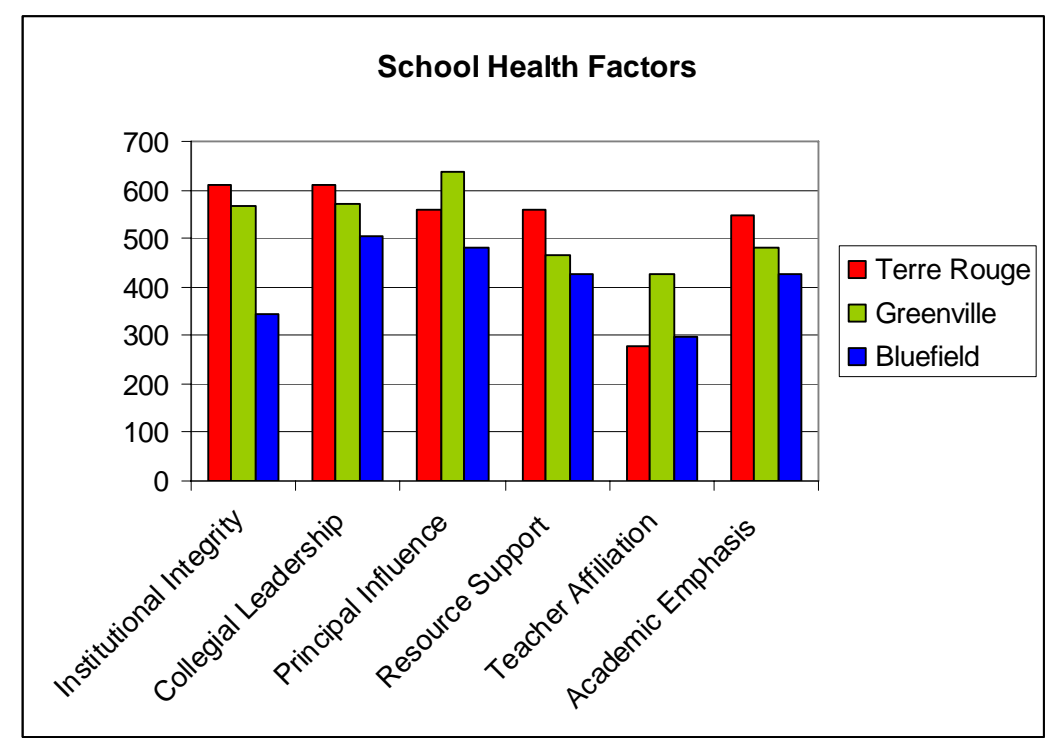

Figure 4-1. School Comparisons of Organizational Health Factors

Significant differences among schools. The three schools of this study were located in the lower mid-west, whereas the schools providing the normative data were in New Jersey. Additionally, socioeconomic status indicators placed the schools of the study in the low category, again confirming that the schools of this study may not be comparable to the school sample used to standardize the data with only $28 \%$ of the sample in the low SES category. Therefore, in addition to the normative comparisons, I used multivariate analysis of variance (MANOVA) techniques, where $\mathrm{N}=108$, to investigate differences in school health factors among the schools of the study, and in 
further interpreting the data, I chose to use comparisons between Terre Rouge, Greenville, and Bluefield instead of comparisons with the normative sample. The independent variable was school with three levels, and the dependent variables were the factors of organizational health from the OHI-M: institutional integrity; collegial leadership; principal influence; resource support; teacher affiliation; and academic emphasis.

In reviewing individual teacher responses to the survey, missing data was found, most particularly on items asking about a principal's influence with the district. While leaving it blank on the survey, a few teachers noted in the margins that they had no knowledge of relationships between the principal and the district. Since the purpose of the instrument was to measure a faculty's collective perception of organizational health, I replaced missing item scores with the mean score for the school on that particular item. Multivariate significance between schools was found among the factors of school health $(\Lambda=.375, p<.05)$. The analysis also identified significant differences among the three schools for each of the six factors, with $F$ values ranging from 39.747 to 8.202 , $(p<.05)$. Table 4-3 provides descriptive statistics for the six factors of school health.

Table 4-3

Descriptive Statistics for School Health Factors

\begin{tabular}{lllr}
\hline & & & \\
& Terre Rouge & Greenville & Bluefield \\
Institutional Integrity & $2.79(.44)^{*}$ & $2.61(.66)$ & $1.72(.60)$ \\
Collegial Leadership & $3.44(.51)^{*}$ & $3.41(.49)$ & $2.97(.67)$ \\
Principal Influence & $2.94(.45)$ & $3.21(.40)^{*}$ & $2.66(.42)$ \\
Resource Support & $3.05(.63)^{*}$ & $2.64(.51)$ & $2.45(.69)$ \\
Teacher Affiliation & $2.83(.47)$ & $3.30(.27)^{*}$ & $2.89(.58)$ \\
Academic Emphasis & $2.39(.40)^{*}$ & $2.18(.30)$ & $2.00(.50)$ \\
$* p<.05$ & & &
\end{tabular}


Using a post-hoc (Tukey) analysis, significant differences among all three schools were found for the factor of principal influence. For institutional integrity and collegial leadership, only Bluefield was significantly lower. For teacher affiliation, Greenville was significantly higher and the other two were not significantly different and for resource support Terre Rouge was significantly higher. For academic emphasis, only Terre Rouge and Bluefield were significantly different.

Institutional integrity. For the institutional integrity factor, Bluefield’s score was significantly lower than the other two schools. Institutional integrity is the extent to which the school can cope with its environment and can remain protected from demands from parents and the community (Hoy \& Hannum, 1997). In one of our interviews, Ms. Baxter expressed to me concern about parent intervention at her school and suggested that parents may not be able to look beyond their own children's best interests to the collective best interests of all the students in the school. In follow-up interviews with Ms. Baxter and the mathematics teacher participants, I asked all three of them about why their school might have been rated significantly lower than the others on this factor. In each interview, I read a definition for the factor and the following sample items included in that factor: the school is vulnerable to outside pressures; community demands are accepted even when they are not consistent with the educational program; select citizen groups are influential with the board; a few vocal parents can change school policy. Ms. Baxter, Ms. Ingram, and Ms. Jones replied unequivocally to this question with some form of the statement, "Yeah, that's who we are."

In piloting the OHI, developers of the instrument were surprised by results of their regression analysis informing them that higher scores for institutional integrity had negative effects on academic achievement (Hoy \& Hannum, 1997) Although school 
personnel had a more positive attitude toward their organization if they felt protected from parental demands, results of the pilot study suggested that it was perhaps intervention from parents that had positive effects on achievement (Hoy \& Hannum, 1997). From observations at Bluefield, I saw high engagement and involvement of parents. My interactions with some of these parents, as well as reports from teachers and administrators, also suggested that they were involved in school decision making and not just as a support group. One area of involvement seemed to be the area of student tracking and of who is enrolled in "honors," the advanced track. From follow-up interviews, it became clear that parents, particularly of girls, were involved in the SBDM's decision to separate classes by gender. There were other interview comments on the nature of parent influence: "They want their kids in honors to separate them from certain other kids”....”Parents both at the lower and upper end of the economic spectrum interfere so that their children will be left alone and not be punished for their offenses”......”Parents protested when students were put on silence in the lunchroom.” Ms. Baxter, Ms. Ingram, and Ms. Jones also spoke of district and community interference. Ms. Baxter reported that, in the year immediately preceding the study, the superintendent had removed their principal at mid-year and replaced him with a principal of the superintendent's choice. Ms. Jones reported that the superintendent had also made negative statements about Bluefield Middle School in the local newspaper. Hence, examples of parent and community interference with institutional integrity at Bluefield appear to be common and varied. When reporting their results about the negative effects of high Institutional Integrity on student achievement, the pilot study investigators called for more research to refine the concept of Institutional Integrity (Hoy \& Hannum, 1997). "We need a way to sort out destructive and constructive forces. Community (and parent) 
involvement in schools does have a contribution to make in improving instructional delivery systems. But not all involvement is helpful, and some is counterproductive (p. 304).”

Collegial leadership. The collegial leadership factor refers to principal behavior that is supportive, open, and friendly. A principal must give teachers a sense of empowerment and not domination, and at the same time, a principal must set a tone for high performance by letting teachers know what is expected of them (Hoy \& Hannum, 1997). For this factor, Bluefield received scores significantly lower than the other two schools. It should be noted here, however, that Bluefield’s principal, Ms. Sandra Warren, was new to the school this year, and perhaps, faculty did not feel they knew her well at this point.

Principal influence. This factor represents a principal's ability to absorb and control district-based influences. Influential principals are persuasive with superiors and can use this persuasion to implement the schools mission (Hoy \& Hannum, 1997).

Faculty responses to this factor of OHI were all significantly different, with Greenville, the highest, followed by Terre Rouge and then Bluefield.

Resource support. Resource support refers to the availability of classroom materials. In a school with a high level of resource support, sufficient materials are readily available, and additional materials that teachers request are frequently provided. The resource support factor for Terre Rouge was significantly higher than the other two schools. At the time of the study, Terre Rouge was designated a Title One school. According to Dr. Russell, this designation provided the school additional resources, such as coaches, computers, and curriculum materials, and over and above other schools in the district. Teacher interview responses to the question, "Do you have the resources you 
need to teach effectively?” were varied. Some responded affirmatively and a few mentioned that they would like to have more, particularly computers and calculators. In her response, Ms. Edwards at Greenville mentioned manipulatives for teaching mathematics that were provided to her and the other mathematics teachers by a grant.

Teacher affiliation. A positive score for teacher affiliation on the $\mathrm{OHI}$ indicates that teachers there support each other, have positive feelings about their teacher associates, and like their jobs and their students (Hannum \& Hoy, 1997). The scores for Terre Rouge and Bluefield were significantly lower than the score for Greenville on this factor. Research suggests that it is the teacher interactions related to their teaching or other professional concerns that have a positive effect on achievement (Marzano, 2003). At Greenville, evidence of professionally oriented interactions included faculty meeting reports and discussions on successful teaching strategies, as well as participation in collaborative sessions for teaching mathematics.

When Bluefield teachers and administrators were questioned further about a possible rationale for this low score, they again referred to the superintendent's removal of their principal in the middle of the year and to the ensuing unfavorable newspaper statements. One teacher commented, "We all just tried to survive, and it seemed to make better sense to us to survive individually rather than collectively.” Dr. Russell at Terre Rouge attributed her school's low score on Teacher Affiliation to the fact that so many of the teachers were new this year, with fourteen of them in their first year of teaching.

Academic emphasis. Academic emphasis is the extent to which the school is driven by the pursuit of academic achievement (Hoy \& Hannum, 1997). Scores for the three schools on this factor had the smallest range (.39) than for any of the other factors, but a significant difference was found on this factor only between Terre Rouge and 
Bluefield. Greenville’s score was between scores for Terre Rouge and Bluefield, and it was not significantly different from either score.

Collective Teacher Efficacy

Research has recently focused on the construct of collective teacher efficacy because of its relationship to positive school goal attainment. One study showed that after controlling for prior achievement, race/ethnicity, and socioeconomic status(SES), collective teacher efficacy had a stronger effect on student achievement than either race or SES (Goddard, et al., 2000). Teacher beliefs about their collective capabilities for teaching their students vary greatly from one school to another. A model of the construct (Goddard, et al., 2000; Goddard, et al., 2004) depicts collective efficacy as a joint analysis of teaching competence and the difficulty of the teaching task. Collective efficacy assessments can be elevated by successful experiences such as realizing test score gains and participating in beneficial professional development. A faculty member's perception of high collective teacher efficacy increases a teacher's effort, persistence, and resistance to adversity. A high sense of collective efficacy can also foster innovative teaching (Goddard, et al., 2004).

Faculty $(\mathrm{N}=108)$ from the three schools of the study responded to the Collective Teacher Efficacy (CE-Scale; Goddard, Hoy, \& Hoy, 2000) at a regular faculty meeting. To analyze the results, developers suggested that totals of item scores for the 21 items should be calculated for each respondent, and then a school mean calculated from the individual totals. Table 4-4 reports descriptive statistics for Terre Rouge, Greenville, and Bluefield Middle Schools on the CE-Scale. Using analysis of variance methods and a post-hoc (Tukey) analysis, the collective teacher efficacy of Greenville Middle School was found to be significantly higher than either of the other two schools. Research 
indicates that teacher efficacy can have a positive effect on teacher affiliation (Hoy \& Woolfolk, 1993), and Greenville’s score for teacher affiliation was also higher than scores for the other two schools.

Table 4-4

Descriptive Statistics for Collective Teacher Efficacy (CE-Scale)

School Mean (s. d.)

\begin{tabular}{ll}
\hline Terre Rouge & $78.00(11.9)$ \\
Greenville & $84.83(10.56)^{*}$ \\
Bluefield & $77.77(11.48)$ \\
\hline
\end{tabular}

$p<.05$

\section{Summary Analysis of School Factors}

As previously mentioned, the research literature contains a large body of work addressing the question, "What makes a school effective?” A definition commonly associated with an effective school is a school in which students are achieving academically and a school that is reaching its academic goals. In his book linking research to practice for K-12 educators, Marzano (2003) reviewed and consolidated research findings on school factors that affect student achievement. He reviewed a number of studies and used results to develop a list of between 20 and 25 factors measuring school effectiveness. He, then, condensed the list into five, and his compiled list stands as follows: a guaranteed and viable curriculum; challenging goals and effective feedback; parent and community involvement; a safe and orderly environment; and collegiality and professionalism. Instead of classifying leadership as a school factor, Marzano characterized leadership as an "overarching variable that impacts the effective implementation of the school level factors, teacher-level factors, and student-level factors 
(p. 20).” Other research on leadership also suggests its complexity, illusive qualities, and difficulty in description (Good \& Brophy, 1986).

After analysis of survey results from the OHI-M and the CE Scale, I evaluated the schools on the according to Marzano's list of five school factors, and added to those, the additional factors of collective teacher efficacy and leadership, making a total of seven. Then, using survey results along with interview and observational data, schools were rated high, medium, or low in each of the seven categories. Table 4-5 presents school ratings of high, medium, or low for each of the seven factors. The overall rating is the median rating for the seven categories. Greenville Middle School was rated highest overall. Explanations and justifications for the ratings in Table 4-5 follow in subsequent sections.

Table 4-5 Comparative Effective School Ratings for the Schools of the Study

\begin{tabular}{|l|c|c|c|}
\hline & Terre Rouge & Greenville & Bluefield \\
\hline Guaranteed and viable curriculum & medium & high & low \\
\hline $\begin{array}{l}\text { Challenging goals and effective } \\
\text { feedback }\end{array}$ & high & medium & low \\
\hline $\begin{array}{l}\text { Parent and community } \\
\text { involvement }\end{array}$ & low & low & medium \\
\hline A safe and orderly environment & low & high & medium \\
\hline Collegiality and professionalism. & low & high & low \\
\hline Collective teacher efficacy & medium & high & medium \\
\hline Leadership & medium & high & low \\
\hline & & & low \\
\hline Overall rating & medium & high & \\
\hline
\end{tabular}

A guaranteed and viable curriculum. If a school has a guaranteed and viable curriculum, then it gives guidance to teachers regarding content to be covered at each grade level and provides adequate time in which to accomplish this task (Marzano, 2003). The schools of the study were in two different states, but both states have specific and detailed standards to guide schools in teaching the content topics that will be assessed on 
the state accountability assessments. My observations and interviews at Greenville and Terre Rouge confirmed that both schools adhered to the state standards and that both schools' teachers mapped courses for their lessons and activities accordingly. At Bluefield, teachers differed from the other two in that they used different curricula for their regular and advanced tracks, thus a curriculum might have different "guarantees" depending on the track the student was placed in.

To fit Marzano’s description for a “guaranteed and viable curriculum,” a school not only should guide teachers about content to be covered, but also should make sure the teacher has adequate time to accomplish this task. Based on eight 50-minute classroom observation for each teacher, Table 4-7 displays the percent of time spent on classroom management and teachers at Greenville were found to spend less time on management issues than teachers at the other two schools. At Terre Rouge, the school required teachers to accompany and monitor students as they traveled through the halls to their next class, and they were also required to monitor the whole class on rest room breaks, as students were not allowed to go to the restrooms unaccompanied. Thus, Greenville teachers had more time allotted for accomplishing the targeted standards. For this first factor, “a guaranteed and viable curriculum,” I scored Terre Rouge as medium; Greenville, as high; and Bluefield, as low.

Challenging goals and effective feedback. The accountability systems in place in the states applied pressures to all of the schools to set high goals and improve academic achievement. Because of its effective tracking and monitoring of achievement goals, I assigned Terre Rouge a high score. Observations indicated that Terre Rouge spent significantly more time on standardized test preparation than the other two schools. Furthermore, its district had created a set of content assessment practice tests that were 
distributed and administered with regularity by the Terre Rouge teachers. These tests included both multiple choice and open response items. They were scored and reviewed by the classroom teachers and results were then entered on a district database.

In both Ms. Alcott's class and Mr. Blake’s, at least one of these preparatory student assessments was administered during the period when I was observing classes. I gave Greenville a score of medium for this factor. As at Terre Rouge, teachers at Greenville considered state assessments when planning their lessons, but not as much attention was given to feedback on where students stood relative to the standards. However, Ms. Glover told me in an interview that, for next year, they were including in their program a computer testing system that is aligned with state standards. The new system will identify school and student weaknesses on core content topics and provide remedial work in these areas for students who need it. At Bluefield, the administrators did not seem to believe that the state accountability system was helpful for monitoring student progress and relied heavily on a norm-referenced assessment as a monitoring device. Achievement score gains and losses were thought of as more related to particular groups of students, as characterized by their abilities and degrees of motivation. I gave Bluefield Middle School a low score for the factor of "challenging goals and effective feedback.”

Parent and community involvement. I assigned low scores to both Greenville and Terre Rouge, because at both schools teachers spoke of lack of parental involvement and lack of parent accountability for monitoring homework efforts and encouraging an academic emphasis. Because of the visible parent involvement at Bluefield, at least in part devoted to academic issues, I rated the school as medium for this factor. I did not 
give Bluefield a high score because of negative effects for Bluefield caused by district and parent interference in school decisions and policy making.

A safe and orderly environment. For this factor, I scored Greenville highest; then came Bluefield, and Terre Rouge. In my experiences visiting all three schools, halls and classes at Greenville were the most orderly. At Bluefield, the narrower halls became crowded at class changing times and were less orderly than at Greenville. On two occasions at Bluefield, I observed two different $7^{\text {th }}$-grade boys wandering the halls and trying to get the attention of students in classrooms. Also, at Bluefield, I observed a higher level of student disruption in classrooms than I observed at Greenville.

Observations and interviews indicated that Terre Rouge was the least orderly environment of the three. As a fairly frequent visitor to the building, I encountered with regularity unsupervised students who were walking in the halls with no clear purpose. Boys were tussling with each other and girls were arguing with each other or a teacher. I encountered stink bombs in stairwells, and on one occasion, I was hit by a globe rolling down the one of the front stairways. In student interviews, boys at Terre Rouge mentioned classroom fights, disruptive behavior, and student bullying, and on several occasions, I heard teachers and administrators warn students about the necessity to protect their personal property.

Collegiality and professionalism. A MANOVA analysis and post-hoc investigation indicated that scores for the $\mathrm{OHI}$ factor of Teacher Affiliation at Greenville were significantly higher than those for the other two schools $(F=4.204, p=.000)$. Therefore, I scored Greenville as high for this factor. I scored the other two schools as low instead of medium because of the large effect size $\left(\eta^{2}=.153\right)$ that appeared in the analysis. I observed collegiality and professionalism firsthand in two faculty meetings 
that I attended at Greenville Middle School. At both meetings of Greenville's faculty, the agenda included time to share instructional strategies they used in their gendered classes. I did not observe anything similar in faculty meetings of the other two schools, and perhaps the smaller size of the faculty also contributed to collegiality.

Collective teacher efficacy. CE-Scale results identified Greenville Middle School as significantly higher in collective efficacy than either of the other two schools, and hence, I assigned a score of high to Greenville. I rated the other two schools as medium, instead of low, in collective teacher efficacy because, of the medium effect size $\left(\eta^{2}=.07\right)$ revealed in the ANOVA analysis.

Leadership. I rated the leadership at Greenville Middle School, under Ms. Pat Glover, as high. Her school received ratings of high and very high on OHI factors of collegial leadership and principal influence, respectively. She was a leader in her district and frequently served as liaison, and sometimes a “peace-maker,” between principals at the high school and elementary schools. Ms. Glover assumed a leadership role in working cohesively with surrounding districts, most particularly in the area of student transfers. The OHI score for teacher affiliation was significantly higher than it was at the other two schools of the study, and there was no teacher turnover for that year. I perceived her as an instructional leader that encouraged teachers to be innovative. She provided time at faculty meetings for exchanging teaching ideas and strategies, and when team leaders for $7^{\text {th }}$ grade came to her, she gave them permission and encouragement to implement single-gender classes.

When Dr. Russell came to Terre Rouge Middle School, four years before, she inherited a school with many problems and the lowest test scores of any middle school in the state. She clearly recognized that Terre Rouge would have to make changes if scores 
were going to improve. She demonstrated strong leadership qualities in her willingness to seek new ideas and demonstrated collegiality in leading her faculty to implement the single-gender program there. In addition to single-gender classes, the school's improvement plan included other interventions such as literacy emphasis and test-taking practice, and under her leadership the school's test scores have increased.

Even so, I assigned Terre Rouge a lower score on leadership than Greenville. Although Terre Rouge and Greenville had similar OHI scores for collegial leadership and principal influence, scores for the two schools differed significantly for teacher affiliation. Dr. Russell attributed this low score to high teacher turnover and a large number of novice teachers. As compared with Ms. Glover who reported 0\% teacher turnover for the year of the study. Dr. Russell and her administration were much less successful in retaining teachers. After the pilot year for the single-gender program, approximately $50 \%$ of the teachers at Terre Rouge left teaching or went to other schools. For the next year, the school had fourteen novice teachers, who were enrolled in a oneyear internship program, and for the year of the study, an additional 13 interning teachers joined the faculty.

Dr. Russell continued to speak to this issue, and she said, "I'd rather have novice teachers than teachers who don't want to stay here; I want teachers who possess passion for their work with the students here.” However, in talking with teachers in the current year and in prior years, I conclude that more than "passion" may be needed to teach at Terre Rouge. Teachers, both novice and experienced, reported that the school's administration was not supporting them sufficiently in the areas of discipline and behavior management, and some specified this lack of support as a reason for leaving. Teachers at Terre Rouge criticized administrators for not being of more help with 
difficult students. There seemed to be a perception that students who should be suspended were being sent back into classes in order to improve the school's suspension record. Teams were expected to handle their own discipline, and yet many teams, consisted of new teachers who needed additional support and training for handling difficult situations. Leadership efforts toward improvements in the areas of teacher development and retention were needed at Terre Rouge for continued progress in successful teaming, classroom management, and student achievement.

Leadership at Bluefield was rated low, but this rating was more reflective of difficulties with district and parent interferences than it was to actions of school administrators. On the OHI, collegial leadership and principal influence received average and slightly low ratings respectively, but the school's rating for teacher affiliation was very low. As was previously mentioned, the superintendent removed Bluefield's former principal in the middle of the previous school year supposedly because of a disagreement on an employee issue. The superintendent replaced him with an administrator of his choice, but for the year of the study, the SBDM overruled the superintendent and selected Ms. Sandra Warren as a more fitting candidate for the principal's position. A teacher reported that the superintendent seemed to bear a grudge against the school and all of its leaders and teachers. Additionally, the superintendent had made negative comments about Bluefield Middle School in the local newspaper.

Middle School Structures and Strategies

A traditionally accepted need in education is for a middle-level program that helps students make transitions from elementary school, where efforts of educators are clearly focused on the individual child, to high school, where there are many pressures to shift emphasis toward external expectations. Beginning in the late 1950's, in an effort to 
relieve overcrowding in elementary schools caused by the post-war "baby boom," the number of junior high schools increased (Beane \& Brodhagen, 2001). In the late 1980’s and early 1990's, research in the education of young adolescents led to the creation of a middle school reform movement that called for the creation of small and personal subgroups within the larger and less connected environments that had become typical of junior high schools.

\section{Middle School Reform Principles}

Two reports, Turning Points (Carnegie Council, 1989) and This We Believe (National Middle School Association, 1995) were central documents for reform efforts and recommended, for middle schools, stronger efforts to build community and to move toward heterogeneous grouping (Beane \& Brodhagen, 2001). A recent meta-analysis of middle school research (Beane \& Brodhagen, 2001) named five common expectations of teachers in reformed middle schools:

1. Teachers understand the young adolescents with whom they work and provide developmentally appropriate instruction. For example, teachers who don't understand adolescent development may observe lack of motivation and engagement in young adolescents and attribute it incorrectly to lack of cognitive ability.

2. Teachers participate in "teaming" and work in small collegial groups of 3-6 teachers. The number of students on a team should be kept low (less than 125 students), and teachers who lead teams should share common planning time.

3. Teachers act as effective mentors. Reform principles recommend that student mentoring should be a teacher responsibility and should be structured by formal arrangements such as advisory programs. 
4. Teachers use a variety of activities, including those providing hands-on

experiences, as well as those providing opportunities peer interaction and student choice.

5. Teachers move beyond the traditional separate-subject approach to curriculum planning and include interdisciplinary activities. Team leaders strive to plan lessons and activities that incorporate learning from several subject areas, selecting topics that young adolescents find relevant to their own lives.

In analyzing the implementation of middle school reform principles, I compared findings for the six teachers and the three schools of the study using the five characteristics from the Beane and Brodhagen (2001) meta-analysis. I have rated the teachers on the characteristics on a scale of one to three. I used the numbers instead of low, medium, and high so that implementation of the characteristics could be looked at as totals. Results of this analysis appear in Table 4-6. The sections following Table 4-6 discuss details of these five middle school teacher expectations as they apply to the teachers and schools of the study.

Table 4-6

Teacher/School Ratings on Middle School Reform Principles

\begin{tabular}{|c|c|c|c|c|c|c|c|c|}
\hline Teacher/ School & $\begin{array}{l}\text { Years } \\
\text { Exp. }\end{array}$ & $\mathrm{D}$ & $\mathrm{T}$ & M & $\mathrm{V}$ & I & $\begin{array}{c}\text { Teacher } \\
\text { Totals }\end{array}$ & $\begin{array}{c}\text { Totals by } \\
\text { School }\end{array}$ \\
\hline Ellen Alcott - T & 3 & 1 & 1 & 1 & 1 & 1 & 5 & \multirow[t]{2}{*}{13} \\
\hline David Blake $-\mathrm{T}$ & 3 & 1 & 3 & 3 & 1 & 1 & 9 & \\
\hline Darrell Fisher - G & 7 & 3 & 3 & 2 & 2 & 2 & 12 & \multirow[t]{2}{*}{25} \\
\hline Julia Edwards - G & 15 & 3 & 3 & 2 & 2 & 2 & 13 & \\
\hline Christine Ingram-B & 7 & 2 & 2 & 2 & 2 & 2 & 10 & \multirow[t]{2}{*}{18} \\
\hline Melanie Jones - B & 8 & 1 & 1 & 2 & 1 & 2 & 7 & \\
\hline
\end{tabular}

Codes: D - Developmentally appropriate instruction, understanding needs of young adolescents; T - Teaming, teachers lead students working in small, collegial groups; M - Mentorship of students by teachers; V-A variety of activities in the classroom; I - Interdisciplinary planning and activities with other teachers on the team 
Adherence to middle school reform principles varied more by school than by teacher. Differences in these scores may also be related to teacher experience, since the collective teacher experience for Greenville is 22 years, 15 years for Bluefield, and 6 years for Terre Rouge. Differences may also relate to the continuity in team leadership. Team structures usually functioned more successfully when the same teachers had worked together over a period of several years (Davis, et al., 2004), and Greenville’s team leadership was more stable than at Terre Rogue. At Bluefield, 7th-grade teachers and school administrators reported that the small and cohesive team environment had been sacrificed this year, because the superintendent had forced them to move closer to a junior- high-school model and form a 7th-grade team composed of approximately 200 students and all of the ten 7th-grade teachers. The following sections discuss details of these five middle school teacher expectations as they apply to the teachers and schools of the study and also provide a rationale for ratings in Table 4-6.

Developmentally Appropriate Instruction

For the purposes of this study, developmentally appropriate instruction included instructional strategies for boys that tailored instruction to boys' learning needs such as scaffolding tasks, directing attention to developing boys’ organizational skills, and encouraging steps and explanations. In reviewing HyperResearch codings of 8 classroom observations of each teacher, Ms. Edwards and Mr. Fisher used these strategies more than the other teachers, with codings of 167 and 117 respectively (See Table 4-9). Hence, Ms. Edwards and Mr. Fisher were each given three points for this characteristic. Ms. Ingram mentioned in an interview that she enjoyed teaching boys and looking for new ways to help them learn better. Observations of Ms. Ingram’s class yielded 93 coded observations of strategies developmentally appropriate for middle school boys, so she received a score 
of two. The last three teachers, Ms. Alcott, Mr. Blake, and Ms. Jones received scores of 62, 50, and 31 respectively (See Table 4-9). In an interview, Ms. Jones reported that she was going at the same pace and not really doing anything differently in her boys and girls classes. She also expressed the concern for equity as a justification for why she did things the same way for the boys and the girls. These three teachers were assigned a score of 1 for developmentally appropriate instruction.

\section{Teaming}

In a previous year at Terre Rouge, teachers of boys on an all-boy team named cohesive team leadership as one of the reasons they mentioned that their boys had been able to focus more on academics and that standardized test scores had increased for students on their team (Davis, et al., 2004). This year, Ms Alcott had not experienced much cohesion in team leadership. Ms. Alcott said that the other teachers on her team did not have the same rules that she did, and interviews with students on the team confirmed her statement. She felt her rules were working for her, and that even though she was team leader, it was difficult to get other teachers on the team to adopt her rules. Under these circumstances, I gave her a score of one for the teaming factor.

Mr. Blake had more support from other teachers on the team than Ms. Alcott. Mr. Blake's team had been strong and cohesive enough to meet some challenges, such as a teacher shortage and several turnovers in personnel. Students reported that teachers of the team cared about them individually. Because the teachers on Mr. Blake’s team seemed to cooperate well in monitoring individual student progress and in keeping the same rules, I assigned, to him, a score of three. At Greenville, teachers on both 6thgrade team and 7th-grade team had two planning periods, a team planning and a personal planning period. The team planning period was used to discuss common rules and 
procedures, to discuss needs of individual students, and to meet with parents as a group. Observations of the mathematics teachers and of other teachers on the sixth- and 7thgrade teams at Greenville revealed that the teachers worked together cohesively in maintaining a stable learning environment and in monitoring students’ academic progress. Hence, both teachers at Greenville received a score of three for the teaming factor.

At Bluefield, the 6th-grade structure included three-teacher teams, where each teacher taught two subjects. Ms. Ingram taught language arts in addition to $6^{\text {th }}$-grade mathematics. The other two teachers on the team also taught two subjects: one, science and writing and the other, social studies and reading. They operated on a block scheduling plan with three 90-minute periods, called Mod 1, Mod 2, and Mod 3. The teachers of Ms. Ingram’s team had common planning periods and worked together to monitor academic progress. However, in interviews of the sixth grade boys on the team, they reported that behavior standards differ somewhat from teacher to teacher, and thus, the score for Ms. Ingram is two on this factor.

For Bluefield's 7th grade, the team structure for the current year shifted away from the middle school teaming model of small groups of students and teachers working together. All of the teachers and students in the 7th grade formed a team, and both the assistant principal and teachers interviewed spoke of difficulties arising in a team led by 10 teachers. Students interviewed also indicated that behavior standards varied from teacher to teacher in 7th grade. Ms. Baxter also attributed an increase in 7th-grade office referrals to this expanded team structure where the teachers did not teach all students on the team and could not work together as cohesively to meet needs of individual students. Hence, the teaming score for Ms. Jones was one. 


\section{Mentoring}

None of the three schools of the study included classroom teachers in formal student advising programs, however, teachers of the study sometimes engaged in student mentoring on a more informal level. An interview question for teachers, "Do your students talk with you about personal problems?” investigated advising and mentoring of students. In response, Ms. Alcott reported that, with team and management issues and preparation for standardized testing, she did not feel as if there was time to counsel students personally. I rated Ms. Alcott as one for the mentoring factor.

I observed that the two African-American teachers of the study, David Blake and Melanie Jones, seemed to be sought after by the students as mentors. At Bluefield, I observed Ms. Jones on several occasions in her role of mentor. Students would regularly stop by her room after school. As she told me in an interview, "Yeah, a lot of it is usually either family issues or how would you handle the situation, that type of thing. They'll give a scenario and ask how you think they should handle it. There's a wide range of things, but those are usually the issues.”

Although a previous study indicated that the role of mentorship usually was assumed by female teachers (Anfara \& Brown, 2000), Mr. Blake served as an effective mentor for his students at Terre Rouge. In interviews with Mr. Blake’s students, the boys said that he taught discipline as well as mathematics and that he really cared about each of them personally. I scored him as three for his efforts at mentoring students. Mr. Blake also felt that being a male was an advantage as he pointed out in the following dialogue.

MR. BLAKE: Yes, they do that with me more than with the women teachers. For one thing, I'm the only male teacher on the team. Two, because I've already built a rapport with the kids I had last year. I have again this year probably about $80 \%$ of the kids I had in class last year.

RESEARCHER: Under what circumstances will a boy come to you? 
MR. BLAKE: Home life. I've just recently explained to a kid why he couldn't see his father. They like to talk to me about team sports, and also they open up to me because of the rapport I've built with them. They trust me because we share similar interests. And, the more I stay on them, the more it seems they come to me and stuff. I throw in positive reinforcement when needed. I may not do it right on the spot, if I find myself getting on a kid more than a few times, I will go out in the hallway with him. Once they see that I am not doing it because I am being harsh and mean, they usually open up and confide more and more.

RESEARCHER: Do they come to you after school?

MR. BLAKE: I have an open door policy. It can be anytime. I won't let them use an excuse to get out of class; I let them know that if they have a problem to come and talk to me. And, they know that what they say stays between me and them unless it is something that needs to be addressed because of being harmful to them they understand that. And they may not achieve at the highest academic level, but they are very smart. Their home lives are different - they understand a lot of mature things. They may not know the basic math skills, but social issues they may know better because they have been exposed to it for so long.

Mentoring was an important factor for the boys of this study. As Dr. Russell said about both boys and girls at Terre Rouge, "If you reach them, they will go with you anywhere.” The two teachers at Greenville, Ms. Edwards and Mr. Fisher, both pointed out something about boys also alluded to by psychiatrist William Pollack in his popular book, Real Boys: Rescuing our Sons from the Myths of Boyhood (1998). Ms. Edwards commented that boys came to talk to her when there was something newsworthy (e.g. fights in the hallway or details of a sports event), but did not generally talk about feelings. She also reported that boys liked to talk and socialize while they worked.

A comment from Mr. Fisher was also reflective of Pollack as he explained that "Boys open up and talk more when there’s something to do.” These teacher reflections illustrated Pollack’s point that although boys have the reputation for being silent and uncommunicative, they will open up, not when asked about feelings, but when they engage in activities with teachers or students. The two teachers at Greenville responded similarly to the question about students and personal problems. They both reported that girls came to them more frequently than boys with personal problems. Mr. Fisher 
wondered out loud why, as a male teacher among a number of female teachers on the team, the girls might come to him. Hence I scored both teachers at Greenville as a two.

At Bluefield, Ms. Ingram said that the boys would occasionally come to her to talk, so I assigned her a score of two. Although Ms. Jones exhibited affinities for student mentorship, she tended to advise female students more than males. Many afternoons, girls would come by her room after school, and I once observed a visit to Ms. Jones form

a former student who was now in high school. But because of the large $7^{\text {th }}$-grade team, Ms. Jones did not feel that she knew her students well this year, so her opportunity to serve as a mentor to her students was decreased. I therefore gave her a score of two for mentoring.

\section{A Variety of Activities}

Research suggests that as students enter middle school, they become less engaged in their schoolwork. This is particularly true of boys. A good strategy for middle school boys and girls is to give them the opportunity to participate in a variety of activities. Using codings from the study's classroom observations, the three teachers with total instances of less than 5 for using a variety of activities were scored as ones. Ms. Ingram and Mr. Fisher received a score of two for codings of 16 and 22, respectively. Ms.

Edwards was observed to use a greater variety of activities than any of the others with 31 coded instances, and hence, I scored her as three on Table 4-6.

Interdisciplinary Learning

Teacher interviews produced a variety of responses to the question, "Do you plan and conduct interdisciplinary activities for your students?” Ms. Alcott and Mr. Blake both mentioned lack of time and opportunity, so I scored them both as a one. They independently talked to me about last year's 6th-grade teams. There were three-teacher 
teams with about 15 students in a class and two subject blocks of about 90 minutes each instead of this year's 50 minutes with 25 or more students to a class. Teachers at Terre Rouge who had worked on one of the smaller teams in sixth grade preferred the small classes as a learning environment. They mentioned activities such as interdisciplinary projects, computer programs, hands-on work, and cooperative or competitive groups, as activities that had been easier to accomplish in the longer and smaller classes.

Teachers at Greenville and Bluefield commented that they did not develop interdisciplinary learning activities for their students as much as they should, but observations and interviews confirmed that they occasionally worked together to plan interdisciplinary lessons and tasks. Therefore, I scored each of these teachers with a two. At Greenville, Mr. Fisher mentioned a 6th-grade interdisciplinary unit they were planning on economic concepts for life. I learned, in both interviews and classroom observations, Ms. Jones's car safety portfolio project, in which she and the writing teacher would join together to help them with computer spreadsheets, internet research, organization, and writing to produce an interdisciplinary portfolio piece.

\section{Classroom Management}

Research indicates that, in teaching all-boy classes, classroom management and student behavior are key issues (Hudley, 1998; Davis, Choi, Ronau, \& Munoz, 2004). Several studies suggested that because of behavior problems in all-boy classes, singlegender education benefits only girls (Herr \& Arms, 2002; Baker, 2002). The purpose of the following sections are to analyze and categorize classroom management structures and strategies used by the mathematics teachers of the study and to look more closely at individual teachers’ methods and styles of management and interaction. 
Modeling vs. correcting behavior. Teachers can spend their classroom management time modeling appropriate behaviors or correcting inappropriate ones. In the all-boy class observations, correcting behavior was sometimes followed by an argument between student and teacher about the existence, extent, and/or reason for that particular behavior. To use a classroom management approach based on modeling appropriate behavior, the teacher must start with a set of specific rules and procedures, along with specific guidelines about where and when certain behaviors are appropriate. The teacher must remind students frequently about what the appropriate behavior is for that situation, describe the behavior, and sometimes describe alternate behaviors that would not be appropriate. Demonstrations of appropriate behaviors, as well as descriptions, can also be helpful. There must also be established and consistently enforced consequences attached to inappropriate behaviors. Several teachers and administrators pointed to the importance of immediate enforcement of the consequences when working with middle school boys. A classroom management strategy emphasizing the modeling of appropriate behaviors, as opposed to frequent correction of bad behavior, is strongly supported by research in middle schools (Beane \& Brodhagen, 2001; Sprick, et al., 1998; Manning, 1995).

Table 4-7 provides percents by teacher for the total portion of eight selected 50minute classroom observations that were used for classroom management (the "\%CM Time” column). Activities classified as classroom management include travel from previous class, correct behavior, discuss classroom procedures, distribute papers, take restroom break, and execute administrative task. Also presented in Table 4-7 are coded instances of teachers' corrections of behaviors or reviews of appropriate behaviors, in eight 50-minute observations of each teacher, Table 4-7 includes class sizes and years of 
teaching experience, as well. For Bluefield Middle School teachers, there are two

numbers in the class size column. The first number represents the number of students in the regular class that I observed, and the second number is class size for the honors class. For the other schools the class size was based on the average attendance for the 8 classes observed. Detailed charts, for each teacher, of time allocations, for all classroom activities of the eight observations are given in Appendix G.

Table 4-7

Summary of Classroom Management Characteristics (8 observations, 50 minutes each)

\begin{tabular}{|l|c|c|c|c|c|c|}
\hline Teacher/School & $\begin{array}{c}\text { Years } \\
\text { Exp. }\end{array}$ & $\begin{array}{c}\text { Class } \\
\text { Size }\end{array}$ & $\begin{array}{c}\text { CM } \\
\text { Time }\end{array}$ & $\begin{array}{c}\text { instances } \\
\text { correct } \\
\text { behave. }\end{array}$ & $\begin{array}{c}\text { instances } \\
\text { mod.app } \\
\text { behv. }\end{array}$ & $\begin{array}{c}\text { total } \\
\text { behav. } \\
\text { instance }\end{array}$ \\
\hline Ellen Alcott -T & 3 & 23 & $26 \%$ & 71 & 8 & 79 \\
\hline Davit Blake -T & 3 & 33 & $35 \%$ & 22 & 24 & 46 \\
\hline Darrell Fisher -G & 7 & 22 & $11 \%$ & 2 & 21 & 23 \\
\hline Julia Edwards - G & 15 & 19 & $12 \%$ & 5 & 12 & 17 \\
\hline Chris. Ingram - B & 7 & $18 / 18$ & $21 \%$ & 8 & 32 & 40 \\
\hline Melanie Jones -B & 8 & $11 / 26$ & $26 \%$ & 40 & 8 & 48 \\
\hline
\end{tabular}

I coded an interaction “modeling appropriate behavior” when a teacher referred to rules or procedures for a certain set of circumstances. The amounts of time spent on management and behavior were lowest for both teachers at Greenville, and other indicators, such as quiet halls, few classroom incidents, and no behavior discussions in faculty meetings, suggested that Greenville had fewer behavior problems than the other two schools. For Mr. Blake, at Terre Rouge, the proportion of time spent on behavior was highest, followed closely by Ms. Alcott and Ms. Jones. Mr. Blake spent a large portion of one class I observed reviewing appropriate behaviors for moving through the halls and entering his classroom. At Terre Rouge, teachers were required to escort students through the halls to the next class and to the restroom, and these procedures accounted a large amount of management time. Ms. Edwards, Mr. Fisher and Ms. 
Ingram seemed to model behavior more frequently, and Ms. Alcott and Ms. Jones

corrected behavior more regularly. I observed Mr. Blake to do almost equal amounts of both.

Modeling appropriate behavior. Two teachers at Terre Rouge indicated that in some students' homes, education was not valued and behaviors that translate readily to the school environment were not being taught. When dealing with students of different ethnicities, teachers frequently face the additional difficulty of a wide variety of cultural norms -- behaviors that may be acceptable in certain cultures or situations but not in others. Using a strategy of modeling appropriate school behavior can help students to understand and become more confident about accepted practices. Ms. Glover, principal at Greenville, commented on this issue.

MS. GLOVER: We had kids that would come up to me and say, "Hey, Glover, how're you doing?” And, I would say to them, "If I were your best friend that would be appropriate. But since I'm your principal, how should you address me?” They need to understand that in some situations we use our formal register of speech and in others we use our casual register. We've been trying to teach them so that when they leave here they can be successful. As our school's slogan states, "Be successful forever."

While at Terre Rouge, I observed Mr. Blake spend approximately 20 minutes of class time modeling and correcting behavior when he did not like the way students entered his classroom. He described in detail, using some exaggeration, what he did not like about their behavior and then led them around the periphery of the second floor hall of the building and scrutinizing their demeanor as they traveled through the halls and entered his classroom again.

MR. BLAKE: If you boys take my time, I'm going to take yours - that's a promise. You fellas act like you don't have any kind of sense. Line up at the door please. Get off the counters, have your eyes facing forward, and face straight ahead. This is not a circus; this is a classroom. For the last time, you're not going to come in here and you're not going to be in here playing around. Come in like you have some sense. If your shirt tail is not tucked in, it needs to be tucked. If your belt is not tight enough, 
it needs to be tightened. If you don't have a belt on, then you have to keep your hands on your pants to hold them up. You are not going to come in here and act like this is a zoo. Mr. Moore, keep your eyes forward.

A pro-active approach to classroom management. At two of the three schools of the study, Terre Rouge and Bluefield, teachers were trained to use CHAMPs, a classroom and behavior management program to create safe and orderly schools. CHAMPs is an acronym for Conversation , Help, Activity, Movement, and Participation (Sprick, et al., 1998). The program presents specific rules about student voice levels for different activities and procedures for how students should move around the classroom, ask for help, and demonstrate participation in the learning activity (Sprick, et al., 1998). The large school district in which Terre Rouge resides has trained all of its middle school teachers in CHAMPs. Bluefield also began using the program in the year of the study, and Ms.Baxter, the assistant principal, complimented the program to me in an interview.

MS. BAXTER: We feel like if we can get the students learning and not disrupting then more learning is going to go on - and I come from discipline background so that's just kind of my focus -- you need to get them in a seat, paying attention, then you can get instruction, but when they're all over the place you don't have that .... Everybody knows what a certain voice level is and we do a count-down....The (CHAMPs) rule system has helped me because if I go down the halls and see two students teasing or pushing each other, I can say, 'What's Rule One?' and it's not an argument. It's not a confrontation.

Christine Ingram, at Bluefield, worked consistently and repeatedly, to remind students about the CHAMPs rules and what the appropriate behaviors were for specific classroom activities. On one of the bulletin boards in her room she posted a list that she referred to as her KIBORA Rules. KIBORA is an acronym using the first initials for each of the six rules. For example the K-rule, rule number one is "Keep your hands and feet to yourself,” and the R-rule, rule number five, is "Respect teachers and classmates for 
maximum learning.” The following excerpts come from teacher/student dialogue, and

Ms. Ingram frequently refers to CHAMPs rules and principles.

MS. INGRAM: Steven, give me an example of the kind of activity I should be seeing right now ....No, you should be looking at me and waiting for directions. What kind of activity tells me you are not on task as you wait for instructions? ... Yes, playing with the pieces. The whole group of you should have the same pieces....I think that we need to review these classroom procedures. We had some problems remembering them, so we're going to review them before we go on.

STUDENT: A-w-w-w!

ANOTHER STUDENT: (to another student) These are boring.

MS. INGRAM: What's the first classroom procedure I expect you to follow today, Todd?

TODD: Get quiet... get your English and math..., I mean, warm-up.

MS. INGRAM: Do your warm-up each day.... I hear talking, but I need hands because that is one of our KIBORA rules.......What's the second thing you should do, Ryan? (He tells her.) That's right; copy the agenda in your student planner. Do you have to copy every thing that's on the board? What's the next procedure, Peter? PETER: Get your homework out so Ms.Ingram can check?

MS. INGRAM: Yes, have you homework out on your desk so I can check it and record it in my book.

Although Greenville had not adopted CHAMPs or another commercial program for classroom management, teachers used cohesive team leadership and classroom structures as frameworks for behavior management. Both Mr. Fisher and Ms. Edwards began each class the same way each day and also had specific procedures for transitions and activities. Mr. Fisher frequently gave explicit instructions for the behaviors he expected in particular situations. "Remove everything from your table except a sheet of paper and a writing tool. I'll know you're ready when you look ready and sound ready,” or in another instance, "Be sure to replace the cap on your marker and lay it beside the overhead projector when you finish presenting your problem.” At the end of class, both teachers required something specific as a “pass out.” Sometimes it was a homework assignment or class work, and other times it would be an agenda check.

Mr. Fisher's procedures for beginning class differed slightly from the others.

Instead of beginning his daily lesson with a warm-up activity, Mr. Fisher gave the boys 
more responsibility for their own behavior to help them develop self-control. One

morning that I observed Mr. Fisher's class, the boys were not practicing correct behavior and came into his class in a rowdy manner. Mr. Fisher, using a similar strategy that Mr.

Blake had used at Terre Rouge, had them all go back out into the hall and reenter. While

they were standing in the hall, he spoke to them.

MR. FISHER: Now in the past I've said you could come in and visit quietly while I get things graded and problems up on the board. But if you can't even get quiet when I ask for your attention -- three, four, five times in a row -- because you are too loud and you can't hear me, then maybe we need to have a starter on the board every morning. I'll be very quick to put that up there every morning if you need that....But you've got to be able to control yourselves. In life, if you can't control yourself, it's then that people write rules for you. I'll be happy to make some rules for you, but you need to learn to control yourselves.

Boys as risk-takers and braggers. Teachers report that boys are more likely to practice risk-taking behavior, especially when they sense some opportunity of getting away with it (Noble \& Bradford, 2000; Gurian, 2001). In a middle school English class, a teacher said to the students, "Raise your hand if you believe it is better to take risks than to be safe.” All but one male student raised his hand. Not one girl raised her hand

(Gurian, 2001). However, when asked about risk-taking behavior in an interview, Mr.

Blake pointed out the necessity in all-boy classes of putting a stop to these tendencies.

RESEARCHER: I've read about risk-taking behavior in boys.

MR. BLAKE: Yeah, they are sneaky. They are manipulative. Behind your back they will do something and then they will play the role. They act like you need the evidence to prove something, otherwise they are not accountable. That's why you have to have consequences. Otherwise, they figure it out about which teachers will and will not correct their behavior. These kids may come from low SES backgrounds, but they are very smart in sensing behaviors. They are very smart streetwise.

Boys also like to brag and a group of 6th-grade boys at Bluefield offered the following comments about bragging in an interview. There may have been a little realworld number sense present in the conversation, also. 
MARK: People showing off how they beat somebody up

RESEARCHER: Bragging?

NEAL: Sometimes

RESEARCHER: What do they brag about?

DAN: I could fill a book. I could fill a book with everything I've heard this year.

RESEARCHER: What about you, Mark? What do hear them bragging about?

MARK: 'My shoes is clean and stuff.'

NEAL: They buy $\$ 500$ shoes and brag about it.

DAN: Clean is cool and things. It don't mean what it seems like it means...It's not like they're 'tight', but actually they're 'cool' and 'not loose.'

RESEARCHER: So clean and tight means cool? And \$500 sounds expensive, too.

Could that be right?

NEAL: I don't know.

DAN: I think they were some type of twenty-six dollar shoes, or something.

RESEARCHER: That's doesn't sound expensive.

DAN: I don't know.

MARK: I think they were around eighty dollars.

Boys cause disruptions when they seek the center of attention in a classroom. Bragging, taking risks, showing off, and acting silly are common ways that boys seize and retain the limelight. As Mr. Blake told me, "You’ve got to have consequences, and immediate consequences generally work best.” Otherwise, some students may continue to show off, brag, and disrupt, no matter what classroom structures are in place.

A voice of understanding and reason. Several times in the study, Ms. Jones expressed doubt to me about whether the gendered classes were helping the boys. She alluded to their "locker room mentality" and also said that she thought that, for equity purposes, all-boys and all girls classes should be taught the same way. Studies have also suggested that adolescent girls are more interested in pleasing and getting along well with the teacher than are boys (Noble \& Bradford, 2000; Gurian, 2001;Baker, 2001). Ms.

Jones found her girl students reasonable and willing to cooperate, and she would try to deal with her all-male classes in a similar manner. She corrected boys’ behaviors and then tried to reason with them as a group about why they should stop showing off, talking 
out, teasing, or “joaning” with each other, as boys called it at Bluefield. The following are three examples of interactions from observations of Ms. Jones’s class.

MS. JONES: It makes no sense that I feel like a lion tamer when I come into this room....You need to get your assignment out from last night, your worksheet...I don't want to hear a sound...This noise level is nowhere acceptable...Danny, have a seat...pencils sharpened... I don't want anybody talking....Tom, what's wrong? TOM: He threw my pencil or something. MS. JONES: Go get it.....Gentlemen, what did I say about the noise?.....This is math class and you need to be doing math.

MS. JONES: I'm waiting for everyone to settle down. We still have about 18 minutes.... Gentlemen, I wouldn't mind giving free time if you were quiet during my time. But you're talking when it's my time, too .... If you had been quiet, you would have gotten to do board races. Now, if I were told that the other class had board races, and you saw me passing out a worksheet. Then, the best thing you could have done would be to sit quietly, hoping that I would have a change of heart.

$$
\text { An “ in-your-face personality.” Sometimes a teacher may perceive a need to }
$$

move beyond the "pro-active” posture, or the reasonable posture, and must assume a more aggressive stance in classroom management. In an interview from a previous study at Terre Rouge, an experienced and successful teacher told me, "You need an in-yourface personality to teach these kids.” An "in your face” style emphasizes the importance of control. The teacher does not shy away from criticizing students openly for their behaviors, their inattention, and lack of effort. Students are constantly reminded of the consequences for off-task and disruptive behaviors and even boys, who frequently seek to be risk-takers in hopes they will get away with it, usually assess the risks as being too great.

Ms. Alcott, a relatively young teacher in her third year, used this interaction style in her classes. It is a common practice for new teachers to place control as a primary concern (Raymond, 1997). I observed that Ms. Alcott mentioned control explicitly and also expressed her dominance implicitly through her interaction style. A reason she may have adopted this style was that she was not getting the support she needed from the other 
teachers on the 6th-grade boys' team that she headed. Several of the other teachers were being more permissive and enforcing rules less consistently.

MS. ALCOTT: I think among teachers, its hard, you can work together, but when it comes down to discussing what needs to be done it's very hard for one adult to tell another adult what to do, especially for me, since I'm younger than all of them. And two, I'm a teacher just like they are, so coming from me, they don't perceive it as much.

Dr. Russell told me that she expected her teachers to send only Level 3 (serious) discipline issues to the administration, and that the teams should handle less serious offenses. Thus, she found herself needing to regularly "tighten up" on rules in her classroom and correct behavior that may have been allowed in the other classrooms, and the "in your face” stance was an expedient way to accomplish that. Ms. Alcott believed that the school's administration approved of her classroom management methods. "I don't have problems in my class, so that eliminates a lot of stress from their (administrators) jobs. They appreciate this and support me.”

Throughout her lessons, she corrected behavior and threatened students with consequences for not cooperating such as calling parents, a writing assignment, or not allowing a restroom break. She convinced the students that she was in control and that any off-task and unapproved behavior in which they may choose to engage would cause them more difficulties than they may have been willing to encounter. The following are complied excerpts from her classroom dialogue with students.

MS: ALCOTT: I asked you to come in and close your mouth. Are you special, Sheldon?...It's ridiculous that I have to keep asking you all to be quiet. I guess I'll just give out some detentions.... What are you chewing on? Spit it out....I guess you want some definitions to write tonight - fifty times ... Tuck your shirt in. ...Paul, why am I talking over you?.....This is a real problem if this is how class is going to go....Y You tucked your shirt in and then you took it right back out. Don't play games with me .... I'm still waiting ... John, I'll call your parents to come in for a conference. You can't just sit there and do what you want. Don't just blow this off. You're going to write sentences tonight if this continues. .... You're in my business which is rude. You're not an adult! You take care of Marcus's business 
and I'll take care of my business.....Now get out a sheet of paper, were going to take notes on some power verbs. If you don't get this you can't get a grade for today.....Stop tapping the pencil...Stop talking. ...I went over that. See, ya'll don't listen. I'm tired of repeating myself....Why is everyone still talking? .... Dustin if you don't quit, your parents will have to come for you....I have charge, John. What are you talking about? I need to know ..... I thought I was up here teaching, but I could be wrong. I mean, I could go home; I'd be much happier sitting at home right now... OK, we're going to talk about mode, median, and range...ok ....Why do you think you have permission to keep yelling out?....You know what, he'll be in trouble for that because he's not going to pass 6th grade. And I'm going to be calling Ted's parents tonight.... OK, I'll wait until everybody's quiet.........It's going to be a long year!

On two occasions, I observed that she would follow through on threats of phone calls to parents. She once called a boy up to her desk and said, "Call your mother." But in that case, the parent did not answer. Another day, however, as I entered the school building, I observed her talking to a father and his sulking 6th-grade son.

MS. ALCOTT: Thank you for coming in. I called you because he was sleeping in class, and when I corrected him he kicked the desk.

FATHER: You are not supposed to sleep in school, son. You're here to learn. SON: I wasn't sleeping.

MS. ALCOTT: He had his head down on his desk.

FATHER: Well, you had your head down, and you're not supposed to be doing that in school either. Are you not getting enough sleep? What time do you go to bed at night? (It became more obvious, throughout the conversation, that the boy did not live with his father.)

SON: After "Fear Factor" is over.

The conversation ended after about five more minutes. As the father left the building, Ms.

Alcott thanked him for his support and assistance.

In one humorous interaction, she reminded students that rewards of challenging

authority or not following the rules may not be great enough to risk the possibility of appearing less than competent or laughable in front of the other boys. The following exchange had everyone in the room, except Ben, laughing hysterically.

MS. ALCOTT: So I want you to do a factor tree for 24; a factor tree for 24 . Soon as we do this factor tree we'll go to the rest room.....Quit sniffing the markers.

That's why I don't usually get them out.

BEN: I have a runny nose. 
MS. ALCOTT: So you're wiping your nose with the marker? ... (all laugh).... You went like this. (Ms. Alcott moved her overhead projector pen close to her nose and says in a mimicking way) I'm not smelling the marker?... (more laughter)... We all know they're scented; we know this by now. If you have a marker, I hope you're writing with it. I guarantee you that when I come back to look at that paper, it better not be blank.

What do you do about the braggers, risk-takers, show-offs, and jokesters? When

asked the question, "What could your teacher do to help you to learn mathematics

better?” a surprising number of the boys that I interviewed named two or three students in the class and suggested that the removal of these students would greatly improve

learning. The boys' comments brought with them a realization that it may be only a few students in the class who were making learning difficult for the others. When I asked teachers about this they told me quickly that students could not be removed from the class for this type of disruption. Administrators frequently do not consider these incidents serious discipline problems, and yet, particularly in an all boy class, it is these disruptions - the bragging, joking, showing-off, sneaking, and risk-taking -- that can cause a class to assume the aura the "locker room" and learning to come to a halt. Reasoning with the adolescent boy does not usually work, and sometimes citing rules and consequences or threats may not be effective either. I talked some with Mr. Blake about how he handles those few students who are persistent in their desire to disrupt, making learning difficult for the others

MR. BLAKE: It can be a trying environment when certain students cause problems and they can change the mood of a class. I don't wait for the problems to occur or wait to figure out who the troublemakers are going to be. I try to establish, on day one, how I want kids to act in my class. I call out any inconsistencies. You have to be firm and do what you say - consequence-wise.

RESEARCHER: What if that doesn't work?

MR. BLAKE: If that doesn't work then in middle school you have a team. That's why a team is so helpful, because you have team members who can help out. You can also get parents involved. I also have an isolation area in my classroom (very large room) and if you put them in isolation in your own classroom rather than 
someone else's, they can't say that they are missing the work. Sometimes you have to make examples of them because they are going to keep pushing it.

RESEARCHER: What if a boy smarts off to you?

MR. BLAKE: It helps me being a male and one that is stern.

RESEARCHER: What do you do to make know that they can't smart-off?

MR. BLAKE: I get in their face. I let them know..... If you get smart with me; I

can get smart, too. I don't physically intimidate them, but I let them know that this

is not going to be allowed. If they want to be loud, I can be loud too. If they want to be serious, I can be serious, too. But I let 'em know and let 'em know by my actions. I don't just tell them what I am going to do. Same thing I expect out of my students. I say, "Don't tell me what you are going to do, you do it." And if you don't then here's the situation.

RESEARCHER: Then what do you do?

MR BLAKE: Uh....(he laughs) You know... I don't know to be honest.

RESEARCHER: You just get in their face and that's all you need to do?

MR. BLAKE: The main thing I do..... If they want to get smart and do stuff in my class I go over to them and get in their face to address it.

RESEARCHER: And they back down?

MR. BLAKE: Yeah, they back down. Some may consider that intimidation. But, what about how kids intimidate teachers? The boys also know I'll pull them aside later and talk to them about what they did, but not in front of the class. I'll ask them, "What's going on, because this is not consistent with what you do in my class." So if the situation calls for immediate attention, I have to be aggressive. Then, I'll pull them aside later in the hallway and talk to them. They know I don't allow fighting or bickering in my classroom. I run my classroom like my house.

I'm not going to let somebody come in and do anything he wants in my house.

So it sounds as if a teacher of all-boy classes needs a number of strategies - a big

bag of tricks. There may be a need to get "in your face” at times but perhaps not so

much that it interferes with what you are trying to do. A cohesive and supportive group

of team leaders can also be an important asset. In summarizing our conversation, I

formed Mr. Blake’s suggestions into the following course of action:

1. Establish your rules and policies and enforce them.

2. Don't overlook consistencies that you see and take immediate action.

3. Place the student in isolation.

4. Call on another team leader to take the student.

5. Get "in his face."

6. Pull him aside, later, and talk with him about the problem.

For successful classroom management in a difficult class, you may also need a particular demeanor and mind-set. Coincidentally, I had a conversation with Dr. Russell 
the same day I spoke with Mr. Blake about classroom management, and she used a

similar home-classroom analogy. Dr. Russell identified “presence” as a quality needed

to teach students at Terre Rouge, and she thus described it to me. "If you have 'presence'

you run your classroom like your home. Those who enter my home are welcome, but

they must follow my rules.”

Summaries of classroom management characteristics. Table 4-8 presents an

overview of each teacher's classroom management styles, practices, and characteristics.

Table 4-8

Characteristics of Classroom Management by Teacher

\begin{tabular}{|c|l|}
\hline $\begin{array}{c}\text { Terre Rouge } \\
\text { Ellen } \\
\text { Alcott }\end{array}$ & $\begin{array}{l}\text { Corrects behavior frequently; “in your face” interactions; } \\
\text { admonishes publicly students' lack of effort; makes threats (e.g. } \\
\text { call parents, repetitive writing; copying from dictionary; failing } \\
\text { grades. }\end{array}$ \\
\hline $\begin{array}{c}\text { Terre Rouge } \\
\text { David } \\
\text { Blake }\end{array}$ & $\begin{array}{l}\text { Exhibits even blend of correcting behavior and modeling } \\
\text { appropriate behavior; uses a variety of strategies, including help } \\
\text { from team; if other strategies don't work he "gets in their face” } \\
\text { and directs the student individually and firmly; aslo draws } \\
\text { students aside for counseling. }\end{array}$ \\
\hline $\begin{array}{c}\text { Greenville } \\
\text { Darrell }\end{array}$ & $\begin{array}{l}\text { Emphasizes personal control of behavior; "If you don't learn to } \\
\text { control yourself then others will make rules for you;" receives } \\
\text { support from other team leaders; on-going efforts for time }\end{array}$ \\
\hline $\begin{array}{c}\text { Greenville } \\
\text { Julia }\end{array}$ & $\begin{array}{l}\text { Implements highly-structured plan; coordinates with other team } \\
\text { timely cooperation; physical movement. }\end{array}$ \\
Edwards & $\begin{array}{l}\text { lunch detention for behavior and no homework; physical } \\
\text { movement; a variety of classroom activities, including hands-on } \\
\text { activities. }\end{array}$ \\
\hline $\begin{array}{c}\text { Bluefield } \\
\text { Christine } \\
\text { Ingram }\end{array}$ & $\begin{array}{l}\text { Refers frequently to classroom rules and standards for } \\
\text { appropriate behavior; CHAMPs rewards and consequences; } \\
\text { collaborates with other team leaders for discipline; long stretches } \\
\text { of time with little physical movement. }\end{array}$ \\
\hline $\begin{array}{l}\text { Corrects behavior frequently and attempts to reason with } \\
\text { students about their behavior; homework/worksheets as threats } \\
\text { and rewards; reports same strategies and teaching for all-boys } \\
\text { and all-girls classes. }\end{array}$ \\
\hline
\end{tabular}


Sample dialogues of classroom management interactions. To further

characterize teachers' approaches to classroom management, several samples of dialogue

from classroom observations are also included. The following three dialogues from

classroom observations of Ms. Alcott, Ms. Ingram, and Ms. Jones exemplify three

different styles of interaction for all-boy classes. In this first dialogue, Ms. Ingram relies

strongly on CHAMPs strategies for modeling appropriate behavior.

\section{Dialogue 1}

MS. INGRAM: Steven, give me an example of the kind of activity I should be seeing right now .....No, you should be looking at me and waiting for directions. What kind of activity tells me you are not on task as you wait for instructions? ... Yes, playing with the pieces. The whole group of you should have the same pieces....I think that we need to review these classroom procedures. We had some problems remembering them, so we're going to review them before we go on.

STUDENT: A-w-w-w!

ANOTHER STUDENT: (to another student) These are boring.

MS. INGRAM: What's the first classroom procedure I expect you to follow today, Todd?

TODD: Get quiet... get your English and math..., I mean, warm-up. MS. INGRAM: Do your warm-up each day.... I hear talking, but I need hands because that is one of our KIBORA rules.......What's the second thing you should do, Ryan? (He tells her.) That's right; copy the agenda in your student planner. Do you have to copy every thing that's on the board? What's the next procedure, Peter? PETER: Get your homework out so Ms.Ingram can check?

MS. INGRAM: Yes, have you homework out on your desk so I can check it and record it in my book.

Ms. Alcott exhibited the most instances for correcting behavior, and I observed her style to have an "in-your-face” aura about it. Dialogue 2 represents compiled examples of Ms. Alcott’s interactions with students.

Dialogue 2

MS: ALCOTT: I asked you to come in and close your mouths. Are you special, Sheldon?...It's ridiculous that I have to keep asking you all to be quiet. I guess I'll just give out some detentions....What are you chewing on? Spit it out....I guess you want some definitions to write tonight - fifty times ... Tuck your shirt in. ...Paul, why am I talking over you?.....This is a real problem if this is how class is going to go. 
Ms. Jones believed that, for equity purposes, boys and girls should be taught the same

way. She found her girl students reasonable and willing to cooperate, and she would try

to also deal with her all-male classes in a similar manner.

\section{Dialogue 3}

MS. JONES: It makes no sense that I feel like a lion tamer when I come into this room....You need to get your assignment out from last night, your worksheet...I don't want

to hear a sound...This noise level is nowhere acceptable...Danny, have a seat...pencils sharpened... I don't want anybody talking....Tom, what's wrong?

TOM: He threw my pencil or something.

MS. JONES: Go get it.....Gentlemen, what did I say about the noise? This is math class and you need to be doing math.

Ms. Alcott's and Ms. Ingram's respective strategies, the modeling of appropriate

behavior and the "in your face" approach seemed to be more successful than reasoning

with the boys. I observed that Ms. Jones was frequently burdened with further

disruptions and her students reported in interviews that these disruptions were barriers for the students' learning of mathematics.

Even in a crowded classroom containing 30-35 boys, I observed Mr. Blake to be a successful manager. There were not enough desks and some sat on the floor or on counters located around the room's periphery. He spent more time on behavior (35\%) than any other teacher, and I once observed Mr. Blake spend approximately 20 minutes of class time modeling and correcting behavior when he did not like the way students entered his classroom. In an interview, I probed Mr. Blake about his approach to management. He recommended beginning by establishing rules and policies and then enforcing them. "Don’t overlook consistencies," he said, “and take immediate action.” I then asked about the particularly difficult cases, those boys that still try to cause problems even if the standards are set and the others are cooperating. "I place the student in isolation or call on another teacher on the team to take the student. If this doesn't 
work, I get in his face. Later, I might pull the boy aside and talk to him about the problem,” said Mr. Blake.

I observed, in my study, a variety of classroom management strategies, and the nature and extent of implementation differed greatly by teacher and by school. Teachers at Greenville Middle School spent approximately half the amount of time on classroom management as teachers at the other two schools. Classroom management at Greenville Middle School received strong support from administrators. Mr. Ted Lewis, an assistant principal at Greenville, commented that he had worked hard during his three-year tenure to strengthen discipline policies and procedures and that the number of office referrals and suspensions had decreased over this period. Ms. Edwards attributed decreases in classroom management problems and referrals to single-gender classes. Teacher experience, collegiality, high teacher retention rates, and school size may also have been contributing factors to the lesser amounts of time spent on management issues at Greenville.

\section{Strategies for Teaching Boys}

Research on schooling for boys remains scarce (Weaver-Hightower, 2003). However, researchers who have studied boys' indicate that how they are taught is important (Noble \& Bradford, 2000; Woody, 2001). The strategies described in this section were identified through observations and interviews of the six mathematics teachers. Some of these strategies for teaching boys have previously been identified by other scholars (Gurian, 2000; Noble \& Bradford, 2000). The suggested strategies may also be successful with girls. Four of the six teachers in the taught all-girls classes, too. They mentioned strategies such as using topics of interest and hands-on activities as also being successful with girls. 
My investigations indicated that the observed teaching strategies fell into two primary categories- strategies used to meet boys' learning needs and engagement and motivational strategies. Strategies used to meet boys' learning needs included structuring learning environments; scaffolding and structuring tasks; assisting boys in learning organizational skills; requiring intermediate steps and explanations; providing for physical movement; and using hands-on activities. Strategies teachers used to engage and motivate students in their all-boy classes included using topics of interest to boys; using jokes, melodrama and tall-tales; incorporating team competition in classroom activities; reciting in unison; and inspiring self-confidence and perceptions of task value; and giving rewards.

The strand of mathematics proficiency that relates to engagement and motivation for doing mathematics is called productive disposition and is described as "the tendency to see sense in mathematics, to perceive it as both useful and worthwhile, to believe that steady effort in learning mathematics pays off, and to see one's self as a learner and doer of mathematics” (Kilpatrick, et al., 2001, page 131). Productive disposition also relates to the enjoyment of doing mathematics and solving mathematics problems. Productive disposition is not something one is born with but can be acquired, particularly if the student is engaged and encouraged by the activities in a class and its teacher (Kilpatrick, et al., 2001). Teachers of this study used a variety of strategies to engage the thoughts and efforts of middle school boys and to motivate them to achieve mathematically. Research on early adolescents indicates that boys are harder to motivate academically at this age and generally exhibit less enjoyment of school activities (Noble \& Bradford, 2000; Gentry \& Gable, 2002). 
Summary Analysis for Boy Strategies

Listed in Table 4-9 are coded instances for strategies used in the observed all-boy mathematics classes. These instances were based on eight 50-minute classroom observations for each teacher. HyperResearch was used to code and categorize observational data and totals were computed. All teachers of the study used the structuring and organizational strategies (e.g. structuring lessons, scaffolding tasks, organization/planning). However, only the teachers from Greenville used many of the engagement and motivation strategies for boys. Teachers and administrators at Greenville adopted a gendered class program primarily to improve boys' test scores and decrease failure rates. Table 4-9 shows that mathematics teachers there exhibited more instances in which they tailored their instruction in all-boy classes.

Table 4-9

Coded Instances for Boy Structures and Strategies (8 observations, 50 minutes each)

\begin{tabular}{|c|c|c|c|c|c|c|}
\hline & EA & DB & DF & JE & $\mathrm{CI}$ & $\mathrm{MJ}$ \\
\hline \multicolumn{7}{|l|}{ Learning Strategies } \\
\hline structuring lessons & 22 & 15 & 38 & 45 & 29 & 3 \\
\hline group/partner work & 0 & 4 & 8 & 18 & 4 & 1 \\
\hline scaffolding tasks & 4 & 10 & 8 & 23 & 12 & 3 \\
\hline $\begin{array}{l}\text { attention to } \\
\text { organization/planning skill }\end{array}$ & 26 & 18 & 12 & 27 & 11 & 14 \\
\hline encourage steps/explanations & 9 & 2 & 43 & 45 & 26 & 8 \\
\hline movement/hands-on learning & 1 & 1 & 8 & 9 & 11 & 2 \\
\hline Learning totals & 62 & 50 & 117 & 167 & 93 & 31 \\
\hline \multicolumn{7}{|l|}{$\begin{array}{c}\text { Engagement/Motivation } \\
\text { Strategies }\end{array}$} \\
\hline topics of interest & 0 & 0 & 13 & 2 & 0 & 0 \\
\hline jokes, big numbers, tall tales & 1 & 0 & 32 & 1 & 1 & 1 \\
\hline competition & 0 & 0 & 7 & 17 & 0 & 2 \\
\hline $\begin{array}{l}\text { "the cheer" and group } \\
\text { recitation }\end{array}$ & 1 & 5 & 9 & 2 & 1 & 0 \\
\hline $\begin{array}{l}\text { confidence/importance/encou } \\
\text { ragement }\end{array}$ & 3 & 6 & 13 & 37 & 2 & 4 \\
\hline rewards & 0 & 0 & 10 & 8 & 0 & 0 \\
\hline technology & 0 & 1 & 0 & 0 & 4 & 3 \\
\hline Engage./Motiva. totals & 5 & 12 & 84 & 67 & 8 & 10 \\
\hline Totals (learning \& motiva.) & 67 & 62 & 201 & 234 & 101 & 41 \\
\hline
\end{tabular}


Mr. Fisher relied frequently on topics of interest, jokes, and "tall tales," as he related problems and explanations of proportional thinking to his "previous career in the NBA.” Ms. Edwards frequently used team competitions in solving problems on the board. Ms. Jones used the fewest total strategies for differentiating instruction for boys. Her teaching decision coincided with her beliefs about equity, that boys and girls should be taught the same way. Several scholars recommend teaching with technology (e.g. computers and calculators) for boys (Gurian, 2001; Baker, 2002) but results indicate that technology was not used to a great extent by teachers in this study. The following sections provide detailed descriptions of how these identified strategies for teaching boys were used by the six mathematics teachers of the study.

\section{Structured Learning Environments}

In addition to structured systems of classroom management, teachers and principals referred often to boys' needs for structure in learning and class activities. Dr. Russell recommended "structure, structure, and more structure” for the boys in her school. A structured learning environment may also work well for girls. Four teachers of this study also taught all-girl classes, they used similar structures for their all-girl classes.

Beginnings and Endings. All six teachers structured their learning environments so that class began the same way every day. Ms. Alcott usually had the boys begin by writing the daily plan and the homework in their agenda books. She frequently checked to see that parents were initialing these agendas at home. Ms. Alcott frequently wrote in a boy's agenda book a note to a parent about behavior or school work and expected it to be initialed when she checked it again. The maintenance and checking of the student agenda was a whole school project, and Nathan Thornton, one of the school's assistant principals, came to Ms. Alcott's team meeting and reminded all of the teachers on her 
team about their importance. "I’m hearing from parents,” said Mr. Thornton, "that blank agenda books are going home. We are being held accountable and if you do your job, I can defend you.”

Ms. Edwards, as well as the other $7^{\text {th }}$-grade teachers on her team at Greenville, stood outside their doors as students entered and checked each student for supplies needed (e.g. binder, clean paper, and pencil) for class that day. After students entered, Ms. Edwards then began a starter activity. The purpose of this activity was usually to review concepts and practice with problems and procedures. Her established routine for tracking starter papers was also highly structured. Each day of the week, the students placed completed starter activities in a folder they kept. At the end of the week they turned in all of their work together, and Ms. Edwards graded them and returned them the following week.

At Bluefield, Ms. Ingram began her class by having students copy the agenda, followed by a warm up activity on the overhead projector. Ms. Jones would begin her class by reciting aloud to her students the date in both Spanish and English, as well as the word of the day and its definition. These words of the day came from a list of "power words” suggested by the state’s department of education to be learned for open response questions on the state achievement test.

Transitions. Mr. Fisher tried very hard to protect his class time for mathematics and his transitions from one activity to the next were creative, efficient, mathematical, and rewarding. He began with the phrase "When I say go..." Students knew that when he said it that they were supposed to freeze and listen for further instructions. He then proceeded with the following speech which was almost verbatim every day.

MR. FISHER: When I say go, I want to make sure that you have your tables completely cleared off except for a writing tool and a half a sheet of graph paper. 
Any time under one minute it takes you to get that done, we'll multiply by 8....Go!...

(There's some noise as they rush to get binders and books on the floor)banging and they do it

STUDENT: Sh-h-h-h ; Oh my gosh!

MR. FISHER: I'll know you're finished when you've done what I asked and sound finished... . (Things get very quiet)...I appreciate that, gentlemen. I appreciate a group that works very hard to get things done quickly. That's important, because the faster we work. --now faster is not necessarily always better, because I can be really fast in getting things cleared off my table by taking this and going "whoosh." (Students laugh) But that's not super effective, so I appreciate you working together. We've saved 23 seconds, so let's go ahead and do the multiplication. We saved 23 seconds. What is the property of multiplication that we use here? What is it called?

STUDENTS: (many voices): Order of operations.

MR.FISHER: That's true, but we can also use what's called the distributive property. If you have a big number times a smaller number, you can use the distributive property here. You can take 8 times 20 plus 8 times 3 to get your answer. That's sometimes easier. But when my fingers get to zero, I want you to tell me, what is 23 times 8 ?

(He has a chart at the right side of the chalkboard with running totals of time saved for each class period. He takes time off for misbehavior, and each of his classes can compare where they stand with other classes.)

Groups. Research suggests that boys can experience more success and accomplishment as they work in groups if each student is assigned a task (Gurian, 2001; Noble \& Bradford, 2000). When Mr. Fisher had groups make a presentation in his class, he assigned various roles to each student in the group. One boy assumed the role of the scribe and another was timekeeper and coach. He asked everyone to stand who did not have a job, and a gasp was heard in the room when he said, "I guess you'll be the presenters.” Ms. Edwards structured her groups in board competitions starting with one or two boys at the board and the other boys at their seats. Then those at the board competed in solving problems, and at the end of one round, they switched. The board task and seat task were separate, and those at the board did not consult with seated team members. If there were two at the board, they could consult with each other but each 
would have a different part of the problem to do. For example, one would solve an equation and the other would check.

No Choice. Although middle school principles suggest that choice can be a motivating factor for early adolescents, the mathematics teachers of this study did not usually advocate or allow many choices in their all-boy classes. Ms. Edwards believed that choice sometimes encouraged boys to take the easy way, omit steps, or choose the easiest problem. She would not allow boys to merely look at a one-step equation and figure out what number worked. Boys frequently wanted to just get the answer, and with elementary equations it was easier to look at the equation and figure out what works. Ms. Edwards told her students repeatedly, "You have no choice about showing your steps. You will make a failing grade on the work if you don’t show your steps....And, you have no choice about showing your check." Ms. Alcott also named "no choice” as one of the strategies she used with boys. If given a choice she felt that her boys would do a less than adequate job of a task or not do it at all.

Scaffolding and Structuring Tasks

Vygotsky theorized that learning is a cultural and social activity and that teachers need to do more than just arrange the environment in a particular way. Vygotsky used the term "scaffolding" to describe supports for learning such as clues, reminders, examples, as well as breaking a problem or activity into steps (Woolfolk, 2001). In this study, I observed numerous instances when the mathematics teachers of boys would structure and scaffold tasks. See Table 16 for total codings in each teacher's observations. Provided here are some specific examples for structuring and scaffolding mathematics tasks. 
Three steps in a factoring problem. When teaching a lesson on factors and primes,

Ms. Alcott structured the task in the following way.

MS. ALCOTT: Now look at question 3. For this one, we're going to list factors, factor pairs, and draw rectangles. Here are the three things you need to do to (She writes an outline on the overhead projector of what they should do for Question 3.)

3. List factors of the number...

*List factors

*List factor pairs

*Draw one rectangle

(On the overhead projector, she draws a picture showing how she wants the rectangle drawn and labeled.)

Seven requirements for a double bar graph. In teaching students how to do bar

graphs, Mr. Fisher used teams that students would cheer for in the upcoming World

Series and structured the task in the following way.

MR. FISHER: You learned early in this classroom that every graph that we create has 6 things, but when we create a double bar graph we automatically have seven things that every graph needs. First, your $\mathrm{x}$ and y axis, we have that. That's good. Second -- a scale. We have that too. Third, categories, we have those...Now we're missing a couple of things up here. We're missing a label. What to these numbers represent? What does the scale represent?

STUDENTS: Fans.

MR. FISHER: Number of fans or number of students. I like students because not everyone's a fan of soccer (wrong on purpose)

STUDENTS: (correcting him) Baseball!

MR. FISHER: I mean baseball. I'm a real big football fan, no baseball. So this is four - labels. Five is title. No, that makes six because five is the data, six is the title. But I said every double bar graph must have seven things.

STUDENTS (a few voices): A key

MR. FISHER: Say it again

STUDENTS: Key! (others join in)

MR. FISHER: Yes! I need to draw a box on the front and label it key. And then we have how many bars on here?

STUDENTS: Two.

MR. FISHER: Two for each category. So we're going to put "Fans" and "Believers" because the fans bar is colored one color, and the believers bar is shaded in a different way.

Ask yourself three questions. The way that Ms. Edwards taught her students to solve one-step and then two-step equations was detailed and specific. She began with a 
set of manipulatives called "Hands-On Equations.” The set contained a mat with a picture of a balancing scale on it, pawn-like pieces for the variables, and dice with digits 0 through 9 and operational symbols. She then had her students model the equations and also describe the process in symbols. As students practiced this process, Ms. Edwards said

Now every time, guys, you solve a one-step equation I want you to ask yourself three questions.

1. What is the operation?

2. What is its opposite?

3. What is the number with the operation?

Then, she explained to the boys that when they added more steps to the process of solving equations (that is when they began to have two-, three-, and four-step equations) the rules would not change. They would then ask themselves these same questions for each subsequent step.

Three necessary parts of a problem presentation. In Mr. Fisher's class, after students had spent several days working problems in groups, I observed his class the day that the presentations were made. In giving instructions about what he wanted to see in each group's presentation, he insisted that they address three main points.

1. What were you to find?

2. What did you know from the problem?

3. Show how you used that to solve the problem.

After presenting these three points, he returned to the specific problems they had worked and gave examples of how to address each of these items for that particular problem.

Two strategies for finding a greatest common factor. Ms. Ingram at Bluefield often gave the students several different strategies or procedures for a mathematics task. In an interview, one student said about Ms. Ingram, "She always shows us the easiest way to do it.” She taught several different strategies for finding a greatest common 
factor and gave specific and visual directions about how each one. She told the students several times that there was not just one strategy for this task, and that they could use the strategy that worked best for them.

Another feature of structured tasks is repetition and clarification in describing it. Several teachers mentioned the importance of repetition of directions, tasks, and procedures when teaching middle school boys, and I observed them use this frequently in their teaching. Ms. Alcott was the only teacher who mentioned it specifically in an interview, but the observations suggested that most of the teachers were using this strategy to structure tasks, to keep boys on task, and to prevent them from falling behind and becoming disengaged with a lesson.

\section{Organizational Skills}

Research on learning suggests that, in early adolescence, boys have more difficulty with organizational skills than girls do ( Noble \& Bradford, 2000; Gurian, 2001). I observed many instances where boys did not have writing tools, left important papers on the floor, and kept binders in obvious states of disarray, stuffed with random and wrinkled papers. The teachers of this study included a variety of strategies in their teaching to help and encourage boys to be more organized in their schoolwork. Ms. Alcott checked to make sure they copied the agenda every day and wrote notes to parents in their agenda books about a student's work or behavior. Parents were supposed to initial the agendas, and she would sometimes follow up with a call to parents to make sure this communication through the agendas was working. She stressed with the boys their individual responsibilities to come to class prepared and made things difficult for students who came to class unprepared. 
Mr. Blake was more generous to his students in accommodations for disorganization and handed out second worksheets when students lost them. However, he frequently stressed the importance of note taking and of how the notes were written and organized. I heard him make some of the following comments to students about taking notes in his class. . “I don’t want anyone to tell me he has bad handwriting. It’s your job to write neatly.”....”Don’t write real big.”......”Leave space for the graph.”......”Keep your columns straight.”...Put this title in the center of a new page.” These were reminders he gave in his classes.

Mr. Fisher placed emphasis on organization and thoroughness in getting the boys to acquire good homework habits. Each day in class he distributed homework problems to be done the following day. The next day in class, he asked several students to present problems on the board and conducted discourse with each student and the rest of the class about correct solutions for the problem. Then, after all five problems were discussed, students turned in their homework papers. Near the end of class he usually returned the previous day’s homework papers after marking the ones that were not correct and subtracting points accordingly. However, a student could earn the full five points by reworking the problems that were incorrect and resubmitting it a day or two later.

To teach the importance of coming to class prepared, Ms. Edwards and all of the teachers on her team enforced a policy requiring that students show them their materials before entering class each day. Students who did not have their supplies, along with students who did not have their homework, were required to have lunch detention with Ms. Edwards that day. After calling for homework, she checked to see which boys submitted no paper and asked them again for it individually. Frequently, the boy had his homework but had forgotten to turn it in. If the student had not done the homework, then 
she would ask him to bring his lunch to her room and to do his assignment then. Each day at the beginning of class, Ms. Fisher gave the students a warm-up activity. Students had folders to keep these in, and at the end of the week, they turned them all in to be graded. Warm-up activities from past days were posted on a bulletin board in the classroom, and students who missed a warm-up knew it is their responsibility to get it from the board and make it up.

Intermediate Steps and Explanations

Boys often resisted showing intermediate steps and explaining their reasoning when doing mathematics. At Terre Rouge, teachers placed a strong emphasis on standardized test preparation. I noticed that for both sixth and 7th graders taking practice tests, boys marked answers quickly to the multiple choice items and left open response questions blank. When asked about this in interviews, boys admitted that they sometimes marked multiple choice responses without doing any computation or intermediate steps. For open response questions, boys commented that they sometimes left them blank or just wrote a quick response without much thinking or analysis. The boys said that on actual standardized tests, they marked answers without thinking about the problem only when they were running out of time. They also said that teachers circulated during achievement testing and discouraged this practice. When I observed students taking practice tests, they were not pressed for time, and yet many still marked responses quickly for multiple choice items and showed no calculations. Additionally, many students left open response items blank on these practice tests.

Ms. Alcott encouraged intermediate steps and reasoning in her teacher-led discussions by not accepting just an answer but would go to other students for explanations or descriptions of intermediate steps. She also believed that many boys had 
trouble stating reasons because of lack of vocabulary. When Ms. Edwards taught her

students to solve linear equations in one variable, she gave full-credit only when students

showed all of the steps of the procedure and included a checking procedure as well.

Otherwise they would fail the test. Many times in class she explained that they had "no

choice” and took great care to explain her reasoning for these requirements.

MS. EDWARDS: Guys, bear with me, and I want all eyes up here, all eyes. Guys, when we get into equations, you guys are going to fight and scream and pull your hair and whatever. I'm going to be your worst enemy, and that's OK. Many of you are going to say, 'Why, Ms. Edwards, are you making us show all this work! I can do it in my head!' Let me say from the beginning that you will be required to show your steps to get any credit. Every problem will be 5 points and if all you have is an answer, you get 1 out of 5 points, which is 20 percent, even if your answer's right. When you move on to the 8th grade to high school, the work doesn't change on how you solve it; they just add more steps to it. Add more steps - OK, but the how to solve does not change. Learn it now and you will not struggle as you move on. Let me give you an example. I had people in a pre-algebra class and a couple of people who thought, "Hey, I really don't need to show those steps. It doesn't matter that much.” But what they found, when they didn't show those steps, was that they got their homework back and it said, "No credit." They kept taking all these zeros. Well, guys, after taking 3 or 4 zeros it took their grade from an A down close to an F. And they were like, "How in the world??” And they fought it, and fought it, and fought it. But the ones who didn't fight and did it from the beginning, they're breezing through it now

In support of these principles Ms. Edwards, awarded no points in board competitions

when the steps were not shown in proper format. She acknowledged that there were

sometimes other strategies that would work for these problems but that understanding and explaining this balancing process for equation solving was essential knowledge for

further learning.

Physical Movement

An activity that involves physical movement around the classroom can help boys to remain on task and enjoy their work (Gurian, 2001). Teachers of this study confirmed that movement accompanied by appropriate behavior could be an effective strategy. In one of Ms. Alcott's lessons, she divided the class into two groups of about 12 boys in 
each group. She instructed them take a sheet of paper and a pencil out of their binders and to move around to the 12 students in the group and have each boy write his first and last name on the paper. The teachers guide for the curriculum suggested several ways to obtain a list of names requiring various levels of physical activity, but Ms. Alcott chose the active method for her boys. After completing his list each boy returned to his desk and counted the number of letters in the twelve names on his list and then find the median and mode for the number of letters in a name.

In Ms. Edwards's board competitions, the boys who worked at their seats in one round moved to the board for the next round. "Switching keeps them active," she told me in an interview. On days that they were not having board competitions, she would also allow them to get up and stretch as they made transitions from one activity to another. Even when the boys were engaged in seat work, she encouraged purposeful moving around the room, such as retrieving graded warm-up work that hung from the chalkboard on a magnet-backed clip or copying make-up work posted in another area of the room.

Mr. Fisher provided the boys with a variety of active ways to learn. At the beginning of many lessons, students went to the board, worked their homework problems, and later presented them to the class. Then, throughout the activity, he gave his problem presenters explicit instructions about where to write, when and what to erase, when to sit down and when to go back to the board again. Another activity in which students moved around the room was one Mr. Fisher "Stations" in which groups of three boys rotated among four stations in the room and engaged in a problem solving activity at each station. I learned about another active learning strategy used by Mr. Fisher in a student interview. When I asked 7th-grade boys about favorite and best ways for learning 
mathematics, they recalled the game of "Chase” that they had played in Mr. Fisher's class

the previous year.

RESEARCHER: All of you, think about something you do in math class, this year or last year, that was especially fun.

MICHAEL: Chase

JACOB: Chase! Yes!

AND: Tell me about Chase.

MICHAEL: That was last year.

ED: Yeah, that was last year. It's where one person goes up to the board and they get a problem. When they solve it, they have to go back to their table and their group and they have to make sure everybody has the right answer and then when you go up to the board you have to correctly answer and sit down. Everybody that gets it right gets a point.

\section{Hands-On Activities}

I observed students and teachers working with manipulatives or engaged in another type of hands-on learning on four different occasions. Ms. Jones said that her boys, but not her girls, preferred to work problems and practice exercises on the dry-erase boards that she kept in her room. "Boys are more hands-on," she said in an interview. “They like to touch it, and they like to move it. Girls had rather use pencil and paper.” The boys used the dry-erase boards to practice changing large and small numbers back and forth from regular notation to scientific notation. They remained on-task and enjoyed holding up their boards and displaying their answers after finishing.

In another observation, Ms. Ingram’s Mod 1 class did a textbook activity on equivalent fractions using pattern blocks. Each color pattern block represented a particular part of the whole, either $1 / 12,1 / 6,1 / 4$ or $1 / 2$, and the tasks of the activity asked students to construct congruent shapes out of one particular color of pattern block and then duplicate the same shape with another color. Ms. Ingram mentioned to me on several occasions how much she had used the many different types of manipulatives that came with her textbook. The boys, working with a partner, talked somewhat noisily but 
appeared to be working. Ms. Ingram placed a final problem on the overhead and told them it was challenging. The problem on the overhead instructed the boys to design a pattern with 1-1/2 block; 3 1/4 blocks; 5 1/6 blocks; and 2 1/12 blocks. They were then to calculate what mixed number their design represented. With the longer class periods, Ms. Ingram had the discretion to use more than 45 minutes for mathematics, and the boys remained engaged longer than usual. In other observations of Ms.Ingram’s classes, I saw boys with their heads down on their desks but not today. Most remained on task and spent even more time at the end creating their designs for the last problem.

On several days of observation, Ms. Edwards’s class worked with manipulatives that were part of an activity set called “Hands-On Equations.” Ms. Jones at Bluefield said that she had also used these manipulatives with her class. Ms. Edwards used it as an individual activity and each boy set up his own mat as his balance scale, along with "pawns” representing variables and dice that could be turned with different sides up to represent numbers. I watched them begin with one-step equations, but Ms. Edwards said that the set came with a series of lessons and that subsequent lessons would involve two and three step equations. On the first day they worked hands-on with the pawns, dice, and mats exclusively, but on the next day, she had them write each equation symbolically, too. The boys' understandings seemed to be clear, as I heard them explain their process clearly and correctly.

In last observation of hands-on learning, Mr. Blake’s 7th-grade boys at Terre Rouge became engaged and worked well on an activity using motion sensors attached to graphing calculators. As a student walked back and forth in front of the sensor, the connected graphing calculator would collect the data and make a graph on the screen of the calculator. After set-up and demonstrations, groups of three boys would take turns 
walking and reading. Then together they would discuss reasons for the results. .Even though they told me that this was the first time they had used graphing calculators this year, they caught on quickly to the procedures and remained busy and engaged in the task. As they came back to their seats from other parts of the room they were able to interpret, explain, and make generalizations about the motion. In all of these four classes, a common observation for the hands-on lessons was that there was very little disruptive or off-task behavior. The boys talked to each other, but as Ms. Edwards pointed out to me several times, "Boys talk while they work and still stick with the task.”

Topics of Interest

Our own experiences, as well as research, suggest that boys and girls may share different topics of interest (Noble \& Bradford, 2000; Gurian, 2001; Newkirk, 2002). The boys in Ms. Jones's mathematics class at Bluefield became interested in an interdisciplinary portfolio project about car safety, led by teachers of mathematics, science, and writing. For completion of the project they were to do internet research about car safety, write about it, and then build a model car that would protect an egg in a crash. Mr. Fisher and Ms. Edwards both liked to talk about sports with the boys and to use sports as a context for mathematics problems and activities. Mr. Fisher, who taught both boys' and girls' classes, mentioned that his lessons for boys and girls frequently involved the same mathematics topics, but that he chose different problem scenarios for his girls and for his boys. "I think a positive effect of the single-gender classes is that, in my lessons, I feel more comfortable bringing out examples that relate to all girls when I'm teaching an all girls class, such as super models or prom dresses. Then, I bring in examples that boys really get into—NASCAR racing, football games, tools, building, and destroying.” 
Mr. Fisher brought a great variety of topics of interest to his all-boy classes including the addition of a bathroom in a home basement, a lawn business, a class opinion poll about the outcome of the World Series, and basketball shot/attempt ratios. In several instances, I observed that boys who became engaged by his example then thought of other applications of the mathematics to their own topic of personal interest. Once when Mr. Fisher was presenting a problem about ratio and proportionality in sizing photographs, a boy in the class raised a question about ratio and proportion applications to the tire specifications on his go-cart.

Jokes, Melodrama, and Tall-Tales

Middle schoolers enjoy a good story, a good joke, and a little dramatic exaggeration. The 6th-grade boys at Greenville Middle School were not exceptions to this rule. Using these tactics, Mr. Fisher daily used these strategies to engage his boys in mathematics problems. To create dramatic impact for a lesson on the order of operations, Mr. Fisher said,

Tomorrow, you will learn why it is so important for some people to learn the order of operations. Guess what? I'm going to be very honest with you. Not everyone in this life needs to know this. Now, I repeat, not everyone in this life needs to know the order of operations, but there are some people in this life, you better hope with your life that they know this. Because if they don't know this and they try to do something for you, it could be dis - as- terous! It could mean your death! (Students sigh, “Oh!”) There are some careers in which they rely on the order of operations. We're going to talk about that tomorrow.

Mr. Fisher also used physical gestures and movement for dramatic effect. One day, he had students make a "foldable", which is a connected series of note cards made with two sheets of paper folded and stapled together. The foldable was to be a reference for them on definitions and comparisons of the concepts of ratio, proportion, percent, and

probability. He was not a tall man, and when talking to the students about ratio, he stood 
on a chair so that he could be even with the definition of ratio on the diagram of the foldable he had drawn on the chalkboard. .

In interviews, two teachers mentioned particularly that it was a little easier to joke with boys. "I appreciate the boys’ senses of humor,” said Ms. Edwards. "Girls are sometimes more sensitive and get embarrassed.” Ms. Ingram, at Bluefield, said “The boys will let you tease them, and they also seem to more open than girls to teasing from each other.” Mr. Fisher sometimes teased and joked with boys by saying things wrong on purpose like in the following dialogue.

MR. FISHER: Ok, gentlemen, we have two sets of data up there and this information should be on the back of your graph paper. Of course, everyone knows that the Astros are going to win the World Series.

STUDENTS: No! (laughter and many voices) You said Astros? They always lose! MR. FISHER: I'm telling you I think the Astros are going to win. (Students laugh)

STUDENT: Astro's stink! The Yankees are going to win.

MR. FISHER: What I can't understand is why they keep hitting the football with a bat. (Boys laugh)...Ok, listen up...

Mr. Fisher even used a discussion of something boring to make a joke and engage his students.

MR. FISHER: We've learned in this room that graphs must have an ab-s-o-o-oo-o-lutely, te-e-e-e-e-rif -fic- ly, ho-o-o-o-r-r-r-r- rif-ly, boring title, or it's not a title for a graph. So, Charles, before you give us a title, I will remind you that the title will always come from these labels - these labels (He points to the labels.) and these data. So what do you have for us? What is the title? CHARLES: The Two Thousand Four World Series and Who Will Win. MR. FISHER: That was pretty boring. Congratulations! That was pretty boring! But, I think we can be more specific than that....but you could use that title if you needed to. Go ahead, John, give us an idea.

JOHN: Number of Students who are Fans of Boston and St. Louis or Are Believers of Those That Are Going to Win the World Series in Mr. Fisher's Third Period Class.

MR. FISHER: That was the absolutely worst title I've ever heard in my life! Congratulations! (to another student) Yes, sir?

STUDENT: Number of Students that Voted for Boston or St. Louis to Win the World Series and Who Think They Are Going to Win. 
MR. FISHER: You know I don't believe that there's ever been a more boring title ever created for a graph. You could use that one. (to another student) Yes, sir? (This student gives an even longer title.)

MR. FISHER: I'd say that if you are going to use that title, you'd need to attach a separate piece of paper. That title is very boring - that was almost too boring very descriptive is what we're looking for. I tease about boring, but you understand that a title must be very descriptive. So, your title should say something like, 'The Number of Students Who Believe In or Are Rooting for Boston or St. Louis.'

Mr. Fisher also used big numbers and tall tales to add interest and fun to

mathematics class, as well as to teach number sense. Here are some examples from Mr.

Fisher

MR. FISHER: When I had a lawn business I charged \$3000 a lawn. I didn’t get many customers, so I had to lower my price to $\$ 10$ a lawn....I could save $\$ 13,000$ by installing that bathroom myself. But that's not so much because I've got $\$ 9,000$ in my pocket right now (just kidding)....When figuring the amount of wall board needed to add a bathroom in the basement, one person failed to use the order of operations rule in making his calculations and he got a huMONG-ous number for the amount needed. Why if he had that much wall board, he could build a wall that was 5 miles high around Greenville!”

On several occasions, I heard Mr. Fisher, and remember that he is not a tall man, entertain the class with a tall tale about his basketball career in the NBA. Excerpts from these teacher/student interactions are compiled in the following dialogue:

MR. FISHER: OK, some of you don't know this, but before I was a teacher. I had to teach Michael Jordan all about how to play basketball.

STUDENTS: Yeah! Right! .... He's older than you.

MR. FISHER: Hey! Hey! ....What?.... Well, I know he's older than me. Heuh...started late. So in my former career as a professional NBA basketball player....(The students interrupt with lots of laughter and disagreement)... When you're ready to learn to play some ball, you let me know and I'll show you....(more excited comments and laughing)... I'm feeling lots of hot air, but.... OK in my former career as an NBA basketball player, I shot an average of 65 shots that I made. I attempted 100. These are all from half court, of course. (The students are all laughing and commenting now.).... Wait, you have to think. You have to think....Sixty-five shots made and 100 attempted. What is the ratio of shots made to shots missed?

(Many voices respond and most say 65 to 35.)

MR. FISHER: Bingo. I have to admit there was a small fib in that example. STUDENTS: Small? It was big! .... You'd have to stand on the roof! 
MR. FISHER: OK....I want you to copy this down please...In a ratio...Gentlemen, (pauses because there is still talking)... In a ratio the numerator shows the part of the group you're interested in, for example shots made, that's a numerator... The denominator is the rest of the group, shots missed, of the whole group, shots attempted.

STUDENT: "I've read about basketball players and I never saw no Mr. Fisher no Darrell Fisher.

MR. FISHER: The reason you didn't read about me is that I like to stay out of the publicity. (There is lots of student laughter and comment.) Gentlemen, I try to use examples you can relate to, but we need to be able to relate to them and keep our focus.... Back to my example, you need reasons to look up to your teachers, and now you have one more reason to look up to me and that is my phenomenal ability to play ball. I'll just say it this way. Have any of you in this room ever beaten me at basketball?

S: I have!....I have !

MR. FISHER: No, you haven't; you've never played me.

STUDENTS: We'll play!

MR. FISHER: I'll play you.

STUDENTS: Yeah, let's play.... We won't go easy on you.

MR. FISHER: Here's the agreement about me playing you in ball. First, it's a mathematics activity, and second, it's fun. If you forget that, the game is over. We'll play that game sometime down the road, I promise - because we use it. We will use it in a manner that helps ups better understand ratios, proportions and percents. Everything we do in this room is first a mathematics activity, and second, fun and exciting. If we forget that order, you've lost the reason for doing it. Gentlemen, you need to gather your belongings and look at your agendas before you leave for your next class.

\section{Competition}

Boys like to compete with each other in games, sports, and other endeavors if they think they have a chance of winning (Evans, 1993; Hudley, 1997; Sommers, 2000).

Several boys mentioned that they preferred to compete in the all-boy settings more than with girls. "Girls like to compete with girls, and boys like to compete with boys," one boy said. Boys in Ms. Jones’s class at Bluefield became totally engaged one day in a participatory video simulating a TV game show. Ms. Edwards named board competitions as one of her favorite strategies for her boys' mathematics classes, and I observed her using them for a variety of topics. Teams of two, three, or four students would alternate with others on their team; one or two students would work at the board, while the others 
worked the same problem at their seats. When they were working on solving one-step and two-step equations, Ms. Edwards grouped the boys in teams of four. Two at a time would be at the board, and one of those would solve for the variable and the other would check.

The boys exerted more energy and showed more enthusiasm for Ms. Edwards’s board competitions when she kept score. From experience, Ms. Edwards also knew that the rules for awarding points needed to be very specific, or there would more likely be an argument. For example, if students did not show required steps, no points were awarded, and if they did not circle their answers, then they did not earn points for their team. Additionally, team members at their seats were not allowed to help those competing for points at the board. Boys at their seats were supposed to write the problem and their solutions on a sheet of paper and turn it in at the end of the period. For problems where students were working at the board, they were supposed to write "B" - for board on their papers.

On the first few rounds, she sometimes gave reminders instead of penalties on the more technical rules. She also knew that she had to watch them carefully to make sure they followed the rules and did not copy the work of other teams. "Slick move, but I caught it”, I heard her once say. She kept the scores on a piece of paper and did not read totals every round. But the boys,however, usually kept up with the scores in their minds and knew which team was ahead. There was frequently some whooping, clapping, and teasing when points were awarded, along with comments of “I’m smart”, “I told you not to mess up”, You're not so smart now!”, I’ll give you part of my lunch if you make a mistake (deliberately)on this problem.” I even saw one fall dramatically to the floor when he missed a problem. 
Speed was not the issue. "It's important that the fastest boys are not necessarily the winners, said Ms. Edwards. Winning is about the correct answer and sometimes an explanation as well.” All teams who found the correct answer and followed instructions received points. Winning was fun for them, and the reward of Jolly Ranchers or popsicles was also enticing. Paul had an especially proud and "winning” moment when he was the only one who found the correct solution of $\mathrm{w}=-22$ to the equation $\mathrm{w}+18=-4$. I watched Paul as he drew a number line on the chalkboard to figure it out. The studentteacher who was working with Ms. Edwards pointed out Paul's moment of glory to the class.

STUDENT TEACHER: Paul, explain how you did it. You are the only one who got it right.

PAUL: Oh my gosh! I'm smart! I drew a number line and say here's negative 4. STUDENT TEACHER: GIBSON: You guys listen.

PAUL: So you minus eighteen and go back 18 spaces. So it's like four plus 18 and you put your negative sign.

MS. EDWARDS: Good. Four plus 18 and put your negative sign and some of you forgot. It was plus 18 so you had to subtract it from both sides. Only one person....Awesome job, Paul!

STUDENT TEACHER: Didn't any of you guys get that right?

ANOTHER STUDENT: I didn't.... Paul was the only one who got it right.... Go, Paul! Do your victory dance. (Teachers and students watched him and laughed)

MS. EDWARDS: Did anyone at your seat get it right? (Two hands went up)

When the period ended, Paul had put his team in first place, and Ms. Edwards called his team to the back of the room to get popsicles and Jolly Ranchers. I heard another boy say that his team would have won if -- "we'd only got that 22-one.”

Some teachers believe that competition may work better for all-boy classes than for all-girl or mixed classes. Ms. Edwards explained in our interview some of the things she had noticed.

MS. EDWARDS: At our team planning meetings, we sometimes talk about how the boys are different from the girls. Instead of getting up in front of the class and 
competing, the girls usually prefer to use the dry erase boards at their seats to work problems. A girl might say, "Why do we have to play that game when all we ever do is lose." They also like to work on the dry-erase boards with a partner and then switch boards. The guys really like the competition; it really works for them. Even if they lose, guys can move forward easier than girls. With guys, once the game is over it's over. Girls tend to hold things inside and remember them forever. If a boy makes a mistake solving a problem on the board, the others encourage him to do better next time. With girls, if one girl makes a mistake, the others would hold it against her. "She doesn't know how to do this. Why does she have to be on my team?” a girl might say. With guys, for the most part, you don't have that.

Mr. Fisher's classes at Greenville had a running competition going between all of his classes in the amount of game time the class could earn by saving seconds when beginning an activity or in making a transition from one activity to the next.

The "Cheer"

Over the past few years of studying gendered classes I have seen a strategy appear in several all-boy classrooms that I have named “the cheer.” I haven’t read about this strategy in classroom studies nor among suggestions for teaching boys from other educators. What I named the "cheer" can be described as group recitation, in which students chant in unison and in rhythm, answers to problems, important principles, vocabulary words, rules, or steps of a procedure. It was usually loud, close to a shout, and there was something team-like about it. The purpose was not competition. The point was not trying to answer first but to work toward a common goal. I call this strategy because it reminded me of uniformed athletes in a planning huddle and how they would cheer together as they disbanded for the next play of the game. Or I thought of fans sitting in bleachers. The clapping and chanting would begin with a few and then grow louder, stronger, and united until it was one overpowering voice. The "cheer” provided teachers with a way to keep boys thinking and on-task, to engage them in a type of group/team activity, and to allow them to be loud and active in a structured way. 
I first saw this type of teacher/student interaction in previous observations at Terre Rouge, and thought to myself, "This is a good strategy for an all-boys class.” The students were learning what it means for an ordered pair to satisfy an equation in $\mathrm{x}$ and $\mathrm{y}$. The teacher worked with students in deciding whether a particular ordered pair was a solution for an equation and the purpose of the recitation was to have them practice with this concept.

TEACHER: First, I want you all work the problem in your head. Don't anybody answer out loud. Here's the equation: $3 \mathrm{x}-\mathrm{y}=49$; and here's the ordered pair (3, $40)$. Now I want you to do this in your head and think. "Is the pair $(3,-40)$ a solution a solution of the equation $3 x-y=49$ ? Remember, don't answer out loud when you think you have the answer. Wait until I raise my hand. And when I raise my hand, say "yes" or "no." Remember that everybody figures this out - on his own- and no one answers until I raise my hand. OK...Is the pair $(3,-40)$ a solution a solution of the equation $3 \mathrm{x}-\mathrm{y}=49$ ?

When she raised her hand - like a cheer - a resounding "Yes!” filled the classroom. The enthusiastic "Yes!” informed the teacher that students are on task and are practicing mental math. By not asking for the answer immediately, it gives all students time to think of their own response. The fastest ones are not the only ones who get to say the answer. Each student can think individually about the problem, and still be part of the group effort for solving it (and exert a little energy as well). Even if a student gets it wrong, he can adjust his thinking as he hears other responses and not suffer the embarrassment of reciting a wrong answer alone.

Mr. Blake believed in emphasizing mathematics vocabulary, and one day I saw him lead the boys in chanting or cheering the four syllables of the word coefficient (CO E - FISH- ENT!) in unison, at different speeds, and with rhythm and clapping. Mr. Fisher frequently used this response strategy for questions when he wanted his students to use mental mathematics to find an answer. He would hold up his open hand with its five fingers extended upward. Then he would say, for example "When my hand gets to zero - 
not now, but when my hand gets to zero - tell me how many minutes and seconds there are in three hundred, seventy-four seconds?” He would then lower fingers and count down at the same time, "Five - four - three - two - one.” He then would make his hand into an O-shape and they would shout in unison, "Six minutes and fourteen seconds!"

Another similar strategy was the recitation of jingles, rhymes, or songs to remember particular rules, conventions, and principles, such as the mathematics convention of the order of operations. In more than one observation, I heard Mr. Fisher and the boys recite the following jingle together. It started slowly, then picked up speed, and by the end was too fast to understand.

MR. FISHER AND CLASS: Now .......the .....order of operations is a simple handy plan that will help me get the answers right just like I know I can.

First grouping symbols, exponents;

Then multiply divide,

Then add subtract from left to right. I'm finished.

Give me five!

“The jingle helps them remember the order of operations principle,” said Mr. Fisher. "It may also reach a few of those who learn in different ways.”

Self-Confidence, Task Value, and Rewards

Students are more likely to become engaged in mathematics if they have confidence in their ability to accomplish mathematics tasks and they appreciate that the task is personally beneficial (Kilpatrick, et al., 2001).

A student's motivation depends on both expectation and value. That is, students are motivated to engage in a (mathematics) learning task to the extent that they expect to be able to perform the task successfully if they apply themselves and the degree to which they value the task or the rewards that performing it will successfully bring (p 339).

“I can do this.” Multiple studies suggest that boys exhibit more confidence about their academic abilities in mathematics than do girls, even when performance assessments favor the girls (Pajares \& Miller, 1994; Pajares, 1996; Bong, 1999). 
Therefore teachers can motivate students by encouraging and prasing student efforts and by helping them appreciate the value of what they are learning (Kilpatrick, et al., 2001). Ms. Edwards frequently told students who worked problems on the board, "That was an awesome job!” and also reminded them, “I don’t give you your grades; you earn them.

But I and the other teachers are here to help you, and our goal, as teachers, is for each of you to be successful.” Mr. Blake had high expectations of his students and corrected them by saying, “Don’t say that problem's difficult; say it’s challenging.” Students also spoke of Mr. Blake’s encouragement of effort and his confidence in them.

RESEARCHER: What are some topics in math that are hard for you?

HANK: Well, algebra. Mr. Blake told us that even if it's just letters, like a plus a, it's got an invisible one in it. But he always explains it to us, so it's not so hard.

RESEARCHER: So what is a plus a?

HANK AND BRYAN: Two a.

BRYAN: All of it is really easy. You can't say that one thing's harder than another because he always explains it.

RESEARCHER: Tell me more about your math teacher.

JUSTIN: He's a good teacher. He takes teaching seriously.

HANK: I like Mr. Blake. He's a pretty tough teacher, but he's just preparing you for college. Like one day when you graduate college, you owe thanks to him. BRYAN: He doesn't only teach math, he teaches discipline, too. He teaches you how to act right and stuff. You can't go in his class acting wild. He'll punish you for that. You can't just do whatever you want in his class and plus, he's a great math teacher. Whatever he says, he explains it. If he says something he's not just going to put it on the board and sit down. Last year he put something on the board that nobody understood, and he explained it for months. He wouldn't give up. He's the kind of teacher -- like he won't give up. He won't give up on you. RESEARCHER: What was he teaching?

HANK: I think it was fractions. We worked on those all last year, and I got everything he taught me last year.

RESEARCHER: So, do you think fractions are hard, Justin?

JUSTIN: I don't think they're hard now. I just didn't get them last year. But he like stuck by us the whole time. He wouldn't give up.

Mr. Fisher frequently engaged in mathematical discourse with students, and one day towards the end of class, I heard him talking with Devin.

DEVIN: Mr. Fisher, I don't get the bottom (last problem on homework). MR. FISHER: You can do it. I believe in you. 
DEVIN: I don't understand.

MR. FISHER: The problem is to solve $8 \mathrm{n}=40$. This is very similar to the problem you put on the board at the beginning of the period. .... What do you think it is? .... That could be what else? .... What else does an 8n mean? .... I'm not letting you leave this room without helping you.

“Mathematics is important!” All boys whom I interviewed told me convincingly

that mathematics was important. Students interviewed spoke of a wide variety of jobs that required mathematics such as banker, cashier, scientist, carpenter, architect, and cook.

Some spoke of the need for mathematics and for doing well in mathematics to prepare them for high school and college. Mr. Fisher alluded to the many needs for mathematics - for tackling difficult problems, for thoroughness and excellence in problem solving. and for all of life's endeavors. "Life will not present you with easy problems," he would say to them. On a day each group was supposed to present solutions to the station problems to the class, Mr. Fisher emphasized the importance of preparation and hard work in any task.

It will be your responsibility to present for your group what the scribe has written on the overhead. Your job is fairly easy. However, I insist, presenters, you sit next to the scribe so that you can know what he's writing and ask if you don't understand anything. CEO's and presidents of big, world-wide corporations will never merely hand the task entirely over to someone to prepare it and then take it right to a meeting and present to the world media something as big and important as what the company has accomplished. The CEO will be right there working with someone and saying "OK tell me what this means; we need to read over this together." Because the CEO does not want to get up and look ridiculous or look like he doesn't know anything in front of all these people that expect him to know everything.

“What's in it for me?” Teachers at Bluefield and Greenville sometimes used rewards as motivating factors and students mentioned rewards as making a difference in student effort. Ms. Ingram rewarded the boys who did their homework by allowing them to play games while everyone else did the homework assignment in class. She only rewards those who do it if there are not many of us. When almost everybody does the 
homework, then we don't get anything. A $6^{\text {th }}$-grade boy at Bluefield made an interesting distinction between rewards and bribes.

RESEARCHER: What are some things that make you want to learn and try hard? NEAL: Rewards.

DAN: I have a horrible idea in my mind that I'm trying to forget.

RESEARCHER: You can say it.

DAN: It's a really funny idea, but it goes against the principles of school. You bribe 'em.

NEAL: We play bingo sometimes.

RESEARCHER: Is that a reward or bribery? Are they the same thing?

DAN: Almost

MARK: Kinda

DAN: A bribe is something you do to make 'em do it; but rewards is something you give 'em for good work. Bribery, you know about. Rewards, it's a surprise.

According to his definitions, if a student knew he was going to receive the reward for performing a certain action or task, then this was "bribery." If he did it without knowing and received something, he thought of it as a reward. Ms. Edwards also spoke about this distinction. When a student asked her if she was giving rewards for a particular classroom task, she said, “If you ask, I do not give.” Boys in Ms. Edwards’s classes reported that prizes of Jolly Ranchers and popsicles for winning board competitions were motivating factors. Mr. Fisher rewarded students with an activity day, on which the boys could play games together such as Battleship, Master Mind, checkers, and chess. The structured process through which the boys earned these activity minutes was engaging in itself and provided opportunities for mental mathematics, as well as for the practice of organizational and measurement skills. Rewards can be given for good behavior as well as for accomplishments and competitions. One day, Ms. Edwards’s students received popcorn in class from the counselors in the office across the hall for not being loud and disturbing their work. Ms. Jones at Bluefield rewarded boy’s good behavior by giving less homework. 
Psychologists suggest that token economies, a system of rewards and consequences, relating to monetary debits and credits, as a motivator for students (Bucher \& Manning, 2001). The CHAMPs program was used at Bluefield and Terre Rouge and suggests systems for rewarding good behavior and punishing unacceptable behavior (Sprick, et al., 1998). Ms. Ingram used a CHAMPs strategy that boys described as a system of "bucks.” The boys reported that students started the week with a certain number of bucks and then throughout the week, disruptive behavior or not following classroom rules and procedures would result in students losing bucks. At the end of a grading period, students who had a certain number of bucks could go on a field trip.

I did not observe either mathematics teacher at Terre Rouge using rewards to encourage student performance or to reward good behavior. Mr. Blake told me that, unlike many teachers, he did not believe in giving rewards for turning in homework.

MR. BLAKE: Giving rewards for homework teaches the student nothing more than if I do this, then I get that. I try to emphasize that I'm not asking them to do it for me I'm asking them to do it for themselves. Do it because you want to do better. And they already know that they'll make better grades. They know that their grade is in jeopardy for not doing homework They know that they won't do well on the test if don't do the homework It's like kicking a dead horse to keep telling them. I do tell them, though, "I may not be able to guarantee that you will be a great math student, but I guarantee that you'll do better in math if you do the homework.

\section{Technology}

A previous study of all-boy classes in middle school found the use of technology, computers and calculators as the only strategy the teachers believed worked well for boys (Baker, 2002). When I first began this study I thought that I would find teachers using computers or calculators frequently in their all-boy classes. However, results of this investigation indicated that teachers did not use technology in their teachings frequently. Even though, for Bluefield and Terre Rouge, the use of graphing calculators was allowed on state accountability tests, I saw graphing calculators used in only one lesson I 
observed. At Bluefield, Ms. Jones had basic calculators that she kept in a basket and would sometimes pass out for students' use. However calculator use was never included in her instruction. One of her students in an interview expressed the view that using a calculator was a little like cheating. In 6th-grade, I never observed Ms. Ingram’s students using calculators. Almost all of the six teachers thought of calculators as less than beneficial and something that promoted laziness and an inability to do simple mathematics mentally and strategically.

At Greenville, I also saw no calculators used in teaching. A student indicated that Ms. Edwards did not allow them in class. Mr. Fisher did not make calculators available in the classroom for student use either. Mr. Fisher, however, used a calculator himself in demonstrating how he would calculate the amount of wall board needed for a home improvement project, and when students needed to add and subtract more than twenty numbers to calculate how much activity time they had earned as a class. At Terre Rouge, problems reported in regard to graphing calculator use were too much time for distribution and a fear that they would be stolen.

Student and teacher interviews at all three schools suggested that writing and portfolio projects monopolized time in computer labs. Both the computers at Terre Rouge and Bluefield contain a comprehensive computer program called Understanding Mathematics (Neufeld, 2002). The program is designed for teaching middle school mathematics concepts and for assessing. student progress. Program developers provide teachers with on-line support in the form of printable student worksheets and supplementary activities. When testing was completed, Ms, Ms. Alcott used "U-Math” on the three computers in her classroom and students took turns working on relevant units At Bluefield, students reported that Ms. Ingram used Understanding Mathematics 
in the computer lab two or three times that semester. In one of my observations, she took her students there to do a lesson on equivalent fractions. Ms. Jones’s students who were interviewed said that they had used Understanding Mathematics once this year, working mainly on one of the topic assessments. At Greenville, boys did not go to the computer lab for any of the mathematics classes I observed. A few students reported that they had used computer programs for mathematics practice, both in elementary school and also at home. Both Bluefield and Greenville Middle Schools used traditional, commercial textbooks, and in both cases, the entire book, homework help, and extra practice were available on-line. The two $6^{\text {th }}$ - grade teachers said that their students used the on-line textbook functions. Mr. Fisher said that a few of his students used a computer homework website developed by a university in the state.. The two $7^{\text {th }}$-grade mathematics teachers said that approximately one-quarter of their students used the on-line textbook functions.

\section{Opportunity to Learn}

Perceptions of boys and teachers suggested that in some instances boys had increased opportunity to learn in the all-boy classes, and in other instances they seemed to have less opportunity. Ms. Alcott and Mr. Blake both expressed the view that boys participated more and worked harder in the all-boy classes. Ms. Edwards explained what she had noticed in the following way.

MS. EDWARDS: Another positive thing about the all-boy classes is that when put into groups, they work. They don't rely on the girls to do their work, while they sit back and do nothing. That was a huge difference that I saw when we put them into single gender classes. The guys actually did the work. When work in groups, I allow the guys to do a little more talking as long as they are still working. Boys tend to talk and socialize while they work.

When considering the positive aspects of the all-male classes, boys who were interviewed mentioned that they focused more on their work and liked the idea of not competing with girls academically. By not having to compete with the girls academically the boys had an 
increased opportunity to excel. Many boys thought of the girls as better students. In coed

classes, boys reported that they had frequently remained in the background and acted as if

they were not interested.

TOM: They beat us on the math team in $5^{\text {th }}$ grade. The girls made us look stupid because they studied....When girls do better, boys get mad and can't think straight....I always used to ask girls questions about schoolwork because they are smarter.

JOE: We work better without girls.......We don't need the girls.....With girls, we didn't learn or work because we used to copy off them....Y You get your work done better.....The stuff sticks in my head better when not distracted by girls.

Even so, a few interviews with boys revealed negative views about increased

learning opportunities and about disruptive behavior in their all-boy classes.

RESEARCHER: What could your teacher do to help you learn math better?

JIM: She could have Jerry, Bryan, and Spencer removed from the class.

STEVE: People are always running around and stuff.

TODD: Spencer's always talking.

JIM: They do stupid things- playing with rubber bands, popping people back there, throwing crayons.

TODD: They argue so much.

STEVE: Yeah, Bryan and Jerry argue across the room.

TODD: Yeah, everybody would do a lot better if she got three or four bad people out of the class.

Sixth graders interviewed at Terre Rouge offered the following thoughts.

DOUG: Boys won't be quiet. Like, you know, boys are all rowdy and stuff and when the teacher tells us to be quiet, we don't be quiet. But almost all girls be quiet --half the class be quiet.

AND: Which half of the class will be quiet?

All: The girls! ( Two boys laugh)

DOUG: And sometimes us.

VICTOR: Because then we ain't got anybody to talk to.

DOUG: We might actually learn something

VICTOR: When everybody be screaming? ....When it's real quiet, then someone may come up and they hit you in the back of the head.

At Bluefield, both Ms. Baxter, the assistant principal, and Ms. Jones the $7^{\text {th }}$-grade mathematics teacher perceived that behavior in all-boy classes was influenced by a “locker room mentality,” and Ms. Jones offered these views on boys’ learning. 
MS. JONES: A lot of times, I think, with boys it almost becomes a locker room mentality. They feed off that. Although they do that whether there are 3,4 , or 5 boys or it's a class of just boys, I don't know. The girls always tell me they like being separated because they don't have to deal with a lot of the behaviors of the boys. You know, the silliness, hearing them getting fussed at-all that. A lot of that is not happening in the girls' classes, so I always feel like I'm able to accomplish a lot more with the girls, because there's not the discipline issue as much as with the boys.

RESEARCHER: You feel like you able to accomplish more with the boys?

MS. JONES: I don't know if I'm accomplishing more-probably the same amount of information. I think maybe sometimes having them separated maybe affords me opportunities to cater more to boys' interests - maybe topics or activities.

Findings about variations in boys’ opportunities to learn in the gendered classes indicated the critical need to manage behavior in creating a learning environment for boys. This evidence suggested that, in some cases, a few boys could disrupt a class and jeopardize everyone’s opportunity to learn. When teachers and principals were asked about the boys' responses about disruptive students, they agreed that removing the boy from the class was not feasible. They suggested other solutions such as video cameras, increased parent responsibility, isolation with another teacher on the team, work with administration to establish consequences and deterrents; or as Mr. Blake said, "I get in his face.”

\section{Teacher Characteristics}

What teacher characteristics affect the development and implementation of allboy mathematics classes in middle school? Do some characteristics seem more important than others? A teacher's ethnicity and gender; mathematics teaching efficacy; and beliefs about teaching and learning mathematics were the primary focus of this study. Other relevant teacher characteristics that arose from findings were also explored.

\section{Gender and Ethnicity}

Research suggests that teacher race and gender may be factors in successful teaching of all-boy classes (Hudley, 1998; Weaver-Hightower, 2003). When asked about 
teacher characteristics, most teachers of my study believed that race and gender were not important factors, and suggested quality of teaching, teaching styles, and expectations for students as more important. One teacher questioned addressed both the issues of race and gender by saying that in her experience, she had seen some African-American and Caucasian teachers who were highly successful with both African-American and Caucasian students and vice versa. Ms. Edwards believed that it depended on the student; some students, regardless of gender, may relate better to a male teacher and some to a female. "I have some gentlemen in my class," she said, "whose fathers are not active in their lives, so they relate well to male teachers. And some, because of the same reason, relate better to female teachers.”

Although I did not ask questions about race and gender in student interviews, a group of 6th-grade boys shared with me some thoughts about gender when asked about whether they thought their teachers liked having a class of all boys.

MATT: I know Mr. Tyndall. doesn't like having boys because they make him frustrated. He had girls last year, and I think he likes them better. ROBERT: You know we respect the girl (meaning female) teachers. We don't respect the boy (male) teachers.

MARTY: Don't nobody respect none of the boy teachers. They respect the lady teachers but none of the...

AND: The males?

MARTY: Yeah; none of 'em.

ROBERT: With the women teachers we're always quiet and with the boy teachers, we always talk and are rowdy.... The women teachers, they're more hard on us and the boy teachers, they're really nice. They let us get away with a lot of stuff, more than the women teachers. And we know that we get in trouble if we talk for the women teachers. For the boy teachers, we can do anything we want, so that's why we talk in the boys' classes.

AND: Marty, anything you want to add?

MARTY: It's probably, because we are boys and they are men. They went through the same thing we're going through.....and they like talking, too. But lately, they don't like talking as much as we do.

AND: Robert, anything you want to add about that?

$\mathrm{K}$ : Yeah, 'cause the boy teachers give you another chance. 
But a review of the team situation for the 6th-grade boys at Terre Rouge suggested that what the boys saw as a gender issue may relate to management style and personality. As the reader may have guessed, Ms. Alcott is one of the "girl teachers" that the boys are referring to in this interview. She was strict with her students, and her interviews revealed that she felt lack of support from other teachers on the team (incidentally "boy teachers”) whose behavior standards were more lax. However, students reported that Mr. Blake did not tolerate bad behavior from his classes, and my observations confirmed these remarks.

In the following interview excerpt, Mr. Blake, the only African-American male teacher of the study, expresses his views on this issue.

RESEARCHER: Does the race or gender of the teacher make a difference? MR. BLAKE: I think it does. It gives --what you say-- more of a real-world perspective. My upbringing and culture may set off a light bulb and allow kids to make connections. At this age, they need to make connections and make it realworld.

RESEARCHER: African-American male or just male?

MR. BLAKE: Both. As a male I'm more likely to talk about things that interest boys, such as sports, and culturally, I also bring things that kids would understand. But I try not to show favoritism (to African-American boys). They are all boys and all need to be loved. So, yeah, I get on all of them and take it personally when they are not achieving and not living up to their potential. But I have kids of many ethnicities. I was frustrated when I was a kid in school, and found that Caucasian teachers would build rapports with students who didn't look like me. Maybe it was because they reminded them of their own kids. But, if you call yourself a teacher, you have the responsibility of nurturing all, and not just identifying with one group.

These results exploring effects of teacher race and gender on relationships with students indicated that factors such as interaction style and personality may also be relevant. Team practices in the form of role modeling, mentorship, and personal support for students perhaps can also affect student/teacher interactions and relationships, regardless of the race and gender of team leaders. In a highly-implemented middle school reform plan, cohesive team leadership and mentorship are key ingredients (Beane 
\& Brodhagen, 2001). And as Ms. Edwards said, “It depends on the student and his individual needs as to with whom he may feel a personal relationship.” In a previous study at of a particular boys' team at Terre Rouge, the leadership included an AfricanAmerican leader and Caucasian leaders, and both male and female leaders as well. The study concluded that the high degree of cohesive team leadership and teacher mentorship for students may have been instrumental in helping boys on an all-boy team to focus on academics and to improve their achievement test scores (Davis, et al., 2004).

\section{Mathematics Teacher Beliefs}

Research indicates that a teacher's beliefs about mathematics and mathematics teaching can have a significant effect on practice (Thompson, 1992; Raymond, 1997). Two instruments relating to mathematics beliefs were completed by the six mathematics teachers of the study. The first instrument was a 25-item survey measuring mathematics teaching efficacy. The Mathematics Teacher Efficacy Beliefs Instrument (MTEBI) was developed Stevens and Wenner (1996) from the Riggs and Enochs instrument (1990) to measure efficacy beliefs in science teaching. The second was a mathematics beliefs questionnaire, a 6-point Likert-scale survey that I developed from Raymond’s (1997) schema of traditional vs. non-traditional teacher beliefs. See Appendix D for items of the MTEBI and Appendix E for a full list of items for the mathematics beliefs questionnaire. Mathematics teacher efficacy beliefs. To the six mathematics teachers of the study, I administered the MTEBI survey measuring how competent they perceive themselves to be in teaching mathematics. Developers and subsequent researchers thought of mathematics teaching efficacy in terms of two factors. The first factor was called personal teaching efficacy (Riggs \& Enochs, 1990) or confidence in teaching ability (Wenner, 2001). In the researchers’ model for collective teaching efficacy this 
dimension is referred to as "assessment of teaching competence." The other factor of the MTEBI relates to the students being taught. This factor was referred to by researchers using the instrument as outcome expectancy (Riggs \& Enochs, 1990) or accountability. In the researchers' model for collective efficacy, this factor is called “assessment of teaching task.”

In studying teacher efficacy beliefs, some researchers have found that the factors of personal teaching efficacy and assessment of task frequently do not separate into two constructs (Tschannen-Moran, 1998; Henson, et al., 1990). Developers of the Collective Teacher Efficacy Scale (CE-Scale, Goddard, Hoy, \& Hoy, 2000) recommend analysis as one construct (see Table 4-4). Therefore, for the purpose of this analysis, I have also considered total scores only. Table 4-10 compares scores and school means.

Table 4-10

Mathematics Teacher Efficacy: Total Scores

\begin{tabular}{|c|c|c|c|}
\hline Teacher & $\begin{array}{c}\text { Yrs. } \\
\text { Exp }\end{array}$ & Math.TE & $\begin{array}{c}\text { Sch } \\
\text { Av. }\end{array}$ \\
\cline { 1 - 3 } Ellen Alcott - T & 3 & 93 & \multirow{2}{*}{86} \\
\cline { 1 - 3 } David Blake - T & 3 & 79 & \\
\hline Darrell Fisher - G & 7 & 90 & \multirow{2}{*}{91.5} \\
\cline { 1 - 3 } Julia Edwards - G & 15 & 93 & \multirow{2}{*}{96.5} \\
\cline { 1 - 3 } Chris Ingram- B & 7 & 95 & \\
\cline { 1 - 3 } Melanie Jones -B & 8 & 98 & \\
\hline
\end{tabular}

Previous research reported that more experienced mathematics teachers frequently had higher perceptions of teaching efficacy (Wenner, 2001). For the teachers of this study, Mr. Blake with fewest years of experience, scored lowest of the six in total efficacy for teaching mathematics. Other explanations for Mr. Blake’s low score might involve the belief he expressed to me on several occasions that not all students can do mathematics. Additionally, Mr. Blake was not using the curriculum materials provided 
by the school and the district, and in my observations of his lessons, I found no evidence of other curriculum materials, other than worksheets.

Other than for Mr. Blake, scores for teacher efficacy did not relate that closely to experience level. Ms. Jones, whose experience level was close to the median, scored the highest in total efficacy for teaching mathematics. Some of her previous teaching experience was in high school mathematics. My observations of Ms. Jones revealed that she explained problem solutions clearly and was comfortable in her ability to answer student questions about particular problems extemporaneously. Thus, her high school teaching experience may have given her increased confidence in subject-matter knowledge of mathematics for middle school teaching.

Mathematics beliefs questionnaire. Mathematics teacher participants responded to a mathematics teacher beliefs questionnaire (see Appendix D) that I developed from Raymond's schema. On the 33-item questionnaire, teachers indicated their levels of agreement with statements about the nature of mathematics, about teaching mathematics, and about learning mathematics. Each item, both in Raymond's schema and the subsequent questionnaire, described beliefs classified along a traditional to nontraditional continuum. A traditional mathematics learning environment is usually teacher-centered, one in which the students passively receive knowledge from the teacher. Teachers demonstrate procedures and ask questions of students for which a particular answer is expected. Practice holds an important position in the traditional mathematics classroom. Non-traditional teaching approaches are primarily studentcentered and include an emphasis on classroom discourse in which teachers ask openended questions about mathematics; ask students to explain reasoning and problem solving strategies; and lead classroom discussions toward high levels of student thinking. 
In non-traditional classroom environments, students have opportunities to work in groups, to participate in hands-on activities and to share thoughts and ideas with other students.

Because the items used for this study's questionnaire had been only used previously for teacher interviews, there were no scoring guidelines available. In order to clarify differences between teachers with beliefs tilting in the traditional direction with those tilting in the non-traditional direction, I assigned a score of either a 1 or a 6 for every item instead of their circled response (1 to 6) and scored responses so that a high score on the questionnaire to denote non-traditional beliefs. For example, if the item described a non-traditional, or primarily non-traditional, belief and the teacher circled a 1 , 2, or 3 (agree) then I scored it as a 6 . If the teacher circled a 4, 5, or 6 (disagree) for this item, then I scored it as a 1. For example, consider Item 13, “The teacher should provide mainly problem-solving and manipulative-driven activities.” That item describes a mathematics teaching belief that tends toward the non-traditional. If the teacher circled 4, 5 , or 6 , that is, any of the three numbers closer to the "disagree” anchor, then I scored the item as denoting beliefs on the traditional side. I scored traditional statements in an opposite way.

Table 4-11 summarizes information from the mathematics beliefs questionnaire. The three teacher beliefs columns record each teacher's mean score for that factor. The columns also include a verbal classification for the mean score. In general, participants’ beliefs about teaching and learning mathematics tended slightly toward the nontraditional. For teaching mathematics, the median questionnaire score was 4.0, just barely on the non-traditional half of the continuum. For learning mathematics, the median was 4.25 or primarily non-traditional. 
Table 4-11

Mathematics Teacher Beliefs

\begin{tabular}{|c|c|c|c|c|}
\hline Teach & $\frac{\text { Years }}{\text { Exp. }}$ & $\frac{\text { Beliefs }}{\text { Nature }}$ & $\underline{\text { Beliefs }}$ & $\frac{\text { Beliefs }}{\text { Learning }}$ \\
\hline Elle & 3 & $5 / \mathrm{NT}$ & $3.8 / \mathrm{E}$ & 4.4 / PNT \\
\hline Davic & 3 & $4.5 / \mathrm{NT}$ & $4.5 / \mathrm{NT}$ & $4.1 /$ PNT \\
\hline Darre & 7 & $4.5 / \mathrm{NT}$ & 4.2 / PNT & $4.1 /$ PNT \\
\hline Julia Edwards-G & 15 & $2.5 / \mathrm{T}$ & 4.2 / PNT & 4.4 / PNT \\
\hline Chris Ingram-B & 7 & 4.5 / NT & $3.9 / \mathrm{E}$ & $5.1 / \mathrm{NT}$ \\
\hline Melanie & 8 & $5.5 / \mathrm{NT}$ & $3.8 / \mathrm{E}$ & $3.8 / \mathrm{E}$ \\
\hline
\end{tabular}

Beliefs Codes (Raymond, 1997): T - Traditional; PT - Primarily Traditional; E - Even mix of traditional and non-traditional beliefs; PNT - Primarily Non-traditional; NT Non-traditional

Individual scores about the nature of mathematics did not seem to align with teaching and learning scores for the teachers of this study and found themselves at opposite ends of the spectrum. Even experts disagree about the nature of mathematics (Thompson, 1992). Traditionalists are generally thought to view mathematics as fixed and unchanging, and those with more non-traditional views perceive mathematics as dynamic and fluid (Raymond, 1997). However, because of these uncertainties of meanings and the disparities and inconsistencies of survey results for the six teachers of the study, teacher opinions concerning the nature of mathematics were not considered in further analysis.

\section{Additional Teacher Characteristics}

To teach effectively in middle school, teachers must connect with their students and select practices that are engaging and developmentally appropriate for their students (Midgely, 2001; Gentry, et al., 2002). Two teacher characteristics that seemed important and relevant to successful mathematics teaching were a willingness to consider new 
approaches - that is to innovate and to reflect on practice - and a future commitment to

classroom teaching.

Innovation and reflection. I identified Mr. Fisher, Ms. Edwards, and Ms. Ingram as teachers who had an affinity for innovation and reflection. During the previous summer break, Greenville mathematics teachers had attended a workshop and learned about new activities and teaching strategies. Ms. Edwards continued, throughout the school year, to plan opportunities for all of the mathematics teachers at Greenville to collaborate and share ideas and experiences. When talking with Ms. Edwards on several occasions, she asked me how I thought the gendered classes were working for the boys and welcomed suggestions. She also asked me to use her video camera and record one of her class presentations using manipulatives so that she could share with other teachers and refine the lesson.

I frequently observed innovative strategies in Mr. Fisher's class as he dressed in construction attire to present a problem related to a home improvement project, taught students a jingle to remember the order of operations, and encouraged mental calculations of seconds saved when preparing tables to begin work. Near the end of the school year, however, I also had an opportunity to participate with Mr. Fisher in his reflections concerning changes in emphasis for his teaching.

RESEARCHER: Are you ready to be finished for this school year?

MR. FISHER: I'm more ready to be finished this year than I have ever been before. I gave a test the other day on things that we had covered this year and only 54 out of 129 students passed.

RESEARCHER: What were you testing?

MR. FISHER: Operations with decimals and other standards topics we had covered recently. Only 3 or 4 students had an A. This was not a difference in boys and girls, but was true of all my classes. ...I was always taught to teach with activities - get your students engaged, get them working together and in groups, get them to explore. But, I'm not so sure that mathematics is the proper stage for that approach. RESEARCHER: Why do you think it's not working? What you're doing is what the research says to do. 
MR. FISHER: It has worked with some groups. Some do well in that type of environment. But so many in my class this year are so weak Ask a student to subtract 12 minus 9 or ask a student what 36 divided by 9 is and they can't do it. I had hoped that by engaging them with exciting activities and fun things that they would learn, but there is such an overwhelming majority of students who are weak this year. I feel bad that I didn't see the problem sooner. Maybe I didn't want to see it. But I can't go back and teach these basics in class and the parents don't seem to be involved or able to help with this either. I have to move forward, teach the standards, and prepare them for the next level.

RESEARCHER: So what are you doing now?

MR. FISHER I'm using the textbook more now. I sent their books home with them for reference. I'm assigning homework five days a week.

RESEARCHER: Is it a longer assignment?

MR. FISHER: Yes, there are usually 20 or more problems instead of five. We go over many of them in class and we practice problems from the book instead of doing activities.

This dialogue suggests that Mr. Fisher perceived a need to add traditional activities, such as practice and demonstration of procedures, to his lessons.

Ms. Ingram was an innovative teacher and liked to use a variety of teaching tools. I observed classes in which she used pattern blocks or took students to the computer lab to work with Understanding Mathematics (Neufeld, 2002). "I enjoy attending workshops and gathering new ideas for teaching,” she said. Several times in our conversations she referred to the manipulative materials that were provided by the textbook publisher and how she had found them beneficial for her teaching. For the upcoming summer break, she eagerly anticipated a workshop for mathematics teachers at a nearby university.

Commitment to classroom teaching. The same teachers who demonstrated interest in innovation and reflection were those who want to remain in the classroom. When asked the question, "Where do you expect to be, career-wise, five years from now?” Mr. Fisher, Ms. Edwards, and Ms. Ingram envisioned themselves as continuing in the middle school classroom. Because of economic reasons, Mr. Fisher mentioned owning his own business as an alternate possibility. However, remaining in the classroom also held a strong attraction for him. His father had recently retired from a teaching career 
and Mr. Fisher liked what he was doing. Ms. Edwards expressed feelings of satisfaction in being a classroom teacher. However, on the encouragement of colleagues, Ms.

Edwards was also considering administration for her future. She mentioned the special relationships and rewards inherent in working with individual students as benefits she was reluctant to give up. Ms. Ingram did not mention any other career interest and said that teaching at Bluefield was where she wanted to remain. When questioned about future career plans, the other three teachers, Ms. Alcott, Mr. Blake, and Ms. Jones, did not mention remaining in the classroom as a preferred career path.

Summary of Teacher Characteristics.

Table 4-12 presents comparative characteristics for the six mathematics teachers of the study. Teaching and learning beliefs categorized according to responses on the mathematics beliefs questionnaire and scores for teacher efficacy beliefs from analysis of the MTEBI.

Table 4-12

Summary of Teacher Characteristics

\begin{tabular}{|l|c|c|c|c|c|c|}
\hline & Ms. Alcott & Mr. Blake & Mr. Fisher & Ms. Edwards & Ms. Ingram & Ms. Jones \\
\hline $\begin{array}{l}\text { ethnicity \& } \\
\text { gender }\end{array}$ & $\begin{array}{c}\text { Caucasian } \\
\text { Female }\end{array}$ & $\begin{array}{c}\text { Afr-Amer. } \\
\text { Male }\end{array}$ & $\begin{array}{c}\text { Caucasian } \\
\text { Male }\end{array}$ & $\begin{array}{c}\text { Caucasian } \\
\text { Female }\end{array}$ & $\begin{array}{c}\text { Caucasian } \\
\text { Female }\end{array}$ & $\begin{array}{c}\text { Afr.-Amer. } \\
\text { Female }\end{array}$ \\
\hline $\begin{array}{l}\text { years } \\
\text { experience }\end{array}$ & 3 & 3 & 7 & 15 & 7 & 8 \\
\hline $\begin{array}{l}\text { math. teach } \\
\text { efficacy }\end{array}$ & 93 & 79 & 90 & 93 & 95 & 98 \\
\hline $\begin{array}{l}\text { beliefs teach } \\
\text { math }\end{array}$ & E & NT & PNT & PNT & E & E \\
\hline $\begin{array}{l}\text { beliefs learn } \\
\text { math }\end{array}$ & PNT & PNT & PNT & PNT & NT & E \\
\hline $\begin{array}{l}\text { innovative/ } \\
\text { reflective? }\end{array}$ & ed. admin. & $\begin{array}{c}\text { ed. admin. } \\
\text { or policy }\end{array}$ & $\begin{array}{c}\text { yeaching } \\
\text { or } \\
\text { business }\end{array}$ & $\begin{array}{c}\text { teaching or } \\
\text { ed. admin. }\end{array}$ & teaching & ed. admin. \\
\hline \begin{tabular}{l} 
career goals \\
\hline
\end{tabular} & & \multicolumn{1}{|l}{} & yes & \\
\hline
\end{tabular}

Codes for Beliefs and Practices: T - Traditional; PT - Primarily traditional; E - Even mix of traditional and non-traditional; PNT - Primarily non-traditional; NT - Nontraditional. 
In general, the six teachers held beliefs about both teaching and learning mathematics that tended toward the non-traditional. Mr. Blake’s score for mathematics teacher efficacy appeared significantly lower than the other scores, and Ms. Jones's score appeared slightly higher that scores for the other teachers. This summary information also indicates that the teachers with inclinations toward innovation and reflection were also those whose future career interests included classroom teaching.

Mathematics Teaching and Learning

What is the nature of the mathematics instruction used by middle school mathematics teachers in all-boy classes? Do some types of instruction seem to be more effective than others? To characterize and analyze mathematics instruction for the six teachers of the study, the following documents serve as benchmarks: standards documents of the National Council for the Teachers of Mathematics (NCTM, 1989 \& 2000) and the National Research Council's research document delineating the "five strands of mathematics proficiency” (Kilpatrick, et al., 2001). Other factors considered in the analysis were time allocation, relationships between teacher beliefs and practices, and textbook use. Data related to mathematics teacher practices and beliefs were collected from observations, interviews, and teacher questionnaires. Mathematics practices, as well as beliefs, were characterized as either traditional or non-traditional. Traditional vs. Non-Traditional

A traditional mathematics learning environment is usually teacher-centered, one in which the students passively receive knowledge from the teacher. Teachers demonstrate procedures and ask questions of students for which a particular answer is expected. Practice holds an important position in the traditional mathematics classroom. Non-traditional teaching approaches are primarily student-centered and include an 
emphasis on classroom discourse in which teachers ask open-ended questions about mathematics; ask students to explain reasoning and problem solving strategies; and lead classroom discussions toward high levels of student thinking. In non-traditional classroom environments, students have opportunities to work in groups, to participate in hands-on activities, and to share thoughts and ideas with other students.

Mathematics Teaching: Observational Data

To analyze teaching and learning in the all-boy classrooms, I observed at least eight 50-minute lessons for each of the six teachers. I took notes, used an audio recorder, and later combined my hand-written notes with these recordings in a written transcript. I then used HyperResearch, a computer program designed for analysis of qualitative data to code the written transcripts. Two main topics for analysis with respect to the observed mathematics teaching were, first of all, how the teachers allocated their classroom time; and secondly, how their teaching related to research in mathematics education and to NCTM Standards (NCTM, 1989; 2000).

\section{Allocation of Classroom Time}

Table 4-13 gives a categorical summarization, along with codes and descriptions, of how each teacher's 400 minutes of observed class time was allocated in this study. Breakdowns for time allocations for each teacher by lesson are given in Appendix F. In the last column of Table 4-13 there is an entry for the percent of time each teacher devoted during my observation periods to preparation for standardized tests. Because only teachers from Terre Rouge spent class time for test preparation, I did not count it as a separate portion of time. For Terre Rouge, this time was also counted as an individual activity (IA). The percent of time spent on mathematics (Ma) was also not part of the 100\% tally. Time spent on mathematics (Ma) was calculated by subtracting time either 
spent on management (M) or free time (F) from 100\%. of class time less the time spent on management $(\mathrm{M})$ and free time $(\mathrm{F})$.

Teachers at Bluefield and Terre Rouge spent more time on classroom management than teachers at Greenville. Mr. Blake spent the most time on classroom management thereby spending less time on mathematics. Mr. Fisher spent the most time of any teacher on discourse, which is a characteristic of non-traditional, student-centered teaching. Sometimes he used teacher/student discourse, as he asked students to present problems on the board. He would help his students correct errors by having them explain their steps and reasoning. Sometimes while solving problems in groups, students would engage in discourse with each other. Mr. Fisher would also circulate among all the groups and talk to students about their problem solving strategies and about whether their answers were reasonable. Ms. Edwards was the teacher with the most classroom experience, and her time allocation was the most balanced among the categories of practice, individual activities, and group activities.

Table 4-13

Summary of Teacher Time Allocation (from eight 50-Minute Observations)

\begin{tabular}{|l|c|c|c|c|c|c|}
\hline & $\begin{array}{l}\text { Ms. } \\
\text { Alcott }\end{array}$ & $\begin{array}{l}\text { Mr. } \\
\text { Blake }\end{array}$ & Mr.Fisher & Ms.Edwards & Ms. Ingram & Ms. Jones \\
\hline Years exp. & 3 & 3 & 7 & 15 & 7 & 8 \\
\hline M-management & $26 \%$ & $35 \%$ & $11 \%$ & $12 \%$ & $21 \%$ & $26 \%$ \\
\hline F-free time & $3 \%$ & $2 \%$ & $2 \%$ & $0 \%$ & $0 \%$ & $6 \%$ \\
\hline D-discourse & $10 \%$ & $0 \%$ & $49 \%$ & $9 \%$ & $12 \%$ & $3 \%$ \\
\hline $\begin{array}{l}\text { T-teacher- } \\
\text { centered act }\end{array}$ & $31 \%$ & $35 \%$ & $4 \%$ & $4 \%$ & $29 \%$ & $34 \%$ \\
\hline P-practice & $18 \%$ & $10 \%$ & $1 \%$ & $25 \%$ & $5 \%$ & $19 \%$ \\
\hline $\begin{array}{l}\text { IA-individual } \\
\text { act. }\end{array}$ & $8 \%$ & $9 \%$ & $9 \%$ & $26 \%$ & $18 \%$ & $7 \%$ \\
\hline GA-group act. & $4 \%$ & $9 \%$ & $24 \%$ & $24 \%$ & $15 \%$ & $5 \%$ \\
\hline \multicolumn{1}{|c|}{ totals } & $\mathbf{1 0 0} \%$ & $\mathbf{1 0 0} \%$ & $\mathbf{1 0 0} \%$ & $\mathbf{1 0 0} \%$ & $\mathbf{1 0 0 \%}$ & $\mathbf{1 0 0 \%}$ \\
\hline Ma-time on math & $71 \%$ & $63 \%$ & $87 \%$ & $88 \%$ & $79 \%$ & $68 \%$ \\
\hline ST -test prep & $26 \%$ & $10 \%$ & $0 \%$ & $0 \%$ & $0 \%$ & $0 \%$ \\
\hline Traditional time & $49 \%$ & $45 \%$ & $5 \%$ & $29 \%$ & $35 \%$ & $53 \%$ \\
\hline Non-trad. time & $22 \%$ & $18 \%$ & $82 \%$ & $59 \%$ & $45 \%$ & $15 \%$ \\
\hline
\end{tabular}


Time Allocation Codes: M- management (travel from previous class or restroom, behavior, distribution of papers, administrative information);F- Free time or down time D- Discourse (open-ended questions and responses, requests for explanations and reasoning, conjectures and generalizations, discourse on mathematics concepts); $\mathrm{T}$ - Teacher-centered activities such as notes, procedures, vocabulary, spelling test, demonstrating solutions to problems, reading aloud); P - Practice (seatwork, homework); IA - Individual Activity (problem solving, making graphs, computer lab, manipulatives, modeling, hands-on, calculators); GA- Group Activity (work with group or partner; problem solving, collect data, manipulatives, modeling, hands-on); $\mathrm{Ma}$ - Percent of time spent on mathematics (not included in 100\% tally); ST - Percent of time spent on preparing for standardized tests (not included in 100\% tally).

Traditional time - Percent of time spent on classroom activities considered to be traditional; combined percentages for teacher-centered activities and practice $(\mathrm{T}+\mathrm{P})$ Non-traditional time - Percent of time spent on classroom activities considered to be nontraditional; combined percentages for discourse, individual activities, and group activities $(\mathrm{D}+\mathrm{IA}+\mathrm{GA})$

Beliefs/Practices Codes (Raymond, 1997): T - Traditional; PT - Primarily traditional; E - Even mix of traditional and non-traditional; PNT - Primarily non-traditional; NT Non-traditional.

\section{Mathematics Proficiency and Teaching Characteristics}

For an overall framework in looking at practices and the relationships of these practices to research and standards, I have adopted the National Research Council's (Kilpatrick, et al., 2001) characterization of mathematics proficiency as five interwoven strands of conceptual understanding, procedural fluency, strategic competence, adaptive reasoning, and productive disposition. In the National Research Council (NRC) book, Adding It Up: Helping Children Learn Mathematics (Kilpatrick,2001), a main point made by the authors was that mathematics proficiency is complex and cannot be characterized as only understanding concepts or competency in performing skills. In further structuring a framework for the analysis of classroom observations, I used the following sources to classify observational information: a list of characteristics of 
mathematics reform (Ross, et. al., 2002); a list of nine characteristics of standards-based instruction (Reys, 2004); and characteristics of metacognition (Bransford, et al., 2000). Finally, I used a list of characteristics for teaching for mathematics proficiency (Kilpatrick, et al., 2001) arranged according to the Teacher/Student/Content Triangle (Ball \& Cohen, 2000).

I used multiple sources because I thought that each list added important aspects of the five strands for mathematics proficiency that were not included in the other lists. The lists for characteristics for NCTM standards-based reform (Ross, et al., 2002) and the list for characteristics of standards-based classroom instruction (Reys, 2004) are closely aligned with characteristics of non-traditional teaching practice, and neither of these lists nor the list of non-traditional teaching practice include homework and practice, and thus may underemphasize the strand of procedural fluency. The list of standards-based instruction characteristics included details needed to better recognize mathematical discourse in an observation situation. Also, if a goal of teaching is to move toward more student-centered classrooms, then metacognitive strategies should be important aspects of proficiency within the various strands.

Characteristics of mathematics reform. This list of characteristics emerged from a meta-analysis of studies about the effects of teaching mathematics based on standards established by the National Council for the Teachers of Mathematics (NCTM, 1989, 2000). The following list was a product of authors' reviews of individual studies and NCTM policy statements.

$\frac{\text { Characteristics of Mathematics Reform (N1-N10) }}{\text { (Ross, McDougall, Hogaboam-Gray, 2002) }}$

1. Broader scope; increased attention to topics less commonly taught like probability. 
2. All students have access to all forms of mathematics, including teaching of complex mathematical (like algebra) ideas to less able students.

3. Student tasks are complex, open-ended problems.

4. Instruction focuses on construction of mathematical ideas through students' talk rather than transmission through presentation, practice, feedback, and remediation.

5. The teacher's role in reform settings is that of co-learner and creator of a mathematical community rather than sole knowledge expert.

6. Mathematical problems are undertaken in reform classes with the aid of manipulatives and ready access to mathematical tools.

7. Student interaction is encouraged rather than discouraged.

8. Assessment is more far-reaching than the unit test at the end of the week. Assessment in a reform classroom includes a wide variety of skills and abilities and is integrated with daily class activities.

9. The conception of mathematics presented by the teacher is that of an active and dynamic pursuit rather than a fixed body of knowledge.

10. Student development of confidence in ability to do mathematics is an important competency in the reformed mathematics classroom.

Standards-based instruction. This list of characteristics of standards-based

instruction was developed by at the University of Wisconsin (1998) and later adapted for use in the University of Missouri’s Middle School Mathematics Study (MS)² (Reys,

2004). These nine descriptors served as observational guides for studying practices of

mathematics teachers (Reys, 2004).

Characteristics of Standards-Based Instruction (S1-S9)

(U of Wisconsin,1998; Reys, 2004)

1. Lessons provided students opportunities to make conjectures about mathematical ideas.

2. The lesson fostered the development of conceptual understanding.

3. Connections within mathematics were explored in the lesson.

4. Connections between mathematics and students daily lives were apparent in the lesson.

5. Students explained their responses or solution strategies.

6. Multiple perspectives/strategies were encouraged and valued.

7. The teacher valued students' statements about mathematics and used them to build discussion or work toward shared understandings for the class.

8. The teacher used student inquiries as a guide for instructional decisions or as a guide to shape the mathematical content of the lesson.

9. The teacher encouraged students to reflect on reasonableness of their responses. 
Teaching for mathematics proficiency. The following classroom and teacher characteristics are suggested in the chapter "Teaching for Mathematics Proficiency" in the NRC book (Kilpatrick, et al. 2001). The chapter provides details to help teachers to learn to teach for mathematics proficiency, characterizing these details as relationships among the teacher, the student, and the mathematics - the three sides of a

“teacher/student/content triangle” (Ball \& Cohen, 2000).

Teaching for Mathematics Proficiency: The Teacher/Student/Content Triangle (T1T12)

(Kilpatrick, Swafford, \& Findell, 2001; Ball \& Cohen, 2000)

Teachers and Content

1. Task selection and use

2. Opportunity to learn

3 Planning

Teachers and Students

4. Teacher expectations

5. Task value and efficacy

6. Learning community

7. Group vs. whole class activities

8. Assessment of student work

9. Mathematics discourse

Students and Content

10. Practice

11. Homework

12. Use of tools (manipulatives, computer programs, calculators)

Metacognition. Another important component of understanding proficiency in any subject area relates to understanding how learners connect pieces of knowledge. Metacognition in mathematics is the knowledge of one's own thinking and the ability to monitor one’s own learning, reasoning, and problem solving ability (Kilpatrick, et al., 2001). Research has demonstrated that children can be taught these strategies (Bransford, et al. 2000). The strategy of apportioning time and memory relates to how to prepare for performance involving memory and how much time it will take to perform a task. 
Students can over-estimate their capabilities to remember information or under-estimate

the amount of time of a task requires.

Characteristics of Metacognition : M1-7

(Bransford, Brown, \& Cocking, 2000)

1. monitor one's own learning

2. predicting outcomes,

3. targeting misunderstandings

4. activating prior knowledge

5. considering alternative strategies

6. self-regulation; apportionment of time and memory.

7. explaining reasoning

Framework for mathematics proficiency. Table 4-14 organizes teaching and learning characteristics from these four lists under the framework of the strands of mathematical proficiency.

Table 4-14

Framework of Mathematics Proficiency for Observation Analysis

\begin{tabular}{|c|c|}
\hline $\begin{array}{l}\text { Conceptual } \\
\text { Underst. }\end{array}$ & 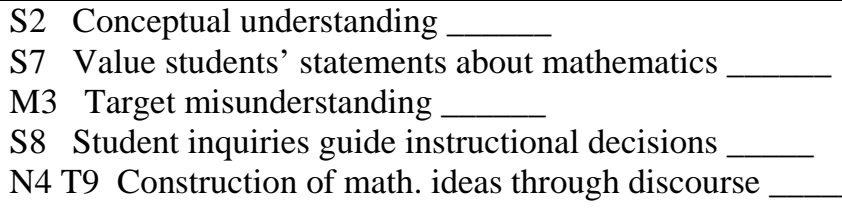 \\
\hline $\begin{array}{l}\text { Procedural } \\
\text { Fluency }\end{array}$ & $\begin{array}{l}\text { T10 Practice } \\
\text { T11 Homework }\end{array}$ \\
\hline $\begin{array}{l}\text { Strategic } \\
\text { Competence }\end{array}$ & $\begin{array}{l}\text { S1 M2 Make conjectures; predict outcomes } \\
\text { S6 M5 Multiple perspectives/strategies } \\
\text { N9 Mathematics is a dynamic, changing discipline } \\
\text { T1 N3 Task selection and use; complex open-ended tasks } \\
\overline{\text { S3, M4 Connections within math; activate prior knowledge }} \\
\text { M1 Metacognition; monitor one’s own learning }\end{array}$ \\
\hline $\begin{array}{l}\text { Adaptive } \\
\text { Reasoning } \\
\end{array}$ & $\begin{array}{l}\text { S5 M7 Explain Reasoning } \\
\text { S9 Reflect on whether answer reasonable } \\
\text { T7 N7 Group activities; student/student interaction }\end{array}$ \\
\hline
\end{tabular}




\begin{tabular}{|c|c|}
\hline $\begin{array}{l}\text { Productive } \\
\text { Disposition }\end{array}$ & $\begin{array}{l}\text { S4 T5 Connections w daily life ; task value } \\
\text { N5 T6 math community; learning community } \\
\text { N10 student confidence; efficacy; } \\
\text { Math is enjoyable (inc. boy motivators) }\end{array}$ \\
\hline $\begin{array}{l}\text { All Strands } \\
\text { of } \\
\text { Math. } \\
\text { Proficiency }\end{array}$ & $\begin{array}{l}\text { T2 N1 N2 Opp. to learn challenging math; broad scope } \\
\text { T4 High teacher expectations } \\
\text { T3 Teacher planning } \\
\text { N8 T8 An integrated and broad assessment of student work } \\
\text { N6 T12 Use of tools (manipulatives, calculators, computers) _ } \\
\text { M6 Planning ahead; self-reg; apportion time \& mem. }\end{array}$ \\
\hline
\end{tabular}

In reviewing the set of lists used for the framework, I noticed that enjoyment of mathematics, which is referred to in the strands of proficiency (Kilpatrick, et al., 2001) but does not appear in a list. Therefore, I added “enjoyment of mathematics” as a subtopic in the productive disposition section. Study findings revealed that the enjoyment of mathematics is an important factor for middle school boys who lose interest in school (Midgley, 2001; Gentry, et al., 2002). Using HyperResearch for analysis of observational data, the eight 50-minute observations were coded for each teacher according to the framework of Table 4-14.

Table 4-15 Teacher Totals for the Five Strands of Mathematics Proficiency (Kilpatrick, et al., 2001)

\begin{tabular}{|l|c|c|c|c|c|c|c|c|}
\hline \multicolumn{1}{|c|}{ Teacher } & $\begin{array}{c}\text { Yr. } \\
\text { Exp. }\end{array}$ & CU & PF & SC & AR & PD & $\begin{array}{c}\text { All } \\
\text { Strands }\end{array}$ & Total \\
\hline Ms. Alcott -T & 3 & 21 & 11 & 12 & 4 & 6 & 2 & 56 \\
\hline Mr. Blake - T & 3 & 9 & 25 & 6 & 10 & 12 & 7 & 69 \\
\hline Mr. Fisher - G & 7 & 56 & 31 & 54 & 52 & 102 & 10 & 305 \\
\hline Ms.Edwards-G & 15 & 54 & 54 & 11 & 29 & 68 & 18 & 234 \\
\hline Ms. Ingram -B & 7 & 43 & 27 & 17 & 29 & 14 & 6 & 136 \\
\hline Ms.Jones -B & 8 & 13 & 35 & 4 & 6 & 16 & 4 & 78 \\
\hline
\end{tabular}

Codes: CU-conceptual understanding; PF-procedural fluency; SC-strategic competence; AR-adaptive reasoning; PD-productive disposition. 
Table 4-15 displays total instances for characteristics of teaching for mathematics proficiency from eight 50-minute classroom observations for each teacher. Detailed tallies for this framework, along with a list of codes, the item descriptions, and other notes are provided in Appendix G.

\section{Beliefs vs. Practices}

To compare beliefs and practices, I classified each teacher's practice along a traditional to non-traditional continuum again using a schema from Raymond (1997) (See Appendix H). While referring to my observational data, I looked through the characteristics of practice in the schema. When I perceived a good fit for a characteristic with one or more of the six teachers, I placed those teachers' names by that characteristic. There were several characteristics on the list for which differences between the teachers had not been examined in this study (e.g. how teachers evaluate students or how closely teachers follow their lesson plans), so I did not assign teacher names to these characteristics.

Table 4-16 presents characterizations of mathematics beliefs and practices for the six teachers of the study. Again, I used a schema developed in a previous study (Raymond, 1997). Details of this analysis for each teacher, along with the lists of characteristics of the schema (Raymond, 1997), appear in Appendix H. In beginning the analysis, I noted that the fewest number of teachers were demonstrating characteristics in the non-traditional list, I began at that end and located each teacher's name five times. For each teacher, I then scored these five characteristics as follows: 5-Non-Traditional; 4Primarily Non-Traditional; 3 - Even Mix; 2 - Primarily Traditional; and 1 - Traditional. Each teacher's mathematics practice rating in Table 4-16 is the median of these five scores. Using these steps for analysis, Ms. Jones’s practice was characterized as 
traditional; and Ms. Alcott and Mr. Blake’s practices were characterized as primarily traditional. Characterizations for Ms. Ingram, Ms. Edwards, and Mr. Fisher were an even mix; primarily non-traditional; and non-traditional, respectively.

Table 4-16

Beliefs and Practices for Teaching Mathematics

\begin{tabular}{|l|c|c|c|c|c|c|}
\hline & $\begin{array}{l}\text { Ms. } \\
\text { Alcott }\end{array}$ & $\begin{array}{l}\text { Mr. } \\
\text { Blake }\end{array}$ & $\begin{array}{l}\text { Mr. } \\
\text { Fisher }\end{array}$ & $\begin{array}{l}\text { Ms. } \\
\text { Edwards }\end{array}$ & $\begin{array}{l}\text { Ms. } \\
\text { Ingram }\end{array}$ & $\begin{array}{l}\text { Ms. } \\
\text { Jones }\end{array}$ \\
\hline years experience & 3 & 3 & 7 & 15 & 7 & 8 \\
\hline math. teach effic. & 93 & 79 & 90 & 93 & 95 & 98 \\
\hline beliefs teach math & E & NT & PNT & PNT & E & E \\
\hline beliefs learn math & PNT & PNT & PNT & PNT & NT & E \\
\hline math practices & PT & PT & NT & PNT & E & T \\
\hline
\end{tabular}

Beliefs/Practices Codes: T - Traditional; PT - Primarily traditional; E - Even mix of traditional and non-traditional; PNT - Primarily non-traditional; NT - Non-traditional.

With the exception of Mr. Fisher and Ms. Edwards from Greenville Middle School, study results revealed inconsistencies between teachers’ beliefs about teaching and learning and teacher's practices. Teaching practices tended toward the traditional, whereas beliefs about teaching and learning tended toward the non-traditional. Inconsistencies among teacher beliefs and practices have also been found in other studies and reasons given for these inconsistencies included time constraints, lack of resources, and issues of classroom management (Thompson, 1992; Raymond, 1997). Ms. Alcott and Mr. Blake, the two teachers of the study with the least teaching experience, held beliefs that tended toward the non-traditional, whereas their practices were observed to be traditional. Teachers of this study attributed inconsistencies mainly to student characteristics and classroom management. Ms. Alcott said, "My boys are not mature enough to work in groups,” and Ms. Jones remarked, “I love non-traditional teaching methods, and I think students benefit from self-discovery and work with hands-on materials. However, the combination of behaviors present makes it difficult.” 
Teachers of the study seemed, collectively, to appreciate the value of nontraditional, student-centered learning experiences, such as hands-on work, solving problems in groups, and real-world connections. General beliefs about learning mathematics strongly favored the non-traditional end of the continuum. Even so, their practices tended toward the traditional end, and this to me, was a notable inconsistency. Although I observed some instances of teacher/student and student/student mathematics discourse, particularly in Mr. Fisher's class, none of the teachers discussed or seemed aware of the importance of this type of discourse as a way to raise student levels of thinking about mathematical ideas. Previous studies indicate a strong connection between teacher beliefs and practices (Thompson, 1992), but how teachers were teaching in this study did not relate as much to beliefs about teaching and learning as it did to their experiences and assessments of students and their particular teaching context. It should also be noted that many studies indicate that teaching in a non-traditional manner requires more skill and a broader knowledge than traditional teaching (Thompson, 1992; Ross, et al., 2002; Windschitl, 2002).

Perhaps these inconsistencies could be clarified by thinking in terms of different types of beliefs. According to Thompson (1992), beliefs can be classified as central or peripheral (Thompson, 1992). Central beliefs involve more strongly held convictions whereas peripheral beliefs are more susceptible to change and examination. A belief that more lasting and transferable learning takes place when conceptual understanding and connections with student knowledge and thinking are emphasized may seem intrinsically plausible. Thus, these beliefs may fall into the central, deeply-held category, whereas beliefs leading teachers toward more traditional practices may be peripheral and influenced by other factors. 


\section{Textbook Use}

Guided by the work of other researchers (Reys, 2004), I considered mathematics textbooks produced and developed by a commercial textbook publisher as traditional. Both Greenville and Bluefield used traditional curriculum materials. Greenville teachers used their state's edition of Glencoe Mathematics: Applications and Concepts, Course 1 and Course 2 (Glencoe, 2004). Bluefield teachers used mathematics texts from two different publishers. For her honors class, Ms. Jones used Glencoe Mathematics: PreAlgebra (Mallory, Price, Willard, Sloan, 2005), and for her regular class, she used Holt Middle School Mathematics: Course 2 (Bennett, Chard, Jackson, Milgram, Scheer, \& Waits, 2004). Ms. Ingram used Holt Middle School Mathematics: Course 1 for both her honors and regular classes.

Terre Rouge Middle School used district-adopted curriculum materials from the Connected Mathematics Project (Lappan, et al., 2002a), which I characterized as nontraditional. These are texts designed to guide student-centered, inquiry-based teaching and were developed by university mathematics education researchers supported by National Science Foundation grants. These non-traditional materials, characterized by high expectations and student-centered, reformed teaching can be described as "educative curriculum materials” because they are designed to promote teacher learning, as well as student learning (Davis \& Krajik, 2005)

Research indicates teachers' uses of textbooks and curriculum materials to be a topic of considerable complexity and that the conceptual underpinnings of the topic reflect various interpretations and inconsistencies (Reys, 2004; Remillard, 2005). Mathematics differs from other disciplines in its long history of being textbook-driven, but research indicates that a district decision to adopt a single textbook and curriculum 
will not result in uniform mathematics instruction (Remillard, 2005). A meta-analysis of studies focused on teacher use of mathematics curricula revealed that curricular modifications and interpretations, as well as the complexities in teacher/curriculum relationships, confound notions “fidelity of implementation” (Remillard, 2005). A study of non-traditional, “educative” curriculum materials for teaching science suggested that designs of these materials were key issues for their effective use. Most teachers do not have time to read extensive curriculum materials even though they might have great potential for teacher learning. Other limitations mentioned included teacher characteristics such as knowledge, beliefs, and teachers' dispositions toward reflection and improving practice (Davis \& Krajik, 2005).

I categorized textbook use for the teachers of this study using a framework developed for the Middle School Mathematics Project or (MS) ${ }^{2}$ (Reys, 2004). Ms. Alcott used her non-traditional textbook as a scope and sequence guide, telling her what to teach and when to teach it, whereas Mr. Blake did not use the textbook at all. At Greenville, both Mr. Fisher and Ms. Edwards used their textbooks mainly for as a resource to provide homework and practice problems. At Bluefield, both Ms. Ingram and Ms. Jones used their respective texts as comprehensive and trusted authorities, as guides for what, when, and how to teach.

Summaries of Teachers' Practices and Textbook Uses

Table 4-17 presents summary information for beliefs, practices, and textbook use. Findings in the current study agreed with other studies in suggesting that non-traditional teaching did not necessarily accompany adoption of non-traditional curriculum materials (Reys, 2004; Remillard, 2005). 
Table 4-17

Mathematics Teachers' Beliefs, Practices, and Textbook Use

Beliefs/Practices Codes (Raymond, 1997)

T - Traditional; PT - Primarily traditional; E - Even mix of traditional and nontraditional; PNT - Primarily non-traditional; NT - Non-traditional.

Time Allocation Codes

Traditional (T) - Percent of time spent on classroom activities considered to be traditional; the total for teacher-centered activities and practice $(T+P)$. Non-traditional (NT) - Percent of time spent on classroom activities considered to be non-traditional; the total for discourse, individual activities, and group activities (D + IA + GA).

Textbook Use Codes (Reys, 2004)

These codes categorize teachers' uses of school- or district-adopted textbooks. A - Comprehensive and trusted authority (what, when, and how to teach) SS - A scope and sequence guide (what and when to teach)

$\mathrm{R}$ - An occasional or regular resource (homework, tasks, exercises, tests) $\mathrm{N}$ - Textbook plays no role

Summary Chart (8 observations, 50 minutes each)

\begin{tabular}{|l|c|c|c|c|c|c|}
\hline & $\begin{array}{l}\text { Ms } \\
\text { Alcott }\end{array}$ & $\begin{array}{l}\text { Mr. } \\
\text { Blake }\end{array}$ & $\begin{array}{l}\text { Mr. } \\
\text { Fisher }\end{array}$ & $\begin{array}{l}\text { Ms. } \\
\text { Edwards }\end{array}$ & $\begin{array}{l}\text { Ms. } \\
\text { Ingram }\end{array}$ & $\begin{array}{l}\text { Ms. } \\
\text { Jones }\end{array}$ \\
\hline Years experience & 3 & 3 & 7 & 15 & 7 & 8 \\
\hline $\begin{array}{l}\text { Math. teach. } \\
\text { efficacy }\end{array}$ & 93 & 79 & 90 & 93 & 95 & 98 \\
\hline Beliefs / teaching & E & NT & PNT & PNT & E & E \\
\hline Beliefs / learning & PNT & PNT & PNT & PNT & NT & E \\
\hline Time allocation-T & $49 \%$ & $45 \%$ & $5 \%$ & $29 \%$ & $35 \%$ & $53 \%$ \\
\hline Time allocation - NT & $22 \%$ & $18 \%$ & $82 \%$ & $59 \%$ & $45 \%$ & $15 \%$ \\
\hline $\begin{array}{l}\text { Math.proficiency } \\
\text { total }\end{array}$ & 56 & 69 & 305 & 234 & 136 & 78 \\
\hline Teaching practice & PT & PT & NT & PNT & E & T \\
\hline Textbook & NT & NT & T & T & T & T \\
\hline Textbook use & SS & N & R & R & A & A \\
\hline
\end{tabular}

The preceding sections have presented analyses and comparisons of data regarding the practices and beliefs of the six mathematics teachers of the study. Results of this study indicated that there were many differences among the six study participants, both in personal characteristics and in various areas of practice. Examined areas of practice included classroom management, uses of strategies directed at boys' interests 
and needs, and the way mathematics was taught. The investigation also revealed differences among the individual teachers' experience levels, career goals, and their tendencies to innovate and reflect. The following sections review in greater detail each mathematics teacher's practice in relation to their beliefs, affinities, and contexts.

Ellen Alcott. Ms. Alcott's entire three-year teaching career had been spent in allboy classes at Terre Rouge Middle School. When she came to Terre Rouge in the pilot year for single-gender classes, she was designated "emergency certified” by her district and assigned to teach mathematics to five all-boy classes in $7^{\text {th }}$ grade. While teaching at Terre Rouge, she had pursued university classes to obtain her certification and participated frequently in training sessions for the district-adopted CMP curriculum. Since that first year, she had taught $6^{\text {th }}$-grade boys for two years and anticipated the same assignment for the following year.

Ms. Alcott's management style combined corrections of behavior and reminders about consequences with presentation of her lessons. She reminded students frequently, both by direct statements and by her "in your face” interactions exactly where the control in the class resided. Students' interview statements confirmed that the boys "respected" Ms. Alcott and did not "respect" teachers on the team with more permissive management styles. School administrators had also expressed to her their approval of the way she ran her classroom, which may have accounted for her high self-scoring for mathematics teaching efficacy. The proportion of classroom time spent on management (26\%) was higher than all of the other teachers except Mr. Blake. For both of these teachers, school policies, which required teachers to accompany students as they changed classes and on restroom breaks, probably accounted for much of this time. 
Even though her beliefs about student learning were non-traditional, her overall teaching practice was judged to be primarily traditional. Teacher-led note taking and procedures occupied $31 \%$ of her classroom time. Her totals for instances when she emphasized the strands of conceptual understanding (21), strategic competence (12), and adaptive reasoning (4), were in the same range as Mr. Blake and Ms. Jones, whose practices were also primarily traditional. There were not many instances in which she engaged in mathematical discourse, and indicated that students' lack of vocabulary was a barrier to these types of interactions. As for strategies for teaching boys, she primarily used those that were structural and organizational (63 instances), rather than those used by other teachers to engage and motivate boys (5 instances). She reported that she did not use group work much in her classes, because the boys were not mature enough for these types of activities.

Practice for standardized testing also received a sizeable portion of classroom time (26\%) in classes that I observed. In addition to the district-developed practice test on factoring and primes, observations of her classes included a practice activity and reviewed definitions for words needed on the open response sections of the state accountability tests. In an interview, she talked some about the challenges of standardized testing for her students.

MS. ALCOTT: Well, the standardized testing -- I don't think it measures what the teachers are doing. I know I do my job, but the test results may not show that all the time. As far as the state curriculum standards, I think that they are good standards. When I teach, I go straight from the core content guide, and I don't think that the standards are above what the students need to know. I think they are right on target. But, as far as the standardized testing, I think the test makes them "freak out." The vocabulary is a little bit higher, even though they say it's sixth grade. The average child, not just here but at the majority of the (district) schools, is not on a sixth grade level. Just like the test I gave last week, my kids knew that information; they knew it. Yet the test -- it didn't show it. So, does that mean that I didn't teach them that? A lot of them know the content, but when you put it in a sentence, they have a hard time reading that sentence, and understanding that 
question, it kind of...the way they word some of the math problems, If I were to reword some of those questions, I think my kids would get them right. And a lot of it is that they just freak out. I don't know what they think -- their minds go every which direction except the right direction.

Research suggests that in a mathematics teacher's practice, there may be inconsistencies between the "intended" curriculum and the "enacted" curriculum, most particularly for non-traditional curriculum materials (Reys, 2004). I observed some of these inconsistencies with Ellen Alcott. “All the stuff I’ve been doing comes straight from the Connected Math book,” she told me. Ms. Alcott used non-traditional curriculum materials, but it was clear that beliefs about her $6^{\text {th }}$-grade boys placed limitations on her ability to use these materials in the way they were intended. Furthermore, comparisons with the teacher's guide and her enacted lessons suggested that she did not have time to read her teachers' guides extensively

When I later asked her about her homework assignments, she told me that her assignments were worksheets that came from workbooks that she had bought with her own money or the funds allotted to her by the school. She also used activities and lessons suggested in the core content guide on the school district's website. Four classroom observations of the first investigation in the CMP booklet "Data About Us" (Lappan, et al., 2002b) provided me with new understandings for the terms, "intended” vs. "enacted" curriculum.

To introduce the investigation, she read a children's story of a Chinese boy named “Tikki Tikki Tembo Nosirimbo Charlie Barley Itchy Pit Perry Pembo,” who fell into a well and almost didn't get rescued because he had such a long name. She said to the class.

MS. ALCOTT: Next Monday we're going to collect some data about students, and this story is a good introduction. .... Joe, come on. Hurry up. You probably don't want to be sent home today, do you? 
She read the story of Tikki, Tikki, Timbo on a Thursday, and it was not until the following Monday that she began the CMP investigation of mode and median. To collect data for the investigation, the boys moved about the classroom and obtained signatures, first and last names, from the other students. Afterwards, they returned to their seats, counted the number of letters for each name on their lists, organized their data from least to greatest, and made a line plot and a bar graph of their data.

On Tuesday, they continued the investigation by discussing mode and median as measures of central tendency. Then on Wednesday, they discussed a problem from the CMP "Data Around Us" booklet that she had placed under the desks at the beginning of the school day for all of her classes to use. This was the only class during my observations of Ms. Alcott that I saw a Connected Mathematics textbook in use by the students. When directed, the students reached down in the bins under their desks, retrieved the books, and located a list of names on page 13 (Lappan, et al. 2002b). The boys were directed to organize their data in the same manner as they had yesterday and to find the median. Then, she proceeded to Problem 1.5 in the investigation and began to ask students to add or remove two names and to then determine whether or not the median changed.

It was in this discussion of Problem 1.5 that planning, reflection, and experience might have made differences in the teaching of the lesson. She asked individual students to give examples of what two numbers (representing number of letters in the names) they would add or delete. Then, she tested each response by rewriting the ordered list and crossing off numbers from the top and the bottom until a new median was found. Then, this new median would be compared to the original one and she would ask, "Did it work?” She then moved on to other questions and other student responses. Each time, 
she located the median by making a new list of numbers and crossing out on the top and bottom of the list to find the new median. By rewriting and crossing out the numbers each time, she did not make generalizations intended by the curriculum about characteristics of median as a measure of central tendency. The CMP teachers guide suggested using sticky notes for the added numbers or for covering numbers to be deleted from the original list. She did not, as also suggested in the teacher's guide, point out why median was a useful value for statisticians. As stated in the teacher notes, "You want the students to realize, that median is a fairly stable value. It doesn’t change significantly when a few additional values- no matter how large or small - are added to the data set (Lappan, et al, 2003b, p 21i).”

Finally, she did not, in this lesson or in the two previous lessons, mention the story of Tikki Tikki Timbo, nor make any reference to the length of a name. She did not use it to make the point that the CMP teachers guide suggested about the stability of median as a measure of central tendency and did not make generalizations about the effects of a name's length in changing a median. Although she had introduced to students in a previous lesson the concept of an outlier, she did not relate this concept to median or mean. From Thursday to the following Wednesday, the story was not mentioned in class discussions. However, on that Wednesday, a boy sitting near me reminded me of the story and its connection to the lesson when he said to me quietly, “Oh, yeah, like Tikki Tikki Tembo.” I told him to raise his hand and tell Ms. Alcott and what he had just said. She responded to him, “Oh, yeah, very good,” but missed the opportunity to make the connection for the other students. And as the period ended, I heard this same boy chant quietly as he left the classroom, "Tikki Tikki Timbo Nosirimbo Charlie Barley Itchy Pit Perry Pembo.” 
David Blake. As a teacher of boys, Mr. Blake possessed special qualities for relating to his students, for gaining their confidences while remaining stern, and for showing them that he cared. Like Ms. Alcott, he was also in his third year of teaching, his second at Terre Rouge, and Mr. Blake attributed this rapport he had with his boys to the fact that he had taught the same students last year in $6^{\text {th }}$ grade and moved up to the $7^{\text {th }}$-grade team along with them. His classroom management style was evenly blended between instances of correcting behavior (22) and modeling appropriate behavior (24). “Mr. Blake not only teaches lessons about mathematics but lessons about behavior,” said one of his students. I observed Mr. Blake’s classes during a month when his team was short one teacher, necessitating that the $7^{\text {th }}$-grade boys be divided into four classes instead of five. Mr. Blake's classes that I observed contained 30 to 35 students. There were not enough desks, and each day, there were at least five boys sitting on counter tops along the periphery of the classroom. Even in overloaded classes, Mr. Blake succeeded in maintaining order and keeping the attention of his students.

During the observational period, he had spent more time than any other teacher on classroom management (35\%), and on one occasion, he spent almost half a period leading them through the halls and counseling them on how they were supposed to act. When explaining details of what he expected of students, he was explicit and demanding. “Don’t tell me you have bad handwriting” ..... "Make your columns straight.”... “I don’t want to hear any insignificant questions”.... “To make an A-plus you must be always on-task and willing to help others; and you must work above expectations and do problems I didn’t assign. ”... “Don’t say it’s hard, say it’s challenging,” were things he would say to them. Like Ms. Alcott, he used mainly the structuring and organizational boy strategies (49), rather than those designed to engage the boys' interest and motivate 
them(6). He expressed to me disapproval about offering rewards, such as candy, for homework, which students should be doing for their own benefit.

When considering beliefs about teaching and learning mathematics, Mr. Blake’s questionnaire responses suggested the most non-traditional schema of all. However, when talking with him about his beliefs, he suggested that he was in favor of an even blend of traditional and non-traditional teaching. When Mr. Blake spoke of nontraditional teaching, he thought primarily of peer tutoring and working with a partner and not in terms of conducting student/teacher discourse about mathematics. His practice was primarily traditional, and he spent $35 \%$ of class time on note taking and teacher-led demonstrations. He used few non-traditional strategies and instances of teaching for conceptual understanding (9), strategic competence (6), and adaptive reasoning (10) were less frequent than most of the other teachers of the study.

As previously mentioned, Terre Rouge used non-traditional, district-adopted curriculum developed by the Connected Mathematics Project (CMP). Mr. Blake did not use this adopted curriculum and told me on several occasions that he did not like it. “Connected Math is designed for kids who can read at a certain level," he said. "It's for kids who already know how to set up problems, and our kids don’t have that base.” Because of his decision not to use Connected Mathematics, his resources for teaching mathematics appeared to be limited. . In a similar manner to Ms. Alcott, he used worksheets from workbooks for homework assignments and classroom practice. This lack of use of any curriculum materials may have related to his relatively low self-rating on mathematics teacher efficacy

My observations confirmed that his teaching was mainly procedural. For three lessons on the addition and subtraction of positive and negative numbers, Mr. Blake 
taught this topic in an unusual, but procedural manner. For an example such as $2-8$, he would have them rewrite it, changing the middle sign to $2+(-8)$, and then change the order of the addends to $-8+2$ before expressing the answer of -6 . The following dialogue provides details of Mr. Blake’s teaching for another problem.

MR. BLAKE: If you have a plus and a positive number then it's what?

STUDENTS (many voices): Positive

MR. BLAKE: And if you have minus and a negative number then it's what?

STUDENTS (many voices): Positive.

MR. BLAKE: Let's look at something like this as an example: (3) - (-3) becomes $3+3$, that equals 6 . That's what we've been doing. Now we're going to make a chart.

[He then erases and starts entering things in the columns of a chart, beginning with the problem -3 - (-2). ]

MR. BLAKE: Now what we're going to do is work the first problem out together. The first thing we are going to do is see if we need a sign change (replacing two signs with one). Does there need to be a sign change?

STUDENTS(a few voices): Yes

MR. BLAKE: We're going to rewrite this problem in the second column of the chart as negative 3 plus two. OK. Now, we're going to take it one step further and we're going to do a switch. The negative 3 comes first and the two comes last. When we switch, the two will come first and the negative three will come last, and that's in the third column. All we're doing is switching the numbers around to do a sign change. OK Now we have positive two and subtract three. What do we have? STUDENTS (many voices): Negative one.

BRYAN: How do you get minus one if one is positive?

MR. BLAKE: Once you switch, the second number (or first)... Robert, quit talking. ... it always takes on the sign in front of it. Good question, Bryan. We're going to do one just like what he's talking about. Four plus negative six.

Mr. Blake then demonstrated three more examples. But in answering Bryan’s question, Mr. Blake focused on the procedure. Although he mentioned to students several times that they should use a number line on these problems, he never drew a number line on the overhead or used it in an explanation that I observed.

In interviews, students reported that Mr. Blake would work with students extensively and had confidence in their abilities.

WALT: If he says something he's not just going to put it on the board and sit down. If he says something, he's going to explain it throughout that whole period until we get the meaning of it. 
ZEKE: Because last year he put something on the board that didn't nobody understand. And he explained it for months. He wouldn't give up. He's the kind of teacher like he won't give up. He won't give up on you.

HANK: I got everything he taught me last year.

WALT: I thought fractions were hard, but I don't think they're hard now. I just didn't get them last year. But he like stuck by us the whole time. He wouldn't give up.

Mr. Blake was a teacher who had gained his students' attention, their trust, and their respect. He also had high expectations for his boys, and in speaking of a mathematics problem he said, “Don’t say it’s hard; say it’s challenging,” I heard him say to students about a mathematics problem. He also believed that his boys were motivated by competition and a challenge and would stick to a task longer than their female counterparts. When asked how he might change for next year, Mr. Blake spoke of new ways to reach particular students rather than new strategies for teaching mathematics. "I look more at learning styles than I do at innovative ways of teaching,” He recognized barriers and inequities encountered by his students, and sought ways to help them succeed in the face of adversities.

However, Mr. Blake, the teacher with the lowest self-assessment for efficacy in teaching mathematics, was not, according to these observations, teaching for mathematics proficiency. He spent 35\% of his classroom time in teacher-centered activities, particularly the teaching of procedures. Furthermore, observations revealed only 9 instances in which he emphasized conceptual understanding and 6 instances in which his teaching emphasized strategic competence. Mathematics education research and results of this investigation suggested that Mr. Blake needed additional development of his mathematics pedagogy to lead his boys to higher levels of mathematics thinking or to further develop their potential for success. However, Mr. Blake did not include remaining in the classroom or continuing mathematics professional development in his 
future career plans. In the next five years, Mr. Blake hopes to complete a doctorate in educational administration and to become involved in educational reform and policy making.

Darrell Fisher. Observations of Mr. Fisher's classes identified him as the teacher with the most instances of teaching for mathematics proficiency (305) and also a high number of instances when he used strategies for teaching boys (201). He spent the least amount of time of any teacher on classroom management (11\%) and planned his time fully for teaching mathematics. He used a variety of activities such as problem solving in groups; board presentations of problems, and a hands-on activity of making a foldable set of notes for concepts and applications of ratio, proportion, percent, and probability. Mr. Fisher's believed that it was important to engage students' interests and that the all-boy classes were conducive to this process.

MR. FISHER: I feel like it engages the boys to focus on their individual interests. If, in a combined class, I use a prom dress example, none of the boys will listen. If I use an example of so many tons of concrete, the boys will pay attention. That's what I can do in an all-boys class. They may get initially distracted and think of the concrete rather than the mathematics, but I "have the hook in." If fish bite the hooks and bite the worms, they are initially distracted with the taste, but they take it away. If I can get the same hooks to students, then they can catch them and bite on. Then, I can lead them through the course of the instructions enough so I can teach them what they need to know.

Mr. Fisher (The pseudonym was a coincidence.) sought to increase students’ productive disposition (102 instances) for doing mathematics through drama, jokes, talltales, and emphasis on the importance of mathematics, and I observed high a high number of instances in which he developed the strands of conceptual understanding, strategic competence, and adaptive reasoning as well (162). I frequently heard him conduct mathematical discourse with individual students, once guiding a student to 
determine that an answer was not reasonable, and another time, helping one find a

computational error.

His beliefs about teaching and learning were primarily non-traditional and his practice was the most non-traditional for any teacher of the study. The district-adopted textbook (Glencoe Mathematics, 2004) was a traditional one, but I rarely observed Mr. Fisher using the textbook in his class. When I asked him early in the year, he said that he used it along with the state standards as a scope and sequence guide and occasionally assigned homework from the textbook. Most of his homework assignments appeared to be five-problem assignments that he had created or adapted that students were to turn it at the end of each class. However, he did not believe in learning that was totally studentcentered and expressed this belief as follows:

MR. FISHER: I don't believe in individual learning, I don't think students can take themselves from the beginning of the school year to the end without teacher intervention. I believe in discovering to a degree, but also in guided learning because in later life you learn through seminars and faculty meetings, where no discovery learning takes place. I try very hard to provide opportunities for movement in my classes. Students present in front of the class, and frequently work in groups. But, I try also to provide direct instruction, as well as have students do some discovery learning on their own.

Three of my observations of Mr. Fisher's class related to the topic of order of operations, and these observations demonstrated strong connections between Mr. Fisher’s beliefs and practices about teaching mathematics. He engaged students in mastering the order of operations principle with a rhythmic jingle.

MR. FISHER AND CLASS: Now .......the .....order of operations is a simple handy plan that will help me get the answers right just like I know I can.

First grouping symbols, exponents;

Then multiply divide,

Then add subtract from left to right. I'm finished.

Give me five! 
In two of the observed lessons, students presented solutions to order of operations

problems on the chalkboard. He would have them explain their reasoning and their steps

for solving a problem. If a student error was discovered in the problem, he would talk

through it with them until they understood his concern. Then, using his time wisely, he

would go to another student's problem presentation before returning to the first student,

giving him an opportunity to correct his work.

One time, I saw him allow a slightly unorthodox but valid approach to an order of

operations problem.

MR. FISHER: Gentlemen, please turn your attention to the people up at the board.

We're going to start with number 5 , Charlie.

(Problem 5 reads as follows: $0.5+1 / 2+0.25+1 / 4$.)

CHARLIE(repeats the problem): Zero and five-tenths plus one-half plus zero and twenty-five hundredths plus one-fourth...First I did this, I put zero and fifty

hundredths and one half is zero and five-tenths also. I added them together and get one whole. Then, I put twenty-five (hundredths) and one-fourth would have to equal twenty-five. So I added both of them together and it equaled 0 - point-five Then I added these two together and it equaled one and five tenths.

MR. FISHER: One and five tenths is exactly correct. Notice, gentlemen, that he did it a little differently than it states in the order of operations but it was still correct. He added the first two numbers and then the second two numbers and then added those two together, which is a little different from adding from left to right. Charlie, can you write your answer as a fraction? You have one and five tenths...(Charlie takes some time)

CHARLIE: One-half.

MR. FISHER: So you start with five over 10 and it reduces to one-half. Thank you very much -a perfect answer. You may erase your work and take a seat...Number four...por favor.

To further engage students in the mathematics topic, order of operations, he dressed up as a builder. Wearing a hat and an apron holding his tools, he told them a story of how forgetting to use the order of operations would lead to an unreasonable answer when calculating how much wall board was needed for the addition of a room in a home basement. 
By both observing his innovative ways of teaching and by talking with him on

several occasions, I concluded that Mr. Fisher was a reflective teacher. However, in our

final interview I was surprised by some of these reflections on his teaching this year.

RESEARCHER: Are you ready to be finished for this school year?

MR. FISHER: I'm more ready to be finished this year than I have ever been before. I gave a test the other day on things that we had covered this year. It was open book and they had two days to work on it and only 54 out of 129 students passed. RESEARCHER: What were you testing?

MR. FISHER: Operations with decimals and other standards topics we had covered recently. And of those 54 who passed, some just barely passed. Only 3 or 4 students had an A. This was not a difference in boys and girls, but was true of all my classes. ...I was always taught to teach with activities - "get your students engaged, get them working together and in groups, get them to explore.” But, I'm not so sure that mathematics is the proper stage for that approach.

RESEARCHER: Why do you think it's not working? What you're doing is what the research says to do.

MR. FISHER: It has worked with some groups. Some do well in that type of environment. But so many in my class this year are so weak Ask a student to subtract 12 minus 9 and or ask a student what 36 divided by 9 is and they can't do it. I had hoped that by engaging them with exciting activities and fun things that they would learn, but there such an overwhelming majority of students who are weak this year. I feel bad that I didn't see the problem sooner. Maybe I didn't want to see it. But I can't go back and teach these basics in class and the parents don't seem to be involved or able to help with this either. I have to move forward, teach the standards, and prepare them for the next level.

RESEARCHER: So what are you doing now?

MR. FISHER I'm using the textbook more now. I sent their books home with them for reference. I'm assigning homework five days a week.

RESEARCHER: Is it a longer assignment?

MR. FISHER: Yes, there are usually 20 or more problems instead of five. We go over many of them in class and we practice problems from the book instead of doing activities.

Thus, Mr. Fisher sensed a need for a shift in emphasis for his teaching. Research

suggested that the five strands of mathematics proficiency to be interwoven and should

be developed simultaneously. He sensed that his teaching had included too many

activities and not enough practice. Results of the analysis for his allocation of classroom

time, with $24 \%$ for group activities and $1 \%$ for practice, confirmed this imbalance. 
When responding to my question about his career in five years, he reiterated something he had told me in an earlier interview. When he completed his degree and began his career in teaching seven years before, he formed a career plan that would include a reevaluation after every five-year period.

MR. FISHER: So I taught for five years and it was exciting. I was enjoying it and feeling successful. I had just seen my first group of students grow up and move out, so I decided to keep going. I'm now finishing the second year of that next fiveyear period, so I have three more years before I reevaluate.

But at this point in time, he expressed professional concerns related to student apathy, as well as the fact that all of the accountability seemed to fall to schools and teachers and none to parents. Although he loved teaching and his father had just retired from a teaching career, Mr. Fisher also thought about difficulties of supporting his family on a teacher's income.

Julia Edwards. Ms. Edwards's teaching practices and goals reflected the Greenville Middle School motto, "Be successful forever.” I heard her use the word "successful" many times in her classroom, as she reminded the boys that she was there to guide them in their efforts and to help them achieve. “I don't give you grades, you earn them,” she told her students. But I'm here to help you be successful and I will help you in any way that I can.” Ms. Edwards had been teaching longer than any other teacher of the study. Her beliefs about teaching and learning mathematics were primarily nontraditional and corresponded to the primarily non-traditional, student-centered character of her practice. She spent $88 \%$ of her time on mathematics, with $26 \%$ devoted to group activities and 26\% to individual activities. I observed in her classes 94 total instances for the strands of conceptual understanding (54), strategic competence (11), and adaptive reasoning (29). 
Although she taught classes to both girls and boys, as well as a mixed honors class, she took a special interest in details about the way boys learn and had the study's highest score for using strategies identified for boys (234). She expressed some of the following thoughts to me about how boys learned:

MS. EDWARDS: Boys want to know when they are going to use it and how they are going to use it......With boys it's like a tool and they are building something; and they want to see how it works....I have guys who say, "I couldn't have done this without this" and "Oh, I get what you are saying and I see that it keeps on building...... Boys talk while they work and still keep working.

She spoke of boys' enjoyment of competition and observations of her class demonstrated frequent use of highly-organized and active board competitions. She said, however, that she did not usually use these board competitions in her all-girl classes and explained that her female students seemed to prefer working on white boards with a partner and not going to the board.

Ms. Edwards, more than any of the other teachers in the study, appeared to value and cultivate relationships with mathematics educators in universities. During my observation period, she had other visitors. One day when I was observing, a student teacher and another visitor from a university were also present in Ms. Edwards’s classroom. The boys were working on some practice problems, and she told them how fortunate they were to have four mathematics teachers there to help them. She demonstrated much interest in pedagogical strategies and in reaching each student. She asked me many times if I thought what she was doing was effective and was always interested in what I was learning in the study.

Two great strengths observed in Ms. Edwards’s teaching were her ability to connect with student thinking and her skill in using manipulatives to model key mathematics concepts. I observed her ability to connect with student thinking and heard 
her say, as she moved from student to student, "Not quite, but I'm glad you're thinking.” She then looked carefully at a student's work, reviewed his process along with him, and engaged in dialogue to correct any misunderstandings. She began the topic of solving linear equations with a lesson using a set of manipulatives called "Hands-On Equations.” The set included a mat with a picture of a balance scale drawn on it, objects with the appearance of the pawn chess piece representing variables, and dice with faces representing digits, operations, and parentheses. For example, the equation $x-5=8$ would be represented by one pawn and then dice on the left side of the scale and a die with its face turned to 8 on the other side.

The boys worked at their seats individually and used their pawns and dice to model the equation on their mats. They would then model the process of adding or subtracting the same thing from both sides to get the pawn by itself on one side. Finally, they would model the checking process by replacing a number for the pawn. By using the concrete materials, the students were able to physically experience the concept of adding or subtracting the same amount from both sides of equations, and thus, maintaining the balance required by the equal sign. After additional practice with the pawns and dice, Ms. Edwards had students set up their model and then symbolize their model on paper. Then, after several lessons, the students began to work exclusively with the symbols, to practice the new concepts.

Ms. Edwards exhibited a dedication to innovative teaching and a willingness to reflect continually on her practice. Three years before the study, she and the other teachers of the $7^{\text {th }}$ grade team asked the school's principal if they could try the singlegender classes as a way to improve male outcomes.

MS.EDWARDS: One of the things I do every night is I reflect on what I did in class, what I could have done differently to help the kids. I am not afraid to go in 
the next day and say, "We could do this better," and "Let's try this." So, that is what I did the first year, and I learned little techniques. There was not a lot of research for the single gender classes so we kept trying things and see if they worked. With the math grant and last summer's workshop, I was able to quite a few new activities that I have already used this year. We learned to work with manipulatives and other types of modeling. I have been thrilled with it. I think most good teachers want to do what is best for their kids so they are going to go and try to find things that are going to work for them.

Ms. Edwards was also involved as a leader in mathematics professional development at Greenville Middle School. Ms. Edwards served as a school leader for continuing professional development and planned monthly meetings for the teachers there.

When I asked her about changes she planned to implement next year, she thought mainly of student differences. The new students, both boys and girls, would be engaged and motivated by different topics. She also thought of getting to know her new students and making them feel more comfortable. Ms. Edwards shared with me that she was currently being sought for an administrative position but was uncertain about whether she should leave the classroom.

MS. EDWARDS: Some of me still wants to be in the classroom and some of me wants to try administration. Right now I am part of a team, but then I would be like a coach. Even so, we are still working together as a team for the good of our kids as we look for new ways to help them be successful.

Ms. Edwards had been teaching middle school mathematics for 15 years, and as the most experienced teacher of the study, her teaching was the most balanced between the five strands of proficiency. Observations of her classes produced 54 instances in which she emphasized conceptual understanding, 54 instances for procedural fluency, 29 instances for adaptive reasoning, and 68 instances emphasizing productive disposition. Instances for strategic competence were lower than other strands with 11 instances. This reminded me that, she may have been focusing more on certain procedures and needed more student encouragement about multiple ways to solve problems. Her allocation of 
classroom time also exhibited a balance between non-traditional and traditional teaching, with 25\% practice; 26\% individual activities; and 24\% of her time spent on group activities.

Christine Ingram. Ms. Ingram had been teaching at Bluefield Middle School for seven years and was a member of the $6^{\text {th }}$-grade team of teachers who piloted the gendered classes in the second semester of the 2001-2002 year. In the year of the study, each three-teacher team in 6th-grade was using single-gender classes and block scheduling. Ms. Ingram had a daily 90-minute block with each group of students and taught both mathematics and language arts. Although divided into three teams, the nine $6^{\text {th }}$-grade teachers formed a supportive sub-group, somewhat set apart from the others. They had lunch together every day in one of the sixth grade classrooms. Ms. Ingram reported that this was a good opportunity to "blow off some steam,” and that it had helped her group survive the past year's school and district problems.

For classroom management, she relied heavily on the newly-adopted CHAMPs program, with its specific rules and emphasis on modeling appropriate behaviors. Results of my classroom observations indicated that $21 \%$ of her class time was spent on management, and that she spoke of appropriate behaviors (32 instances) more frequently than she corrected inappropriate ones (8 instances). “Classroom management,” said Ms. Ingram, "is a crucial but very difficult part of teaching for me, especially with the more numerous behavior problems I've encountered this year.” She hoped that as she became more experienced with CHAMPs, classroom management would become easier. She also recalled that she had learned very little about classroom management in her university courses and suggested that teacher education programs include more work in this area, particularly for middle school preparation. 
Study results revealed that Ms. Ingram’s teaching beliefs, as well as her practices, were a blend of traditional and non-traditional teaching characteristics. On the traditional side, she spent $29 \%$ of her class time for teacher-led instruction, in which she demonstrated procedures and problem solutions. She frequently spent more than half of her 90-minute class on mathematics, spending the extra time reviewing more examples from the textbook. She felt a need to demonstrate solutions until there were no more questions or requests. This was perhaps more than necessary, as I heard students say, “Let’s us do some by ourselves now.” I saw boys who begin to work on other things and others who would close their eyes or put their heads on the desk. This extra time may have had more benefit to students if she had used it for student-centered work and activities.

She used the textbook as her primary authority, and lessons that I observed from this traditional textbook often used a procedural approach. Factorization was presented using a series of divisibility rules, such as, "A number is divisible by three if the sum of its digits is divisible by three.” The text also presented specific procedures for factoring such as T-charts, ladder diagrams, and factor trees. I also heard Ms. Jones in a $7^{\text {th }}$-grade class mention these same divisibility rules and factoring procedures.

Bluefield's school and community also demonstrated a philosophy for mathematics teaching that focused on procedures in recommending that teachers exclude certain factorization procedures from the curriculum.

MS. INGRAM: Ok, turn your spiral to your note section and we're going to look at factors and prime factorization today. Turn in your spiral to your note section. Now there's one thing I want you to do in your book today that I would never let you do otherwise. I want you to open your book to page 157. Is everybody there? DANNY: No.

MS. INGRAM: I want you to open your book to page 157...page 157, Paul....page 157, Danny...Now I want you to look at Example 2A. We're looking at factor trees. 
Now, I want you to take your pencil and very lightly put an "x" through Example 2A. We will not use factor trees.

STUDENTS: Why?...factor trees?...in the book?

MS. INGRAM: Put an x through...Excuse me, folks, example 2A...It's something you used in elementary school quite often. But I've been asked by the 7th and 8th grade teachers and by teachers from the high school that you not use factor trees anymore --that you use, instead, this is ladder diagram and that you factor by division. Really when we start talking about prime factorization it's a lot easier if we use that ladder diagram. So, right now everybody should have put a line through Example 2A in your book.

On the non-traditional side, however, I observed student-centered aspects of Ms.

Ingram's mathematical discourse as she engaged students in adaptive reasoning (29

instances) or directed students toward strategic competency (17 instances). "She always

shows us the short cuts and different ways for working the problem,” one student said.

The following three dialogues exemplify discourse on topics of factoring and fractions.

\section{Dialogue 1}

MS. INGRAM: Is 57 divisible by 3, James?

JAMES: No

MS. INGRAM: What's our rule about divisibility by 3 ?

JAMES: (interrupts) Oh, yeah, I guess it's not.

MS. INGRAM: What's our rule about divisibility by 3. Just because I ask another question doesn't mean you're wrong. What's our divisibility rule by 3 ? If it's divisible by 3 ,then....?

JAMES: When you add all the numbers together and three goes into that number. MS. INGRAM: So we add 5 and 7 together and what do we get?

STUDENTS(2-3 voices): Twelve

MS. INGRAM: Is that divisible by 3 ?

STUDENTS (2-3 voices): Yes...No....Yes

MS. INGRAM: Yes it is divisible by three. How many times does three go into 57?

STUDENTS: (2-3 voices) 19

(There's lots of answering out and they go through additional trials of divisibility rules until they determine that 19 is prime.)

DWAYNE: I got a question. You said 19 can't be divided because it's a odd number, but 57's an odd number, too.

MS. INGRAM: No, remember what we said it's not divisible by 2 because it's an odd number, but it doesn't mean that it can't be divided by other numbers.

Dialogue 2

MS. INGRAM: You should be dividing these (pattern blocks) into color groups. What does the yellow piece represent according to the key at the top of the page? STUDENTS (2 to 4 voices each): one whole...one-half 
MS. INGRAM: Thank you for your hands. Remember that you raise your hands; that's a part of our activity guidelines. What did you say it represented?

STUDENTS (2 to 4 voices each): one whole...one-half

MS. INGRAM: A whole? No, a half. It takes two of them to represent a whole and one represents a half. What about the red pieces?

STUDENTS: one-fourth (2 voices)

MS. INGRAM: One-fourth. Raise your hands, guys. Matt, what'd you say?

MATT: One-fourth.

MS. INGRAM: And how can you check to make sure that' it's going to represent one-fourth?

MATT: Add two on top of the half and then it fits.

MS. INGRAM: Thank you. If you've got the yellow that represents one-half and you can put two of those pieces on top of that one half. Why can you do that?

DOUG: Because it's half of the half.

MS. INGRAM: Because it's a half of the half, and a half of a half is ...?

DOUG: One-fourth

MS. INGRAM: One-fourth and it takes how many fourths to make a half?

HANK: one...two-fourths.

MS. INGRAM: So look at your pieces. This one represents one-half, and these represents one-fourth. Of course you automatically know that two of those onefourths is going to equal a one-half.

\section{Dialogue 3}

JAMES: Wesley drinks 2/13 gallons of juice a day. Find the answer for the amount he drinks in five days. I did 5 over 1 and 2 over 13.

MS. INGRAM: This actually ......what they probably wanted you to do was to add $2 / 13$ together 5 times. Isn't that just repeated addition? ...and what's repeated addition?

STUDENTS (1 or 2 voices): Multiplication.

MS. INGRAM: Multiplication. So there is absolutely nothing wrong with the way you solved it. What did you get, James?

JAMES: 10 over 13.

MS. INGRAM: So you can either do multiplication, or you could have solved it through repeated addition, because we have five days. Here's day 1, day 2, day 3, and day 5 . Because we have that common denominator, what are we going to add...the numerators, 2 plus two...You get the same answer but you can solve it either way. Remember what I've told you. Use the way you're comfortable with as long as that way gives you the right solution every time.

These examples illustrate that in her discourse with students, there was also a mix of non-traditional and traditional teaching. She spoke of strategies and concepts, yet her dialogue was interspersed with rules and procedures. The strong influence of her traditional textbook may have deprived her of opportunities to promote number sense (e.g. comparing 10/13 with a whole number.) By developing lessons using more non- 
traditional, educative curriculum materials, she could have built her skills and expertise in the area of mathematical discourse. Ms. Ingram was an innovative teacher in that she liked to use a variety of teaching tools. I observed classes in which she used pattern blocks or took students to the computer lab to work with Understanding Mathematics (Neufeld, 2002). "I enjoy attending workshops and gather new ideas for teaching," she said. When asked about he career plans, she said that she enjoyed teaching and planned to remain in the classroom. For the upcoming summer break, she eagerly anticipated a workshop for mathematics teachers at a nearby university.

Melanie Jones. Ms. Jones had been teaching mathematics at Bluefield Middle School for four years and had previously taught high school mathematics for four years in another city. When I first spoke with her about participating in the study, she expressed approval for the single-gender classes at Bluefield. She had taught sixth grade the year before the school instituted the single-gender classes and moved to 7th grade the following year, teaching the same students for two years in a row. "I don't think it was just the maturity level," she said about the changes she observed in her students. "It was also the new environment which has made a difference for these students.”

However, I later understood that when Ms. Jones spoke of benefits of singlegender classes, she was thinking mainly about girls. Her purposes and goals for the gendered classes reflected those identified by teachers, administrators, and parents who wanted to separate girls from boys to decrease exposure to sexual interactions and behavior problems. Ms. Jones also expressed doubts about benefits of the single-gender classes for the boys and she said, “I don't know if I'm accomplishing more with the boys.” Ms. Jones also expressed the belief that, due to equity issues, she should teach the boys and girls classes the same way. Accordingly, Ms. Jones used the strategies, 
identified in the study as compatible with boys' ways of learning, less frequently than the other five teachers (46 instances, as opposed to over 200 instances for Mr. Fisher and Ms. Edwards).

Unlike Ms. Ingram, who more frequently modeled behavior, much of Ms. Jones’s management time, totaling 26\%, was spent correcting behavior (40 instances). She also tried to reason with boys about their behaviors and thought aloud about why she should perhaps be less permissive.

MS. JONES: Excuse me guys, we have had constant conversation, (phone rings) and I need you to stop so that I can answer this... (They talk some while she's on the phone. Some laugh and some say "Sh-h-h!” to others. She hangs up). That was far from silent....Shawn! ....(Shawn has tied his shoe laces together and the others are laughing loudly)... Gentlemen, if you had used your time wisely, you could have done half the homework. Guys, wait, maybe it's been my fault, because I have been too nice. I am tired of the talking. I still have people talking; I don't even want you whispering -- nothing! ....Gentlemen, the room does not sound any better. And I was trying to give you a break by not giving you homework on a game night. Maybe I shouldn't do that anymore.

On several occasions, I heard her use extra homework as a threat for bad behavior, and students reported that she had, on occasion, used less homework as a reward for good behavior.

ANDREW: We talk a lot in math class. RESEARCHER: Do you talk about math? MAX: Not really. We talk about other things.

ANDREW: Unless we don't want homework. Then we'll be quiet and she'll usually take it away. But that doesn't happen very often.

As far as teaching style, Ms. Jones was rated the most traditional of all of the teachers. She devoted large portions of classroom time to teacher-led demonstrations (34\%) and practice (19\%). Total instances, in which she taught for conceptual understanding (13), strategic competence (4), and adaptive reasoning (6), were the lowest of all the other teachers. She usually began class each day by reading the agenda, the date in Spanish, and the word of the day and by placing a list of answers for the homework 
problems on the overhead. While the students checked their answers, she would circulate and check to make sure that homework was done. She would then ask for numbers from the homework that the students would like to see worked out. Ms. Jones upheld her traditional textbooks (Bennett et al., 2004; Malloy, et al., 2005) as the sole authority for her teaching and also used provided companion materials, such as tests, worksheets, a video quiz, and electronic lesson presentations on Power Point.

The eight observations for the study included four in Ms. Jones’s $6^{\text {th }}$ period regular all-boy class and four in her $7^{\text {th }}$ period all-boy honors class. In the honors class, Ms. Jones used a different textbook, entitled "Pre-Algebra” (Malloy, et al., 2005). In her regular classes that I observed, she covered the topics of integers and rational numbers, and in the honors classes, she covered positive and negative exponents. Two additional activities that she included for her $7^{\text {th }}$-period honors class were a video quiz competition and a problem-solving competition activity from a regional mathematics league. Time allocations for the two classes were also somewhat different. In honors, she devoted $47 \%$ of the time to teacher-centered activities (principally demonstrations of problem solutions) and $0 \%$ to practice (See Appendix $\mathrm{H}$ for time allocation details.), whereas in the regular class, $20 \%$ of the time was devoted to teacher-led activities and $38 \%$ to practice. In speaking of her honors class Ms. Jones expressed the following thoughts:

MS. JONES: With them, I think probably part of the reason that they have been identified for being in honors classes is that they probably learn in the way that schools have traditionally taught and receive the information as it is traditionally presented. So, they learn very easily from a lecture style. All you have to do is show them an example and explain something, and they pretty much can do it. They may have a few questions as to "what ifs," but for the most part, they catch on.

These descriptions of how boys in the honors class learned were confirmed by several boys in interviews, and students interviewed said that they expected this type of learning in mathematics class. 
The teaching of both the honors and regular class possessed a predominance of traditional characteristics of teacher-led demonstrations of procedures. She tried to reason with boys about their behaviors, and her classes were mainly in lecture format, either presenting new material or demonstrating solutions to particular problems. She knew the mathematics and presented clear and correct explanations for problems on the chalkboard, but students were frequently not engaged. In the honors class, the boys focused primarily on getting their homework done. If the teacher was willing to work problems for them, they would sometimes continue to ask. Several boys said that the work was easy or that they had covered the same topics last year.

Ms. Jones's regular class was smaller, having only 11 students as compared with 26 boys in the honors class. Ms. Jones's beliefs questionnaire reported that her beliefs about teaching and learning mathematics possessed an even mix of traditional and nontraditional characteristics. When I asked her to confirm beliefs about traditional and nontraditional teaching, she said that she valued non-traditional teaching methods, including hands-on materials and discovery learning, but the "combination of behaviors present” in her all-boy classes made teaching this way difficult. When asked about her future, Ms. Jones expressed the desire to move into school administration and to be an assistant principal in a middle school. Several years before, she had returned to a university near Bluefield to study educational administration and had recently obtained a master’s degree.

\section{School Achievement Data}

The following sections report on mathematics achievement data by gender from 2002 to 2004 for the three schools of the study. Because the focus of the current study was mathematics learning for middle school boys, the main outcomes considered were 
those for boys and those concerning their achievement levels in mathematics. Although it would be difficult to make direct connections, a comparison of scores from 2002 with 2004 provides somewhat of a before and after look at the single-gender experiments in the three schools. With the exception of Bluefield whose $8^{\text {th }}$-grade students remained in coed classes, all three schools began their single-gender class experiment on a schoolwide basis by the fall of 2003. Bluefield had piloted the program in sixth grade one previous semester, and Greenville piloted their program in 7th grade for the 2002-2003 year. For each school, information on other relevant changes such as failure rates, number of suspensions and referrals, was gathered from administrators and is also reported.

Achievement data considered in this study came from published school reports, and focus on school progress rather than track achievement for individual students. Furthermore, in the two states, students were not tested in every subject every year. For these reasons, scores for 2002 and 2004 only were compared to look generally at changes for the period after the gendered classes were instituted at the three schools. As mentioned previously, the three schools of the study instituted the gendered classes to improve a variety of school outcomes. Targeted areas for improvement included test scores, grades, behavior, or school environment.

\section{Terre Rouge Middle School}

Before making the change to single-gender classes in the fall of 2002, Terre Rouge Middle School was the lowest scoring middle school in the state. Hence, an increase in test scores was the primary goal for teachers and administrators there, and they adopted gendered classes among other interventions as part of a school improvement plan. With the change to the single-gender teams and classes, the faculty also sought to 
improve behavior and reduce interactions of a sexual nature between boys and girls. At Terre Rouge, a large portion of the students still tested in the Novice category, so a major challenge was to move students out of the Novice category to the Apprentice category or above.

From 2002 to 2004, test scores increased overall at Terre Rouge, and males made some of the largest gains. In the state where Terre Rouge was located, the yearly accountability exam tested $8^{\text {th }}$-grade students in mathematics and social studies and $7^{\text {th }}$ grade students in science, reading, and writing. At Terre Rouge, $8^{\text {th }}$-grade mathematics scores for boys in 2002 were 32\% in the Apprentice or above category, and in 2004, $43 \%$ of the boys tested at the apprentice or above level, whereas for $8^{\text {th }}$-grade girls, the percent scoring in the same category decreased by $1 \%$, from $32 \%$ to $31 \%$. Figure $4-2$ represents the percent, by gender, of students at Terre Rouge who scored at the Apprentice level or above on the state achievement test.

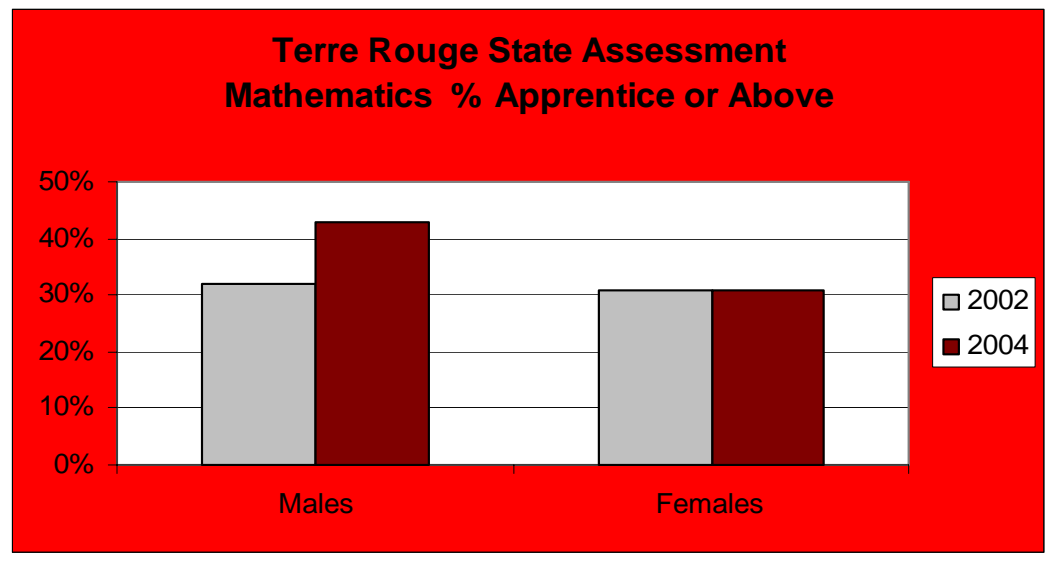

Figure 4-2. Terre Rouge: Percent of Students Scoring Apprentice or Above

Although still remaining quite low when compared with other schools, the percent of students testing at the proficient level or above also rose at Terre Rouge, and again, 
males increased their numbers in the proficient category more than females. Figure 4-3 presents comparisons for males and females for the percent of students testing at the Proficient level or above in mathematics. In 2004 13\% of the boys tested at the proficient level or above in mathematics and that was up from $2 \%$ in 2002. For the girls the percent proficient increased from $3 \%$ to $7 \%$ over that period.

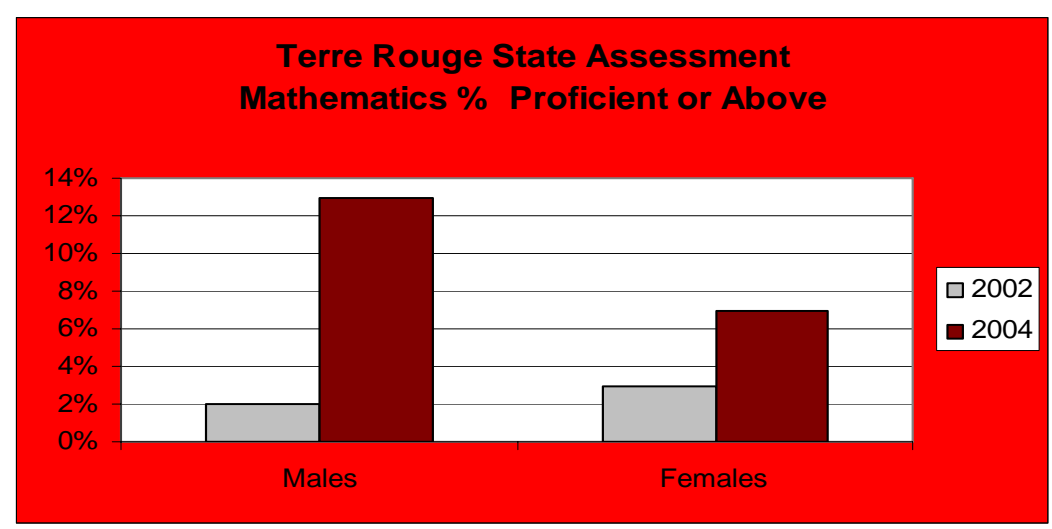

Figure 4-3. Terre Rouge: Percent of Students Scoring Proficient or Above

For 2003 testing at Terre Rouge, males also experienced greater gains in test scores than did females. The academic progress for an all-boy team called the "Dreambuilders" was largely responsible for these increases for males. I studied the Dreambuilders in the pilot year for the gendered classes at Terre Rouge (Davis et al., 2004). The boys on the Dreambuilders team were tested in reading and science in 7th grade and tested in mathematics and social studies in eighth grade. They were led by three of the same teachers for both their $7^{\text {th }}$-grade and $8^{\text {th }}$-grade years. Study results attributed test score gains to factors such as cohesive leadership of the all-boy team, mentorship for individual students, and tailoring instruction to meet boys' learning needs (Davis, et al., 2004). Figure 4-4 details gains for the percent of boys testing at the Apprentice level or above in science, reading, mathematics, and social studies, comparing 
scores of boys from the Dreambuilders team with the $7^{\text {th }}$ and $8^{\text {th }}$ grade students of 2002, the year before the change to gendered classes. These data suggest that the way the teachers tailored teaching for their students on their all-boy team may have affected testing outcomes.

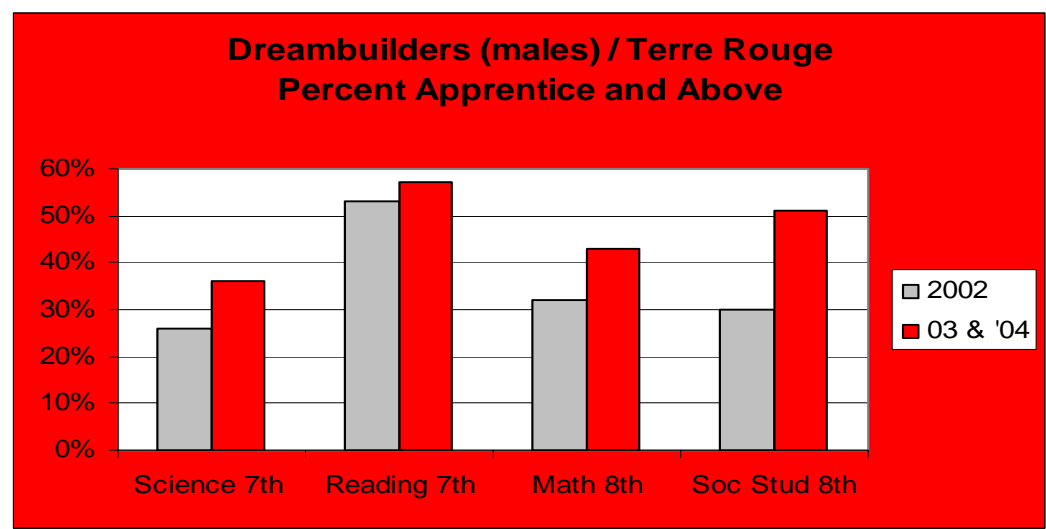

Figure 4-4. Terre Rouge: Comparative Scores for Boys on Dreambuilders Team

Terre Rouge Middle School, along with other schools in the state, used a normreferenced test to assess progress of its $6^{\text {th }}$-grade students in the areas of reading, language, and mathematics. Figure 4-5 reports percentile ranks for scores on this normreferenced test in mathematics for 2002, 2003, and 2004. Average percentile ranks for both boys and girls at Terre Rouge increased over this period, with girls showing the greatest increase. Percentile ranks for girls on the $6^{\text {th }}$ grade norm-referenced assessment increased from $19 \%$ in 2002, to $22 \%$ in 2003, and $28 \%$ in 2004. For boys, percentile ranks did not increase from 2002 to 2003, remaining at 18\%. However, in 2004, percentile ranks rose from $18 \%$ to $21 \%$. Both Ms. Alcott and Mr. Blake had taught 6thgrade boys in 2003-2004, and they attributed these gains to smaller classes and the opportunity to give students more individual attention. 
Both males and females experienced gains in mathematics on the norm-referenced assessment given to all students in the state at the end of $6^{\text {th }}$ grade. Scores for girls increased more than scores for boys. Mr. Blake and Ms. Alcott had taught in $6^{\text {th }}$ grade at Terre Rouge for 2003-2004, and both Ms. Alcott and Mr. Blake, as well as other teachers, expressed the view that the smaller classes and longer class periods may have contributed to these increases. In 2003-04, the 6th-grade teachers had increased opportunities for giving students individual attention and increased time for computer or hands-on activities.

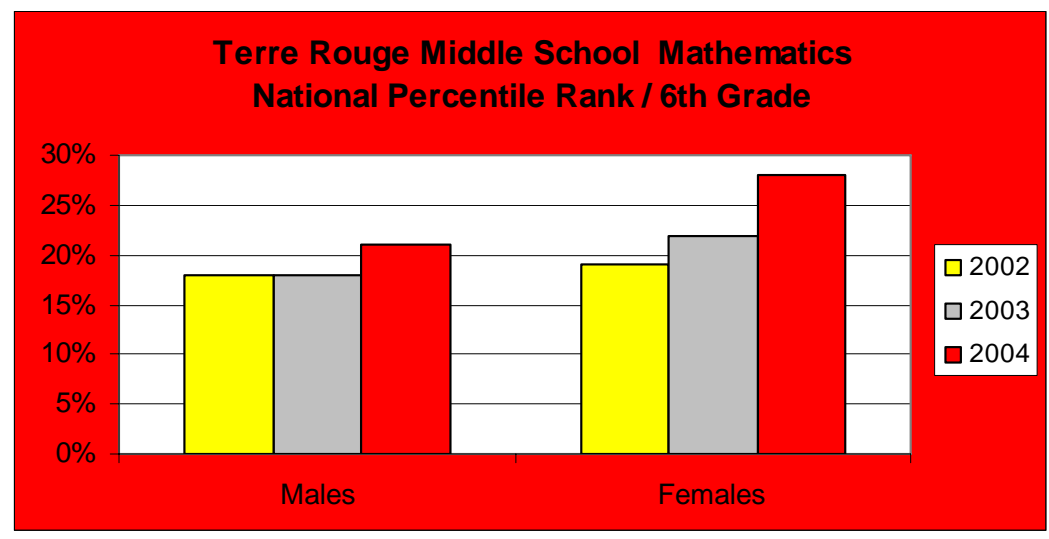

Figure 4-5. Terre Rouge: 6th-Grade Scores for Norm-Referenced Test

At Terre Rouge, faculty and administrators were pleased with the school's overall test score gains over these first two years of the gendered class experiment. They attributed them to many factors, including a new literacy program, test-taking practice, and single-gender classes. Dr. Alice Russell, principal at Terre Rouge, also reported that suspensions, referrals, and retention rates had improved overall since 2002.

Improvements for boys may be related to particular teachers and team leaders who were able to engage and motivate their students. 


\section{Greenville Middle School}

The faculty and administration of Greenville Middle School considered a singlegender class program for their school in response concerns about males lagging behind females in passing rates for all classes and for the state accountability tests. Figure 4-6 follows the decreases in failure rates of the 2004-05 $8^{\text {th }}$ grade students over a three-year period in single-gender classes, and Figure 4-7 provides similar information for the students in 7th grade.

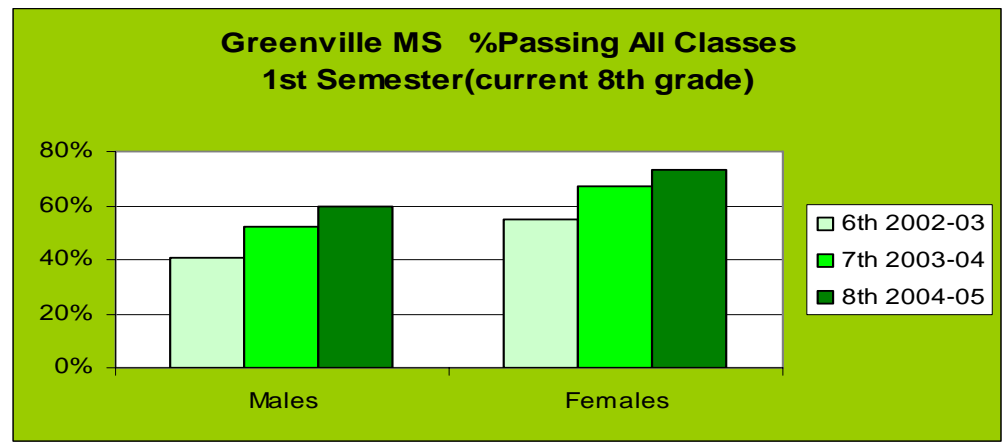

Figure 4-6. Greenville: Percent of Students Passing All Classes (current $8^{\text {th }}$ grade)

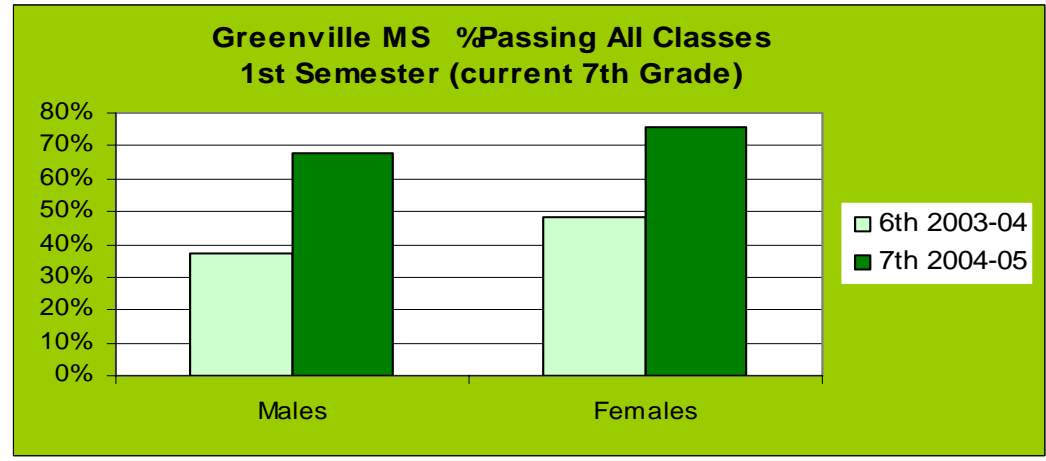

Figure 4-7. Greenville: Percent of Students Passing All Classes (current $7^{\text {th }}$ grade)

Teachers and administrators expressed satisfaction about the progress that had been made to increase the number of both boys and girls who passed all of their classes. 
There were also decreases in the number of referrals and out-of-school suspensions, and Mr. Ted Lewis, the assistant principal in charge of discipline, attributed these improvements to the single-gender classes and to some "tightening-up" in rule enforcement. Teachers reported fewer discipline problems in their classrooms, due to the removal of boy/girl interactions.

Another goal for separating the boys and the girls in middle school at Greenville was to improve performance on the state accountability assessment for both genders. Located in a different state than Terre Rouge and Bluefield, Greenville's state test was given in the fall and used the benchmarks of "pass" or "fail" on tests of content standards in mathematics and language arts. Figure 4-8 presents comparative mathematics pass rates for males and females, as well as overall pass rates for both subject areas.

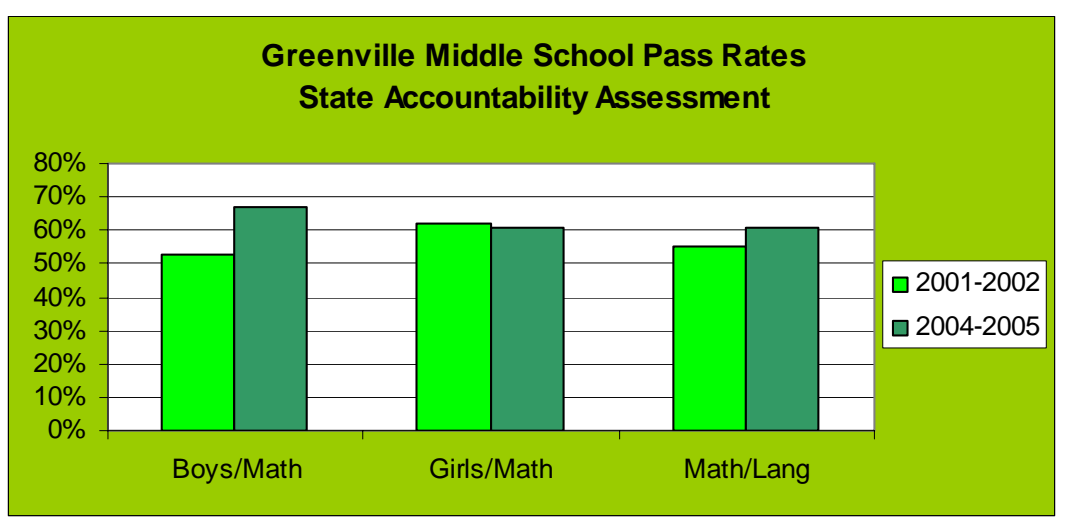

Figure 4-8. Greenville: Pass Rates for State Accountability Assessment

Although until recently students were only tested in $6^{\text {th }}$ and $8^{\text {th }}$ grades, they are now tested every year. Hence scores for 2001-2002 include combined percentages for only $6^{\text {th }}$ - and $8^{\text {th }}$-grade students, and scores for 2004-2005, given in the fall of 2004, are for $6^{\text {th }}, 7^{\text {th }}$, and $8^{\text {th }}$ graders. Over this period Greenville boys increased their pass rates in 
mathematics from 53\% to $67 \%$, whereas girls’ pass rates in mathematics decreased slightly from $62 \%$ in $2001-2002$ to $61 \%$ in $2004-2005$.

On the state assessment exams, teachers and administrators had expected gains for girls as well as boys. More boys were now passing all their classes, but so were more girls. However on the standardized tests, the girl's mathematics scores girls did not improve over this period. In the 1990's separating girls from boys was a frequently suggested intervention for improving girls’ performances in mathematics (Riordan, 1990; Sadker \& Sadker, 1994). In follow-up interviews with Ms. Glover and Ms. Edwards, both expressed concern about the increases only for boys and spoke of efforts to improve girls' scores in mathematics in the future.

Bluefield Middle School

Approximately four years before the study, Bluefield Middle School began thinking of the gendered classes for their school for the purpose of separating boys and girls in hallways and classrooms. In $6^{\text {th }}$ grade that year, several incidents of inappropriate behavior of a genderual nature by boys to girls were reported. Additional research by administrators, parents, and the SBDM committee suggested other possible benefits of the single-gender classes, such as opportunities for gender-specific teaching and higher achievement. Figure 4-9 compares percents by gender of students scoring at the Apprentice level or above on the state assessment. In comparing 2002 scores with 2004 scores at Bluefield both males and females decreased, with scores for females decreasing by a larger amount. For males, the number of students scoring at the apprentice or above level decreased by only $1 \%$ to $62 \%$ from $63 \%$ in 2002 . For girls, the scores decreased from $74 \%$ apprentice or above to $65 \%$ testing at this level. It was important to note that these scores were from two different groups of $8^{\text {th }}$ grade students who were not in single- 
gender classes for this $8^{\text {th }}$-grade year. It is also important to note, when considering these scores, that Bluefield was a school of two separate programs.

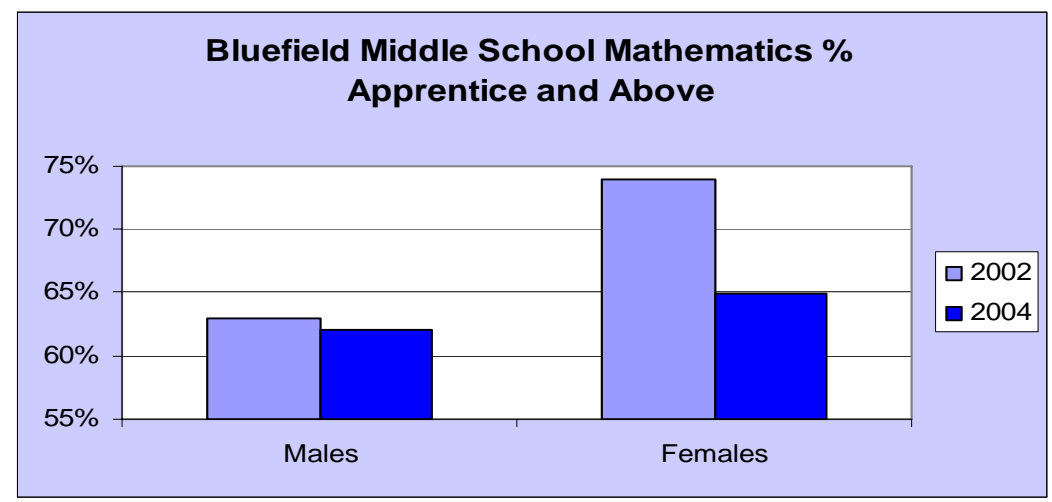

Figure 4-9. Bluefield: Percent of Students Scoring Apprentice or Above

When I asked Ms. Baxter about the scores, her thoughts went to the class of girls that were in $8^{\text {th }}$ grade in 2002. "They were hard workers and just a very bright group of girls,” she said. Figure 4-10 represents changes in percentages for students ranked as "Proficient" in mathematics. The percent of boys testing at the proficient level increased from $28 \%$ to $34 \%$ over this period, but the percent of girls testing at the proficient level decreased from $34 \%$ to $29 \%$.

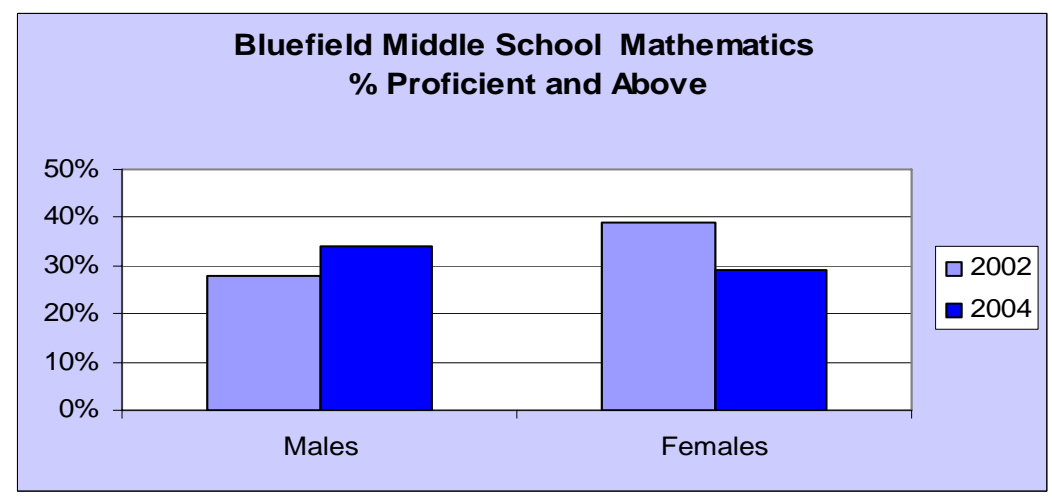

Figure 4-10. Bluefield: Percent of Students Scoring Proficient or Above 
Bluefield and Terre Rouge are in the same state, and the 6th-grade students at Bluefield also took the same norm referenced test in $6^{\text {th }}$ grade. Figure 4-11 compares boys and girls at Bluefield on this norm-referenced assessment in mathematics.

Performance improved for $6^{\text {th }}$ grade girls at Bluefield, but not for $6^{\text {th }}$-grade boys over this three-year period.

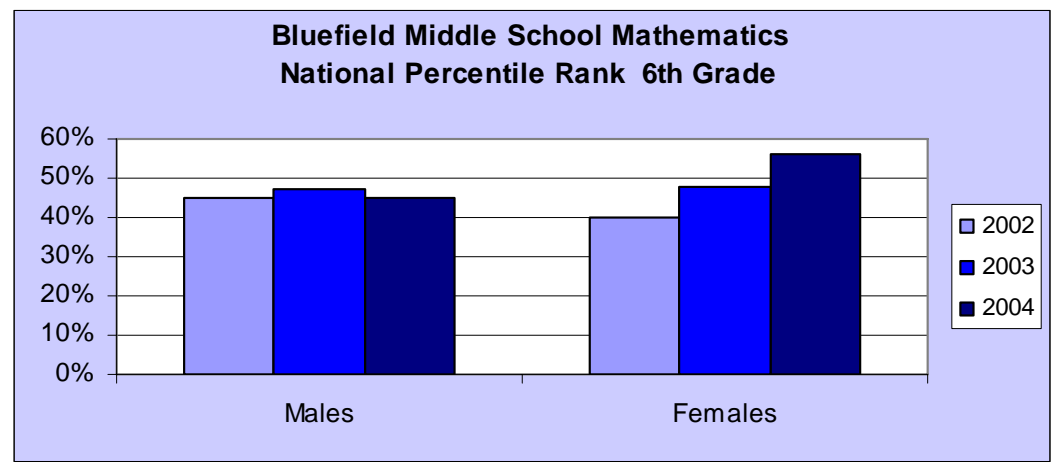

Figure 4-11. Bluefield: 6th-grade Percentile Ranks on the Norm-Referenced Test

\section{Overall Comparisons of Achievement Scores}

Figure 4-12 compares percentages by gender of students, at the three schools of the study, who scored at the proficient level (or pass level) for the state achievement.

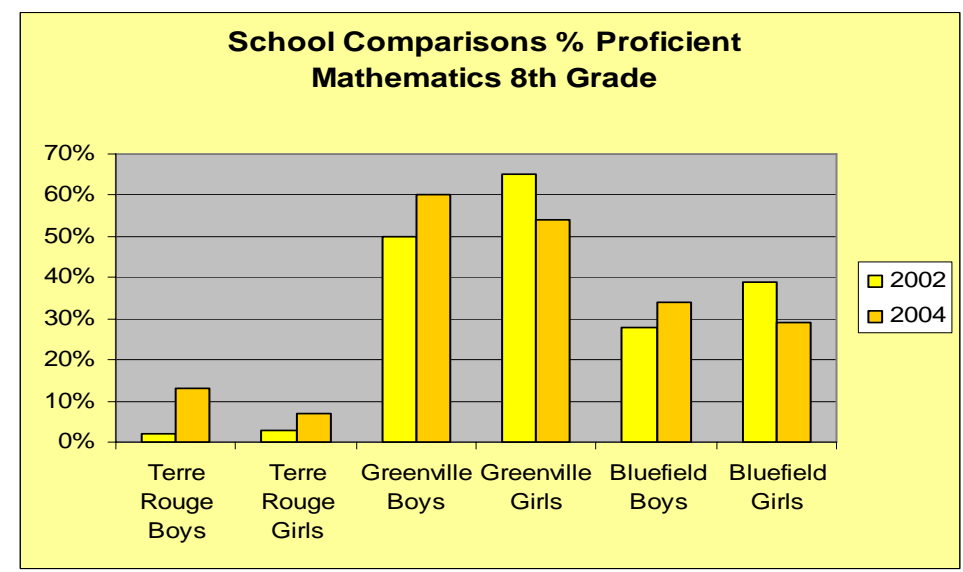

Figure 4-12. School Comparisons: $8^{\text {th }}$ Graders Testing at Proficient (or Passing) Level 
Greenville was in a different state from Bluefield and Terre Rouge, and their state accountability exam rated schools by the percent of students who passed the state assessment in the areas of mathematics and language arts. Figure 4-12 comparisons include only $8^{\text {th }}$ grade students, a class that tested in 2002 and another class in 2004. Table 4-18 represents the same information as Figure 4-12.

Table 4-18

School Comparisons: $8^{\text {th }}$ Graders Testing at Proficient (Passing) Level in Mathematics

\begin{tabular}{|l|c|c|}
\hline & 2002 & 2004 \\
\hline Terre Rouge Boys & $2 \%$ & $13 \%$ \\
\hline Terre Rouge Girls & $3 \%$ & $7 \%$ \\
\hline Greenville Boys & $50 \%$ & $60 \%$ \\
\hline Greenville Girls & $65 \%$ & $54 \%$ \\
\hline Bluefield Boys & $28 \%$ & $34 \%$ \\
\hline Bluefield Girls & $39 \%$ & $29 \%$ \\
\hline
\end{tabular}

At Terre Rouge, both boys and girls improved over this period, but the boys improved more than the girls. Scores at Terre Rouge were lower than the other two schools of the study. Of all three schools, the largest portion of students at Greenville Middle School scored at the proficient (or pass) level in mathematics. Even so, over the time period of the single-gender classes, scores for the boys rose and scores for the girls fell. Bluefield's scores generally fell between those of the other two schools. Greenville is in a different state from Bluefield and Terre Rouge, and their state accountability exam rates schools by the percent of students who pass the state assessment in the areas of mathematics and language arts. Figure 4-12 and Table 4-18 comparisons include only $8^{\text {th }}$ grade students, a class that tested in 2002 and another class in 2004. 


\section{CHAPTER V}

\section{SUMMARIES AND IMPLICATIONS}

What happens when three public middle schools experiment with single-gender education to improve a specified set of outcomes? This investigation focused on six mathematics teachers of all-boy classes, a $6^{\text {th }}$-grade teacher and a $7^{\text {th }}$-grade teacher at each school. In 2002, I began studying single-gender education in an urban middle school having the state's lowest test scores. Educators there had voted unanimously to adopt a gendered class program as part of an improvement plan. Contrary to other studies of single-gender experiments (Baker, 2002; Herr \& Arms, 2002), test scores increases were greatest for males, and findings indicated that strategies teachers were using in their all-boy classes may have contributed to these increases (Davis, Choi, Ronau, \& Munoz, 2004).

Before conducting the current study, I concluded, as have other researchers (AAUW, 1998; Mael, 1998), that general comparisons between single-gender and coeducation are problematic. The myriad of educational contexts, purposes, and venues (public, private, religious, preparatory, elementary, or secondary) often produce confounding background factors and research yielding conflicting results. Thus, for my dissertation, I decided against forms of the question. "Is single-gender education more effective than coeducation?” I chose instead to study three middle schools that had recently adopted single-gender class programs. Investigations focused on school factors, 
teacher characteristics, mathematics teaching, as well as structures and strategies used by mathematics teachers in all-boy classes. Chapter 4 of this study provided details of how these three schools and six teachers implemented their single-gender programs. Chapter 5 summarizes findings; explores implications of the results, both for middle schools leaders and mathematics teachers; and identifies avenues of future study.

\section{An Abbreviated Review of Literature}

The purpose of this dissertation study was to conduct investigations of mathematics teachers in middle schools experimenting with single-gender classes. Because a broad range of factors present in a school can affect implementation of an educational change, such as a single-gender program, the following review of literature examines several different lines of research. Study results then demonstrate how these seemingly distinct topics connect as they affect the complex processes of teaching early adolescents in public schools.

\section{Single-Gender Education}

Sociologist Cornelius Riordan (1990) noted that, originally, public schools may have favored coeducation over single-gender education for economic reasons and not because of fairness or quality. With the 1972 passage of Title IX legislation banning sex discrimination in federally funded education, the number of single-gender schools in both the public and private sector, began to decline (Salomone, 2003). In the early nineties, evidence emerged suggesting that public schools might be failing to provide girls with equitable learning opportunities, especially in science and mathematics (AAUW, 1992; 1998; Sadker \& Sadker, 1994). These concerns raised questions about whether equity in programming always produced equitable outcomes and whether single-gender schooling should be an option in public education. 
To address low achievement and other school issues, public school educators have begun to reconsider single-gender programs and to experiment with different models. In 1991, the Detroit School Board, motivated by concern about dropout and failure rates for African-American males, established three all-male academies. In 1996, the Young Women’s Leadership School (TYWLS) opened in East Harlem to provide a better educational choice for minority and poor girls. In spite of legal challenges based on equity issues and Title IX, interest in single-gender education in the public sector has continued to grow. There are now over 100 public schools in the U.S. which offer singlegender options, up from four schools in 1996 (Murray, 2003). Even so, results of recent single-gender experiments in public education revealed that schools were merely separating boys and girls and that most teachers did not tailor instruction for their gendered classes (Datnow, Hubbard, and Conchas, 2001;Baker, 2002; Herr \& Arms, 2002).

\section{Effective Schooling}

The research on effective schools began in reaction to the Coleman Report (1966), which proposed that schools had little or no effect on academic achievement independent of background factors. Contrarily, further investigations suggested that the impact of schooling on achievement had been underestimated due to the selection of language competence, which was highly influenced by background factors, as the dependent variable (Marzano, 2003). Subsequent researchers used test scores in other subject areas, such as mathematics, and found that some schools had better achievement outcomes even when background factors were similar (Brookover, Beady, Flood, Schweitzer, \& Wisenbaker, 1979; Good \& Brophy,1986; Marzano, 2003). Qualitative studies revealed that characteristics of high-achieving schools differed greatly from 
school to school making results difficult to generalize (Good \& Brophy, 1986). Even so, research suggests that when teachers, principals, and students believe that they can make a difference for their students, then improved outcomes result from acting on that belief (Good \& Brophy, 1982; Marzano, 2003).

Teacher Efficacy and Collective Teacher Efficacy

Research suggests that a teacher's beliefs about his or her own competence may account for individual differences in student achievement (Ashton \& Webb, 1982; Riggs \& Enochs, 1990). A teacher who possesses a high degree of efficacy will experiment more with teaching strategies, plan more thoroughly, and persist longer to help students (Henson, Krogan, \& Vacha-Haase, 2001). Collective teacher efficacy combines beliefs of educators in a school about their ability as a faculty unit to educate their students and can have effects on achievement, even when controlling for prior achievement, ethnicity, and SES (Goddard, Hoy, \& Hoy, 2000). Collective efficacy assessments can be elevated by successful experiences, professional development opportunities, or a group initiative relating to a particular plan for improvement (Goddard, Hoy, \& Hoy, 2004).

\section{Middle School Structures}

A reform movement for middle schools arose in the late 1980's from beliefs among educators, researchers, and psychologists that schools for early adolescents should not employ high school models. Middle school reform characteristics include interdisciplinary teams, teacher mentoring, and non-traditional approaches to learning (Hoy \& Hannum, 1997; Beane \& Brodhagen, 2001). Research in middle school supports a belief that program implementation is a primary issue for successful reform (Felner \& Jackson, 1997). In middle school, a strong relationship also exists between classroom management and academic performance, with behavior management being 
particularly important for middle school boys (Hudley, 1998; Woody, 2002; Davis, et al., 2004).

\section{Teaching and Learning of Mathematics}

Results of the Third International Mathematics and Science Study (TIMSS, 1995) indicated that U. S. middle school students were performing below the mean for industrialized nations. Subsequently, a report from the U.S. Department of Education (Riley, 1997) recommended advanced courses in mathematics, particularly algebra, for all students in secondary school. Furthermore, the report identified students who take advanced mathematics courses in middle school as much more likely to enroll in advanced mathematics and science courses in high school, and in turn, students who study advanced mathematics and science in high school are more likely to graduate from high school and college (Riley, 1997).

Standards-based reform. In the early 1980's, before TIMSS or the Riley Report, mathematics educators questioned whether students were learning the mathematics they needed to know (Ball, Lubienski, \& Mewborn, 2001). To adapt to a rapidly changing and high-tech world, educators and business leaders agreed that American students needed to understand and do mathematics for real life situations, as well as the workplace (Bandlow, 2001). To address these concerns, the National Council for the Teachers of Mathematics (NCTM) published Curriculum and Evaluation Standards for School Mathematics (1989), which marked beginnings of a reform movement. The 1989 Standards stressed the importance of high expectations and conceptual understanding and advocated non-traditional methods, such as group work, the use of concrete materials, and teaching with technology. 
Traditional vs. non-traditional teaching. A traditional mathematics learning environment is usually teacher-centered, one in which students passively receive knowledge. Teachers demonstrate procedures and problem solutions, asking questions for which a particular answer is expected. The practice of skills and procedures holds an important position in the traditional mathematics classroom. Non-traditional teaching approaches are primarily student centered. In non-traditional classroom environments, students have opportunities to work in groups, to participate in hands-on activities, and to share mathematical ideas with teachers and other students.

Revised standards and teaching for mathematics proficiency. Several years after the 1989 NCTM Standards were published, mathematics educators raised concerns basic skills and practice were not receiving proper emphasis, and disagreements arose about how mathematics should be taught. In 2000, NCTM published a set of revised standards that placed increased emphasis on skills and practice, including phrases like "compute fluently" and "work flexibly." About the same time that NCTM published its revised standards, the National Research Council published a report, Adding It Up: Helping Children Learn Mathematics, (Kilpatrick, Swafford, \& Findell, 2001). According to the report, doing challenging and important mathematics requires an understanding of concepts, fluency in performing skills - and much more. Authors framed a model for proficiency based on five interconnected strands: conceptual understanding; procedural fluency; strategic competence, adaptive reasoning and productive disposition (Kilpatrick, et al., 2001).

Rationale for the Study

I undertook this study to contribute to knowledge in the areas of single-gender education, middle school, mathematics learning, and teaching boys. Additionally, I hope 
that results of this study can be beneficial to middle school boys by providing information and research perspectives to administrators and teachers who are implementing a gendered class program in efforts to improve student outcomes. Single-gender education in public schools is still a new area of inquiry in educational research. A study of single-gender schooling is timely because of widespread experimentation and 2004 legislation relaxing Title IX restrictions on separating males and females for educational purposes. Research in middle schools also seemed appropriate because of evidence that successful implementation of middle school principles, such as teaming and mentoring, can contribute to improved student outcomes (Felner \& Jackson, 1997; Davis, et al., 2004). Concerns about mathematics achievement and disagreements about how mathematics should be taught indicate a need for detailed investigations of mathematics teaching and learning in middle school (Riley, 1997; Silver, 1998; Becker \& Jacob, 2000; Bandlow, 2001).

I have chosen to study boys because previous research has focused on almost exclusively on girls (AAUW,1992;1998; Sommers, 2000; Weaver-Hightower, 2003). Furthermore, a robust accumulation of data from the U.S. and other countries indicate that public education may not be meeting boys' needs in any academic subject (Noble \& Bradford, 2000; Foster, Kimmel, \& Skelton, 2001), for male college enrollment and graduation rates continue to decline (Sommers, 2000; Weaver-Hightower, 2003).

\section{Research Questions}

In attempting to answer the four research questions for the study, I sought to gain an overview of a gendered class program and to explore school factors and structures affecting its implementation for boys. Additionally, the study probed deeply into the beliefs and practices of teachers as they taught all-boy mathematics classes. 
1. What are school and district factors that affect the development and implementation of all-boy mathematics classes in middle school? Do some factors seem stronger than others as they relate to successful implementation?

2. What classroom structures and instructional strategies are used by teachers in allboy mathematics classes? Do some structures and strategies seem more effective than others?

3. What teacher characteristics affect the development and implementation of allboy mathematics classes in middle school? Do some characteristics seem more important than others?

4. What is the nature of the mathematics instruction used by middle school mathematics teachers in all-boy classes? Do some types of instruction seem to be more effective than others?

\section{Participants}

To locate middle schools who were experimenting with single-gender classes, I used websites and newspaper articles and corresponded with administrators and teachers in California, Connecticut, Georgia, Indiana, Kentucky, Pennsylvania, and Texas. None of the schools selected were single-gender schools but were coeducational schools who had separated boys and girls in their core subjects. All used middle school teaming structures to some extent. However, some teams of the study were all-boys and some were mixed. I chose to study three schools: Terre Rouge Middle School, Greenville Middle School, and Bluefield Middle School (pseudonyms). These schools had been experimenting with single-gender classes for two or three years and had originally adopted them because of faculty suggestions and positive media reports on single-gender programs in other schools. Even so, they implemented gendered class programs for 
somewhat different reasons. Two mathematics teachers of all-boy classes from each

school were also selected for observation. Table 5-1 presents a summary of preliminary information for the three schools of the study.

Table 5-1

Overview of Schools

\begin{tabular}{|c|c|c|c|}
\hline & Terre Rouge & Greenville & Bluefield \\
\hline $\begin{array}{l}\text { District } \\
\text { size/type } \\
\text { SES (\% } \\
\text { free/red) }\end{array}$ & $\begin{array}{l}\text { large/urban } \\
\text { low SES (90\%) }\end{array}$ & $\begin{array}{l}\text { small/town/suburban } \\
\text { low SES }(56 \%)\end{array}$ & $\begin{array}{l}\text { small/town/rural } \\
\text { mixed SES (64\%) }\end{array}$ \\
\hline $\begin{array}{l}\text { School size } \\
\text { (approximate) }\end{array}$ & 800 & 400 & 600 \\
\hline Ethnicity & $\begin{array}{l}\text { 50\% Cauc/ Oth } \\
50 \% \text { Afr-Am. }\end{array}$ & $\begin{array}{l}\text { 92\% Cauc/Oth } \\
\text { 8\% Afr.-Am. }\end{array}$ & $\begin{array}{l}\text { 46\% Cauc./Oth } \\
\text { 54\% Afr.-Am. }\end{array}$ \\
\hline Principal & $\begin{array}{l}\text { Dr. Alice } \\
\text { Russell }\end{array}$ & $\begin{array}{l}\text { Ms. Pat Glover } \\
\text { AP- Mr. Ted Lewis }\end{array}$ & $\begin{array}{l}\text { Ms. Sandra } \\
\text { Warren } \\
\text { AP-Ms. Cheryl } \\
\text { Baxter } \\
\end{array}$ \\
\hline $\begin{array}{l}\text { Mathematics } \\
\text { Teachers }\end{array}$ & $\begin{array}{l}\text { Ms. Ellen } \\
\text { Alcott }-6^{\text {th }} \\
\text { Mr. David } \\
\text { Blake- } 7^{\text {th }}\end{array}$ & $\begin{array}{l}\text { Mr. Darrell Fisher- } \\
6^{\text {th }} \\
\text { Ms. Julia Edwards- } \\
7^{\text {th }}\end{array}$ & $\begin{array}{l}\text { Ms. Chris Ingram } \\
6^{\text {th }} \\
\text { Ms. Melanie } \\
\text { Jones- }^{\text {th }} \\
\end{array}$ \\
\hline $\begin{array}{l}\text { Reasons for } \\
\text { Implementing } \\
\text { Gendered } \\
\text { Program }\end{array}$ & $\begin{array}{l}\text { Raise test } \\
\text { scores; } \\
\text { decrease } \\
\text { boy/girl } \\
\text { interactions }\end{array}$ & $\begin{array}{l}\text { Improve boys’ } \\
\text { performance } \\
\text { (failure rates \& } \\
\text { test scores) }\end{array}$ & $\begin{array}{l}\text { Decrease boy/girl } \\
\text { interactions; raise } \\
\text { scores; modify } \\
\text { teaching. }\end{array}$ \\
\hline $\begin{array}{l}\text { Gendered } \\
\text { Program } \\
\text { Chronology }\end{array}$ & $\begin{array}{l}\text { Fall } 2002 \text { - } \\
\text { Implement in } \\
\text { core subjects, } \\
\text { grades } 6-8 \text {. } \\
\text { 2004-05 - } 3^{\text {rd }} \\
\text { year for prog.. }\end{array}$ & $\begin{array}{l}\text { 2002-03 - Piloted } \\
\text { program in } 7^{\text {th }} \text { grade } \\
\text { Fall 2003- } \\
\text { Implement in core } \\
\text { subjects, 6-8 } \\
\text { 2004-05- } 2^{\text {nd }} \text { year for } \\
\text { gendered program. }\end{array}$ & $\begin{array}{l}\text { Spring 2002- } \\
\text { Piloted program in } \\
6^{\text {th }} \text { grade } \\
\text { Fall 2002- } \\
\text { Implement, } 6^{\text {th }} \text { and } \\
7^{\text {th }} \text { grades only } \\
\mathbf{2 0 0 4 - 0 5}-3^{\text {rd }} \text { year } \\
\text { for gendered } \\
\text { program }\end{array}$ \\
\hline
\end{tabular}

Question 1: School and District Factors

What school and district factors affect the development and implementation of

all-boy mathematics classes in middle school? Do some factors seem stronger than others 
as they relate to successful implementation? Responses to Question 1 emerged from the following data: two faculty surveys; principal, teacher, and student interviews; and classroom and school observations.

Results of Faculty Surveys

For the Organizational Health Instrument for Middle Schools (OHI-M, Hoy \& Sabo, 1997) and the Collective Teacher Efficacy Scale (CE-Scale, Goddard, Hoy, \& Hoy, 2000), a total of 108 responses were analyzed (39 faculty from Terre Rouge; 29 from Greenville, and 40 from Bluefield).

School health. Comparisons of school health scores with a normative sample (Hoy \& Sabo, 1998) indicated that total school health scores for both Terre Rouge and Greenville were above average and that school health for Bluefield was far below average. A multivariate analysis of variance (MANOVA) confirmed these ratings for school health and further interpreted data by investigating differences among schools for the six school health factors (see Table 5-2). Multivariate significance between schools was found $(\Lambda=.375, p<.05)$, and the analysis also identified significant differences for the six factors, with $\mathrm{F}$ values ranging from 39.747 to 8.202, $(p<.05)$.

Collective teacher efficacy. Faculty also responded to the Collective Teacher Efficacy Scale (CE-Scale; Goddard, Hoy, \& Hoy, 2000). Using analysis of variance methods, the collective teacher efficacy of Greenville Middle School was found to be significantly higher than either of the other two schools ( $\mathrm{F}=3.936, p<.05)$.

Summary Information for School Factors

In Table 5-2, means are reported by school on the factors of school health and on collective teacher efficacy. Approximate averages of teacher retention rates for 20022005 are also provided. A comparative analysis of school and district factors identified 
Greenville as having the most positive ratings overall. Survey results rated Greenville as significantly higher than the other two schools on collective teacher efficacy and teacher affiliation. High scores may have related to Greenville’s successes in meeting goals of increasing boys' pass rates in classes and on state assessments. Teacher retention rates may have also contributed to ratings of teacher affiliation. In the year of the study Greenville’s principal, Pat Glover, reported having no new teachers on the staff.

Table 5-2

Summary of School Factors with Descriptive Statistics

$\begin{array}{lllr} & & & \\ & \text { Terre Rouge } & \text { Greenville } & \text { Bluefield } \\ \text { Institutional Integrity } & 2.79(.44)^{*} & 2.61(.66) & 1.72(.60) \\ \text { Collegial Leadership } & 3.44(.51)^{*} & 3.41(.49) & 2.97(.67) \\ \text { Principal Influence } & 2.94(.45) & 3.21(.40)^{*} & 2.66(.42) \\ \text { Resource Support } & 3.05(.63)^{*} & 2.64(.51) & 2.45(.69) \\ \text { Teacher Affiliation } & 2.83(.47) & 3.30(.27)^{*} & 2.89(.58) \\ \text { Academic Emphasis } & 2.39(.40)^{*} & 2.18(.30) & 2.00(.50) \\ \text { Total School Health } & \text { Above Avg. } & \text { Above Avg. } & \text { Far Below Avg. } \\ \text { Collective Teacher } & 78.00(11.92) & 84.83(10.56)^{*} & 77.77(11.47) \\ \text { Efficacy } & & & \\ \text { Teacher Retention } & 50 \% & 90 \% & \\ \text { Rate (approximate) } & & & \\ * p<.05 & & & \end{array}$

Greenville’s faculty expressed positive opinions about the school’s leadership and administrator support and the principal influence factor was higher. Ms. Glover acted as an instructional leader who worked directly with her faculty to continually improve teaching and learning in her school. When members of her faculty came to her with the idea of single-gender classes, she supported their efforts both within the school and the district. Efforts had been successful, for achievement scores had improved. Passing rates for boys in mathematics rose from 50\% in 2002 to $60 \%$ in 2004 . However, in looking 
back over Greenville’s single-gender experiment, both Ms. Glover and Ms. Edwards expressed concern that girls’ passing rates on the state assessment in mathematics had shown slight decreases. Even so, guided by Ms. Glover's strong presence as an instructional leader, Greenville teachers once again became reflective and innovative and began to seek out new strategies for teaching girls.

Terre Rouge. The Terre Rouge score for total school health was comparable to that for Greenville, for both schools felt as if their single-gender programs had been successful and had contributed to targeted improvements. Although recent school and district recognition for gains in achievement scores may have boosted faculty perceptions of school health factors, only $7 \%$ of the girls and $13 \%$ of the boys performed at the proficient level in mathematics. Furthermore, scores were not increasing at a pace proscribed by the state accountability system. When compared with Greenville, teacher affiliation and collective teacher efficacy at Terre Rouge were low. Dr. Russell attributed her school's low score for teacher affiliation to large number of novice teachers, twelve for last year and fourteen for the current year. As compared to the other two schools, teacher turnover was high.

Perhaps because of size or other factors, Dr. Russell's leadership was not as hands-on or as focused on instruction as Ms. Glover’s leadership. Unlike Greenville, Terre Rouge had 5-8 academic coaches on their staff, and Dr. Russell delegated instructional leadership to coaches and counselors. These educators were available to help teachers and individual students but did not have the classroom teachers' daily responsibilities for managing a large number of students. Dr. Russell believed it more beneficial for novice teachers, as well as other teachers, to receive assistance from coaches instead of teachers on the same team or those teaching in the same subject area. 
A major concern for teachers at Terre Rouge was discipline, and faculty members there expressed negative opinions about administrator support in this area, and several indicated that this lack of support was a reason teachers left. Students, whom faculty members felt should be suspended, were being returned to their classes with seemingly few actions taken, and many novice teachers were not receiving the extra support they needed with behavior management. Dr. Russell commented in an interview that most matters of discipline should be handled by the team, and only students with the more serious offenses should receive referrals. Ms. Alcott confirmed this administrative position at Terre Rouge. However, observations and discussions with other teachers on her team indicated that some were having severe difficulties with classroom and behavior management. In order to improve its retention statistics, efficacy, and affiliation for teachers, the administration at Terre Rouge needed to provide more teacher support for discipline issues, as well as on-going training and professional development.

Bluefield. Bluefield Middle School's low score on school health, and particularly institutional integrity and teacher affiliation, served as an indicator of the school's difficulties with parent and district interference. Institutional integrity is the extent to which a school can cope with its environment and can remain protected from the demands of parents and the community (Hoy \& Hannum, 1997). Teachers and administrators spoke of parent and district interference at all levels of school decisionmaking. The separation of girls and boys seemed to be motivated, not by desires for improvement, but by parent desires to separate some children from others. Ms. Jones spoke of parent interference and separation in relation to tracking students. "In some grade schools,” said Ms. Jones, “being in honors seems to be a social thing,” said Ms. Jones. "In middle school, they want their kids in honors to separate them from certain 
other kids.” In the four groups of boys interviewed at Bluefield, three groups mentioned parent influence as part of the selection process for students to be placed in the honors track.

Leadership at Bluefield appeared to be severely hampered by district interference. In the previous school year, the superintendent removed the school's principal at midyear and replaced him with a "hand-picked" candidate. He also made negative comments about Bluefield Middle School and its administration in the local newspaper. Teachers attributed the low score for the teacher affiliation factor to the interferences and criticisms from the superintendent. "Some of us decided that it would be easier to survive this alone, rather than as a group,” said Ms. Ingram. Low scores for Bluefield on collegial leadership and principal influence also suggested that administrators and teachers at Bluefield had significantly less control over their own affairs. Parents and district influences were making it difficult for the leadership at Bluefield to effectively implement any improvement program they might have chosen, including the singlegender program. Even in our opening interview, Ms. Baxter expressed doubts about the success of the gendered class program at Bluefield, and as faculty members had predicted in interviews, the SBDM (Site-Based Decision Making committee) decided not to continue single-gender classes for the following year.

Question 2: Classroom Structures and Instructional Strategies

What classroom structures and instructional strategies are used by teachers in allboy mathematics classes? Do some structures and strategies seem more effective than others?

Structures and strategies that most affected environments and interactions in the all-boy mathematics classes of the study fell into three main areas: teacher and school 
implementation of middle school principles, particularly teaming and mentoring;

classroom management; and strategies for teaching boys. Table 5-3 provides summary

information for structures and strategies identified from study data. The percent of time a

teacher spent on classroom management and observed instances of teacher behavior were

based on eight, 50-minute classroom observations for each teacher. With the aid of

HyperResearch, a program used for analysis of qualitative data, a variety of classroom

occurrences, such as correcting student behavior, were coded and tallied. Details of time

allocation analyses are located in Appendix F, and a list of specific strategies that

teachers of the study used in their all-boy mathematics classes are given in Table 5-5.

Table 5-3

Summary Information by Teacher of Structures and Strategies for Boys

(based on eight 50-minute observations)

\begin{tabular}{|l|c|c|c|c|c|c|}
\hline \multicolumn{1}{|c|}{ teacher } & EA & DB & DF & JE & CI & MJ \\
\hline effective teams & no & yes & yes & yes & yes & no \\
\hline mentoring skills & low & high & med. & med. & med. & med. \\
\hline $\begin{array}{l}\text { \% time on } \\
\text { management }\end{array}$ & $26 \%$ & $35 \%$ & $11 \%$ & $12 \%$ & $21 \%$ & $26 \%$ \\
\hline $\begin{array}{l}\text { \# instances } \\
\text { correct behavior }\end{array}$ & 71 & 22 & 2 & 5 & 8 & 40 \\
\hline $\begin{array}{l}\text { \# instances } \\
\text { model behavior }\end{array}$ & 8 & 24 & 21 & 12 & 32 & 8 \\
\hline $\begin{array}{l}\text { \# instances } \\
\text { engage.\& motiv. }\end{array}$ & 5 & 12 & 84 & 67 & 8 & 10 \\
\hline $\begin{array}{l}\text { \# instances } \\
\text { boys' learning }\end{array}$ & 62 & 50 & 117 & 167 & 93 & 31 \\
\hline $\begin{array}{l}\text { total \# } \\
\text { boy strategies }\end{array}$ & 67 & 62 & 201 & 234 & 101 & 41 \\
\hline
\end{tabular}

Middle School Teaming

Teaming emerged in this study as a factor contributing to success in all-boy

classes. Results confirmed findings of other studies indicating that implementation of middle school reform principles, such as teaming, could promote better learning (Felner \& Jackson, 1997; Davis, et al., 2004). A team’s success was not determined by what 
one teacher did but on whether all teachers in a team functioned as a cohesive unit.

Cohesive team leadership for boys focused on having the same rules and procedures and enforcing them consistently. At Terre Rouge, Dr. Russell confirmed that effective teaming made a difference.

DR. RUSSELL: I've seen a lot of (student) improvement on teams having plans. Teams that are well-tuned machines and have a plan in place have done a really great job. You rarely see a referral come out of one of those teams, because they handle their own business.

Terre Rouge. Dr. Russell confided that only about half of the teams there were “well-tuned machines.” As team leader, Ms. Alcott did not receive the support she needed from other teachers on her team. In interviews, boys reported that other teachers on the team were more permissive and did not adhere to rules and procedures as strictly as Ms. Alcott. Thus, Ms. Alcott assumed a large part of the burden for discipline on her team, which possibly contributed to her high frequency in correcting student behavior. Although Mr. Blake’s team experienced challenges, such as overloaded classes and turnovers in personnel, he reported receiving support from other team leaders in managing student behavior and in monitoring individual student progress.

Greenville. At Greenville Middle School, teachers leading both $6^{\text {th }}$ - and $7^{\text {th }}$-grade teams worked together cohesively, and both groups established common rules and procedures. Several teachers on the $6^{\text {th }}$-grade team at Greenville also spoke enthusiastically about an interdisciplinary unit on personal finance. The $7^{\text {th }}$-grade team leaders had worked together for a number of years and served as initial advocates for the gendered class program. Ms. Glover, as well as teachers, spoke of the team's successful plan to increase the amount of homework that $7^{\text {th }}$-grade students produced.

Bluefield. At Bluefield, the $6^{\text {th }}$-grade boys' team seemed to be operating successfully, but the mixed, $7^{\text {th }}$ grade team was not operating as effectively. Ms. 
Ingram's three-teacher team worked cohesively to implement strategies to meet learning needs in their all-boy classes. The sixth grade teams occupied a separate hall of the school and had also adopted a two-subject block scheduling structure. Ms. Ingram expressed positive views of the small classes and flexibility of scheduling. In 7th-grade, however, teachers and administrators reported that the team structure and cohesive environment had been sacrificed this year because the superintendent had forced them form one team for $7^{\text {th }}$ grade, a team composed of approximately 200 students and all of the 7th-grade teachers. Teachers did not know the students well and found it difficult to collaborate successfully with each other about procedures, strategies, or particular students. Ms. Baxter, the assistant principal, also related an increase in referrals in $7^{\text {th }}$ grade to this new, less personal team organization.

Mentoring

While schools of the study did not have structured mentorship programs, I found evidence of teacher mentoring and of building relationships with students. A teacher's ability to mentor students emerges as an important factor for success with male adolescents in both the current study and in previous research (Hudley, 1998; Beane \& Brodhagen, 2001; Hansen, 2002; Davis, et. al., 2004). As principal, Alice Russell, said about her students at Terre Rouge, "You have to form relationships with these kids, and if you reach them, they will go with you anywhere.” If team leadership is cohesive, then students may not think of their team leaders in terms of "nice teachers" and "mean teachers" and feel the "respect” for all of their leaders that students reported they felt for Ms. Alcott. This gave students the opportunity to select their own mentors from the team leaders. In a previous study at Terre Rouge, teachers reported that boys chose their own confidants or confidantes and that building a relationship with a boy was an important 
first step for helping him academically (Davis, et al., 2004). Mr. Blake said that if he got

“on their case” about things, they would confide in him more.

In using mentoring as a strategy, I found Ms. Alcott to be the lowest and Mr.

Blake to be the highest in mentoring skills with the boys. When asked if boys came to her

with personal problems, Ms. Alcott was the only teacher of the study who responded

negatively, and she further suggested that there was no time available to address personal

issues for particular students. Contrarily, I observed that Mr. Blake seemed to have

special ways in building relationships with his students and interviews of students

confirmed this. "Mr. Blake doesn't just teach math, he teaches us about life,” one boy

said. Another said that he never gave up on them and would continue going over

concepts with students until they understood them. Mr. Blake mentioned that he had

taught the same group of boys last year and these prior connections had enhanced his

abilities in building relationships. He described instances of helping students in a

mentor's role as follows:

RESEARCHER: Do students come to you with personal problems?

MR. BLAKE: Yes, they do that with me more than with the women teachers. For one thing, I'm the only male teacher on the team. Two, because I've already built a rapport with the kids I had last year. I have again this year probably about $80 \%$ of the kids I had in class last year.

RESEARCHER: Under what circumstances will a boy come to you?

MR. BLAKE: Home life. I've just recently explained to a kid why he couldn't see his father. They trust me because we share similar interests. And, the more I stay on them, the more it seems they come to me and stuff. I throw in positive reinforcement when needed. I may not do it right on the spot, if I find myself getting on a kid more than a few times, I will go out in the hallway with him. Once they see that I am not doing it because I am being harsh and mean, they usually open up and confide more and more. RESEARCHER: Do they come to you after school?

MR. BLAKE: I have an open door policy, but I won't let them use an excuse to get out of class; I let them know that if they have a problem to come and talk to me. And, they know that what they say stays between me and them unless it is something that needs to be addressed because of being harmful to them - they understand that. 
Mr. Blake also thought that being African-American might have made him more approachable, although he said that he tried not to show favoritism to his AfricanAmerican boys. "They are all just boys and all need to be loved,” he said. Bluefield students also sought after Ms. Jones, the other African-American teacher of the study, for counseling and advice. Ms. Jones described to me how students would confide in her. "Yeah, a lot of it is usually either family issues or how would you handle a situation -that type of thing.” I also observed Ms. Jones’s former students, now high school students, returning to the middle school to visit with her at the end of a school day. However, Ms. Jones taught both boys’ and girls' classes and her mentoring relationships seemed principally to be formed with her female students. Ms. Ingram reported that she actually preferred teaching the boys and sometimes would help and counsel them in personal matters.

The teachers at Greenville seemed to form relationships with their students though the teaching of mathematics. Both of the Greenville teachers also taught girls and both suggested that building relationships with boys may be different than with female students. Ms. Edwards said that boys would talk to her about something or socialize with each other while they worked and would then go right back to the task they were working on, whereas her female students liked to finish their work and then talk. Mr. Fisher said that he was surprised, since he was male, that both boys and girls came to him with their problems. Even so, he observed that boys seemed to form relationships differently.

"Boys seem to open up and talk to me when we are doing something together," he said. Psychologists who have studied boys express a similar view that boys tend to bond with mentors and peers over common interests and mutual endeavors (Pollack, 1998; Gurian, 2001). 


\section{Classroom Management}

Results in this study confirmed findings of previous research suggesting that classroom management and behavior were key issues with boys (Baker, 2002; Woody, 2002). Unlike girls, who more frequently want to please teachers, boys frequently tend toward risk-taking behavior and challenges to authority (Connell, 1996; Hudley, 1998; Noble \& Bradford, 2000; Gurian, 2001). Unless behavior management structures are in place and teachers work consistently on developing and perfecting effective strategies for managing behavior, learning opportunities for boys may be hampered. Classroom management data for each teacher, including time allocation information and instances of corrected behavior, appear in Table 5-3

Classroom management for boys needed to be rule-based, specific, immediate, and consistent. Cohesive team structures, ensuring that all of the teachers on the team followed the same rules contributed to classroom management that focused more on modeling appropriate behaviors than on correcting behavior. Ms. Jones and Ms. Alcott were observed to correct behavior approximately two or three times as much as the other teachers. Students reported that they "respected" Ms. Alcott more than some of the other teachers on the team. However, these intermittent corrections and her overall management style did not encourage higher levels of discussion or exchanges of mathematical ideas. Ms. Jones tried to reason with her students about changing their behaviors and seemed to be frequently burdened with further disruptions.

The CHAMPs program and modeling appropriate behaviors. To model appropriate behavior , a teacher explains, demonstrates, and exemplifies behaviors considered appropriate for particular class activities. Strategies that modeled appropriate behavior seemed to be more successful and less distracting for learners than frequent 
corrections of behavior. Both Terre Rouge and Bluefield, had implemented the CHAMPs classroom and behavior management program (Sprick, et al., 1998). The program modeled appropriate behaviors by establishing specific rules and procedures for student voice levels; movement about the classroom; requests for help; and participation in various learning activities (Sprick, et al., 1998). The CHAMPs program also provided structures of rewards and consequences. Faculty and administrations at both schools expressed satisfaction with CHAMPs. In a previous study at Terre Rouge, teachers reported that consistent implementation of principles from CHAMPs, as well as continuous teacher development of its proscribed skills had positive affects on student achievement (Davis, et al., 2004). Bluefield began using the program this year and I observed Ms. Ingram using CHAMPs strategies, such as references to appropriate voice levels and acronyms to remember a list of rules.

Dealing with disruptive students. When interviewing at all three schools, I asked boys the question, “How do you learn mathematics best?” I expected suggestions such as computers, graphing calculators, and hands-on activities, but at all three schools, boys suggested that removing the disruptive people from the class would help them learn. In our focus group discussions, they mentioned - and sometimes by name - two or three who were the problems. Observations confirmed that it seemed to be the same few students who caused daily disruptions. When I discussed this finding with teachers, they immediately commented that it was impossible to remove these students. However, in managing an all-boy classroom, these disruptive influences must be stopped before successful mathematics teaching can take place.

My classroom; my home. Even in a crowded classroom containing 30-35 boys, I observed Mr. Blake to be a successful manager. He commanded the respect of his 
students and provided an environment conducive to learning and discussion. In an interview, I probed Mr. Blake about his approach to management. “I run my classroom like my house and I'm not going to let somebody come in and do anything they want to in my house,” he said. Dr. Russell also expressed a similar classroom/ home analogy when discussing principles of management. When I asked Mr. Blake for additional details or insights, he recommended beginning by establishing rules and policies and then enforcing them. “Don’t overlook inconsistencies,” he said, “and take immediate action.” I then asked about those few disruptive students who might continue to be uncooperative. "I place the student in isolation or call on another teacher from the team to take the student," he said. "If this doesn't work, I get in his face. Later, I might pull the boy aside and talk to him about the problem individually.”

Teaching Strategies for Boys

Research on teaching boys remains scarce (Weaver-Hightower, 2003), whereas researchers who have studied boys' indicate that how they are taught is important (Noble \& Bradford, 2000; Woody, 2001). The strategies described in this section emerged from interviews and observational data. Some of these strategies for teaching boys have previously been identified by other scholars and practitioners (Gurian, 2000; Hansen, 2000; Noble \& Bradford, 2000; Baker, 2002). The suggested strategies may also be successful with girls. Three of the six teachers taught all-girl classes, too, and they mentioned strategies such as using topics of interest and hands-on activities as also being successful with girls.

Listed in Table 5-4 are coded instances by teacher for strategies used in the allboy classes of this study. Table 5-4 identifies the mathematics teachers at Greenville as those who tailored their instruction in the all-boy classes most frequently. Mr. Fisher 
motivated boys through topics of interest and "tall tales," as he related problems and explanations of proportional thinking to his "previous career in the NBA.” Ms. Edwards used team competitions and active problem-solving work on the chalkboard to engage her students. Although several scholars recommended teaching with technology for boys (Gurian, 2001; Baker, 2002) and mathematics education research also favors the use of computers and graphing calculators on the middle school level (Waits \& Demana, 2000;

Kilpatrick, et al., 2001), study results indicate that technology was not being used to great extent. Details of how the six teachers of this study used these strategies in their all-boy classes are provided by the section entitled “Strategies for Teaching Boys” in Chapter 4.

Table 5-4

Coded Instances for Boy Structures and Strategies (8 observations, 50 minutes each)

\begin{tabular}{|c|c|c|c|c|c|c|}
\hline Strategy & EA & DB & DF & $\mathrm{JE}$ & $\mathrm{CI}$ & MJ \\
\hline \multicolumn{7}{|l|}{ Learning Strategies } \\
\hline structuring lessons & 22 & 15 & 38 & 45 & 29 & 3 \\
\hline group/partner work & 0 & 4 & 8 & 18 & 4 & 1 \\
\hline scaffolding tasks & 4 & 10 & 8 & 23 & 12 & 3 \\
\hline $\begin{array}{l}\text { attention to } \\
\text { organization/planning skill }\end{array}$ & 26 & 18 & 12 & 27 & 11 & 14 \\
\hline encourage steps/explanations & 9 & 2 & 43 & 45 & 26 & 8 \\
\hline movement/hands-on learning & 1 & 1 & 8 & 9 & 11 & 2 \\
\hline Learning totals & 62 & 50 & 117 & 167 & 93 & 31 \\
\hline \multicolumn{7}{|l|}{$\begin{array}{c}\text { Engagement/Motivation } \\
\text { Strategies } \\
\end{array}$} \\
\hline topics of interest & 0 & 0 & 13 & 2 & 0 & 0 \\
\hline jokes, big numbers, tall tales & 1 & 0 & 32 & 1 & 1 & 1 \\
\hline competition & 0 & 0 & 7 & 17 & 0 & 2 \\
\hline $\begin{array}{l}\text { "the cheer" and group } \\
\text { recitation }\end{array}$ & 1 & 5 & 9 & 2 & 1 & 0 \\
\hline $\begin{array}{l}\text { confidence/importance/encou } \\
\text { ragement }\end{array}$ & 3 & 6 & 13 & 37 & 2 & 4 \\
\hline rewards & 0 & 0 & 10 & 8 & 0 & 0 \\
\hline technology & 0 & 1 & 0 & 0 & 4 & 3 \\
\hline Engage./Motiva. totals & 5 & 12 & 84 & 67 & 8 & 10 \\
\hline Totals (learning \& motiva.) & 67 & 62 & 201 & 234 & 101 & 41 \\
\hline
\end{tabular}


“The Cheer,” or group recitation, was used in mathematics classes to encourage mental mathematics, problem solving, connections within mathematics, or memorizing rules and basic skills. It provided teachers with a way to keep a class of boys on-task, and yet, allow them to be loud and active in a structured way. The boys were not competing with each other and it was not a race to see who could answer first; they were working together as a team toward a common goal. With the exception of Mr. Fisher, teachers favored learning strategies over strategies for engagement and motivation. Teachers of the study noted that boys frequently failed to provide explanations, steps, or reasoning details when solving mathematics problems and some teachers assessed work based on both explanations and correct answers. Observations and interviews confirmed that uses of movement and hands-on learning (e.g. manipulatives, board work, and individual dry-erase boards) were successful in engaging boys and keeping them on-task. Management vs. Boy Strategies

Study results suggested links between the use of gender-specific strategies and time spent on classroom management. Table 5-5 and Figure 5-1 present data and a scatter-plot predicting a possible inverse relationship. Although this case study provides only six data points, the graph suggests that using boy strategies may influence the amount of time spent on management. Ms. Edwards and Mr. Fisher spent the least amount of time on classroom management and they used more than twice as many strategies for teaching and engaging boys. Ms. Jones, Ms. Alcott, and Mr. Blake spent the most time on management and used fewer gender-specific teaching strategies than the other three teachers. As shown in the graph (Figure 5-2), the data point for Ms. Ingram fell close to the center relative to the other two groups of points. 
Table 5-5

Time Spent on Management vs. Boy Strategies

\begin{tabular}{|c|c|c|c|c|c|c|}
\hline & & & & & \\
& Mr. Fisher & Ms.Edwards & Ms. Ingram & Ms. Jones & Ms. Alcott & Mr. Blake \\
\hline \% time on CM & 11 & 12 & 21 & 26 & 26 & 35 \\
\hline \# strategies & 201 & 234 & 101 & 41 & 67 & 62 \\
\hline
\end{tabular}

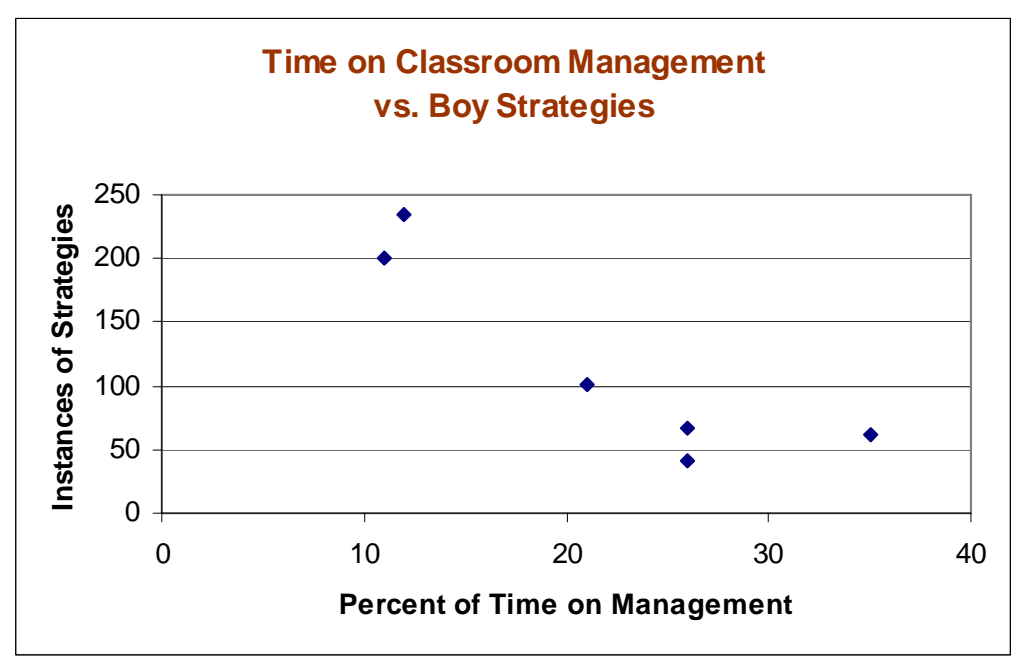

Figure 5-1. Scatterplot for Time on Management vs. Boy Strategies

Question 3: Teacher Characteristics

What teacher characteristics affect the development and implementation of all-

boy mathematics classes in middle school? Do some characteristics seem more important than others? The investigation examined teacher characteristics such as gender, ethnicity, mathematics teaching efficacy; and beliefs about teaching and learning mathematics.

Other relevant characteristics that arose from study findings were capacity for innovation and reflection; and a commitment to classroom teaching.

Summary of Teacher Characteristics.

Table 5-6 presents comparative characteristics for the six mathematics teachers of the study. Discussions and details for table entries follow in subsequent sections. 
Table 5-6

Summary of Teacher Characteristics

\begin{tabular}{|l|c|c|c|c|c|c|}
\hline & Ms. Alcott & Mr. Blake & Mr. Fisher & Ms. Edwards & Ms. Ingram & Ms. Jones \\
\hline $\begin{array}{l}\text { ethnicity \& } \\
\text { gender }\end{array}$ & $\begin{array}{c}\text { Caucasian } \\
\text { Female }\end{array}$ & $\begin{array}{c}\text { Afr.-Amer. } \\
\text { Male }\end{array}$ & $\begin{array}{c}\text { Caucasian } \\
\text { Male }\end{array}$ & $\begin{array}{c}\text { Caucasian } \\
\text { Female }\end{array}$ & $\begin{array}{c}\text { Caucasian } \\
\text { Female }\end{array}$ & $\begin{array}{c}\text { Afr-Amer. } \\
\text { Female }\end{array}$ \\
\hline $\begin{array}{l}\text { years } \\
\text { experience }\end{array}$ & 3 & 3 & 7 & 15 & 7 & 8 \\
\hline $\begin{array}{l}\text { math. teach } \\
\text { efficacy }\end{array}$ & 93 & 79 & 90 & 93 & 95 & 98 \\
\hline $\begin{array}{l}\text { beliefs teach } \\
\text { math }\end{array}$ & E & NT & PNT & PNT & E & E \\
\hline $\begin{array}{l}\text { beliefs learn } \\
\text { math }\end{array}$ & PNT & PNT & PNT & PNT & NT & E \\
\hline $\begin{array}{l}\text { innovation \& } \\
\text { reflection }\end{array}$ & & yes & yes & yes & \\
\hline \begin{tabular}{l} 
career goals \\
\hline
\end{tabular} & ed. admin. & $\begin{array}{c}\text { ed. admin. } \\
\text { policy }\end{array}$ & $\begin{array}{c}\text { teaching } \\
\text { business }\end{array}$ & $\begin{array}{c}\text { teaching } \\
\text { ed. admin. }\end{array}$ & teaching & ed. admin. \\
\hline
\end{tabular}

Beliefs/Practices Codes: T - Traditional; PT - Primarily traditional; E - Even mix of traditional and non-traditional; PNT - Primarily non-traditional; NT - Non-traditional.

\section{Gender and Ethnicity}

Research suggests that ethnicity and gender of a teacher may be factors relating to

successful teaching of all-boy classes (Hudley, 1998; Weaver-Hightower, 2003).

However, five out of six teachers in my study felt that ethnicity and gender were not as

important as quality of teaching, teaching styles, and expectations for students. Ms.

Edwards believed that a boy's response to male or female teachers depended on the

individual. Mr. Blake was the only African-American male teacher of the study and

expressed views that his ethnicity and gender did make a difference.

RESEARCHER: Does the ethnicity or gender of the teacher make a difference? MR. BLAKE: I think it does. It gives --what should I say-- more of a real-world perspective. My upbringing and culture may set off a light bulb and allow kids to make connections. At this age, they need to make connections and make it realworld.

RESEARCHER: African-American male or just male?

MR. BLAKE: Both. As a male I'm more likely to talk about things that interest boys, such as sports, and culturally, I also bring things that kids would understand. But I try not to show favoritism (to African-American boys). They are all boys and all need to be loved. So, yeah, I get on all of them and take it personally when they are not achieving and not living up to their potential. But I have kids of many ethnicities. I was frustrated when I was a kid in school, and found that teachers 
would build a rapport with students who didn’t look like me. Maybe it was because the others reminded them of their own kids. But, if you call yourself a teacher, you have the responsibility of nurturing all, and not just identifying with one group.

\section{Mathematics Teacher Efficacy}

To measure how teachers perceived their own competence in teaching mathematics, the six study participants rated themselves according to the items on the Mathematics Teacher Efficacy Beliefs Instrument (MTEBI; Riggs \& Enochs, 1990; Stevens \& Wenner, 1996). The lowest score on the MTEBI was recorded by Mr. Blake and the highest score by Ms. Jones (See Table 5-7). A previous study reported that less experienced mathematics teachers frequently had lower perceptions of teaching efficacy (Wenner, 2001), and Mr. Blake was one of two teachers with three years of experience. Ms. Jones's experience level was close to the median, and some of her previous teaching experience was in high school mathematics and this may have given her increased confidence in subject-matter knowledge of mathematics for middle school teaching. Practically speaking, however, only Mr. Blake’s score of 79 was significantly different from the others, which were all in the nineties.

Teaching and Learning Mathematics: Beliefs and Practices

To assess teachers' beliefs about teaching and learning mathematics, I designed a 33-item questionnaire from an inventory developed in another study (Raymond, 1997). Each item exemplified beliefs that could be classified along a traditional to nontraditional continuum. The complete questionnaire is found in Appendix E. A sample item reflecting traditional learning of mathematics was, "Memorization and mastery of algorithms signify learning.” A sample item reflecting non-traditional teaching of mathematics was, “The teacher should provide mainly problem solving and manipulative-driven materials” (Raymond, 1997). In general, the six teachers held beliefs 
tending toward the non-traditional end of the continuum about teaching and learning mathematics. Although beliefs about teaching and learning mathematics generally tended toward the non-traditional, teaching practices tended toward the traditional end of the continuum. Observations and interviews suggested that contextual factors seemed to account for this inconsistency. As Ms. Alcott said, "My boys are not mature enough to work in groups,” and Ms. Jones remarked, "I love non-traditional teaching methods, and I think students benefit from self-discovery and work with hands-on materials. However, the combination of behaviors present makes it difficult.”

Innovation and Reflection in Teaching

To teach effectively in middle school, teachers must manage behavior and connect with their students, as well as select practices that are engaging and developmentally appropriate (Midgely, 2001; Gentry, et al., 2002). A characteristic that arose from the data as relevant to successful mathematics teaching was a willingness to consider new approaches -- to innovate and to reflect on practice. Research suggests that the innovative and reflective teacher possesses a higher degree of teacher efficacy (Riggs \& Enochs, 1990; Henson, et al., 2001). Furthermore, a faculty, as a whole, that is willing to try new teaching strategies possesses a higher sense of collective teacher efficacy (Goddard, et al., 2004).

In the current study, I identified Mr. Fisher, Ms. Edwards, and Ms. Ingram as teachers who had an affinity for innovation and reflection. Ms. Edwards planned opportunities for all of the mathematics teachers at Greenville to collaborate and share ideas and experiences. When talking with Ms. Edwards on several occasions, she asked me how I thought the gendered classes were working for the boys and welcomed suggestions. Ms. Ingram was also an innovative teacher and liked to use a variety of 
teaching tools. "I enjoy attending workshops and gather new ideas for teaching," she

said. For the upcoming summer break, she eagerly anticipated a workshop for

mathematics teachers at a nearby university.

I frequently observed innovative strategies in Mr. Fisher’s class, and he once

dressed in construction attire to present a problem related to a home addition. He taught

students a jingle to remember the order of operations and encouraged mental calculations

of seconds saved in preparing tables to begin work. Near the end of the school year,

however, I also had an opportunity to participate in Mr. Fisher in his reflections

concerning a change in emphasis for his teaching.

RESEARCHER: Are you ready to be finished for this school year?

MR. FISHER: I'm more ready to be finished this year than I have ever been before. I gave a test the other day on things that we had covered this year and only 54 out of 129 students passed. Only 3 or 4 students had an A. This was not a difference in boys and girls, but was true of all my classes. ...I was always taught to teach with activities - get your students engaged, get them working together and in groups, get them to explore. But, I'm not so sure that mathematics is the proper stage for that approach.

RESEARCHER: Why do you think it's not working? What you're doing is what the research says to do.

MR. FISHER: It has worked with some groups, but so many in my class this year are so weak Ask a student to subtract 12 minus 9 or ask a student what 36 divided by 9 is and they can't do it. I had hoped that by engaging them with exciting activities and fun things that they would learn, but there is such an overwhelming majority of students who are weak this year. I feel bad that I didn't see the problem sooner. Maybe I didn't want to see it... and the parents don't seem to be involved or able to help with this either. I have to move forward, teach the standards, and prepare them for the next level.

RESEARCHER: So what are you doing now?

MR. FISHER I'm using the textbook more now. I sent their books home with them for reference. I'm assigning homework five days a week.

RESEARCHER: Is it a longer assignment?

MR. FISHER: Yes, there are usually 20 or more problems instead of five. We go over many of them in class and we practice problems from the book instead of doing activities.

It was interesting to note that the same teachers who demonstrated interest in innovation and reflection were those who wanted to remain in the classroom. When 
asked the question, “Where do you expect to be, career-wise, five years from now?” Mr. Fisher, Ms. Edwards, and Ms. Ingram envisioned themselves, although not exclusively, as remaining in the classroom. Because of economic reasons, Mr. Fisher also mentioned owning his own business as an alternate possibility. Ms. Edwards entertained thoughts of future posts in administration but also expressed reluctance to leave classroom teaching, mentioning special relationships and rewards inherent in working with individual students. The other three teachers, Ms. Alcott, Mr. Blake, and Ms. Jones, did not mention remaining in the classroom, and independently spoke of school administration as a preferred career path.

Question 4: Mathematics Teaching

What is the nature of the mathematics instruction used by middle school mathematics teachers in all-boy classes? Do some types of instruction seem to be more effective than others? To investigate the mathematics instruction, the following documents served as benchmarks: standards documents of the National Council for the Teachers of Mathematics (NCTM, 1989 \& 2000) and the National Research Council’s research document delineating the "five strands of mathematics proficiency" (Kilpatrick, et al., 2001). The five strands of proficiency include conceptual understanding, procedural fluency, strategic competence, adaptive reasoning, and productive disposition. Other factors considered were time allocations and textbook uses.

\section{Allocation of Classroom Time}

Table 5-7 provides details for how teachers of the study allocated time in eight 50-minute classes. Breakdowns for time allocations by lesson are given in Appendix F. Types of activities were then further categorized as either traditional or non-traditional. Teacher-centered activities ( $\mathrm{T}$ ) and practice (P) were placed in the traditional category; 
and discourse (D), individual activities (IA), and group activities (GA) were placed in the non-traditional category. The percent of time spent on mathematics was determined by taking away percent of time spent on management and free time from $100 \%$.

Table 5-7

Summary of Teacher Time Allocation (from eight 50-minute observations)

\begin{tabular}{|l|c|c|c|c|c|c|}
\hline & MsAlcott & Mr.Blake & Mr.Fisher & Ms.Edwards & Ms. Ingram & Ms. Jones \\
\hline Years exp. & 3 & 3 & 7 & 15 & 7 & 8 \\
\hline M-management & $26 \%$ & $35 \%$ & $11 \%$ & $12 \%$ & $21 \%$ & $26 \%$ \\
\hline F-free time & $3 \%$ & $2 \%$ & $2 \%$ & $0 \%$ & $0 \%$ & $6 \%$ \\
\hline D-discourse & $10 \%$ & $0 \%$ & $49 \%$ & $9 \%$ & $12 \%$ & $3 \%$ \\
\hline $\begin{array}{l}\text { T-teacher- } \\
\text { centered act }\end{array}$ & $31 \%$ & $35 \%$ & $4 \%$ & $4 \%$ & $29 \%$ & $34 \%$ \\
\hline P-practice & $18 \%$ & $10 \%$ & $1 \%$ & $25 \%$ & $5 \%$ & $19 \%$ \\
\hline $\begin{array}{l}\text { IA-individual } \\
\text { act. }\end{array}$ & $8 \%$ & $9 \%$ & $9 \%$ & $26 \%$ & $18 \%$ & $7 \%$ \\
\hline $\begin{array}{l}\text { GA-group } \\
\text { activity }\end{array}$ & $4 \%$ & $9 \%$ & $24 \%$ & $24 \%$ & $15 \%$ & $5 \%$ \\
\hline \multicolumn{1}{|c|}{ totals } & $\mathbf{1 0 0} \%$ & $\mathbf{1 0 0 \%}$ & $\mathbf{1 0 0 \%}$ & $\mathbf{1 0 0 \%}$ & $\mathbf{1 0 0 \%}$ & $\mathbf{1 0 0 \%}$ \\
\hline $\begin{array}{l}\text { Ma- time on } \\
\text { math. }\end{array}$ & $71 \%$ & $63 \%$ & $87 \%$ & $88 \%$ & $79 \%$ & $68 \%$ \\
\hline ST -test prep & $26 \%$ & $10 \%$ & $0 \%$ & $0 \%$ & $0 \%$ & $0 \%$ \\
\hline Traditional time & $49 \%$ & $45 \%$ & $5 \%$ & $29 \%$ & $35 \%$ & $53 \%$ \\
\hline Non-trad. time & $22 \%$ & $18 \%$ & $82 \%$ & $59 \%$ & $45 \%$ & $15 \%$ \\
\hline
\end{tabular}

Time Allocation Codes: M- management (travel from previous class or restroom, behavior, distribution of papers, administrative information); F- Free time or down time; D- Discourse (open-ended questions and responses, requests for explanations and reasoning, conjectures and generalizations, discourse on mathematics concepts); T Teacher-centered activities such as notes, procedures, vocabulary, spelling test, demonstrating solutions to problems, reading aloud); P - Practice (seatwork, homework); IA - Individual Activity (problem solving, making graphs, computer lab, manipulatives, modeling, hands-on, calculators); GA- Group Activity (work with group or partner; problem solving, collect data, manipulatives, modeling, hands-on); Traditional - Percent of time spent on classroom activities considered to be traditional. This is the total for teacher-centered activities and practice $(\mathrm{T}+\mathrm{P})$; Non-traditional - Percent of time spent on classroom activities considered to be non-traditional. This is the total for discourse, individual activities, and group activities (D + IA + GA)

Percentages reported in Table 5-7 reveal information about how mathematics was being taught in the classes under investigation and also relate to other collected data. Analysis of time allocation could prove to be a helpful tool as teachers reflect on their 
practices. Ms. Edwards, the most experienced teacher of the study, was balanced in the amount of time she spent on practice, individual activities, and group activities. Time allocation for Ms. Ingram was the most balanced between traditional and non-traditional, but the shortage of student practice in favor of teacher-centered activities should be noted. Ms. Ingram spent significantly more time than either Mr. Fisher or Ms. Edwards in demonstrations of problem solutions and procedures. As Mr. Fisher reflected on his teaching during the current year, he mentioned that his emphasis on non-traditional teaching did not seem to be raising levels for student performance and that his current students needed more practice. Time allocation data suggest that Mr. Fisher was only spending $4 \%$ of his classroom time on practice, as opposed to $82 \%$ on activities and discourse and that more of a balance might be needed.

Teaching for Mathematics Proficiency

The National Research Council’s (Kilpatrick, et al., 2001) characterization of mathematics proficiency as five interwoven strands served as a framework for examining related results. Four lists of teaching and learning characteristics developed by other researchers structured further analysis: (1) Ten characteristics (N1-N10) of NCTM standards-based reform (NCTM, 1989; 2000; Ross, et. al., 2002); (2) nine characteristics of standards-based instruction (S1-S9) to be observed in classrooms (University of Wisconsin, 1998; Reys, 2004); (3) a list of twelve characteristics for teaching for mathematics proficiency (T1 - T12) arranged according to the Teacher/Student/Content Triangle (Ball \& Cohen, 2000; Kilpatrick, et al., 2001); and (4) a list of characteristics of metacognition (M1-M7), as presented in How People Learn: Brain, Mind, Experience, and School (Bransford, Brown, \& Cocking, 2000). Metacognition is the ability to monitor one’s own learning. 
Table 5-8 presents the resulting framework used to analyze the nature of teaching for the six mathematics teachers of the study. Details of the analysis for each teacher are provided in Appendix G.

Table 5-8

Framework of Mathematics Proficiency for Observation Analysis

\begin{tabular}{|c|c|}
\hline $\begin{array}{l}\text { Conceptual } \\
\text { Underst. }\end{array}$ & 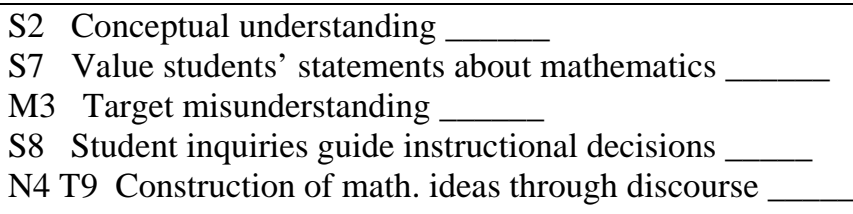 \\
\hline $\begin{array}{l}\text { Procedural } \\
\text { Fluency }\end{array}$ & $\begin{array}{l}\text { T10 Practice } \\
\text { T11 Homework }\end{array}$ \\
\hline $\begin{array}{l}\text { Strategic } \\
\text { Competence }\end{array}$ & $\begin{array}{l}\text { S1 M2 Make conjectures; predict outcomes } \\
\text { S6 M5 Multiple perspectives/strategies } \\
\text { N9 Mathematics is a dynamic, changing discipline } \\
\text { T1 N3 Task selection and use; complex open-ended tasks } \\
\overline{\text { S3, M4 Connections within math; activate prior knowledge }} \\
\text { M1 Metacognition; monitor one’s own learning }\end{array}$ \\
\hline $\begin{array}{l}\text { Adaptive } \\
\text { Reasoning }\end{array}$ & $\begin{array}{l}\text { S5 M7 Explain Reasoning } \\
\text { S9 Reflect on whether answer reasonable } \\
\text { T7 N7 Group activities; student/student interaction }\end{array}$ \\
\hline $\begin{array}{l}\text { Productive } \\
\text { Disposition }\end{array}$ & $\begin{array}{l}\text { S4 T5 Connections w daily life ; task value } \\
\text { N5 T6 math community; learning community __ } \\
\text { N10 student confidence; efficacy; } \\
\text { Math is enjoyable (inc. boy motivators) }\end{array}$ \\
\hline $\begin{array}{l}\text { All Strands } \\
\text { of } \\
\text { Math. } \\
\text { Proficiency }\end{array}$ & $\begin{array}{l}\text { T2 N1 N2 Opp. to learn challenging math; broad scope } \\
\text { T4 High teacher expectations } \\
\text { T3 Teacher planning } \\
\text { N8 T8 An integrated and broad assessment of student work } \\
\text { N6 T12 Use of tools (manipulatives, calculators, computers) } \\
\text { M6 Planning ahead; self-reg; apportion time \& mem. }\end{array}$ \\
\hline
\end{tabular}


The use of multiple lists introduced a variety of lenses through which to view and consider the observational data. The list of instructional characteristics (Reys, 2004) provided more detailed descriptions of discourse and another list included emphasis on practice (Kilpatrick, et al., 2001). Mathematics education research supports the importance of student-centered teaching and learning (Fennema, et al., 1996; Cohen \& Ball, 2000; Kilpatrick, et al., 2001; Neumann, 2003), and this emphasis suggests a need for metacognitive strategies.

Using the framework of Table 5-8 as a guide in the analysis of eight 50-minute classroom observations, instances in which teachers exhibited these characteristics were coded with HyperResearch, tallied, and totaled. Table 5-9 provides a summary analysis of teaching for mathematics proficiency. Mr. Fisher and Ms. Edwards, followed by Ms. Ingram, demonstrated more characteristics of teaching for mathematics proficiency than the other three teachers. Mr. Blake and Ms. Alcott, the least experienced teachers, had lower totals than the others. However, it is interesting to note that Mr. Fisher, Ms.

Edwards, and Ms. Ingram seemed to have more affinities for innovation and reflection in their teaching, and these teachers also considered remaining in the classroom as a favored career plan.

Table 5-9

Teacher Totals for the Five Strands of Mathematics Proficiency (Kilpatrick, et al., 2001)

\begin{tabular}{|l|c|c|c|c|c|c|c|c|}
\hline \multicolumn{1}{|c|}{ Teacher } & $\begin{array}{c}\text { Yr. } \\
\text { Exp. }\end{array}$ & CU & PF & SC & AR & PD & $\begin{array}{c}\text { All } \\
\text { Strands }\end{array}$ & Total \\
\hline Ms. Alcott -T & 3 & 21 & 11 & 12 & 4 & 6 & 2 & 56 \\
\hline Mr. Blake - T & 3 & 9 & 25 & 6 & 10 & 12 & 7 & 69 \\
\hline Mr. Fisher - G & 7 & 56 & 31 & 54 & 52 & 102 & 10 & 305 \\
\hline Ms.Edwards-G & 15 & 54 & 54 & 11 & 29 & 68 & 18 & 234 \\
\hline Ms. Ingram -B & 7 & 43 & 27 & 17 & 29 & 14 & 6 & 136 \\
\hline Ms.Jones -B & 8 & 13 & 35 & 4 & 6 & 16 & 4 & 78 \\
\hline
\end{tabular}

Codes: CU-conceptual understanding; PF-procedural fluency; SC-strategic competence; AR-adaptive reasoning; PD-productive disposition. 
Mr. Fisher and Ms. Edwards at Greenville exhibited the more instances of teaching for mathematics proficiency in the all-boy classes than the teachers at the other schools of the study, and scores for their boys rose on the state achievement tests in mathematics. However, the five interwoven strands of proficiency set high standards, and most agree that these standards are higher and sometimes misaligned with the usual state standards for student proficiency (Kilpatrick, et al., 2001). The current analysis suggests that all of the teachers of the study demonstrate a need for growth if students are to reach these high standards of proficiency. For example, strategic competence is important for mathematics problem solving, and other research places successful strategizing (e.g. eliminating the less efficient strategies) in a list of capabilities of experts (Bransford, et al., 2000). Mr. Fisher was the only teacher to emphasize strategic competence in problem solving. The framework used to describe teaching mathematics proficiency also identified teaching characteristics that related to all strands of proficiency, such as maintaining high expectations, teaching with manipulatives, and using technology. However, all teachers of the study demonstrated relatively few of these instances.

\section{Textbook Use}

Observations and interviews with the teachers of this study revealed a variety of ways that teachers used their textbooks and a variety of opinions about the school- or district-selected mathematics textbook Guided by the work of other researchers (Reys, 2004), I considered a mathematics textbooks produced and developed by commercial textbook publishers as traditional. Both Greenville and Bluefield used traditional textbooks, but Terre Rouge’s district had adopted non-traditional curriculum materials. These non-traditional texts were designed to guide student-centered, inquiry-based 
teaching and were developed by university mathematics education researchers supported by National Science Foundation grants. Data collected through observation and interviews were used to characterize each teacher's use of the adopted textbook (See Table 5-10). Ms. Alcott used her non-traditional text as a scope and sequence guide, supplementing it with other materials, including worksheets for homework assignments and district-provided practice for standardized tests, and Mr. Blake did not use it at all and reported that he did not feel that these materials were meeting the needs of his students.

Throughout most of the year, Mr. Fisher used his textbook mainly as an occasional resource, but I observed that he created his own activities or relied on other sources more frequently. However, upon reflection on his need to include more practice and fewer activities in his teaching, he began to rely on his textbook more heavily. Using their textbooks as sole authorities may have influenced both Ms. Ingram and Ms. Jones toward an emphasis on procedures and demonstration of problem solutions. Both teachers spent large amounts of time on traditional, teacher-led activities, 35\% and 53\% respectively.

\section{Summary Information for Mathematics Teaching}

Table 5-10 summarizes information relevant to the mathematics teaching for the six teachers of the study. It is interesting to note in Table 5-10 that time allocations for non-traditional practices increase along the continuum from traditional to non-traditional with ratings for teaching practices in Raymond's (1997) schema. Although Ms. Edwards's teaching practice was rated as primarily non-traditional, she was the teacher who devoted the highest portion of her classroom time to practice (See Table 5-7), and again, this most experienced teacher exhibits the most balanced teaching. A practice 
activity in mathematics is sometimes thought of as repetitious drill on memorized facts

and procedures, but practice that is more student-centered may have the potential to increase a student’s strategic competence, as well as procedural fluency.

Table 5-10

Mathematics Teachers’ Practices, Beliefs, and Textbook Uses

\begin{tabular}{|l|c|c|c|c|c|c|}
\hline & $\begin{array}{l}\text { Ms } \\
\text { Alcott }\end{array}$ & $\begin{array}{l}\text { Mr. } \\
\text { Blake }\end{array}$ & $\begin{array}{l}\text { Mr. } \\
\text { Fisher }\end{array}$ & $\begin{array}{l}\text { Ms. } \\
\text { Edwards }\end{array}$ & $\begin{array}{l}\text { Ms. } \\
\text { Ingram }\end{array}$ & $\begin{array}{l}\text { Ms. } \\
\text { Jones }\end{array}$ \\
\hline Years experience & 3 & 3 & 7 & 15 & 7 & 8 \\
\hline $\begin{array}{l}\text { Math. teach. } \\
\text { efficacy }\end{array}$ & 93 & 79 & 90 & 93 & 95 & 98 \\
\hline Beliefs/ teaching & $\mathrm{E}$ & $\mathrm{NT}$ & PNT & PNT & $\mathrm{E}$ & $\mathrm{E}$ \\
\hline Beliefs / learning & PNT & PNT & PNT & PNT & NT & E \\
\hline $\begin{array}{l}\text { Time allocation } \\
\text { Trad. }\end{array}$ & $49 \%$ & $45 \%$ & $5 \%$ & $29 \%$ & $35 \%$ & $53 \%$ \\
\hline $\begin{array}{l}\text { Time allocation } \\
\text { Non-Trad. }\end{array}$ & $22 \%$ & $18 \%$ & $82 \%$ & $59 \%$ & $45 \%$ & $15 \%$ \\
\hline $\begin{array}{l}\text { Math.proficiency } \\
\text { totals }\end{array}$ & 56 & 69 & 305 & 234 & 136 & 78 \\
\hline Teaching prac. & PT & PT & NT & PNT & E & T \\
\hline Textbook & NT & NT & T & T & T & T \\
\hline Textbook use & SS & N & R & R & A & A \\
\hline
\end{tabular}

Beliefs/Practices Codes (Raymond, 1997): T - Traditional; PT - Primarily traditional; E - Even mix of traditional and non-traditional; PNT - Primarily non-traditional; NT Non-traditional.

Time Allocation Codes: Traditional (T) - Percent of time spent on classroom activities considered to be traditional; the total for teacher-centered activities and practice $(\mathrm{T}+\mathrm{P})$. Non-traditional (NT) - Percent of time spent on classroom activities considered to be non-traditional; the total for discourse, individual activities, and group activities (D + IA + GA).

Textbook Use Codes_(Reys, 2004): A - Comprehensive and trusted authority (what, when, and how to teach); SS - A scope and sequence guide (what and when to teach); $\mathrm{R}$ - An occasional or regular resource (homework, tasks, exercises, tests); $\mathrm{N}$ - Textbook plays no role

There were inconsistencies between mathematics beliefs and teaching practices for teachers of this study, and similarly, there did not seem to be a clear relationship between using a non-traditional curriculum and teaching mathematics in a non-traditional way. Research suggests that teacher/curriculum relationships can be complex and how 
teachers use their materials can vary greatly (Remillard, 2005; Davis \& Krajcik, 2005). In reviewing teacher scores on the Mathematics Teaching Efficacy Beliefs Instrument (MTEBI; Riggs \& Enochs, 1990; Wenner \& Stevens, 1996). I perceived possible connections between textbook use and efficacy beliefs for teaching mathematics. On the MTEBI, Mr. Blake scored lowest and Ms. Jones scored highest of the teachers in the study. Ms. Jones relied on her textbook as a trusted authority instructing her in what, when, and how to teach, whereas Mr. Blake did not use his text at all. Even so, limitations arise from studying beliefs and practices of only six mathematics teachers, and future research might be needed to explore relationships between teacher textbook use and efficacy for teaching mathematics.

\section{Overall Findings}

The previous sections summarized and analyzed results for the four research questions of the study, addressing separately school factors, structures and strategies, teacher characteristics, and mathematics teaching. The section presents an overview of study results, suggestions for implementation of a single-gender class program; and recommendations for teaching mathematics to boys. Single-Gender Classes as an Improvement Strategy

A broad analysis of the complex social structures that were in place at Terre Rouge, Greenville, and Bluefield Middle Schools in the year of this study allows consideration of multiple factors and can thus clarify how findings relate to each school's strengths, challenges, and future directions. At each of the three schools of the study, single-gender classes seemed to function as other improvement strategies, such as middle school reform, block scheduling, reduced class size, or implementation of a particular curriculum. Although each school adopted single-gender classes for somewhat different 
reasons, success was based on how the programs were implemented. Research confirms that the level and nature of implementation are important in determining effectiveness for a variety of educational strategies. For example, if teaming and other middle school reform principles are to produce higher achievement, then levels of implementation are key issues (Felner \& Jackson, 1997). Likewise, the success of a mathematics curriculum in facilitating improved learning may depend on teacher understanding and acceptance of the rationale and purposes of its developers (Ross, et al., 2002; Reys, 2004; Davis \& Krajik, 2005; Remillard, 2005).

Previous research and the current study demonstrate that for single-gender education to be a successful improvement strategy, the school community must embrace the concept as a way to improve student outcomes, and teachers must adapt instruction for their gendered classrooms (Baker, 2002; Herr \& Arms, 2002; Davis, et al., 2004). Results of the study may be used to hypothesize possible relationships among the layered factors. The diagram in Figure 5-2 describes these relationships visually, presenting two outer levels of influence and placing mathematics teaching in the central core.

The outermost level of the model represents school and district factors as they affect (1) teacher characteristics, (2) structures and strategies used in all-boy mathematics classes, and (3) the teaching and learning of mathematics (See Figure 5-2). School and district factors that seemed to have an impact were faculty "buy-in"; high collective teacher efficacy; relevant professional development; teacher retention; teacher input in curricular decisions; support with discipline; support from district; and conflicting agendas. Moving inward to the next circle, structures, strategies, and teacher characteristics affect each other and also affect mathematics instruction. Structures and strategies that seemed important were rule-based and consistent classroom management; 
cohesive teaming; building relationships and mentoring; structured tasks and organizational aids; and engagement and motivation strategies. Important teacher characteristics worthy of consideration included gender and ethnicity; a willingness to innovate and try new teaching strategies and a commitment to classroom teaching.

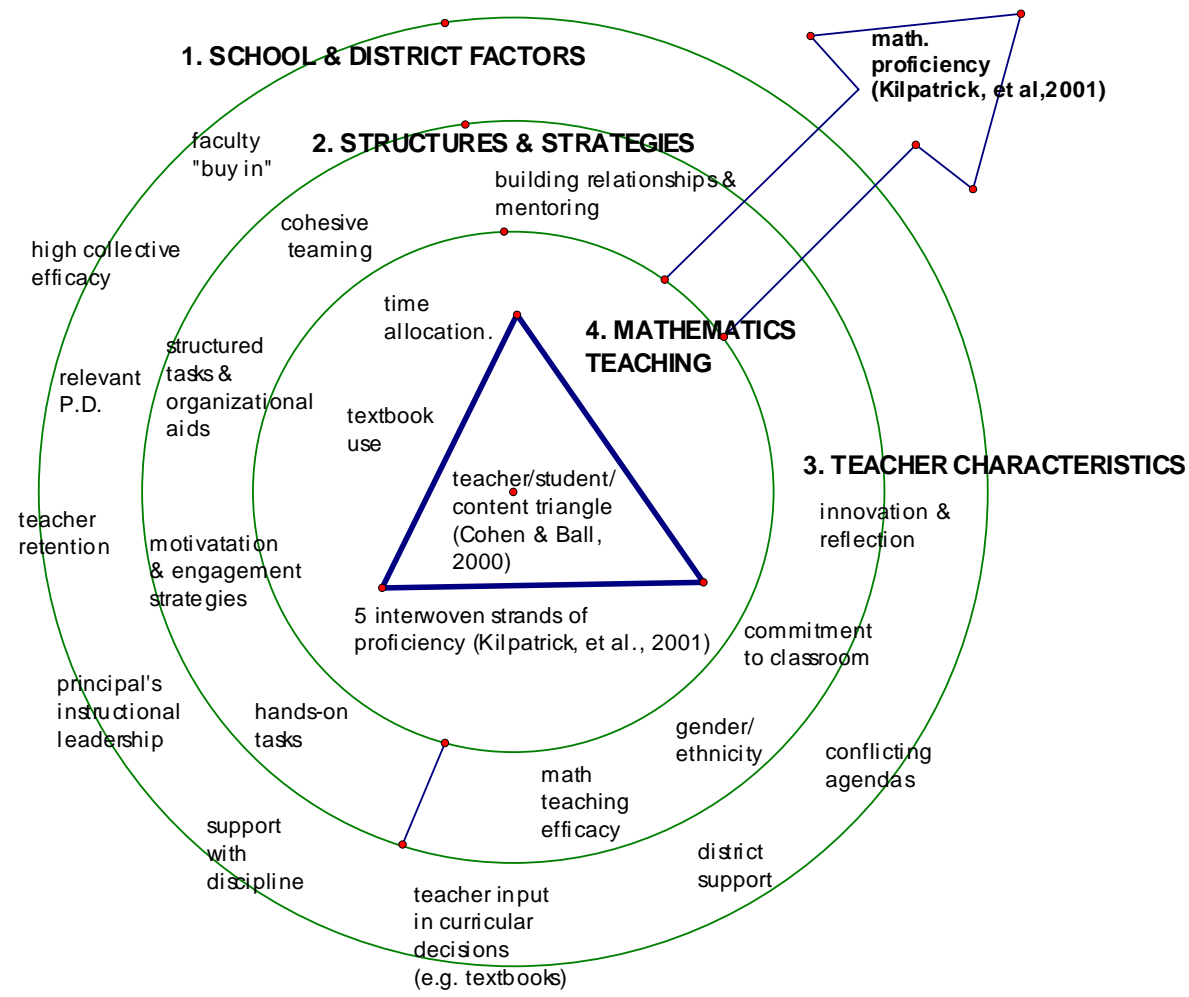

Figure 5-2. All-Boy Mathematics Classes in Middle School: Diagram of Study Results

The circle for mathematics teaching contains the teacher/content/ student triangle (Cohen \& Ball, 2000) and resides in the central core of the diagram, thus suggesting that the outer levels of factors supported and contributed to the successful teaching of mathematics. The purpose for this study was to investigate the nature of the mathematics 
teaching in these all-boy classrooms in light of the levels of influential factors that were also examined. Study results suggest that high levels of mathematics proficiency, as described by the five interwoven strands (Kilpatrick, et al, 2001), cannot be reached by employing these supporting structures and strategies alone. Greenville teachers exhibited three times as many characteristics of teaching for mathematics proficiency and over five times as many students scored at the proficient level in mathematics.

Greenville. When compared with the other two schools of the study, Greenville Middle School seemed to implement the all-boy class strategy most effectively. All school and classroom factors identified as important in the study diagram contributed to the school's success in a positive way. School health was above average when compared to a normative sample, collective teacher efficacy was high, and Greenville’s faculty believed in the single-gender strategy as a way to improve learning and thus supported it. Teacher retention was high, for Ms. Glover reported that there were no new teachers that year. Ms. Glover, the school's principal, had enlisted district support, as well as approval of the entire faculty. Greenville’s primary reason for implementing the gendered classes was to improve boys' outcomes. Percentages of boys passing all classes rose from $40 \%$ in 2002 to $60 \%$ in 2004 , and on the state mathematics assessment, pass rates for boys rose from $53 \%$ to $67 \%$ over this same time period. These successes may have served to increase the faculty's "buy-in,” encourage additional experimentation and innovation, and to further build collective efficacy.

Ms. Glover functioned effectively as an instructional leader as she praised teachers for their successes in improving outcomes. She encouraged faculty meeting discussions of successful teaching strategies, both general and gender-specific. Teaming structures functioned cohesively and teacher/leaders worked collaboratively to help 
students grow in areas such as personal responsibility, appropriate behavior, and homework completion. Classroom management did not seem to be an obstacle for the teaching of mathematics. Mr. Lewis, the Assistant Principal, made efforts over the past two years to improve discipline throughout the school, and Ms. Edwards attributed a decrease in office referrals to single-gender classes and Mr. Lewis’s efforts.

Accordingly, Greenville teachers spent comparatively less time on classroom management, embraced more teaching strategies for boys, and exhibited more characteristics of teaching for mathematics proficiency. Both Mr. Fisher and Ms. Edwards were innovative teachers, and they believed that their mathematics teaching had been enhanced by participating in summer professional development focused on studentcentered teaching. When asked about future career goals, both Mr. Fisher and Ms. Edwards spoke of their continuing interest in working directly with students and envisioned remaining in the classroom as a desired possibility.

Terre Rouge. Terre Rouge Middle School had also experienced increased test scores and school health was above average. Faculty felt a great sense of accomplishment when their principal Dr. Russell announced in an October 2004 faculty meeting that overall scores had risen by a significant amount. At the inception of Terre Rouge's single-gender program, the faculty had voted in favor of it unanimously. In their third year of implementation, "buy-in” still seemed high. However, collective teacher efficacy and teacher affiliation were relatively low when compared with Greenville Middle School. Furthermore, only approximately $10 \%$ of Terre Rouge $8^{\text {th }}$ graders tested at the proficient level in mathematics, as compared with approximately 55\% at Greenville, and test score progress did not meet state accountability expectations. Although Terre Rouge faced more pronounced demographic challenges such as higher 
poverty and a higher minority population, differences in other factors, particularly in the areas of teacher retention and the quality of mathematics teaching, may have also contributed to these lower levels of mathematics proficiency for students at Terre Rouge. Unlike Greenville or Bluefield, Terre Rouge had experienced high teacher turnover rates, approaching 50\% for the last two years. And each year, the cadre of new teachers included over a dozen first-year teachers. When I asked Dr. Russell about Terre Rouge's low OHI-M score for teacher affiliation, she spoke of the prevalence of novice teachers.

Results also suggest that the lack of teacher experience may have contributed to problems with team structures at Terre Rouge. Dr. Russell recognized the importance of cohesive teaming, but even so, suggested that only half of the teams at Terre Rouge were functioning at a high level of implementation. Cohesive and successful teaming seemed to relate to experience in teaching and in working together. Ms. Alcott, with only three years experience, was one of the more experienced teachers on her team and served as team leader. However, she did not feel supported by other teachers of her team. They did not seem to enforce the same rules or adhere to the same procedures in their classrooms. Several other teachers at Terre Rouge spoke of the importance in working with the same team leaders over a period of years.

Both in the current investigations and in a previous one, teachers at Terre Rouge exhibited skills for mentoring students and building relationships with them (Davis, et al., 2004). Dr. Russell recognized the importance of teacher-mentoring, and on several occasions, she reminded me of what it was like to teach at Terre Rouge and of what life was like for many of her students outside of school.

Teachers can't come to school and decide it's a bad day. These kids have bad days every day of their lives; it is when they come to school that they feel safe. Even 
though they push every button you have, teachers here must work to form relationships with their students. And if you reach them, they will go with you anywhere.

I observed Mr. Blake to have skills and affinities for mentoring his boys. In both interviews and observations, Mr. Blake emerged as a teacher who could reach his students - a teacher who had an open door for assistance with homework and learning and an open ear for their personal concerns. Even so, the mathematics teaching I observed in Mr. Blake’s classroom seemed much less student-centered or successful when compared with the teachers at Greenville. Both teachers at Terre Rouge were relatively inexperienced and spent large amounts of time on classroom management. Furthermore, neither teacher adapted their practices to engage and motivate the boys in their classes.

In discussions with Mr. Blake, the issue of the district-adopted textbook arose. Mr. Blake did not use it at all and felt that it was not meeting his students' needs. He expressed the view that other teachers at the school also did not find the textbook accessible to their students, but that the district had strongly discouraged the use of other textbooks. It also might be relevant that responses to a questionnaire placed Mr. Blake at a significantly lower level for mathematics teaching efficacy than the other five teachers of the study. Even though Mr. Blake was a teacher that was able to connect with his students, he was not adapting his teaching, as were the teachers at Greenville, and was not teaching for mathematics proficiency. Observations confirmed that he was not using a textbook at all, and this seemed to be a factor that limited his capabilities as a mathematics teacher. Thus, input into relevant curricular decisions, most particularly textbook selection, might have provided him with materials that seemed useful to him and might have improved his teaching of mathematics. 
The single-gender class program at Terre Rouge had been Dr. Russell’s vision. She was inspired by literacy gains that might be realized by separating boys and girls and adapting instruction. She worked to sustain teacher "buy-in” and promoted teacher efficacy by scheduling professional development sessions including motivational speakers about teaching boys and girls differently and workshops about using music to improve writing skills. However, Dr. Russell did not seem to be as directly connected with instruction as did Ms. Glover at Greenville. Perhaps school size and demographics made it imperative that she focus her leadership on other issues. As mentioned previously, Ms. Glover encouraged discussions about teaching strategies at faculty meetings, whereas at Terre Rouge, administrator approval of teacher activities seemed to be more focused on handing their own discipline issues rather than finding new instructional strategies.

Unlike the other schools of the study, Terre Rouge engaged experienced teachers as literacy and mathematics coaches, and Dr. Russell seemed to defer instructional leadership to them. The coaches helped individual students as well as teachers. Dr. Russell felt that the novice teachers might prefer to ask coaches for assistance than to ask other teachers, but collective teacher efficacy was not high at Terre Rouge. In analysis of study findings, it occurred to me that teachers who were in classrooms and were dealing with a large number of students every day might be in better positions than coaches to lead and mentor the novice teachers toward growth in teaching competency, confidence and efficacy.

Bluefield. Analyses of school and classroom factors did not produce a favorable picture of single-gender classes at Bluefield Middle School. School health was low, and teachers and administrator “buy-in” for the gendered class program was not strong. 
Teachers of $8^{\text {th }}$-grade students never adopted the single-gender classes, and others also expressed uncertainties about the strategy's success. Ms. Jones was doubtful that the single-gender classes were of benefit to the boys. Ms. Baxter, the long-time assistant principal, reported that the single-gender strategy did not seem to be producing modified instruction in the classrooms she observed. Additionally, Ms Baxter did not attribute achievement score changes to the single-gender classes.

I observed that in $6^{\text {th }}$ grade, team leadership was cohesive and effective on Ms. Ingram's all-boy team. However, in $7^{\text {th }}$ grade, for supposedly financial reasons, the district superintendent required that $7^{\text {th }}$-grade teachers and students form one large "team,” and these teachers did not feel able to build relationships with their students nor to collaborate successfully in solving team and student problems. Ms. Baxter also attributed the increase in the number of office referrals in $7^{\text {th }}$ grade to this large and ineffective team structure.

Mathematics teachers at Bluefield did not demonstrate as many characteristics of teaching for mathematics proficiency nor did they use engagement and motivation strategies as did the teachers at Greenville. Ms. Ingram used some student-centered activities, such as manipulatives and mathematics computer programs, but Ms. Jones did not modify her instruction to accommodate all-boy classes. Both teachers, however, spent a large portion of class time demonstrating procedures and problem solutions. Bluefield teachers were the only ones in the study who relied on their textbooks as a sole authority (Reys, 2004), and the teacher-centered nature of the mathematics instruction may have been related to the nature of textbook use. Every lesson that I observed came directly from the textbook, and Ms. Jones used a textbook from a different publisher for her honors class. 
Faculty surveys on school health indicated Bluefield's severe challenges in maintaining institutional integrity while responding to demands of parents and the district. Parents frequently interfered by applying pressure to separate their children from others and by having them placed in the honors track. It also seems noteworthy that Bluefield's first thoughts for implementing single-gender classes related to the purpose of separating girls from inappropriate behaviors of certain boys rather than to improve learning for all students. Ms. Baxter and Ms. Ingram reported that parents also interfered in the area of student discipline and district interference had created additional problems. In the school year before the study, the district superintendent removed Bluefield's principal and replaced him with a candidate of his choice. Several faculty members also mentioned that while this was occurring, the superintendent had made negative remarks about the middle school in the city's newspaper.

These outside interferences and other school and district factors seemed to be primarily responsible for the failure of the single-gender program at Bluefield. The other schools of the study did not have the same interferences from parents and district administrators. School leadership was sabotaged by conflicting agendas and Ms. Sandra Warren, the third principal in two years, suffered leadership obstacles encountered by neither Ms. Glover nor Dr. Russell. Except for the reduction in inappropriate boy-girl interactions, three years of experimentation with single-gender classes at Bluefield did not seem to improve academic outcomes. In a follow-up conversation, Ms. Baxter reported that the school's SBDM had decided to discontinue the single-gender program. She also reported that there was again a new principal, the fourth in three years, but that things seemed to be going smoothly with the change back to mixed-gender classes. 


\section{Suggestions for Implementation of a Single-Gender Program}

In today's educational climate dominated by standardized testing, educators at all levels are experimenting with a variety of instructional and organizational strategies in order to improve test scores for their students. Single-gender education is one improvement strategy that seems to be currently popular. Although results of this comparative case study cannot be generalized, findings suggested that two of the three schools experienced academic improvements related to their single-gender classes and how they were implemented. On the school level, successes related to faculty "buy-in" and a lack of conflicting agendas. At the classroom level, teachers from all three schools demonstrated successful classroom management strategies, cohesive teaming, and abilities to build relationships with students. However, only teachers at Greenville placed and emphasis on engaging and motivating students and in student-centered mathematics instruction. The following suggestions for educators about program characteristics and points of consideration are based on both results from this study and previous research in the areas of single-gender education, effective schooling, middle school reform, and the teaching and learning of mathematics.

\section{School and District Factors}

All three schools of the study adopted gendered class programs because of the literature and positive media reports. Faculty experiences also suggested that middle school boys and girls may learn in different ways and may learn better in single-gender classes. A key school factor that must be in place for single-gender programs to be successful is the support and commitment of teachers and administrators. School leaders should strive to engage faculty, as well as other segments of the school community, thus enlisting them to "buy-in" to the belief that single-gender classes can be a viable way to 
increase achievement and improve outcomes at the school. The following are other possible leadership objectives and points to consider:

Build collective teacher efficacy. To implement a gendered class intervention successfully over a period of years, a faculty needs to build continually a sense of collective teacher efficacy That is, they, as a cohesive body, must believe they have the capabilities to make a difference for their students. School leaders should promote efforts to increase collective teacher efficacy, as well as subject-matter teaching efficacy among the members of its faculty. In characterizing collective teacher efficacy dynamically, researchers in the field use a cyclical model (Goddard, et al, 2000; Goddard, et al., 2004). According to this model, collective efficacy beliefs trigger a continuing cycle of actions, results, evaluations of results, and changes in efficacy beliefs (Goddard, et al, 2000; Goddard, et al., 2004). The four sources of collective teacher efficacy beliefs are mastery experiences, vicarious experiences, social persuasion, and affective state (Goddard, et al, 2000; Goddard, et al., 2004). These sources can serve as guides in leading and selecting professional development activities to build and strengthen efficacy beliefs.

Mastery experiences provide the most powerful source of efficacy information and come from actual successes (Goddard, et al, 2000; Goddard, et al., 2004). If a school has been successful in raising students’ standardized scores, administrators should speak publicly and often of this mastery experience and praise the faculty as a whole for its efforts and accomplishments. Although success can be attributed frequently to the efforts of certain teachers, administrators should not say, “The scores went up because of what Ms. X. and her team did, so do what they are doing.” However, if it is not already known, administrators should find out what these teachers are doing and also talk with them about what they believe is causing the differences. Perhaps, as learned at Terre 
Rouge, practices such as cohesive teaming, effective classroom management strategies, and strategies to meet learning needs, contributed to test score increases for boys (Davis, et al., 2004). Or perhaps, as at Greenville, the strategies used to engage and motivate boys related to improved mathematics performance. Administrators should schedule professional development opportunities that increase teachers' skills and expertise in relevant areas, asking teachers at the school who have been successful and are familiar with the particular context, to plan and participate in these sessions.

Vicarious experience, opportunities to see relevant skills modeled by someone else, can be another way of building collective teacher efficacy. When Terre Rouge first adopted the single-gender classes, Dr. Russell sent several members of her faculty to a Long Beach, California middle school to observe a well-established single-gender program. Subsequently, Terre Rouge Middle School used this middle school in California as a model for their program. Ms. Alcott was among a group of Terre Rouge teachers who traveled to California to observe and learn from the staff there. "I was in awe,” said Ms. Alcott. "The school was very well-run, and many teachers had been there a long time.” As a school continues to build a program, additional vicarious experiences may result from additional observations of successful single-gender programs and attendance at conferences where gender-specific and general strategies are being shared. Social persuasion can contribute to teachers' positive beliefs about single-gender programs, thereby encouraging them to try innovative strategies in all-boy classes. These persuasive interactions can be feedback from a supervisor, a conversation in the teachers' lounge, or communication with other educators involved in single-gender programs.

Administrators should encourage experienced teachers to serve as mentors and advisors to other teachers and to share successful practices. Teachers may receive more 
applicable strategies and advice from other teachers at their schools than from coaches who are not as familiar with the contextual challenges nor are responsible for managing large groups of students every day. Media and on-line sources, such as the website for National Association of Single-Sex Public Education (www.singlesexschools.org), may also serve as vehicles for social persuasion. For example, teachers at Bluefield became interested in a single-gender program because of a TV news show.

A faculty's affective state is the level of emotions present - both positive and negative - and can influence self-perceptions of capabilities. Administrators can positively influence teachers' emotions and enthusiasm about single-gender education by showing that they value what teachers are doing and appreciate the difficulty of the job. The opportunity to influence instructionally relevant decisions can have a positive effect on teacher commitment to a program, and subsequently, to a faculty's affective state (Goddard, et al, 2004). Additional suggestions for school leaders for promoting success of all-boy classes in middle school include the enlistment of district support, teacher assistance with classroom management, and the maintenance of a strong commitment to single-gender program as an improvement strategy.

Enlist district support. School districts supported Terre Rouge and Greenville middle schools in their single-gender class experiments. Terre Rouge was the lowest scoring middle school in a large urban district when its leadership proposed single-gender classes. The district has supported single-gender classes as a strategy to help Terre Rouge improve test results. Ms. Glover at Greenville had the support of her superintendent; however actions of the superintendent in Bluefield were not supportive and seemed to inhibit success of the single-gender classes. 
Support classroom discipline. Boys, more than girls, tend to seek attention by defying authority or causing disruptions, and a few disruptive boys can inhibit learning in an entire class. Administrators need to support teachers strongly in efforts to neutralize the negative influences of difficult students. Teachers of this study sometimes did not feel adequately supported by the administration in areas of classroom management. Teachers at Terre Rouge reported that problem students were not suspended and that office referrals to administrators were not helping teachers to deter disruptive behavior. Administrators should not only support teachers on office referrals but also work diligently with all of the teachers to provide deterrents for further disruptive behavior. On a more positive note, leaders should remind teachers that once standards are set and used consistently, an all-boy class can provide boys with learning opportunities (e.g. leadership, topics of interest, opportunities to work with each other in a team-like atmosphere) that may not be present in mixed classes.

Provide teachers with a structured classroom management program. To promote success in all-boy classes, teachers should consider CHAMPs (Sprick, et al., 1998) or another structured management program that models appropriate behaviors for particular situations and employs a system of rewards and consequences. Other important characteristics for all-boy class environments may include predictable daily routines, clear instructions, consistency, and strategies directed toward immediate results in handling a behavior problem (Hester, Gable, \& Manning, 2003; Davis, et al, 2004).

Work toward effective teaming. To be effective, teaming must be cohesive, with all teachers adhering to the same rules and following the same procedures. These principles seem to be particularly important for boys and all-boy teams. Experienced teachers on a team must help new teachers and mentor them as they grow in their skills 
and capabilities. Team leadership can be coordinated (1) to improve student performance on homework and class work in all subject areas; (2) to reward good behavior and academic performance; (3) and to maintain high standards for behavior and participation within the classes. Leaders of cohesive teams can also collaborate to monitor progress and mentor individual students. Study results suggested that teacher experience in working together over a period of several years also contributed to a team's ability to function successfully.

Be an instructional leader. The leadership of Ms. Glover at Greenville served as a possible model for instructional leadership. Also, research suggests that teacher efficacy and competence can be increased when the school's administration provides relevant professional development and allows teachers to participate in instructionally relevant descision-making (Goddard, Hoy, \& Hoy, 2000; 2004).

Make a strong commitment to single-gender education. Once a faculty embraces single-gender classes as a key component for improved achievement, they should avoid the adoption of other agendas. A strong "buy-in" to the single-gender program was present among faculty at both Terre Rouge and Greenville. At Bluefield, however, separating other students from those in the honors track seemed to be a priority that detracted from implementing the gendered-class program. On the other hand, educators at Terre Rouge and Greenville focused on the implementing single-gender classes as essential pieces of overall plans to improve. Accordingly, they directed efforts toward modification of structures and teaching strategies for both boys and girls.

\section{Teacher Characteristics}

Research indicates that low-scoring, high-poverty schools have the least experienced teachers (Barth, 2000). Yearly tallies of new teachers at Terre Rouge agreed 
with this finding. So when principals in low-scoring schools are seeking new teachers, they may not be able to recruit those that are the most experienced. Thus, school administrators may need to consider seeking teachers who seem to have qualities and characteristics that can be developed and nurtured as they grow in skill and expertise for teaching in a particular context. Important characteristics to consider include a teacher's gender and ethnicity and a teacher's affinities for innovation and reflection.

Gender and ethnicity. Other research (Hudley, 1998; Gurian, 2000) has found that males, and particularly African-American males, can have special affinities for teaching and mentoring middle school boys of mixed ethnicities. Mr. Blake believed that as an African-American male, he was able to develop relationships with his students and more successfully guide and mentor them.

Innovative and reflective teachers. Research indicates that teachers cannot learn all they need to know about the profession in teacher preparation programs and that most of their knowledge for teaching is based on what they do after they enter their own classrooms (Cooney \& Stinson, 2003; Hiebert, et al., 2003). Hence, administrators should look for teachers who are willing to be innovative, reflect on practice, and experiment with new strategies. They should also seek new teachers who are resourceful and seek out others for advice and collaboration. In a previous study, I had the opportunity to interview and observe a dedicated teacher at Terre Rouge, who had begun there as a new teacher over a decade before.

These are tough kids to teach. When I first started teaching here, I could have gone home everyday and cried. I could have felt sorry for myself and accepted defeat. But when I finished each school day, I asked myself, "What can I do to help these kids; what can I do to teach them better?” And, all along the way, I have sought advice and help from other teachers and have tried new ways to reach and teach my students. 
From the beginning of her career, she appreciated the importance of innovation and reflection. In talking with prospective teachers, administrators should look for teachers like this one.

\section{Suggestions for Teaching Boys}

Both teachers and administrators at Greenville were encouraged by increases in boys’ mathematics achievement scores. At Terre Rouge, boys also led the test score increases. Results of this study, as well as other investigations of boys' learning can provide guidance for those teaching mathematics to boys.

Classroom management and behavior as priorities. The study revealed that, in teaching boys, classroom behavior management was a first priority and that relevant structures had to be in place before learning benefits could be realized. Cohesive team leadership facilitated shared structures and consistent rule enforcement, because boys often tend to test limits of structures established for them (Gurian, 2001; Baker, 2002). In interviews, boys reported that a few disruptive students inhibited student learning. Observations confirmed that it usually was just a few who caused the problems, but the silent, cooperative majority relied on the adults to rid classes of negative influences and provide an environment conducive to learning. Teachers argued that removal of these students was not possible, but as Mr. Blake had done, teachers of boys must develop strategies for dealing with problem students.

Engagement and motivation. Psychologists and educational researchers agree that middle school boys are frequently unmotivated academically and do not enjoy school (Noble \& Bradford, 2000; Gurian, 2000; Gentry,et al., 2002). Others claim that schools are not boy-friendly (Pollack, 1998; Sommers, 2000). Teachers at Greenville demonstrated that strategies such as jokes and theatrics, movement in learning, 
competition, games, and work with manipulatives engaged and motivated middle school boys for the study of mathematics and improved student outcomes.

Competition. Teachers and administrators at Terre Rouge and Greenville spoke frequently of the competitiveness they had observed among their male students. Mr. Blake commented that boys enjoyed competition, making them frequently persistent when encountering difficult problems. Ms. Edwards identified the lure of competition as her most successful strategy with boys. When I questioned Dr. Russell at Terre Rouge about why she thought that boys' scores had increased more than girls, she commented as follows:

These boys seem to have competitive spirits. They respond to academic competitions with girls and take it very seriously, whereas the girls don't really become engaged in it. Boys far surpassed the girls on their writing portfolios last year. It was the boys who came in during spring break and stayed several days a week after school to improve their writing. Boys will take it to the highest levels possible because being proficient, being distinguished is an allure with them. I don't think we've moved our girls far enough along where those kinds of carrots have the same kind of appeal. The girls will comply but won't exceed the standard.

It is important to interpret Dr. Russell's comments as statements about middle school girls at Terre Rouge and not about female students in general. Previous research at Terre Rouge showed that teacher leadership of boys may have been a factor contributing to their academic attitudes (Davis, et al., 2004). Ms. Baxter reported that, at Bluefield, students who pursued excellence most frequently were girls.

Sustained engagement. Once disruptive behaviors were kept under control and boys were engaged in class activities, this study suggested that boys sustained their engagement and remained on-task in the all-boy classes. Teachers also observed boys’ gifts for learning and affinities for mathematics. Teachers suggested that boys sustained their engagement even as they communicated with their classmates. "Boys work while they talk,” said Ms. Edwards. She also noticed that while boys were working, she could 
talk to them briefly about sports and they would go right back to the task. Mr. Fisher also noticed that boys' communication and socialization related to common interests and tasks. "My boys tend to open up to me when we're working on a math problem," he said. Mr. Blake noted that boys stuck to a task and did not get frustrated. Ms.Ingram added, "If boys don't get a problem right, they don't quit and shut down. Boys who were interviewed agreed that learning mathematics was important and many gave specific reasons for its importance to them in areas of employment, personal finance, and family life.

\section{Suggestions for Teaching Mathematics}

Research in mathematics education strongly suggests that, if all are to reach higher levels of mathematics proficiency, mathematics teaching should be more contextual. It should focus on relationships between students and teachers as they interact with the mathematics content and balance itself among the five interconnected strands of proficiency: conceptual understanding; procedural fluency; strategic competence; adaptive reasoning; and productive disposition (Cohen \& Ball, 2000; Kilpatrick, et al., 2001). The following suggestions apply to teachers for improving their mathematics teaching and may pertain to the teaching of mathematics in all-boy, all-girl, and mixed classes.

Build efficacy, knowledge, and skill for teaching mathematics. Teachers of this study believed student-centered learning was beneficial for their classes, however observations indicated a shortage of student-centered activities during lessons. Mathematics teachers reported that boys enjoyed student-centered activities, such as hands-on work with manipulatives and problem solving. Observations of classes also suggested that boys became engaged in these types of activities and required fewer 
teacher reminders about behavior. Other research indicates that to teach mathematics effectively, teachers must continue to deepen their own understandings and to develop skills in mathematics discourse and in communicating their knowledge with students (Kilpatrick, et al., 2001; Hiebert, et al., 2003). For teachers to increase skills and knowledge for student-centered teaching, they should have opportunities for on-going professional development where teachers discuss mathematical ideas, explain thinking, and explore a variety of problem solving strategies.

Focus on balanced teaching. According to the framework of the five strands of mathematics proficiency (Kilpatrick, et al., 2001), teaching should be balanced so that the interwoven strands are developed simultaneously and with equal emphasis (Kilpatrick, et al., 2001). To maintain balance, teachers should include a variety of activities - handson, group, teacher-led explanations, practice, homework review, problem solving, and games. Observations of all-boy classes revealed that instruction was frequently teachercentered. Boys quickly lost interest when teacher explanations of problem solutions and procedures became too long. Even though Mr. Fisher's classes were innovative and entertaining, he concluded that he had spent too much time on all-class activities and not enough time on individual practice. Table 4-13 and Appendix F provide details for measuring the amount of time devoted to various types of class activities and could be of assistance to teachers who strive for more balance in their lessons.

Encourage higher level thinking through problem solving. The study showed that once teachers implemented an effective classroom management system and enfoced it, they sustained boys' engagement for the study of mathematics. Mathematics teachers should use these opportunities to raise student levels of thinking through discussions and questions about problems, strategies, and mathematical ideas. Boys' affinities for 
problem solving strategies, particularly short cuts, became apparent in studying the allboy classes. In their own preparations, teachers should explore a variety of strategies, both for solving problems and for connecting with student thinking and prior knowledge.

To raise levels of student thinking, teachers should work through as many problems provided in curriculum materials as possible. To develop the interwoven strands of proficiency simultaneously, exercises should include both skills practice and problem-solving activities. By working a large number of problems from a variety of types and applications, mathematics teachers should learn to appreciate student thinking; better help students strategize, generalize, and apply a lesson's concepts more broadly; and recognize errors, both students' and one’s own, in computation and reasoning. Working a problem means checking and correlating results with answers provided by the curriculum; the problem cannot be fully understood until these points of view are reconciled.

For additional questions a teacher may have about particular problems or activities, teachers should consult with other teachers. Some of the new and nontraditional curriculum materials are designed to be educative curriculum materials (Davis \& Krajcik, 2005). Careful study of these materials may provide teachers with a variety of problems that encourage higher level thinking and provide real-world applications.

Use technology. Technology was rarely used in the boys' classes of this study, although male preferences for activities which emphasize mastery of objects and using technological tools have been frequently documented (Leder, 1990; Baker, 2002). Computers and calculators give boys many things they really like - practicality, hands-on activities, instant results, and easy accessibility to graphs and tables (Noble \& Bradford, 2000). The use of calculators can reduce a student's focus on procedures when it is not 
part of the lesson, enhance learning of both concepts and skills, and improve student attitudes (Hembree \& Dessart, 1992; Waits \& Demana, 2000).

Implications for Further Research

Further research is needed to verify relationships, clarify findings, and seek additional details surrounding the four questions of this study of all-boy mathematics classes in middle school. Future research may also explore ways that school, teacher, and classroom factors relate to teaching mathematics in all-girl classes or to other experimental strategies that educators might use to improve targeted student outcomes. The following sections describe a few possible areas for future inquiry.

\section{A Single-Gender Program in Long Beach, California}

Additional and confirmatory information about single-gender education might be gained by testing and refining the relational diagram (See Figure 5-2) in other singlegender programs, as well as seeking additional structures and strategies found to be successful for teaching in the all-boy context. Study of the program at Jefferson Leadership Academy in Long Beach, California might be beneficial because of its longevity and success. The Long Beach program began approximately five years before schools of this study adopted single-gender classes, and leaders at Terre Rouge Middle School used this California middle school as a model for their single-gender program. Future research might use the relational diagram developed in this study to build a model for implementation of an all-boy class program and to then test it quantitatively.

Single-Gender Schools vs. Gendered Classes.

All three schools of the current study were coeducational middle schools that had instituted single-gender classes as part of an improvement program. Using the same design, future investigations might explore similar factors and their relationships in 
single-gender schools and provide additional information for educators interested in implementing a single-gender program. There is currently a nationwide study being conducted on the effectiveness of single-gender schools on all educational levels. Under the directorship of sociology professor Cornelius Riordan, the study team will collect data through a web-based survey and classroom observations. Investigators have also planned to explore theoretical constructs concerning the operation of single-gender schools and to seek reasons that they may have different educational and developmental outcomes (Riordan, Faddis, Seager, \& Mael, 2004).

Single-Gender Education for Girls

Another possible line of research would be detailed study of all-girl mathematics classes. Teachers reported that girls were not as engaged by competition as were the boys and that they had preferred to complete their work and then talk about other things. Perhaps there are differences in how to engage and motivate girls for reaching higher levels of proficiency. Research methods might include beginning with the current model; using a similar study design (comparative cases of several schools and several all-girl mathematics teachers in each school); and asking the same four research questions about factors affecting implementation of a single-gender program for girls.

\section{Research on Characteristics of Mathematics Teaching}

Research in mathematics education suggests that student-centered teaching and teaching for mathematics proficiency require additional teacher knowledge and expertise (Kilpatrick, et al., 2001; Ross, et al., 2002). In an NCTM position statement of July 2005, "highly qualified" mathematics teachers were defined as those who major in mathematics in college; understand how students learn mathematics; know how to engage students from different backgrounds; and commit to lifelong professional 
learning. Mathematics educators also speak of a shortage of qualified teachers in classrooms (Reys \& Reys, 2004). Results of this study revealed many differences in the nature of the mathematics teaching. Two tools were developed in the current study, an observational framework of time allocation (See Table 5-7 and Appendix F) and an observational framework of teaching for mathematics proficiency (See Table 5-8 and Appendix G), that might prove useful for gathering further details about teaching practices and student learning.

A limitation of the current study was having only one observer of instances occurring in observations that related them to research on teaching. Many questions arose: What constitutes mathematics discourse or an open-ended question? What is the relationship between strategic competence and procedural fluency? Is practice teachercentered or student-centered? Additional qualitative research, using video-taped observations and collaborations of several researchers, is needed to clarify classifications and answer questions. A design-based research methodology could be used to create teacher/researcher collaborative partnerships and employ cycles of enactment, evaluation, and modification of lessons and teaching strategies. Beginning with framework from the current study, teachers and researchers could monitor student learning and continually improve practices toward a goal of higher levels of mathematics proficiency.

So, What about the Boys?

This study's perspectives on boys and their learning - bonding over common interests, a reluctance to quit, revelations of talents, and “competitive spirits” -- reminded me of a camera shot of the basketball court following the final game for the 2005 NCAA basketball championship. The Tar Heels had just won the title, fans and players covered the court, and celebrations had begun. A particular visual image from those post-game 
moments lingered in my memory and connected in my mind to findings about boys. It was the image of North Carolina basketball star Rashad McCants as he embraced his coach, Roy Williams. It was a long embrace, and McCants draped his overly tall, lanky frame over the grey-haired coach’s shoulders and was weeping (See Figure 5-3).

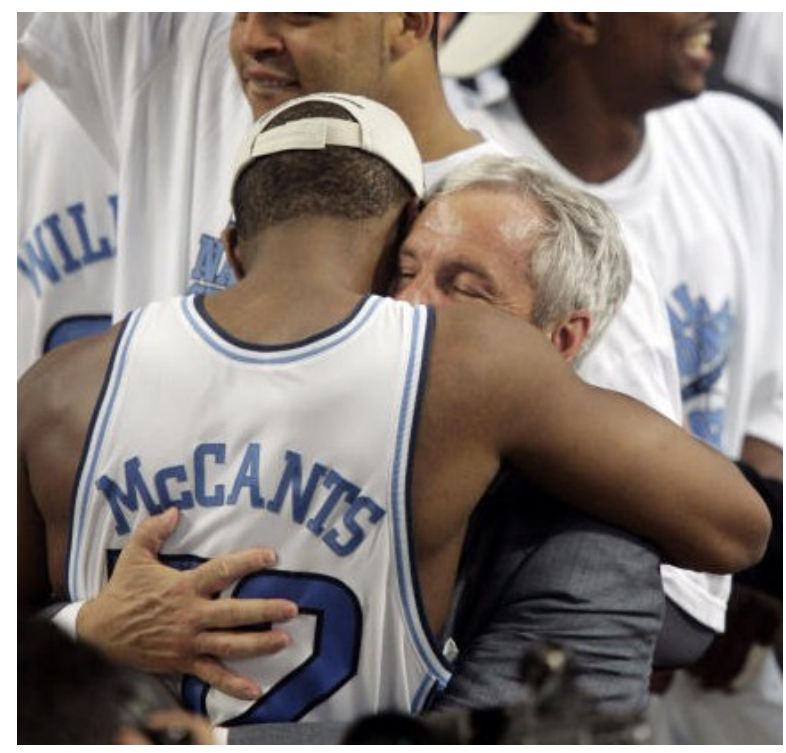

Figure 5-3. Rashad McCants hugs Roy Williams after the 2005 NCAA Championship

Why was he weeping as he held tightly to his coach? He was weeping for joy, for victory, for love, for gratitude - embracing all of his coaches, teachers, mentors, and family members, both in his mind and in his heart. Just like those at Terre Rouge, Greenville, and Bluefield, Rashad McCants was once a middle school boy; and like too many middle school boys, he could have remained unengaged, unmotivated, and unaware of his many gifts. But his coaches, teachers, and mentors, bonded with him through a common interest, guided him in developing his gifts, and encouraged his unyielding and competitive spirit. As Dr. Russell said about her students at Terre Rouge Middle School, "Once you reach them, they will go with you anywhere." 
In the area of sports, society accepts that proficiency, excellence and expertise are acquired through coaching, practice, and sustained effort. Children are encouraged to work hard and try their best at every level. But for academic pursuits all students may not be receiving the support and encouragement they need to pursue excellence. The conceptualization of mathematics proficiency as five interwoven strands moves achievement beyond test performance based on memorized procedures and facts and into the realm of expertise and multiple competencies. All-boy classes may provide opportunities to reach boys at risk of failing or dropping out of school and encouragement for boys to seek higher standards of proficiency and excellence. Research suggests that effective teaching of mathematics, characterized by engaging students in mathematical discourse and high-level thinking to be student-centered and contextual in nature. Singlegender contexts could support teaching directed toward mathematics proficiency for all students, and thus, could open doors for boys in high school, college, and beyond. 


\section{REFERENCES}

American Association of University Women. (1995). How schools shortchange girls. New York: Marlowe \& Company.

American Association of University Women. (1998). Separated by gender: A critical look at single-gender education for girls. Washington, DC: American Association of University Women.

Anfara, V. A., \& Brown, K. M. (2000). An unintended consequence of a middle school reform: Advisories and the feminization of teachers. Middle School Journal, 2631.

Artzt, A.\& Armour-Thomas, E. (2002). Becoming a reflective mathematics teacher: A guide for observations and self-assessment. Mahwah, NJ: Lawrence Erlbaum Associates.

Ashton, P. T., \& Webb, R. B. (1986). Making a difference: Teachers' sense of efficacy and student achievement. New York: Longman.

Baker, D. (1999). Winners and Losers in Single-gender Science and Mathematics Classrooms. Paper presented at the Annual Meeting of National Association of Research in Science Teaching, Boston, MA.

Baker, D. R. (2002). Good intentions: An experiment in middle school single-gender science and mathematics classrooms with high minority enrollment. Journal of Women and Minorities in Science and Engineering, 8(1), 1-23.

Ball, D. L. (2000). Working on the inside: Using one's own practice as a site for studying teaching and learning. In R. A. Lesh \& A. E. Kelly (Eds.), Research Design in Mathematics and Science Education (pp. 365-402). Mahwah, NJ: Lawrence Erlbaum and Associates.

Ball, D. L. B., Lubienski, S. T., \& Mewborn, D. S. (2001). Research on teaching mathematics: The unsolved problem of teachers' mathematical knowledge. In V. Richardson (Ed.), Handbook on Teaching (4th ed.). Washington, DC: American Educational Research Association.

Bandlow, R. J. (2001). The misdirection of middle school reform: Is a child-centered approach incompatible with achievement in mathematics and science. Clearing House, 75(2), 69. 
Bandura, A. (1997). Self-Efficacy: The Exercise of control. New York: Freeman.

Baron-Cohen, S. (2003). The essential difference: The truth about the male and female brain. New York: Basic Books.

Barth, P. (Ed.). (2000). Honor in the boxcar: Equalizing teacher quality. Thinking K-16, 4 (1). Washington, DC: Education Trust.

Beane, J. A. (1999a). Middle schools under siege: Points of attack. Middle School Journal, 30(4), 3-9.

Beane, J. A. (1999b). Middle schools under siege: Responding to the attack. Middle School Journal. 30 (5), 3-6.

Beane, J. A., \& Brodhagen, B. L. (2001). Teaching in Middle Schools. In V. Richardson (Ed.), Handbook of Research on Teaching (4th Edition ed., pp. 1157-1174). Washington, DC: American Educational Research Association.

Becker, J. P., \& Jacob, B. (2000). The politics of California school mathematics. Phi Delta Kappan, 81(7), 529-537.

Bennett, J., Chard, D. Jackson, A., Milgram, J., Sheer, J., \& Waits, B. (2004). Holt Middle School Mathematics: Course 1. Austin, TX: Holt, Rinehart, \& Winston.

Bennett, J., Chard, D. Jackson, A., Milgram, J., Sheer, J., \& Waits, B. (2004). Holt Middle School Mathematics: Course 2. Austin, TX: Holt, Rinehart, \& Winston.

Boaler, J. (1997). Experiencing school mathematics: Teaching styles, gender, and setting. Buckingham, UK: Open University Press.

Boaler, J. (1998). Open and closed mathematics: Student experiences and understandings. Journal for Research in Mathematics Education, 29 (1), 41-42.

Bong, M. (1999). Personal factors affecting the generality of academic self-efficacy judgments: Gender and ethnicity. Journal of Experimental Education, 67(4), 315.

Borsuk, A. J. (2003, October 4, 2003). Division flares up over math. Milwaukee Journal Sentinel.

Borsuk, A. J. (2003). Rhetoric aside, math does matter: But as technological demands rise, performance in U.S. seen as inadequate. Milwaukee Journal Sentinel.

Boyle, M., Benbow, C., \& Alexander, J., (1995) Sex differences, hemispheric laterality, and associated brain activity in the intellectually gifted. Developmental Neuropsychology 11, 415-443

Bradley, A. (1998). Muddle in the middle. Education Week, 17(31). 
Brand, S., Felner, R., Shim, M., Seitsinger, A., \& Dumas, T. (2003). Middle school improvement and reform: Development and validation of a school-level assessment of climate, cultural pluralism, and school safety. Journal of Educational Psychology, 95(3), 570-588.

Bransford, J. D., Brown, A. L., \& Cocking, R. R. (Eds.). (2000). How People Learn: Brain, Mind, Experience, \& School. Washington, DC: National Academy Press.

Brolin, H., \& Bjork, l. (1992). Introducing calculators in Sweedish schools. In J. T. Fey \& C. Hirsch (Eds.), Calculators in mathematics education (1992 Yearbook) (pp. 226-232). Reston, VA: National Council for the Teachers of Mathematics.

Brookover, W. B., Beady, C., Flood, P., Schweitzer, J., \& Wisenbaker, J. (1979). School social systems and student achievement: Schools can make a difference.

Bucher, K. T., \& Manning, M. L. (2001). Exploring the foundations of middle school classroom management. Childhood Education, 78(2), 84-90.

Cairns, E. (1990). The relationship between adolescent perceived self-competence and attendance at single-gender secondary schools. British Journal of Educational Psychology, 60, 210.

Campbell, P. B., \& Storo, J. (1994a). Why me? Why my classroom? The need for equity in coed math and science classes. Washington, D.C.: Department of Education.

Campbell, P. B., \& Storo, J. N. (1994b). Girls are... boys are...: Myths, stereotypes, \& gender differences. Washington, D.C.: Department of Education.

Carnegie Council on Adolescent Development (1989). Turning points: Preparing American youth for the 21st century. New York: Carnegie Corporation.

Carpenter, T. P., Fennema, E., \& Franke, M. L. (1996). Cognitively Guided Instruction: A knowledge base for reform in primary mathematics instruction. Elementary School Journal, 97(1).

Cohen, D. K., \& Ball, D. L. (2000, April 2000). Instructional innovation: Reconsidering the story. Paper presented at the Annual Meeting of the American Educational Research Association, New Orleans, LA.

Coleman, J. S., Campbell, E. Q., Hobson, C. J., McPartland, J., Mood, A. M., Weinfield, F. D., et al. (1966). Equality of Educational Opportunity. Washington, D.C.: U.S. Government Printing Office.

Connell, R. W. (1996). Teaching the boys: New research on masculinity and gender strategies for schools. Teachers College Record, 98(2), 206-236. 
Cooney, T., \& Stinson, D. (2003, April, 2003). What constitutes good mathematics teaching and how it develops: Nine high school teachers' perspectives. Paper presented at the Research pre-session for the annual meeting of National Council for the Teachers of Mathematics, San Antonio, TX.

Cramer, K. A., Post, T. R., \& delMas, R. C. (2002). Initial fraction learning by fourthand fifth grade students: A comparison of the effects of using commercial curricula with the effects of using the Rational Number Project curricula. Journal for Research in Mathematics Education, 33(2), 111-144.

Datnow, A., Hubbard, L., \& Conchas, G. Q. (2001). How context mediates policy: The implementation of single gender public schooling in California. Teachers College Record, 103(2), 184-206.

Davis, A. N., Choi, N., Ronau, R. N., \& Munoz, M. (2004, April 12-16, 2004). Singlegender Classes in an Urban Middle School: The Pilot Year. Paper presented at the American Educational Research Association, San Diego, CA.

Davis, E. \& Krajcik, J.(2005) Designing educative curriculum materials to promote teacher learning. Educational Researcher 34(3), p 3-14.

Design-Based Research Collaborative. (2003). Design-based research: An emerging paradigm for educational inquiry. Educational Researcher 32(1), 5-8.

Durost, R. (1996). Single-gender math classes: What and for whom? One school's experience. NASSP Bulletin, 80(557), 27-31.

Earnest, P. (1989). The knowledge, beliefs, and attitude of the mathematics teacher: A model. Journal of Education for Teaching, 15(10), 13-33.

Edmonds, R. (1979). Effective schools for the urban poor. Educational Leadership, 37, 15-23.

Erb, T. O. (2000). Middle schools: Requiem or renewal? Middle School Journal, 30 (1), 2.

Evans, M. D. (1993). A single-gender learning strategy. Principal, 73(1), 52-53.

Feller, B. (2004, March 6, 2004). Limits on single-gender public schools to be loosened. Associated Press.

Felner, R., \& Jackson, A. (1997). The impact of school reform for the middle years: Longitudinal study of a network engaged in Turning-Points-based comprehensive school transformation. Phi Delta Kappan, 78(7), 528-543.

Fennema, E. (1972). Models in mathematics. Arithmetic Teacher, 19(8), 635-640.

Fennema, E. (1990a). Justice, equity, and mathematics education. In E. Fennema (Ed.), Mathematics and Gender (pp. 1-9). New York: Teachers College Press 
Fennema, E. (1990b). Teachers' beliefs and gender differences in mathematics. In E. Fennema \& G. C. Leder (Eds.), Mathematics and Gender (pp. 214). New York: Teachers College Press.

Fennema, E., Carpenter, T. P., Franke, M. L., Levi, L., Jacobs, V. R., \& Empson, S. B. (1996). A longitudinal study of learning to use children's thinking in mathematics instruction. Journal for Research in Mathematics Education, 27, 403-434.

Fennema, E., \& Leder, G. C. (1990). Gender differences in mathematics: A synthesis. In E. Fennema \& G. C. Leder (Eds.), Mathematics and Gender (pp. 214). New York: Teachers College Press.

Fennema, E., \& Leder, G. C. (Eds.). (1990). Mathematics and Gender. New York: Teachers College Press.

Fennema, E., \& Leder, G. C. (Eds.). (1990). Mathematics and Gender. New York: Teachers College Press

Foon, A. (1988). Relationship between school type and adolescent self-esteem, attribution, styles, and affiliation needs. British Journal of Educational Psychology, 58, 44-54.

Foster, V., Kimmel, M., \& Skelton, C. (2001). "What about the boys?": An overview of the debates. In W. Martino \& B. Meyenn (Eds.), What about the boys? Issues of masculinity in schools. Philadelphia, PA: Open University Press.

Friedkin, N. E., \& Slater, M. R. (1994). School leadership and performance: A social network approach. Sociology of Education, 67, 139-157.

Gentry, M. \& Gable, R. (2001). My class activities: A survey instrument to assess students' perceptions of interest, challenge, choice, and enjoyment in their classrooms. Mansfield Center, CT: Creative Learning Press.

Gentry, M., Gable, R. K., \& Rizza, M. G. (2002). Students' perceptions of classroom activities: Are there grade-level and gender differences. Journal of Educational Psychology, 94(3), 539-544.

George, P., \& Shewey, K. (1994). New Evidence for the Middle School. Columbus, OH: National Middle School Association.

Gibson, S., \& Dembo, M. H. (1984). Teacher efficacy: A construct validation. Journal of Educational Psychology, 76, 569-582.

Gilbert, R., \& Bush, W. S. (1988). Familiarity, availability, and use of manipulative devices in mathematics at the primary level. School Science and Mathematics, 88(6), 459-469.

Glencoe Mathematics (2004). Applications and concepts: Course 1. New York:Glencoe McGraw Hill 
Glencoe Mathematics (2004). Applications and concepts: Course 2. New York:Glencoe McGraw Hill

Glencoe Mathematics (2004). Pre-Algebra. New York: Glencoe McGraw Hill.

Goddard, R. D. (2002). Collective efficacy and school organization: A multilevel analysis of teacher influence in schools. Theory and Research in Educational Administration, 1, 169-184.

Goddard, R. D., Hoy, W. K., \& Hoy, A. W. (2000). Collective teacher efficacy: Its meaning, measure, and impact on student achievement. American Educational Research Journal, 37(2), 479-507.

Goddard, R. D., Hoy, W. K., \& Hoy, A. W. (2004). Collective Efficacy Beliefs: Theoretical Developments, Empirical Evidence, and Future Directions. Educational Researcher, 33(3), 3-13.

Good, T. L., \& Brophy, J. E. (1986). School Effects. In M. C. Wittrock (Ed.), Handbook of Research on Teaching (third ed., pp. 570-602). New York: Macmillan.

Groves, S. (1993). The effect of calculator use on third graders' solutions of real-world division and multiplication problems. Paper presented at the Seventeenth International Conference for the Psychology of Mathematics Education, Tsukuba, Japan.

Groves, S. (1994, April 1994). Calculators: A learning environment to promote number sense. Paper presented at the Annual meeting of the American Educational Research Association, New Orleans, LA.

Gurian, M. (2001). Boys and girls learn differently! A guide for teachers and parents. San Francisco, CA: Jossey Bass.

Haag, P. (2000). K-12 single-gender education: What does the research say? Washington, DC: Office of Educational Research and Improvement.

Hansen, D. T. (2002). The moral environment of an inner-city boys' high school. Teaching and Teacher Education, 18(2), 183-204.

Hatfield, M. (1994). Use of manipulative devices: Elementary school cooperative teacher self-report. School Science and Mathematics, 94(6), 303.

Heller, P. M., Post, T. R., Behr, M., \& Lesh, R. (1990). Qualitative and numerical reasoning about fractions and rates by seventh and eighth grade students. Journal for Research in Mathematics Education, 21(5), 388-402.

Hembree, R., \& Dessart, D. J. (1986). Effects of hand-held calculators in pre-college mathematics education. Journal for Research in Mathematics Education, 17, 8399. 
Hembree, R., \& Dessart, D. J. (1992). Research on calculators in mathematics education. In J. T. Fey \& C. Hirsch (Eds.), Calculators in mathematics education (1992 Yearbook) (pp. 23-32). Reston, VA: National Council for the Teachers of Mathematics.

Henson, R. K., Krogan, L. R., \& Vacha-Haase, T. (2001). A reliability generalization study of the Teacher Efficacy Scale and related instruments. Educational and Psychological Measurement, 61(3), 404-420.

Herr, K., \& Arms, E. (2002). The intersection of educational reforms: Single gender academies in a public middle school. In A. Datnow \& L. Hubbard (Eds.), Gender in policy and practice: perspectives on single-gender and coeducational schooling (pp. 74-89). New York, NY: RoutledgeFalmer.

Hester, P., Gable, R. A., \& Manning, M. L. (2003). A positive learning environment approach to middle school instruction. Childhood Education, 79(3), 130-136.

Hiebert, J., Morris, A. K., \& Glass, B. (2003). Learning to learn to teach: An "experiment" model for teaching and teacher preparation. Journal of Mathematics Teacher Education, 6(3), 201-222.

Hiebert, J., Wearne, D., \& Taber, S. (1991). Fourth graders' gradual construction of decimal fractions during instruction using different physical representations. 91 (4), 321-341. This finding is supported by Wearne and Hiebert (1988). Elementary School Journal,, 91(4), 321-341.

Hoy, W. K., \& Hannum, J. W. (1997). Middle school climate: Assessment of organizational health and student achievement. Educational Administration Quarterly, 33(3), 290-311.

Hoy, W. K., \& Sabo, D. J. (1998). Quality middle schools: Open and healthy. Thousand Oaks, CA: Sage Publications.

Hoy, W. K., \& Woolfolk, A. (1993). Teachers' sense of efficacy and the organizational health of schools. Elementary School Journal, 93(4), 355-372.

Hudley, C. (1997). Teacher practices and student motivation in a middle school program for African-American males. Urban Education, 32(2), 304-319.

Hudley, C. (1998, April 13-17, 1998). Urban Minority Adolescents' Perceptions of Classroom Climate. Paper presented at the Annual Meeting of the American Educational Research Association, San Diego, CA.

Kaplan, R. G. (1991, October 1991). Teacher beliefs and practices: A square peg in a round hole. Paper presented at the Annual meeting of the North American Chapter of the International Group for the Psychology of Mathematics Education, Blacksburg, VA. 
Kaukas, D. (2003, September 16, 2003). Single-gender classes found to cut failure rate. Courier-Journal.

Kilpatrick, J., Swafford, J., \& Findell, B. (Eds.). (2001). Adding it up: Helping children to learn mathematics. Washington, DC: National Academy Press.

Kloosterman, P. (1990). Attributions, performance following failure, and motivation in mathematics. In E. Fennema (Ed.), Mathematics and Gender. New York: Teachers College Press.

Koehler, M. S. (1990). Classrooms, teachers, and gender differences in mathematics. In E. Fennema (Ed.), Mathematics and Gender. New York: Teachers College Press.

Kuhs, T. M., \& Ball, D. L. (1986). Approaches to teaching mathematics: Mapping the domains of knowledge, skills, and dispositions. East Lansing, MI: Center on Teacher Education.

Lappan, G., Fey, J. T., Fitzgerald, W. M., \& Phillips, E. D. (2002). Connected Mathematics: Data About Us ( $6^{\text {th }}$ grade) Glenview, IL: Prentice Hall.

Leder, G. C. (1990). Gender differences in mathematics: An overview. In E. Fennema (Ed.), Mathematics and Gender. New York: Teachers College Press.

Leder, G. C. (1990). Teacher/student interactions in the mathematics classroom: A different perspective. In E. Fennema (Ed.), Mathematics and Gender (pp. 214). New York: Teachers College Press.

Leder, G. C., \& Fennema, E. (1990). Synthesis: Gender differences in mathematics. In E. Fennema \& G. C. Leder (Eds.), Mathematics and Gender (pp. 188-199). New York: Teachers College Press.

Lee, V., \& Bryk, A. (1986). Effects of single-gender secondary schools on student achievement and attitudes. Journal of Educational Psychology, 78, 381-395.

Lee, V., \& Burkham, D. T. (1996). Gender differences in middle grade science achievement: Subject domain, ability level, and course emphasis. Science Education, 80(6), 613-650.

Lee, V., \& Smith, J. (1993). Effects of school restructuring on the achievement and engagement of middle grades students. Sociology of Education, 66, 164-187.

Lerman, S. (1983). Problem solving or knowledge centered: The influence of philosophy on mathematics teaching. International Journal of Mathematics Education in Science and Technology, 14(1), 59-66.

Mael, F. A. (1998). Single-gender and coeducational schooling: Relationships to socioemotional and academic development. Review of Educational Research, 68(2), 101-129. 
Manning, M. L., Lucking, R., \& MacDonald, R. H. (1995). What works in urban middle schools. Childhood Education, 221- 224.

Marsh, H. W., Smith, I. D., Marsh, M., \& Owens, L. (1988). The transition for singlegender to coeducational high schools: Effects on multiple dimensions of selfconcept and on academic achievement. American Educational Research Journal, 25(2), 237-269.

Marzano, R. J. (2003). What works in schools: Translating research into action. Alexandria, VA: Association for Supervision and Curriculum Development.

McCleery, B. (2002, August 1, 2002). Idea proposed in New Palestine (Indiana) may improve learning, but some aren't convinced. Indianapolis Star.

Meyer, M. R., \& Koehler, M. S. (1990). Internal Influences on Gender Differences in Mathematics. In E. Fennema (Ed.), Mathematics and Gender. New York: Teachers College Press

Michie, F., Glachan, M., \& Bray, D. (2001). An evaluation of factors influencing the academic self-concept, self-esteem, and academic stress for direct and re-entry students in higher education. Educational Psychology, 21(4), 455-472.

Midgley, C. (2001). A goal theory perspective on the current status of middle level schools. In F. Pajares \& T. Urdan (Eds.), Adolescence and Education (pp. 33-59). Greenwich, CT: Information Age Publishing.

Murgendollar, J. R. (1993). Introduction: The role of research in middle grades reform. The Elementary School Journal, 93(5), 443-446.

National Council for the Teachers of Mathematics. (1989). Curriculum and evaluation standards for school mathematics. Reston, VA: National Council for the Teachers of Mathematics.

National Council for the Teachers of Mathematics. (2000). Principles and Standards for school mathematics. Reston, VA: National Council for the Teachers of Mathematics.

National Middle School Association (1995) This we believe: Developmentally responsive middle schools. Columbus, OH.: The Association.

Neumann, M. (2003, June 2003). Enhancing teachers' understanding of effective mathematics instruction. Paper presented at the Ethnographic and Qualitative Research in Education, Pittsburgh, PA.

Neufeld, R. (2001) Understanding Mathematics. [Computer software]. London, Ontario, Canada: Neufeld Learning Systems, Inc

Newcomb, A. (2000, August 1). Back-seat boys. Retrieved May 29, 2003 
Newkirk, T.(2002). Misreading masculinity: boys, literacy, and popular culture. Portsmouth, NH: Heinemann.

Noble C. \& Bradford, W. (2000) Getting it right for boys...and girls. London: Routledge

O'Brien, V., Martinez-Pons, M., \& Kopala, M. (1999). Mathematics self-efficacy, ethnic identity, gender, and career interests related to mathematics and science. Journal of Educational Research, 92(4), 231-235.

Pajares, F. (1996). Self-efficacy beliefs in academic settings. Review of Educational Research, 66(4), 543-578.

Pajares, F., \& Miller, M. (1994). Role of self-efficacy and self-concept beliefs in mathematical problem solving: A path analysis. Journal of Educational Psychology, 86(2), 193-203.

Parsons, T. (1967). Some ingredients of a general theory of formal organization. In A.W. Halpin (Ed.), Administrative Theory in Education (pp 40-72). New York: Macmillan.

Perry, W. (1996). Gender-based education: Why it works at the middle school level. NASSP Bulletin, 80(577), 32-35.

Phillips, M. (1997). What makes schools effective? A comparison of the relationships of communitarian climate and academic climate to mathematics achievement. American Educational Research Journal, 34(4), 633-662.

Pollack, W. (1998). Real boys: Rescuing our sons from the myths of boyhood. New York: Henry Holt and Company.

Raymond, A. M. (1997). Inconsistency between a beginning elementary school teacher's mathematics beliefs and teaching practice. Journal for Research in Mathematics Education, 28(5), 550-576.

Remillard, J.(2005) Examining key concepts in research on teachers' use of mathematics curricula. Review of Educational Research, 75 (2), 211-246.

Rennie, L. J., \& Parker, L. H.(1997). Students' and teachers' perceptions of single-gender and mixed-gender mathematics classes. Mathematics Education Research Journal, 9(3), 257-273.

Reys, B. (2004). Student achievement and reform curricula. Paper presented at the Research Pre-Session, National Council for the Teachers of Mathematics, April $19-21$.

Reys, B. J., \& Reys, R. E. (2004). Recruiting mathematics teachers: Strategies to consider. Mathematics Teacher, 97(2), 93-95.

Richardson, J. (1995). Separated by gender. Teacher Magazine, 6(8), 14-15. 
Riggs, I. M., \& Enochs, L. G. (1990). Toward the development of an elemenatry teachers' science teaching efficacy belief instrument. Science Education, 74(6), 625-637.

Riley, R. (1997). Mathematics Equals Opportunity (Caucasian Paper for US Education Secretary Richard W. Riley): U.S. Department of Education.

Riordan, C. (1990). Girls and boys in school: Together or separate? New York: Teachers' College Press.

Riordan, C., Faddis, B., Seager, A., \& Mael, F. (2004). Single-sex schools: Their characteristics and effects. A report submitted to the U.S. Department of Education.

Ritsch, M. (2002, June 2, 2002). Same-gender classes finding growing acceptance. The Salt Lake Tribune.

Robinson, P., \& Smithers, A. (1999). Should the sexes be separated for secondary education: Comparisons of single-gender and coeducational schools. Research Papers in Education, 14(1), 23-49.

Rodriguez, N. C. (2004, January 4, 2004). State's math scores trail gains in reading. Courier-Journal.

Ross, J. A., McDougall, D., \& Hogaboam-Gray, A. (2002). Research on reform in mathematics education, 1993-2000. Alberta Journal of Educational Research, 48(2), 122138.

Rotter, J. B. (1966). Some problems and misconceptions related to the construct of internal versus external locus of control of reinforcement. Journal of Consulting and Clinical Psychology, 74, 243-250.

Ruhlman, M. (1996). Boys themselves: A return to single-gender education. New York: Henry Holt and Company.

Sadker, M., \& Sadker, D. (1994). Failing at fairness. New York, NY: Touchstone/Simon and Schuster.

Salomone, R. C. (2003). Same, different, equal: Rethinking single-gender education. New Haven, CT.: Yale University Press.

Sampson, R. J., Morenoff, J. D., \& Earls, F. (2000). Beyond social capital: Spatial dynamics of collective efficacy for children. American Sociological Review, 64, 633-660.

Sampson, R. J., Raudenbush, S. W., \& Earls, F. (1997). Neighborhoods and violent crime: A multilevel study of collective efficacy. Science, 277, 918-924. 
Schram, P., Wilcox, S. K., Lanier, P., \& Lappan, G. (1988). Changing mathematical conceptions of pre-service teachers: A content and pedagogical intervention (No. 1988-4). East Lansing, MI: National Center for Research on Teacher Education.

Shouse, R. D. (1996). Academic press and sense of community: Conflict, congruence, and implications for student achievement. Social Psychology of Education, 1, 4768.

Shulman, L. S. (1986). Those who understand: Knowledge growth in teaching. Educational Researcher, 15(2), 4-14.

Shulman, L.S. (1987) Knowledge and teaching: foundations of new reform. Harvard Educational Review, 57 (1), 1-22.

Sills-Briegel, T., \& Bell, M. (1998). A survey of middle-level student and teacher attitudes toward various aspects of their advisory program. Paper presented the American Educational Research Association, San Diego, CA.

Silver, E. A. (1998). Improving mathematics in middle school: Lessons from TIMSS and related research (Reports-Evaluative (142) No. ORAD-98-1107). Washington, DC: Office of Educational Research and Improvement.

Silver, E. A., \& Stein, M. K. (1996). The Quasar Project: the "revolution of the possible" in mathematics instructional reform in middle school. Urban Education, 30(4), 476-571.

Skemp, R. R. (1978). Relational understanding and instrumental understanding. Arithmetic Teacher, 26(3), 9-16.

Smith, N. (1999). Student and teacher perceptions of a single-gender middle school learning environment. Pennsylvania.

Sommers, C. H. (2000). The war against boys: How misguided feminism is harming our young men. New York: Touchstone.

Sprick, R., Garrison, M., \& Howard, l. (1998). CHAMPs: A proactive and positive approach to classroom management. Longmont, CO: Sopris West.

Springer, S. P., \& Deutsch, G. (1998). Ch 1 Evidence from brain damage and the rise of neuropsychology. In Left brain, right brain: Perspectives from cognitive neuroscience (5th Edition ed., pp. 9-29). New York: W.H. Freeman \& Co.

Springer, S. P., \& Deutsch, G. (1998). Ch. 6- Gender differences in cognition and asymmetry. In Left brain, right brain: Perspectives from cognitive neuroscience (pp. 139-156). New York: W.H. Freeman \& Co.

Stabiner, K. (2002). All girls: Single-gender education and why it matters. New York: Riverhead Books; Penguin Putnam, Inc. 
Steinback, M., \& Gwizdala, J. (1995). Gender differences of mathematics attitudes of secondary students. School Science and Mathematics, 95(1), 36-41.

Stevens, C. \& Wenner, G. Elementary preservice teachers’ knowldege and beliefs regarding Science and Mathematics. School Science and Mathematics, 96(1), 2-9.

Stevenson, C., \& Erb, T. O. (1998). How implementing Turning Points improves student outcomes. Middle School Journal, 49-52.

Stigler, J. W., \& Hiebert, J. (1999). The Teaching Gap. New York: The Free Press.

Suydam, M. N., \& Higgins, J. L. (1977). Activity-based learning in elementary school mathematics: Recommendations from research. Columbus, $\mathrm{OH}$ : Ohio State University.

Tartre, L. (1990). Spatial Skills, Gender, and Mathematics. In E. Fennema (Ed.), Mathematics and Gender (pp. 27-59). New York: Teachers College Press

Tharp, R., \& Gallimore, R. (1988). Rousing minds to life: Teaching, learning, schooling, in a social context. Cambridge, UK: Cambridge University Press.

Thompson, A. G. (1992). Teachers' beliefs and conceptions: A synthesis of the research. In D. A. Grouws (Ed.), Handbook of Research on Mathematics Teaching and Learning (pp. 127-146). Reston, VA: NCTM.

Tschannen-Moran, M., Hoy, A. W., \& Hoy, W. K. (1998). Teacher efficacy: Its meaning and measure. Review of Educational Research, 68, 202-248.

Turner, J. C., Meyer, D. K., Midgley, C., \& Patrick, H. (2003). Teacher discourse and sixth graders' reported affect and achievement behaviors in two highmastery/high-performance mathematics classrooms. Elementary School Journal, 103(4), 357-382.

Urdan, T., Pajares, F., \& Lapin, A. (1997, March 24-28, 1997). Achievement goals, motivation, and performance: A closer look. Paper presented at the AREA, Chicago.

Vezeau, C., Bouffard, T., \& Chouinard, R. (2000). The impact of single-gender versus coeducational school environment on girls' general attitudes, self-perceptions, and performance in mathematics. Journal of Research and Development in Education, 34(1), 49-59.

Waits, B., \& Demana, F. (2000). Calculators in Mathematics Teaching and Learning. In Learning mathematics for a new century (Vol. 2000, pp. 1-16). Reston, VA: NCTM.

Wearne, D. (1988). A cognitive approach to meaningful mathematics instruction: Testing a local theory using decimal numbers. Journal for Research in Mathematics Education, 19(5), 371-384. 
Wearne, D., Hiebert, J., \& Taber, S. (1991). Fourth graders' gradual construction of decimal fractions using different physical representations. Elementary School Journal,, 91(4), 321-341.

Weaver-Hightower, M. (2003). The "boy turn" in research on gender and education. Review of Educational Research, 73(4), 471-498.

Wenner, G. (2001). Science and mathematics efficacy beliefs held by practicing and prospective teachers: A 5-year perspective. Journal of Science Education and Techonology, 10(2).

Windschitl, M. (2002). Framing constructivism in practice as the negotiation of dilemmas: An analysis of the conceptual pedagogical, cultural, and political challenges facing teachers. Review of Educational Research, 72(2), 131-175.

Woody, E. L. (2002). Constructions of masculinity in California's single-gender academies. In A. Datnow \& L. Hubbard (Eds.), Gender in Policy and Practice (pp. 280-303). New York: RoutledgeFalmer.

Woolfolk, A. (2001) Educational Psychology, $8^{\text {th }}$ Edition. Boston: Allyn and Bacon.

Yates, L. (2000). The "facts of the case:" Gender equity for boys as a public policy issue. In N. Lesko (Ed.) Masculinities at school (pp305-322). Thousand Oaks, CA:

Sage. 


\section{APPENDICES}

Appendix A; page 1

\section{APPENDIX A \\ Organizational Health Inventory for Middle Schools}

(OHI-M; Hoy \& Sabo,1997)

Directions: The following are statements about your school. Please indicate the extent to which each statement characterizes you school by circling the appropriate response.

$$
\begin{gathered}
\mathrm{RO}=\text { Rarely Occurs } \\
\mathrm{SO}=\text { Sometimes Occurs } \\
\mathrm{O}=\text { Often Occurs } \\
\mathrm{VFO}=\text { Very Frequently Occurs }
\end{gathered}
$$

1. The principal explores all sides of topics and admits that other options exist

2. Students make provisions to acquire extra help from teachers.

3. The principal gets what he or she asks for from supervisors.

4. The principal discusses classroom issues with teachers.

5. The principal accepts questions without appearing to snub or quash the teacher.

6. Extra materials are available if requested.

7. Students neglect to complete homework.

8. The school is vulnerable to outside pressures.

9. The principal is able to influence the actions of his or her superiors.

10. The principal treats all faculty members as his or her equal.

11. Teachers are provided with adequate materials for their classrooms.

12. Teachers in this school like each other.

13. Community demands are accepted even when they are not consistent with the educational program.

14. The principal lets faculty know what is expected of them.

15. Teachers receive necessary classroom supplies.

16. Students respect others who get good grades.

17. Good grades are important to the students of this school.

18. Teachers feel pressure from the community.

19. The principal's recommendations are given serious consideration by his or her superiors.

20. Supplementary materials are available for classroom use. 
21. Teachers exhibit friendliness to each other.

22. Students seek extra work so they can get good grades.

23. Select citizen groups are influential with the board.

24. The principal looks out for the personal welfare of faculty members.

25 . The school is open to the whims of the public.

26. A few vocal parents can change school policy.

27. Students try hard to improve on previous work.

28. Teachers accomplish their jobs with enthusiasm.

29. The learning environment is orderly and serious.

30. The principal is friendly and approachable.

31. Teachers show commitment to their students.

32. Teachers are indifferent to each other.

33. Teachers are protected from unreasonable parental and community demands.

34. The principal is able to work well with the superintendent.

35 . The principal is willing to make changes.

36. The teachers have access to needed instructional materials.

37. The teachers in this school are cool and aloof to each other.

38. The teachers in this school feel that their students have the ability to achieve academically.

39. The principal is understanding when personal concerns cause teachers to arrive late or leave early.

40. Our school gets its fair share of resources from the district.

41. The principal is rebuffed by the superintendent.

42. Teachers volunteer to help each other.

43. The principal is effective in securing the superintendent's approval for new programs or activities.

44. Academically oriented students in this school are ridiculed by their peers.

45. Teachers do favors for each other. 
APPENDIX B

CE-SCALE - Form L

(Goddard, Hoy, \& Hoy, 2000)

Indicate your level of agreement with each of the following statements from

STRONGLY AGREE (1) to

STRONGLY DISAGREE (6)

1. Teachers in the school are able to get through to the most difficult students.

2. Teachers here are confident they will be able to motivate their students.

3. If a child doesn't want to learn, teachers here give up.

4. Teachers here don't have the skills to produce meaningful student learning.

5. If a child doesn't learn something the first time then the teachers will try another way.

6. Teachers in this school are skilled in various methods of teaching.

7. Teachers here are well-prepared to teach the subjects they are assigned to teach.

8. Teachers here fail to reach some students because of poor teaching methods.

9. Teachers in this school have what it takes to get the children to learn.

10. The lack of instructional materials and supplies makes teaching very difficult.

11. Teachers in this school do not have the skills to deal with student disciplinary problems.

12. Teachers in this school think that there are some students no one can reach.

13. The quality of the facilities really facilitates the teaching and learning process.

14. The students here come in with so many advantages that they are bound to learn.

15. These students come to school ready to learn.

16. Drug and alcohol abuse in the community make learning difficult for students.

17. The opportunities in the community help ensure that these students will learn.

18. Students here are just not motivated to learn.

19. Learning is more difficult at the school because students are worried about their safety.

20. Teachers here need more training to know how to deal with these students.

21. Teachers in this school truly believe every child can learn. 


\section{APPENDIX C}

\section{Mathematics Teacher Efficacy Beliefs Instrument}

(MTEBI, Riggs \& Enochs, 1990; Stevens \& Wenner, 1996; Wenner, 2000)

Please indicate the degree to which you agree or disagree with each statement below by circling the appropriate letters to the right of each statement.

$$
\begin{gathered}
\text { SA = Strongly Agree } \\
\text { A = Agree } \\
\text { UN = Uncertain } \\
\text { D = Disagree } \\
\text { SD = Strongly Disagree }
\end{gathered}
$$

1. When a student does better than usual in mathematics, it is often because the teacher exerted a little extra effort.

2. I am continually finding better ways to teach mathematics.

3. Even when I try very hard, I don't teach mathematics as well as I do other subjects.

4. When the mathematics grades of students improve, it is most often due to their teacher having found a more effective teaching approach.

5. I know the steps necessary to teach mathematics concepts effectively.

6. I am not very effective in monitoring group activities in mathematics

7. If students are underachieving in mathematics class, it is most likely due to ineffective teaching.

8. I generally teach mathematics ineffectively.

9. The inadequacy of a student's mathematics background can overcome good teaching.

10. The low mathematics achievement of some students cannot generally be blamed on their teachers.

11. When a low achieving child progresses in mathematics, it is usually due to the extra attention given by the teacher.

12. I understand mathematics concepts well enough to be effective in teaching middle school mathematics.

13. Increased effort in mathematics teaching produces little change in some mathematics students' achievement.

14. The teacher is generally responsible for the achievement of students in mathematics.

15. Students' achievement in mathematics is directly related to their teacher's effectiveness.

16. If parents comment that their child is showing more interest in mathematics at school, it is probably due to the performance of the child's teacher.

17. I find it difficult to explain mathematics to students.

18. I am typically able to answer students' mathematics questions.

19. I wonder if I have the necessary skills to teach mathematics.

20. Effectiveness in mathematics teaching has little influence on the achievement of students with low motivation.

21. Given a choice, I would not invite the principal to evaluate my mathematics teaching. 
Appendix C; page 2

22. When a student has difficulty understanding a mathematics concept, I am usually at a loss as to how to help the student understand it better.

23. I usually welcome students' mathematical questions.

24. I don't know what to do to turn a student on to mathematics.

25. Even teachers with good mathematics teaching abilities cannot help some kids learn mathematics. 
APPENDIX D

Mathematics Teacher Beliefs Questionnaire

(Developed from schema; Raymond, 1997)

Indicate your level of agreement with each of the following statements from

STRONGLY DISAGREE (6) to STRONGLY AGREE (1)

1. Mathematics is fixed, predictable, absolute, certain, and applicable.

2. The teacher should value correct answers over process.

3. Students learn mathematics by working individually.

4. The teacher's role is to lecture and dispense mathematical knowledge.

5. Lessons should be planned and implemented explicitly without deviation.

6. Mathematics is an unrelated collection of facts, rules, and skills.

7. There is only one way to learn mathematics.

8. Many students are just not able to learn mathematics.

9. The teacher's role is to assign individual seat work.

10. Students learn mathematics mainly without textbook or pencil-and-paper activities.

11. Students' learning of mathematics depends principally on the teacher.

12. Memorization and mastery of algorithms signify learning.

13. The teacher should provide mainly problem-solving and manipulative-driven activities.

14. The teacher should have students work mainly in cooperative groups.

15. Mathematics is a static but unified body of knowledge with interconnecting structures.

16. The teacher's role is to guide learning and pose challenging questions.

17. Students passively receive knowledge from the teacher.

18. The teacher should emphasize memorization over understanding.

19. The teacher should instruct principally from the textbook.

20. Students learn mathematics mainly through problem-solving activities.

21. The teacher's role is to promote knowledge sharing.

22. Students learn mathematics mainly from the textbook and worksheets.

23. The teacher should help students to like and value mathematics.

24. Students learn mathematics through cooperative group interactions.

25. All students can learn mathematics.

26. Students engage in repeated practice for mastery of skills.

27. Lessons and activities should follow the same plan daily.

28. Students learn mathematics primarily as active learners.

29. Mathematics can be surprising, relative, doubtful, and aesthetic.

30. The teacher should promote student autonomy.

31. Mathematics is dynamic, problem-driven, and continually expanding.

32. The student's role in learning mathematics is that of autonomous explorer.

33. Each student learns mathematics in his or her own way. 


\section{Appendix E}

Master Code List for All-Boy Class Study (4/15/05)

Additional descriptions for some codes are provided in italics

agenda check or reminder

assessment alternative

assessment learn for test

boy active learning

boy big things tall tales

boy competition

boy games

boy jobs for group work

boy leadership opps

boy rewards

boy sixty second rule

boy structure-procedures

boy topic of interest

boy-no choices

boys bragging

boys figeting fiddling

boys omit steps hurry incomplete

Boys frequently skip steps, sacrifice accuracy to speed, and sometimes just mark

something down for multiple choice tests.

boys reading

boys recitation chanting in unison

boys scaffold task

boys test limits disrupt

boys- lack organization and planning

Boys of this age are frequently unorganized and unprepared. They are likely not to have a pencil or supplies. They also do not plan their work well.

boys-handwriting

boys-talk while work

calls on same students

$\mathrm{CM}$ address group

CM admonishes lack of effort

This code is used when a teacher tells student that he is not paying attention, listening, or trying. It can also be used for teacher to avoid spoon-feeding and to answer questions that student could find out for himself.

CM argument stud-teach

CM authority control

The teacher issues a reminder about where the authority and control lies in the class.

$\mathrm{CM}$ consequences

CM corrects behavior 
Appendix E; page 2

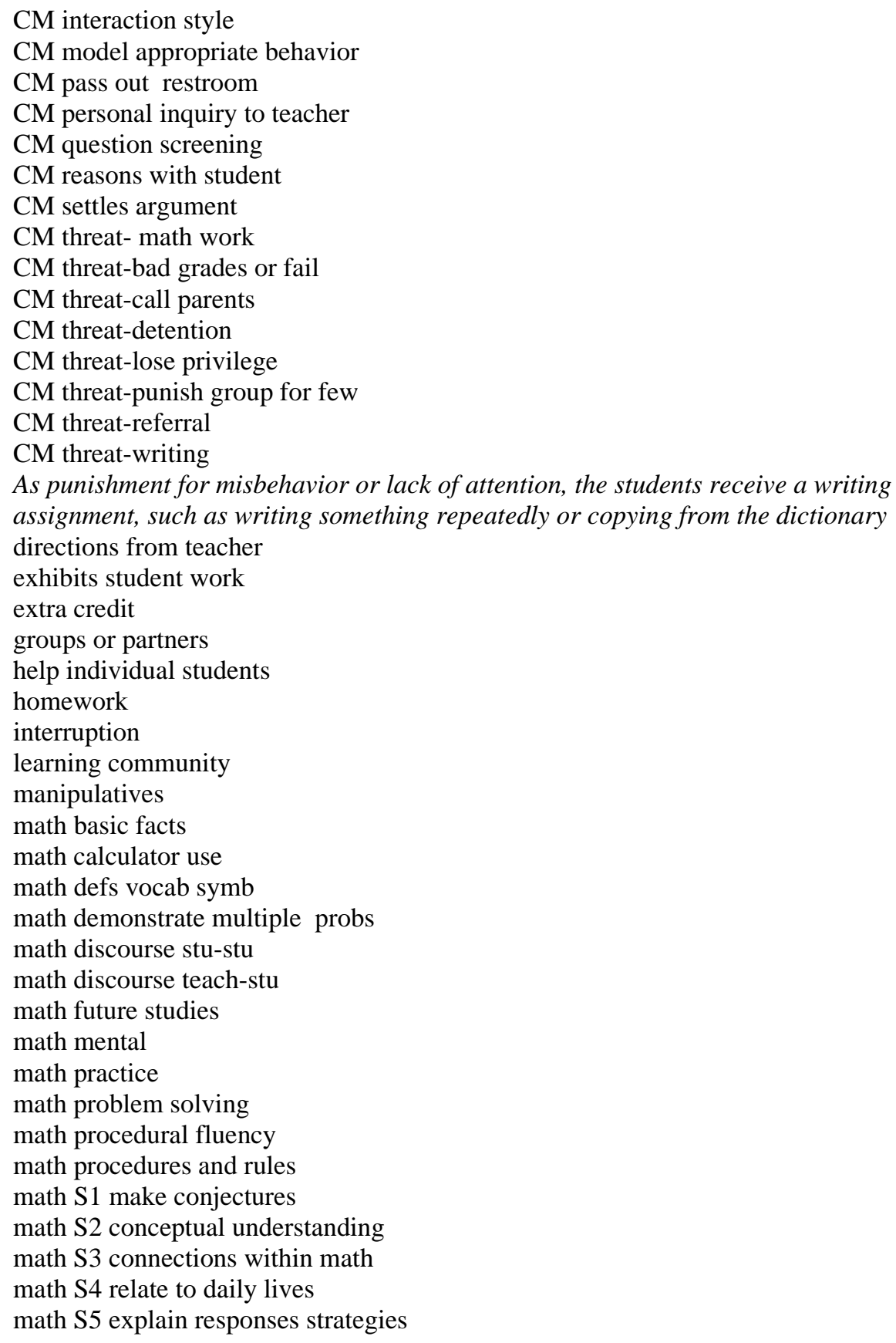


math S6 multiple strat/ reps

Teacher uses multiple representations of a math situation visual, number relatioship, concrete. Also multiple strategies and perspectives for solving a problem

math S7 valued-used student statement

math S8 inquiries thinking as guide

math $\mathrm{S9}$ reasonable response

math self efficacy

math spatial reasoning

math strategic competence

math topic covered previously

math unclear explanation example

metacog activate prior knowledge

metacog allocate time

metacog misunderstanding

metacognition

MS choice

MS interdisciplinary

MS mentoring pers interest

MS variety of activities

N10 self-conf over answer

N3 tasks challenging

N6 math tools and tech

note taking

off-task behavior

on task behavior

parent contact-participation

planning of teacher

praise-encouragement group

prod disp importance

productive disp

productive disp drama

productive disp jokes

repeats instructions or problem

respond freely

SCH environ safety

SCH resource support

SCH standardized tests

SCH tracking

seatwork

student argument

student corrects behavior

This behavior of students saying be quiet and shut up loudly to other students is disruptive. Students told me about it in the interviews.

student frustration 
Appendix E; page 4

student seeks spoon-feeding

Student asks a question or makes a comment that is too general like "I don't get it" or I don't understand"

teacher expectations

teacher-led activity

test-taking skills

textbook

word error student

worksheet 
Appendix F; page 1

\section{Appendix F}

\section{Time Allocations for Teacher Observations}

Teacher: Ellen Alcott, $6^{\text {th }}$ grade at Terre Rouge Time spent on mathematics: $71 \%$ Time Allocation for Teacher Observations (8 observations, 50 minutes each)

Codes: M- management (travel from previous class, behavior, distribution of papers, administrative information); F- Free time or down time; D- Discourse (open-ended questions and responses, requests for explanations and reasoning, conjectures and generalizations, discourse on mathematics concepts); $\mathrm{T}$ - Teacher-centered activities such as notes, procedures, vocabulary, spelling test, demonstrating solutions to problems, reading aloud); P - Practice (seatwork, homework); IA - Individual Activity (problem solving, making graphs, computer lab, manipulatives, modeling, hands-on, calculators); GA- Group Activity (work with group or partner; problem solving, collect data, manipulatives, modeling, hands-on); ST - Percent of time spent on preparing for standardized tests (not included in 100\% tally).

For these eight observations, four were made in the teacher's $3^{\text {rd }}$ period class where there was an average attendance of 23 students and four were made in the teacher's $4^{\text {th }}$ period class, where there was an average attendance of 27 students.

\begin{tabular}{|l|l|l|l|l|l|l|l|c|l|}
\hline Obs \# & M & F & D & T & P & IA & GA & $\begin{array}{l}\text { Total } \\
\text { (min.) }\end{array}$ & ST \\
\hline $\begin{array}{l}13^{\text {rd }} \\
9 / 20 / 04\end{array}$ & 10 & & & 25 & & 15 & & 50 & $80 \%$ \\
\hline $\begin{array}{l}23^{\text {rd }} \\
9 / 21 / 04\end{array}$ & 15 & & 15 & 20 & & & & 50 & $10 \%$ \\
\hline $\begin{array}{l}3 \quad 3^{\text {rd }} \\
9 / 22 / 04\end{array}$ & 10 & 10 & & & 30 & & & 50 & $80 \%$ \\
\hline $\begin{array}{l}43^{\text {rd }} \\
9 / 23 / 04\end{array}$ & 20 & & & 30 & & & & 50 & $10 \%$ \\
\hline $\begin{array}{l}5 \quad 4^{\text {th }} \\
9 / 27 / 04\end{array}$ & 10 & & & 10 & & 15 & 15 & 50 & $0 \%$ \\
\hline $\begin{array}{l}6 \quad 4^{\text {th }} \\
9 / 28 / 04\end{array}$ & 10 & & 15 & 15 & 10 & & & 50 & $0 \%$ \\
\hline $\begin{array}{l}7 \quad 4 \text { th } \\
9 / 29 / 04\end{array}$ & 15 & & 30 & & 5 & & & 50 & $0 \%$ \\
\hline $\begin{array}{l}8 \quad 4^{\text {th }} \\
10 / 6 / 04\end{array}$ & 15 & & & 10 & 25 & & & 50 & $50 \%$ \\
\hline totals & 105 & 10 & 60 & 110 & 70 & 30 & 15 & 400 & \\
\hline $\begin{array}{l}\text { percent } \\
\text { of time }\end{array}$ & $26 \%$ & $3 \%$ & $10 \%$ & $31 \%$ & $18 \%$ & $8 \%$ & $4 \%$ & $100 \%$ & $26 \%$ \\
\hline
\end{tabular}


Teacher: David Blake, $7^{\text {th }}$ grade at Terre Rouge Time spent on mathematics: $63 \%$

Time Allocation for Teacher Observations (8 observations, 50 minutes each)

Codes: M- management (travel from previous class, behavior, distribution of papers, administrative information); F- Free time or down time; D- Discourse (open-ended questions and responses, requests for explanations and reasoning, conjectures and generalizations, discourse on mathematics concepts); $\mathrm{T}$ - Teacher-centered activities such as notes, procedures, vocabulary, spelling test, demonstrating solutions to problems, reading aloud); P - Practice (seatwork, homework); IA - Individual Activity (problem solving, making graphs, computer lab, manipulatives, modeling, hands-on, calculators); GA- Group Activity (work with group or partner; problem solving, collect data, manipulatives, modeling, hands-on); ST - Percent of time spent on preparing for standardized tests (not included in $100 \%$ tally).

All of these eight observations were made in Mr. Blake's $6^{\text {th }}$ period class and there was an average attendance of 33 students.

\begin{tabular}{|c|c|c|c|c|c|c|c|c|c|}
\hline Obs \# & $\mathrm{M}$ & F & $\mathrm{D}$ & $\mathrm{T}$ & $\mathrm{P}$ & IA & GA & $\begin{array}{l}\text { Total } \\
\text { (min.) }\end{array}$ & ST \\
\hline $\begin{array}{l}16 \text { th } \\
9 / 20 / 04\end{array}$ & 50 & & & & & & & $50 \mathrm{~min}$ & $0 \%$ \\
\hline $\begin{array}{l}2 \text { 6th } \\
9 / 21 / 04\end{array}$ & 15 & & & & & & 35 & 50 & $0 \%$ \\
\hline $\begin{array}{l}3 \text { 6th } \\
9 / 22 / 04\end{array}$ & 15 & & & 35 & & & & 50 & $0 \%$ \\
\hline $\begin{array}{l}4 \text { 6th } \\
9 / 23 / 04\end{array}$ & 15 & & & 40 & & & & 50 & $0 \%$ \\
\hline $\begin{array}{l}5 \text { 6th } \\
9 / 27 / 04\end{array}$ & 10 & & & 20 & 15 & 5 & & 50 & $0 \%$ \\
\hline $\begin{array}{l}66^{\text {th }} \\
9 / 28 / 04\end{array}$ & 10 & 10 & & & & 30 & & 50 & $80 \%$ \\
\hline $\begin{array}{l}76^{\text {th }} \\
9 / 29 / 04\end{array}$ & 10 & & & 30 & & & & 50 & $0 \%$ \\
\hline $\begin{array}{l}86^{\text {th }} \\
10 / 6 / 04\end{array}$ & 10 & & & 15 & 25 & & & 50 & $0 \%$ \\
\hline totals & 140 & 10 & & 140 & 40 & 35 & 35 & 400 & \\
\hline $\begin{array}{l}\text { percent } \\
\text { of time }\end{array}$ & $35 \%$ & $2 \%$ & $0 \%$ & $35 \%$ & $10 \%$ & $9 \%$ & $9 \%$ & $100 \%$ & $10 \%$ \\
\hline
\end{tabular}


Appendix F; page 3

Teacher: Darrell Fisher, $6^{\text {th }}$ grade at Greenville Time spent on mathematics: $89 \%$

Time Allocation for Teacher Observations (8 observations, 50 minutes each)

Codes: M- management (travel from previous class, behavior, distribution of papers, administrative information); F- Free time or down time; D- Discourse (open-ended questions and responses, requests for explanations and reasoning, conjectures and generalizations, discourse on mathematics concepts); $\mathrm{T}$ - Teacher-centered activities such as notes, procedures, vocabulary, spelling test, demonstrating solutions to problems, reading aloud); P - Practice (seatwork, homework); IA - Individual Activity (problem solving, making graphs, computer lab, manipulatives, modeling, hands-on, calculators); GA- Group Activity (work with group or partner; problem solving, collect data, manipulatives, modeling, hands-on); ST - Percent of time spent on preparing for standardized tests (not included in $100 \%$ tally).

All of these eight observations were made in Mr. Fisher's $6^{\text {th }}$ period class and there was an average attendance of 22 students.

\begin{tabular}{|c|c|c|c|c|c|c|c|c|c|}
\hline Obs \# & $\mathrm{M}$ & F & $\mathrm{D}$ & $\mathrm{T}$ & $\mathrm{P}$ & IA & GA & $\begin{array}{l}\text { Total } \\
\text { (min.) }\end{array}$ & ST \\
\hline $\begin{array}{l}13^{\text {rd }} \\
10 / 25 / 04\end{array}$ & 5 & & 25 & & & 20 & & $50 \mathrm{~min}$ & \\
\hline $\begin{array}{l}23^{\text {rd }} \\
10 / 26 / 04 \\
\end{array}$ & 5 & & 45 & & & & & 50 & \\
\hline $\begin{array}{l}33^{\text {rd }} \\
10 / 27 / 04\end{array}$ & 10 & & 20 & & & & 20 & 50 & \\
\hline $\begin{array}{l}43^{\text {rd }} \\
10 / 28 / 04\end{array}$ & 5 & & 5 & & & 5 & 35 & 50 & \\
\hline $\begin{array}{l}53^{\text {rd }} \\
11 / 1 / 04\end{array}$ & 5 & & 20 & & & & 25 & 50 & \\
\hline $\begin{array}{l}63^{\text {rd }} \\
11 / 3 / 04\end{array}$ & 5 & & 20 & 15 & & 10 & & 50 & \\
\hline $\begin{array}{l}73^{\text {rd }} \\
11 / 4 / 04\end{array}$ & 5 & & 45 & & & & & 50 & \\
\hline $\begin{array}{l}83^{\text {rd }} \\
11 / 5 / 04\end{array}$ & 5 & 10 & 15 & & 5 & & 15 & 50 & \\
\hline total & 45 & & 195 & 15 & 5 & 35 & 105 & 400 & \\
\hline $\begin{array}{l}\text { percent } \\
\text { of time }\end{array}$ & $11 \%$ & $2 \%$ & $49 \%$ & $4 \%$ & $1 \%$ & $9 \%$ & $24 \%$ & $100 \%$ & $0 \%$ \\
\hline
\end{tabular}


Teacher: Julia Edwards, $7^{\text {th }}$ grade at Greenville Time spent on mathematics: $88 \%$

Time Allocation for Teacher Observations (8 observations, 50 minutes each)

Codes: M- management (travel from previous class, behavior, distribution of papers, administrative information); F- Free time or down time; D- Discourse (open-ended questions and responses, requests for explanations and reasoning, conjectures and generalizations, discourse on mathematics concepts); $\mathrm{T}$ - Teacher-centered activities such as notes, procedures, vocabulary, spelling test, demonstrating solutions to problems, reading aloud); P - Practice (seatwork, homework); IA - Individual Activity (problem solving, making graphs, computer lab, manipulatives, modeling, hands-on, calculators); GA- Group Activity (work with group or partner; problem solving, collect data, manipulatives, modeling, hands-on); ST - Percent of time spent on preparing for standardized tests (not included in 100\% tally).

All of these eight observations were made in Ms. Edwards's $4^{\text {th }}$-period class and there was an average attendance of 19 students.

\begin{tabular}{|l|l|l|l|l|l|l|l|l|l|}
\hline Obs \# & M & F & D & T & P & IA & GA & $\begin{array}{l}\text { Total } \\
\text { (min.) }\end{array}$ & ST \\
\hline $\begin{array}{l}14^{\text {th }} \\
10 / 11 / 04\end{array}$ & 5 & & & & 5 & & 40 & 50 min & \\
\hline $\begin{array}{l}24^{\text {th }} \\
10 / 12 / 04\end{array}$ & 5 & & & & 5 & 40 & & 50 & \\
\hline $\begin{array}{l}34^{\text {th }} \\
10 / 14 / 04\end{array}$ & 5 & & 10 & & 10 & 25 & & 50 & \\
\hline $\begin{array}{l}44^{\text {th }} \\
10 / 15 / 04\end{array}$ & 5 & & 15 & & 10 & 20 & & 50 & \\
\hline $\begin{array}{l}54^{\text {th }} \\
10 / 25 / 04\end{array}$ & 10 & & & & 10 & & 30 & 50 & \\
\hline $\begin{array}{l}64^{\text {th }} \\
10 / 26 / 04\end{array}$ & 5 & & 10 & & 10 & & 25 & 50 & \\
\hline $\begin{array}{l}74^{\text {th }} \\
10 / 27 / 04\end{array}$ & 5 & & & 15 & 30 & & & 50 & \\
\hline $\begin{array}{l}84^{\text {th }} \\
10 / 28 / 04\end{array}$ & 5 & & & & 20 & 25 & & 50 & \\
\hline total & 45 & & 35 & 15 & 100 & 105 & 95 & 400 & \\
\hline $\begin{array}{l}\text { percent } \\
\text { of time }\end{array}$ & $12 \%$ & $0 \%$ & $9 \%$ & $4 \%$ & $25 \%$ & $26 \%$ & $24 \%$ & $100 \%$ & $0 \%$ \\
\hline
\end{tabular}


Teacher: Christine Ingram, $6^{\text {th }}$ grade at Bluefield Time spent on mathematics: $79 \%$

Time Allocation for Teacher Observations (8 observations, 50 minutes each)

Codes: M- management (travel from previous class, behavior, distribution of papers, administrative information); F- Free time or down time; D- Discourse (open-ended questions and responses, requests for explanations and reasoning, conjectures and generalizations, discourse on mathematics concepts); $\mathrm{T}$ - Teacher-centered activities such as notes, procedures, vocabulary, spelling test, demonstrating solutions to problems, reading aloud); P - Practice (seatwork, homework); IA - Individual Activity (problem solving, making graphs, computer lab, manipulatives, modeling, hands-on, calculators); GA- Group Activity (work with group or partner; problem solving, collect data, manipulatives, modeling, hands-on); ST - Percent of time spent on preparing for standardized tests (not included in $100 \%$ tally).

For these eight observations, four were made in the teacher's Mod 1 (honors) class where there was an average attendance of 18 students and four were made in the teacher's Mod 2 (regular) class, where there was an average attendance of 18 students.

\begin{tabular}{|c|c|c|c|c|c|c|c|c|c|}
\hline Obs \# & $\mathrm{M}$ & $\mathrm{F}$ & $\mathrm{D}$ & $\mathrm{T}$ & $\mathrm{P}$ & IA & GA & $\begin{array}{l}\text { Total } \\
\text { (min.) }\end{array}$ & ST \\
\hline $\begin{array}{l}1 \text { Mod } 1 \\
11 / 12 / 04\end{array}$ & 5 & & & & 5 & & 40 & $50 \mathrm{~min}$ & \\
\hline $\begin{array}{l}2 \text { Mod } 1 \\
11 / 15 / 04\end{array}$ & 15 & & & & & 35 & & 50 & \\
\hline $\begin{array}{l}3 \text { Mod } 1 \\
12 / 3 / 04\end{array}$ & 5 & & 15 & 25 & 5 & & & 50 & \\
\hline $\begin{array}{l}4 \text { Mod } 1 \\
12 / 9 / 04\end{array}$ & 5 & & 10 & 15 & & & 20 & 50 & \\
\hline $\begin{array}{l}\text { Mod } 1 \\
\text { Totals }\end{array}$ & 30 & & 25 & 40 & 10 & 35 & 60 & 200 & \\
\hline $\begin{array}{l}\text { Mod } 1 \\
\%\end{array}$ & $15 \%$ & & $12 \%$ & $20 \%$ & $5 \%$ & $18 \%$ & $30 \%$ & $100 \%$ & \\
\hline $\begin{array}{l}5 \text { Mod } 2 \\
11 / 11 / 04\end{array}$ & 5 & & 10 & 30 & 5 & & & 50 & \\
\hline $\begin{array}{l}6 \operatorname{Mod} 2 \\
11 / 12 / 04\end{array}$ & 15 & & 15 & 15 & 5 & & & 50 & \\
\hline $\begin{array}{l}7 \text { Mod } 2 \\
11 / 15 / 04\end{array}$ & 15 & & & & & 35 & & 50 & \\
\hline $\begin{array}{l}8 \operatorname{Mod} 2 \\
11 / 17 / 04\end{array}$ & 20 & & & 30 & & & & 50 & \\
\hline $\begin{array}{l}\text { Mod } 2 \\
\text { total }\end{array}$ & 55 & & 25 & 75 & 10 & 35 & & 200 & \\
\hline $\begin{array}{l}\text { Mod } 2 \\
\%\end{array}$ & $27 \%$ & & $12 \%$ & $38 \%$ & $5 \%$ & $18 \%$ & $0 \%$ & $100 \%$ & \\
\hline $\begin{array}{l}\text { all } 8 \\
\%\end{array}$ & $21 \%$ & $0 \%$ & $12 \%$ & $29 \%$ & $5 \%$ & $18 \%$ & $15 \%$ & $100 \%$ & $0 \%$ \\
\hline
\end{tabular}


Teacher: Melanie Jones, $7^{\text {th }}$ grade at Bluefield $\quad$ Time spent on mathematics: $68 \%$

Time Allocation for Teacher Observations (8 observations, 50 minutes each)

Codes: M- management (travel from previous class, behavior, distribution of papers, administrative information); F- Free time or down time; D- Discourse (open-ended questions and responses, requests for explanations and reasoning, conjectures and generalizations, discourse on mathematics concepts); $\mathrm{T}$ - Teacher-centered activities such as notes, procedures, vocabulary, spelling test, demonstrating solutions to problems, reading aloud); P - Practice (seatwork, homework); IA - Individual Activity (problem solving, making graphs, computer lab, manipulatives, modeling, hands-on, calculators); GA- Group Activity (work with group or partner; problem solving, collect data, manipulatives, modeling, hands-on); ST - Percent of time spent on preparing for standardized tests (not included in $100 \%$ tally).

For these eight observations, four were made in the teacher's $7^{\text {th }}$ period (honors) class, where there was an average attendance of 26 students, and four were made in the teacher's $6^{\text {th }}$ period (regular) class where there was an average attendance of 11 students.

\begin{tabular}{|l|c|l|l|l|l|l|l|c|l|}
\hline Obs \# & M & F & D & T & P & IA & GA & $\begin{array}{l}\text { Total } \\
(\text { min. }\end{array}$ & ST \\
\hline $\begin{array}{l}17^{\text {th }} \\
11 / 11 / 04\end{array}$ & 10 & & 10 & 30 & & & & 50 min & \\
\hline $\begin{array}{l}27^{\text {th }} \\
11 / 12 / 04\end{array}$ & 15 & & & 25 & & 10 & & 50 & \\
\hline $\begin{array}{l}37 \text { th } \\
11 / 15 / 04\end{array}$ & 10 & & & 40 & & & & 50 & \\
\hline $\begin{array}{l}47 \text { th } \\
11 / 16 / 04\end{array}$ & 20 & 10 & & & & & 20 & 50 & \\
\hline $\begin{array}{l}7^{\text {th }} \text { per } \\
\text { Totals }\end{array}$ & 55 & 10 & 10 & 95 & & 10 & & 200 & \\
\hline $\begin{array}{l}7^{\text {th }} \text { per } \\
\%\end{array}$ & $28 \%$ & $5 \%$ & $5 \%$ & $47 \%$ & $0 \%$ & $5 \%$ & $10 \%$ & $100 \%$ & \\
\hline $\begin{array}{l}56 \text { th } \\
11 / 11 / 04\end{array}$ & 10 & 15 & & & 25 & & & 50 & \\
\hline $\begin{array}{l}66 \text { th } \\
11 / 12 / 04\end{array}$ & 15 & 10 & & 20 & 15 & & & 50 & \\
\hline $\begin{array}{l}76 \text { th } \\
11 / 15 / 04\end{array}$ & 10 & & 20 & 20 & & 50 & \\
\hline $\begin{array}{l}86 \text { th } \\
11 / 16 / 04\end{array}$ & 15 & & & 20 & 15 & & & 50 & \\
\hline $\begin{array}{l}6^{\text {th }} \text { per } \\
\text { totals }\end{array}$ & 50 & 15 & & 40 & 75 & 20 & & 200 & \\
\hline $\begin{array}{l}6^{\text {th }} \text { per } \\
\%\end{array}$ & $25 \%$ & $7 \%$ & $0 \%$ & $20 \%$ & $38 \%$ & $10 \%$ & $0 \%$ & $100 \%$ & \\
\hline $\begin{array}{l}\text { all } 8 \\
\%\end{array}$ & $26 \%$ & $6 \%$ & $3 \%$ & $34 \%$ & $19 \%$ & $7 \%$ & $5 \%$ & $100 \%$ & $0 \%$ \\
\hline
\end{tabular}




\section{Summary Information}

Time Allocation Codes

M- management (travel from previous class, behavior, distribution of papers, administrative information)

F- Free time or down time

D- Discourse (open-ended questions and responses, requests for explanations and reasoning, conjectures and generalizations, discourse on mathematics concepts)

$\mathrm{T}$ - Teacher-centered activities such as notes, procedures, vocabulary, spelling test, demonstrating solutions to problems, reading aloud)

$\mathrm{P}$ - Practice (seatwork, homework)

IA - Individual Activity (problem solving, making graphs, computer lab, manipulatives, modeling, hands-on, calculators)

GA- Group Activity (work with group or partner; problem solving, collect data, manipulatives, modeling, hands-on)

Ma - Percent of time spent on mathematics (not included in 100\% tally)

ST - Percent of time spent on preparing for standardized tests (not included in 100\% tally).

Textbook Use Codes

Tx - Use of School/District Adopted Textbook (Reys, 2004)

A - Comprehensive and trusted authority (what, when, and how to teach)

SS - A scope and sequence guide (what and when to teach)

$\mathrm{R}$ - An occasional or regular resource (homework, tasks, exercises, tests)

$\mathrm{N}$ - Textbook plays no role

Summary Chart for Time Allocations (8 observations, 50 minutes each)

\begin{tabular}{|l|c|c|c|c|c|c|c|c|c|c|c|}
\hline & Ex & M & D & T & P & IA & GA & F & Tx & Ma & ST \\
\hline EA & 3 & $26 \%$ & $10 \%$ & $31 \%$ & $5 \%$ & $21 \%$ & $4 \%$ & $3 \%$ & SS & $71 \%$ & $26 \%$ \\
\hline DB & 3 & $35 \%$ & $0 \%$ & $35 \%$ & $10 \%$ & $9 \%$ & $9 \%$ & $2 \%$ & N & $63 \%$ & $10 \%$ \\
\hline DF & 7 & $11 \%$ & $49 \%$ & $4 \%$ & $1 \%$ & $9 \%$ & $24 \%$ & $2 \%$ & R & $87 \%$ & $0 \%$ \\
\hline JE & 15 & $12 \%$ & $9 \%$ & $4 \%$ & $25 \%$ & $26 \%$ & $24 \%$ & $0 \%$ & R & $88 \%$ & $0 \%$ \\
\hline CI & 7 & $21 \%$ & $12 \%$ & $29 \%$ & $5 \%$ & $18 \%$ & $15 \%$ & $0 \%$ & A & $79 \%$ & $0 \%$ \\
\hline MJ & 8 & $26 \%$ & $3 \%$ & $34 \%$ & $19 \%$ & $7 \%$ & $5 \%$ & $6 \%$ & A & $68 \%$ & $0 \%$ \\
\hline
\end{tabular}


Appendix G; page 1

\title{
APPENDIX G Mathematics Teaching Analysis from 8 Classroom Observations
}

\author{
Characteristics of Mathematics Teaching and Strands of Mathematics Proficiency
}

The following four lists of teaching and learning characteristics, principles, and standards were aligned with the five strands of mathematics proficiency (Kilpatrick, et al., 2001). Items on these lists were then used to create a framework by which observations of the six mathematics teachers of the study were analyzed. One additional category, mathematics as enjoyable was added to the productive disposition strand and included the boy motivators coded in the classroom analysis. See another appendix (Appendix ?) for a list of all the codes used for analysis of the classroom observations. This appendix contains the following lists and tables.

O Four lists of teaching and learning characteristics

O A blank copy of the framework table

O Teacher observation time allocation chart for each teacher (Teachers 1-6)

O A framework table of codes and analysis for each teacher (Teachers 1-6)

0 A summary table for the six teachers with totals for the five strands of mathematics proficiency (Kilpatrick, et al., 2001), along textbook and textbook use information

\section{Lesson Characteristics of Standards-Based Teaching}

(Reys, 2004) S1-9

10. Lessons provided students opportunities to make conjectures about mathematical ideas

11. The lesson fostered the development of conceptual understanding

12. Connections within mathematics were explored in the lesson

13. Connections between mathematics and students daily lives were apparent in the lesson.

14. Students explained their responses or solution strategies

15. Multiple perspectives/strategies were encouraged and valued.

16. The teacher valued students' statements about mathematics and used them to build discussion or work toward shared understandings for the class.

17. The teacher used student inquiries as a guide for instructional decisions or as a guide to shape the mathematical content of the lesson.

18. The teacher encouraged students to reflect on reasonableness of their responses.

Teaching for Mathematics Proficiency and Teacher/Student/Content Triangle (Kilpatrick, Swafford, \& Findell, 2001; Ball \& Cohen, 2000) T1 -T12

Teachers and Content

1. Task selection and use

2. Opportunity to learn

3 Planning 
Teachers and Students

4. Teacher expectations

5. Task value and efficacy

6. Learning community

7. Group vs. whole class activities

8. Assessment of student work

9. Mathematics discourse

$\underline{\text { Students and Content }}$

10. Practice

11. Homework

12. Use of tools CU (manipulatives, computer teaching programs)

13. Use of tools PF (calculators, computer practice programs)

14. Use of tools SC (calculators in problem solving)

Characteristics of Metacognition

M1-7 (Bransford, Brown, \& Cocking, 2000)

8. monitor one's own learning

9. predicting outcomes,

10. targeting misunderstandings

11. activating prior knowledge

12. considering alternative strategies

13. self-regulation; apportionment of time and memory.

14. explaining reasoning

10 Characteristics of NCTM Standards

N1-10 (Ross, McDougall, Hogaboam-Gray, 2002)

The following are a list of chief characteristics of math education reform that emerge from the review and NCTM policy statements

1. Broader scope; increased attention to topics less commonly taught like probability.

2. All students have access to all forms of mathematics, including teaching of complex mathematical (like algebra) ideas to less able students.

3. Student tasks are complex, open-ended problems

4. instruction focuses on construction of mathematical ideas through students' talk rather than transmission through presentation, practice, feedback, and remediation.

5. The teacher's role in reform settings is that of co-learner and creator of a mathematical community rather than sole knowledge expert.

6. Mathematical problems are undertaken in reform classes with the aid of manipulatives and ready access to mathematical tools

7. Student interaction is encouraged rather than discouraged.

8. Assessment is more far-reaching than the unit test at the end of the week. Assessment in a reform classroom includes a wide variety of skills and abilities and is integrated with daily class activities. 
9. The conception of mathematics presented by the teacher is that of an active and dynamic pursuit rather than a fixed body of knowledge

10. Student development of confidence in ability to do mathematics is an important competency in the reformed mathematics classroom.

Framework of Mathematics Proficiency for Observation Analysis

\begin{tabular}{|c|c|}
\hline $\begin{array}{l}\text { Conceptual } \\
\text { Understanding }\end{array}$ & $\begin{array}{l}\text { S2 Conceptual understanding } \\
\text { S7 Value students' statements about mathematics } \\
\text { M3 Target misunderstanding } \\
\text { S8 Student inquiries guide instructional decisions } \\
\text { N4 T9 Construction of mathematical ideas through discourse } \\
\text { M1 Metacognition; monitor one’s own learning }\end{array}$ \\
\hline $\begin{array}{l}\text { Procedural } \\
\text { Fluency }\end{array}$ & $\begin{array}{l}\text { T10 Practice } \\
\text { T11 Homework }\end{array}$ \\
\hline $\begin{array}{l}\text { Strategic } \\
\text { Competence }\end{array}$ & $\begin{array}{l}\text { S1 M2 Make conjectures; predict outcomes } \\
\text { S6 M5 Multiple perspectives/strategies } \\
\text { N9 Mathematics is a dynamic, changing discipline } \\
\text { T1 N3 Task selection and use; complex open-ended tasks } \\
\text { S3, M4 Connections within math; activate prior knowledge }\end{array}$ \\
\hline $\begin{array}{l}\text { Adaptive } \\
\text { Reasoning }\end{array}$ & $\begin{array}{l}\text { S5 M7 Explain Reasoning } \\
\text { S9 Reflect on whether answer reasonable } \\
\text { T7 N7 Group activities; student/student interaction }\end{array}$ \\
\hline $\begin{array}{l}\text { Productive } \\
\text { Disposition }\end{array}$ & $\begin{array}{l}\text { S4 T5 Connections w daily life ; task value } \\
\text { N5 T6 math community; learning community } \\
\text { N10 student confidence; efficacy; } \\
\text { Math is enjoyable (inc. boy motivators) }\end{array}$ \\
\hline $\begin{array}{l}\text { All Strands of } \\
\text { Mathematics } \\
\text { Proficiency }\end{array}$ & $\begin{array}{l}\text { T2 N1 N2 Opp. to learn challenging math; broad scope } \\
\text { T4 High teacher expectations } \\
\text { T3 Teacher planning } \\
\text { N8 T8 An integrated and broad assessment of student work } \\
\text { N6 T12 Use of tools (manipulatives, calculators, computers) } \\
\text { M6 Planning ahead; self-reg; apportion time \& mem. }\end{array}$ \\
\hline
\end{tabular}


O Codings included under the general category for Conceptual Understanding: help individual students

O Codings included under the general category for Procedural Fluency: basic facts; mental math. The Practice number is composed of the percent of time spent on practice plus the number of codings for "math practice" in the observational data.

O Codings included under the general category for Strategic Competence: problem solving, math strategic competence

O Codings included under the general category for Productive Disposition: praise/ encouragement; active learning; variety of activities; productive disposition importance; productive disposition; productive disposition drama; productive disposition jokes.

O Codings included under the general category for all strands: calculator use; manipulatives; alternative assessment

0 The number of codes for groups or partner work was multiplied by 5 to account for student/student interactions not actually recorded

O Coding totals for mathematical discourse were divided by 2 for the three least experienced teachers because their discussions with students were less openended and exhibited fewer of the lesson characteristics (S1-S9, Reys, 2004).

\section{Code Lists for Strands of Mathematics Proficiency}

Conceptual Understanding

Math discourse teacher/student

Math S2 The lesson fostered the development of conceptual understanding

Math S7 The teacher valued students' statements about mathematics and used them to build discussion or work toward shared understandings for the class.

Math S8 The teacher used student inquiries as a guide for instructional decisions or as a guide to shape the mathematical content of the lesson.

Metacognition-misunderstanding

Metacognition

Help individual students

Procedural Fluency

Homework

Math basic facts

Math mental

Math practice

Math procedural fluency

\section{Strategic Competence}

Math problem solving

Math S1 Lessons provided students opportunities to make conjectures about mathematical ideas 
Math S3 Connections within mathematics were explored in the lesson

Math S6 Multiple perspectives/strategies were encouraged and valued.

Math strategic competence

Metacognition- activate prior knowledge

N3 Tasks challenging

Adaptive Reasoning

Math S5 Students explained their responses or solution strategies

Math S9 The teacher encouraged students to reflect on reasonableness of their responses.

Groups or partners ( $x 5$ for student/student discourse)

Productive Disposition

Boy motivators (active learning; big things,tall tales; competition; games; rewards; topic of interest, group recitation)

Learning community

Math S4 Connections between mathematics and students daily lives were apparent in the lesson.

Math self-efficacy

MS variety of activities

N10 Student development of confidence in ability to do mathematics is an important competency in the reformed mathematics classroom.

Praise/encouragement

Productive disposition importance

Productive disposition

Productive disposition drama

Productive disposition jokes

All Strands

Manipulatives

Math calculator use

N6 Mathematical problems are undertaken in reform classes with the aid of manipulatives and ready access to mathematical tools

Planning of teacher

Teacher expectations 
Teacher: Ellen Alcott, $6^{\text {th }}$ at Terre Rouge

Framework of Mathematics Proficiency for Observation Analysis

\begin{tabular}{|c|c|}
\hline $\begin{array}{l}\text { Conceptual } \\
\text { Understanding }\end{array}$ & $\begin{array}{l}\text { S2 } \\
\text { Conceptual understanding } 1 \\
\text { S7 Value students' statements about mathematics } 8 \\
\text { M3 Target misunderstanding } 2 \\
\text { S8 Student inquiries guide instructional decisions } 1 \\
\text { N4 T9 Construction of mathematical ideas through discourse } 9 \\
\text { M1 Metacognition: monitor one’s own learning }\end{array}$ \\
\hline $\begin{array}{l}\text { Procedural } \\
\text { Fluency } 1\end{array}$ & $\begin{array}{l}\text { T10 Practice } 5(\%)+0=5^{1} \\
\text { T11 Homework } 5\end{array}$ \\
\hline $\begin{array}{l}\text { Strategic } \\
\text { Competence }\end{array}$ & $\begin{array}{l}\text { S1 M2 Make conjectures; predict outcomes } 3 \\
\text { S6 M5 Multiple perspectives/strategies } 5 \\
\text { N9 Mathematics is a dynamic, changing discipline } \\
\text { T1 N3 Task selection and use; complex open-ended tasks } 3 \\
\text { S3, M4 Connections within math; activate prior knowledge } 1\end{array}$ \\
\hline $\begin{array}{l}\text { Adaptive } \\
\text { Reasoning }\end{array}$ & $\begin{array}{l}\text { S5 M7 Explain Reasoning } 3 \\
\text { S9 Reflect on whether answer reasonable } 1 \\
\text { T7 N7 Group activities; student/student interaction }\end{array}$ \\
\hline $\begin{array}{l}\text { Productive } \\
\text { Disposition }\end{array}$ & $\begin{array}{l}\text { S4 T5 Connections with daily life; task value } 2 \\
\text { N5 T6 Math community; learning community } \\
\text { N10 Student confidence; efficacy } 1 \\
\text { Math is enjoyable (inc. boy motivators) } 3\end{array}$ \\
\hline $\begin{array}{l}\text { All Strands of } \\
\text { Mathematics } \\
\text { Proficiency }\end{array}$ & $\begin{array}{l}\text { T2 N1 N2 Opp. to learn challenging math; broad scope } \\
\text { T4 High teacher expectations } \\
\text { T3 Teacher planning } \\
\text { N8 T8 An integrated and broad assessment of student work } 2 \\
\text { N6 T12 Use of tools (manipulatives, calculators, computers) } \\
\text { M6 Planning ahead; self-reg; apportion time \& mem. }\end{array}$ \\
\hline
\end{tabular}

Total score 56

Notes:

1. Ms. Alcott spent $5 \%$ of class time in practice and no codings for math practice $(5+0=5)$ 
Teacher: David Blake $7^{\text {th }}$ at Terre Rouge

Framework of Mathematics Proficiency for Observation Analysis

\begin{tabular}{|c|c|}
\hline $\begin{array}{l}\text { Conceptual } \\
\text { Understanding } 6\end{array}$ & $\begin{array}{l}\text { S2 } \\
\text { S7 Conceptual understanding } \\
\text { S7 Value students' statements about mathematics } \\
\text { M3 Target misunderstanding } \\
\text { S8 Student inquiries guide instructional decisions 2 } \\
\text { N4 T9 Construction of mathematical ideas through discourse } 1 \\
\text { M1 Metacognition; monitor one’s own learning }\end{array}$ \\
\hline $\begin{array}{l}\text { Procedural } \\
\text { Fluency } 5\end{array}$ & $\begin{array}{l}\text { T10 Practice } 10(\%)+4=14^{1} \\
\text { T11 Homework } 6\end{array}$ \\
\hline $\begin{array}{l}\text { Strategic } \\
\text { Competence }\end{array}$ & $\begin{array}{l}\text { S1 M2 Make conjectures; predict outcomes } \\
\text { S6 M5 Multiple perspectives/strategies } 4 \\
\text { N9 Mathematics is a dynamic, changing discipline } \\
\text { T1 N3 Task selection and use; complex open-ended tasks } 2 \\
\text { S3, M4 Connections within math; activate prior knowledge }\end{array}$ \\
\hline $\begin{array}{l}\text { Adaptive } \\
\text { Reasoning }\end{array}$ & $\begin{array}{l}\text { S5 M7 Explain Reasoning } \\
\text { S9 Reflect on whether answer reasonable } \\
\text { T7 N7 Group activities; student/student interaction } 10^{2}\end{array}$ \\
\hline $\begin{array}{l}\text { Productive } \\
\text { Disposition }\end{array}$ & $\begin{array}{l}\text { S4 T5 Connections with daily life; task value } \\
\text { N5 T6 Math community; learning community } \\
\text { N10 Student confidence; efficacy } 2 \\
\text { Math is enjoyable (inc. boy motivators) } 10\end{array}$ \\
\hline $\begin{array}{l}\text { All Strands of } \\
\text { Mathematics } \\
\text { Proficiency }\end{array}$ & $\begin{array}{l}\text { T2 N1 N2 Opp. to learn challenging math; broad scope } \\
\text { T4 High teacher expectations } 5^{3} \\
\text { T3 Teacher planning } \\
\text { N8 T8 An integrated and broad assessment of student work } 2 \\
\text { N6 T12 Use of tools (manipulatives, calculators, computers) } \\
\text { M6 Planning ahead; self-reg; apportion time \& mem. }\end{array}$ \\
\hline
\end{tabular}

Total score 69

1. $10 \%$ of class time spent on practice and 4 codings for math practice $(10+4=14)$. 2. Multiply five times number of codings to account for student/student interactions not recorded.

3. Additional evidence of high expectations from and student interviews. 
Teacher: Darrell Fisher, $6^{\text {th }}$ at Greenville

Framework of Mathematics Proficiency for Observation Analysis

\begin{tabular}{|c|c|}
\hline $\begin{array}{l}\text { Conceptual } \\
\text { Understanding } 5\end{array}$ & 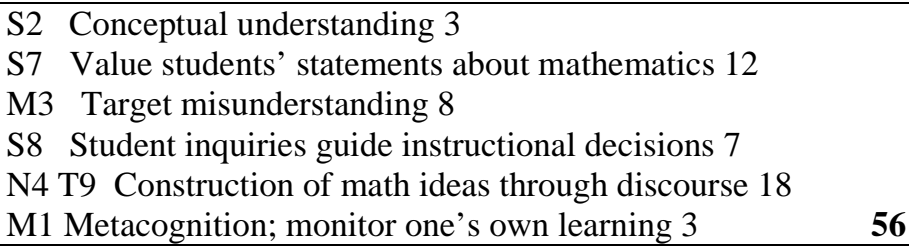 \\
\hline $\begin{array}{l}\text { Procedural } \\
\text { Fluency } 17\end{array}$ & $\begin{array}{l}\text { T10 Practice } 2(\%)+3=5^{1} \\
\text { T11 Homework } 9\end{array}$ \\
\hline $\begin{array}{l}\text { Strategic } \\
\text { Competence } 17\end{array}$ & $\begin{array}{l}\text { S1 M2 Make conjectures; predict outcomes 3 } \\
\text { S6 M5 Multiple perspectives/strategies } 16 \\
\text { N9 Mathematics is a dynamic, changing discipline } \\
\text { T1 N3 Task selection and use; complex open-ended tasks } 7 \\
\text { S3, M4 Connections within math; activate prior knowledge } 11\end{array}$ \\
\hline $\begin{array}{l}\text { Adaptive } \\
\text { Reasoning }\end{array}$ & $\begin{array}{l}\text { S5 M7 Explain Reasoning } 19 \\
\text { S9 Reflect on whether answer reasonable } 13 \\
\text { T7 N7 Group activities; student/student interaction } 20^{2}\end{array}$ \\
\hline $\begin{array}{l}\text { Productive } \\
\text { Disposition } 12\end{array}$ & $\begin{array}{l}\text { S4 T5 Connections with daily life; task value } 20 \\
\text { N5 T6 Math community; learning community } \\
\text { N10 Student confidence; efficacy } 12 \\
\text { Math is enjoyable (inc. boy motivators) } 58\end{array}$ \\
\hline $\begin{array}{l}\text { All Strands of } \\
\text { Mathematics } \\
\text { Proficiency }\end{array}$ & $\begin{array}{l}\text { T2 N1 N2 Opp. to learn challenging math; broad scope } \\
\text { T4 High teacher expectations } 1 \\
\text { T3 Teacher planning } 9 \\
\text { N8 T8 An integrated and broad assessment of student work } \\
\text { N6 T12 Use of tools (manipulatives, calculators, computers) } \\
\text { M6 Planning ahead; self-reg; apportion time \& mem. }\end{array}$ \\
\hline
\end{tabular}

Total score 305

1. $2 \%$ of class time spent on practice and 3 codings for math practice $(2+3=5)$.

2. Multiply five times number of codings (4) to account for student/student interactions not recorded. 
Teacher: Julia Edwards, $7^{\text {th }}$ at Greenville

Framework of Mathematics Proficiency for Observation Analysis

\begin{tabular}{|c|c|}
\hline $\begin{array}{l}\text { Conceptual } \\
\text { Understanding } \\
\quad 14\end{array}$ & $\begin{array}{l}\text { S2 } \\
\text { S7 } \text { Valueptual understanding } 6 \\
\text { M3 Target misunderstanding } 7 \\
\text { S8 Student inquiries guide instructional decisions } 2 \\
\text { N4 T9 Construction of math. ideas through discourse } 23 \\
\text { M1 Metacognition; monitor one’s own learning }\end{array}$ \\
\hline $\begin{array}{l}\text { Procedural } \\
\text { Fluency } 6\end{array}$ & $\begin{array}{l}\text { T10 Practice } 37^{1} \\
\text { T11 Homework } 11\end{array}$ \\
\hline $\begin{array}{l}\text { Strategic } \\
\text { Competence } \\
\quad 1\end{array}$ & $\begin{array}{l}\text { S1 M2 Make conjectures; predict outcomes } \\
\text { S6 M5 Multiple perspectives/strategies } 8 \\
\text { N9 Mathematics is a dynamic, changing discipline } \\
\text { T1 N3 Task selection and use; complex open-ended tasks } 1 \\
\text { S3, M4 Connections within math; activate prior knowledge } 1\end{array}$ \\
\hline $\begin{array}{l}\text { Adaptive } \\
\text { Reasoning }\end{array}$ & $\begin{array}{l}\text { S5 M7 Explain Reasoning } 16 \\
\text { S9 Reflect on whether answer reasonable } 3 \\
\text { T7 N7 Group activities; student/student interaction } 10^{2}\end{array}$ \\
\hline $\begin{array}{l}\text { Productive } \\
\text { Disposition } \\
\quad 22\end{array}$ & $\begin{array}{l}\text { S4 T5 Connections with daily life; task value } 2 \\
\text { N5 T6 Math community; learning community } 1 \\
\text { N10 Student confidence; efficacy } 10 \\
\text { Math is enjoyable (inc. boy motivators) } 33\end{array}$ \\
\hline $\begin{array}{l}\text { All Strands of } \\
\text { Mathematics } \\
\text { Proficiency }\end{array}$ & $\begin{array}{l}\text { T2 N1 N2 Opp. to learn challenging math; broad scope } \\
\text { T4 High teacher expectations } 8^{3} \\
\text { T3 Teacher planning } \\
\text { N8 T8 An integrated and broad assessment of student work } 7 \\
\text { N6 T12 Use of tools (manipulatives, calculators, computers) } 3 \\
\text { M6 Planning ahead; self-reg; apportion time \& mem. }\end{array}$ \\
\hline
\end{tabular}

Total score 234

1. $25 \%$ of class time spent on practice plus 12 coded items $(25+12=37)$.

2. Five times the number of codes $(2)=10$.

3. From interviews and talk of "being successful" 
Teacher: Christine Ingram, $6^{\text {th }}$ at Bluefield

Framework of Mathematics Proficiency for Observation Analysis

\begin{tabular}{|c|c|}
\hline $\begin{array}{l}\text { Conceptual } \\
\text { Understanding }\end{array}$ & $\begin{array}{l}\text { S2 } \text { Conceptual understanding } 4 \\
\text { S7 Value students' statements about mathematics } 7 \\
\text { M3 Target misunderstanding } 3 \\
\text { S8 Student inquiries guide instructional decisions } 5 \\
\text { N4 T9 Construction of math.ideas through discourse } 16 \\
\text { M1 Metacognition; monitor one's own learning } 8\end{array}$ \\
\hline $\begin{array}{l}\text { Procedural } \\
\text { Fluency } 8\end{array}$ & $\begin{array}{l}\text { T10 Practice } 10^{1} \\
\text { T11 Homework } 9\end{array}$ \\
\hline $\begin{array}{l}\text { Strategic } \\
\text { Competence } \\
2\end{array}$ & $\begin{array}{l}\text { S1 M2 Make conjectures; predict outcomes } 1 \\
\text { S6 M5 Multiple perspectives/strategies } 12 \\
\text { N9 Mathematics is a dynamic, changing discipline } \\
\text { T1 N3 Task selection and use; complex open-ended tasks } 1 \\
\text { S3, M4 Connections within math; activate prior knowledge } 1\end{array}$ \\
\hline $\begin{array}{l}\text { Adaptive } \\
\text { Reasoning }\end{array}$ & $\begin{array}{l}\text { S5 M7 Explain Reasoning } 14 \\
\text { S9 Reflect on whether answer reasonable } \\
\text { T7 N7 Group activities; student/student interaction } 15^{2}\end{array}$ \\
\hline $\begin{array}{l}\text { Productive } \\
\text { Disposition }\end{array}$ & $\begin{array}{l}\text { S4 T5 Connections with daily life; task value } \\
\text { N5 T6 Math community; learning community } \\
\text { N10 Student confidence; efficacy } 2 \\
\text { Math is enjoyable (inc. boy motivators) } 12\end{array}$ \\
\hline $\begin{array}{l}\text { All Strands of } \\
\text { Mathematics } \\
\text { Proficiency }\end{array}$ & $\begin{array}{l}\text { T2 N1 N2 Opp. to learn challenging math; broad scope } \\
\text { T4 High teacher expectations } \\
\text { T3 Teacher planning } \\
\text { N8 T8 An integrated and broad assessment of student work } \\
\text { N6 T12 Use of tools (manipulatives, calculators, computers) } 6 \\
\text { M6 Planning ahead; self-reg; apportion time \& mem. }\end{array}$ \\
\hline
\end{tabular}

Total score 136

1. $5 \%$ of class time spent on practice plus 5 coded items $(5+5=10)$.

2. Five times the number of codes $(3)=15$ 
Teacher: Melanie Jones, $7^{\text {th }}$ at Bluefield

Framework of Mathematics Proficiency for Observation Analysis

\begin{tabular}{|c|c|}
\hline $\begin{array}{l}\text { Conceptual } \\
\text { Understanding } \\
\quad 2\end{array}$ & 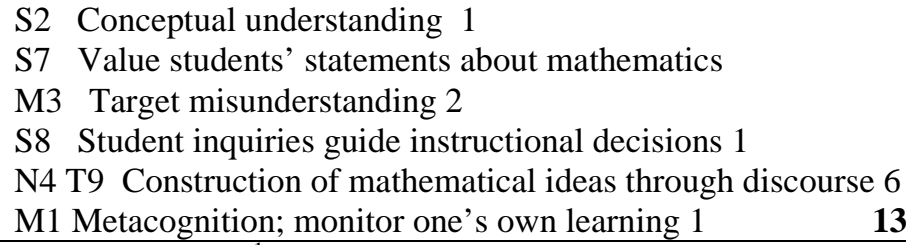 \\
\hline $\begin{array}{l}\text { Procedural } \\
\text { Fluency } 2\end{array}$ & $\begin{array}{l}\text { T10 Practice } 22^{1} \\
\text { T11 Homework } 11\end{array}$ \\
\hline $\begin{array}{l}\text { Strategic } \\
\text { Competence } \\
\quad 1\end{array}$ & $\begin{array}{l}\text { S1 M2 Make conjectures; predict outcomes } 1 \\
\text { S6 M5 Multiple perspectives/strategies } 2 \\
\text { N9 Mathematics is a dynamic, changing discipline } \\
\text { T1 N3 Task selection and use; complex open-ended tasks } \\
\text { S3, M4 Connections within math; activate prior knowledge }\end{array}$ \\
\hline $\begin{array}{l}\text { Adaptive } \\
\text { Reasoning }\end{array}$ & $\begin{array}{l}\text { S5 M7 Explain Reasoning } 1 \\
\text { S9 Reflect on whether answer reasonable } \\
\text { T7 N7 Group activities; student/student interaction } 5\end{array}$ \\
\hline $\begin{array}{l}\text { Productive } \\
\text { Disposition } \\
5\end{array}$ & $\begin{array}{l}\text { S4 T5 Connections with daily life; task value } \\
\text { N5 T6 Math community; learning community } \\
\text { N10 Student confidence; efficacy } 6 \\
\text { Math is enjoyable (inc. boy motivators) } 5\end{array}$ \\
\hline $\begin{array}{l}\text { All Strands of } \\
\text { Mathematics } \\
\text { Proficiency }\end{array}$ & $\begin{array}{l}\text { T2 N1 N2 Opp. to learn challenging math; broad scope } \\
\text { T4 High teacher expectations } \\
\text { T3 Teacher planning } \\
\text { N8 T8 An integrated and broad assessment of student work } \\
\text { N6 T12 Use of tools (manipulatives, calculators, computers) } 4 \\
\text { M6 Planning ahead; self-reg; apportion time \& mem. }\end{array}$ \\
\hline
\end{tabular}

Total score 78

1. $19 \%$ of class time spent on practice plus 3 coded items $(19+3=22)$.

2. Five times the number of codes $(1)=5$ 
Teacher Totals for the Strands of Mathematics Proficiency (Kilpatrick, et al., 2001)

\begin{tabular}{|l|c|c|c|c|c|c|c|c|}
\hline \multicolumn{1}{|c|}{ Teacher } & $\begin{array}{c}\text { Yrs. } \\
\text { Exp. }\end{array}$ & CU & PF & SC & AR & PD & $\begin{array}{c}\text { All } \\
\text { Strands }\end{array}$ & Total \\
\hline Ms. Alcott 6 $6^{\text {th }}(\mathrm{T})$ & 3 & 21 & 11 & 12 & 4 & 6 & 2 & 56 \\
\hline Mr. Blake $7^{\text {th }}(\mathrm{T})$ & 3 & 9 & 25 & 6 & 10 & 12 & 7 & 69 \\
\hline Mr. Fisher $6^{\text {th }}(\mathrm{G})$ & 7 & 56 & 31 & 54 & 52 & 102 & 10 & 305 \\
\hline Ms.Edwards $7^{\text {th }}(\mathrm{G})$ & 15 & 54 & 54 & 11 & 29 & 68 & 18 & 234 \\
\hline Ms. Ingram $6^{\text {th }}(\mathrm{B})$ & 7 & 43 & 27 & 17 & 29 & 14 & 6 & 136 \\
\hline Ms. Jones $7^{\text {th }}(\mathrm{B})$ & 8 & 13 & 35 & 4 & 6 & 16 & 4 & 78 \\
\hline
\end{tabular}


Appendix H; page 1

\title{
APPENDIX $\mathrm{H}$ \\ Categorization of Mathematics Teaching Practice
}

\author{
Criteria for the Categorization of Teachers' Mathematics Teaching Practice
}

(Raymond, 1997)

Traditional

- The teacher instructs solely from the textbook. (Jones $5^{\text {th }}$ )

- The teacher follows the lesson plan rigidly.

- The teacher approaches mathematics topics in isolation. (Alcott $5^{\text {th }}$, Blake $5^{\text {th }}$, Jones $4^{\text {th }}$ )

- The teacher approaches mathematics instruction in the same pattern daily.

- The teacher has students engage only in individual paper-and-pencil tasks.

- The teacher creates an environment in which students are passive learners.

- The teacher poses question in search of specific, predetermined responses. (Blake $4^{\text {th }}$, Jones $3^{\text {rd }}$ )

- The teacher allows no student-to-student interactions. (Alcott $4^{\text {th }}$ )

- The teacher evaluates students solely via exams seeking "right answers."

Primarily Traditional

- The teacher instructs primarily from the textbook with occasional diversions from the text. (Ingram $5^{\text {th }}$ )

- The teacher creates and environment in which students are passive learners, occasionally calling on them to play a more active role. (Alcott $3^{\text {rd }}$, Blake $3^{\text {rd }}$, Jones $2^{\text {nd }}$ )

- The teacher primarily evaluates students through standard quizzes and exams, only occasionally using other means.

- The teacher primarily encourages teacher-directed discourse, only occasionally allowing for student-directed interactions. (Alcott $2^{\text {nd }}$, Blake $2^{\text {nd }}$, Ingram $4^{\text {th }}$, Jones $1^{\text {st }}$ )

Even Mix of Traditional and Non-Traditional

- The teacher teaches equally from textbook and problem-solving activities. (Edwards $5^{\text {th }}$, Blake $1^{\text {st }}$, Alcott $1^{\text {st }}$ )

- The teacher creates a learning environment that at times allows students to be passive learners and at times active explorers. (Ingram $3^{\text {rd }}$ )

- The teacher evaluates students' learning through standard quizzes and exams and alternative means, such as observations and writing.

- The teacher encourages teacher directed and student directed discourse. (Edwards $4^{\text {th }} ;$ Ingram, $2^{\text {nd }}$ ) 
Primarily Non-Traditional

- The teacher primarily engages students in problem-solving tasks. (Fisher $5^{\text {th }}$ )

- The teacher primarily presents an environment in which students are to be active learners, occasionally having them play a more passive role. (Fisher $4^{\text {th }}$, Edwards $3^{\text {rd }}$, Ingram $1^{\text {st }}$ )

- The teacher primarily evaluates students using means beyond standard exams.

- The teacher encourages mostly student-directed discourse.

Non-Traditional

- The teacher solely provides problem solving tasks.

- The teacher selects tasks based on students' interests and experiences. (Fisher $3^{\text {rd }}$ )

- The teacher selects tasks that stimulate students to make connections. (Fisher $2^{\text {nd }}$ )

- The teacher selects tasks that promote communication about mathematics.

- The teacher creates an environment that reflects respect for student ideas and structures the time necessary to grapple with these ideas and problems. (Edwards, $2^{\text {nd }}$ )

- The teacher poses questions that challenge and engage student thinking.

- The teacher has students clarify and justify their ideas orally and in writing.

- The teacher has the students work cooperatively, encouraging communication. (Fisher $1^{\text {st }}$ )

- The teacher observes and listens to students to assess learning. (Edwards $1^{\text {st }}$ )

\section{$\underline{\text { Ratings }}$}

Ellen Alcott: $1-1-2-2-3$; median $=2$; Primarily Traditional

David Blake: $1-1-2-2-3$; median $=2$; Primarily Traditional

Darrell Fisher: $5-5-5-4-4$; median $=5$; Non-Traditional

Julia Edwards: $5-5-4-3-3$; median $=4$; Primarily Non-Traditional

Christine Ingram: $4-3-3-2-2$; median $=3$; Even Mix

Melanie Jones: $1-1-1-2-2$; median $=1$; Traditional 
APPENDIX I

Human Studies Committee Approval Form

(Attach copy of HSC acceptance memo dated 8/19/04 here) 


\title{
Curriculum Vitae Amanda Neel Davis
}

\author{
2100 Ohio Blvd., Terre Haute, IN 47803 \\ Telephone: 812-235-7026 Email: amandand@verizon.net
}

Education: B.A. mathematics: Hollins College (Roanoke, VA).

M.S. mathematics: University of Alabama at Birmingham.

Ph. D.(December 15, 2005) Curriculum and Instruction, Mathematics Education; College of Education and Human Development, University of Louisville.

Dissertation: "All-Boy Mathematics Classes in Middle School" Successfully defended November 15, 2005

\author{
University Teaching Experience \\ Spring 2003 University Coordinator for M.A.T. candidate's student teaching course, University \\ of Louisville. \\ Fall 2002 Instructor, Middle and Secondary Mathematics Methods (graduate course), \\ University of Louisville. \\ Spring 2003 Guest Instructor, Research Methods in Education and Design of Experiments \\ (two doctoral courses), University of Louisville. \\ Fall 1985 Instructor, Pre-calculus mathematics, University of Alabama in Birmingham. \\ 1976-1977 Instructor, Pre-calculus mathematics, University of Alabama in Birmingham. \\ Secondary/Middle School Teaching Experience \\ (Currently certified for teaching 7-12 mathematics in Kentucky) \\ 2000-2004 Substitute teacher for Jefferson County Public Schools (Louisville, KY). \\ 2000-2004 Tutor for high school students: Algebra II, Pre-Calculus, AP Calculus AB. \\ May 2001 Mathematics teacher, Atherton High School (Louisville, KY): long-term substitute \\ for teacher who resigned, Algebra 2. \\ March 2001 Mathematics teacher, Trinity High School (Louisville,KY): long-term substitute for \\ teacher having back surgery, BC Calculus, Geometry, and Algebra 2. \\ 1999-2000 Mathematics teacher, Assumption High School (Louisville, KY): Advanced \\ Placement Calculus, College Placement Calculus, Algebra 2, Algebra 1. \\ 1998-1999 Mathematics teacher, St. Martha School (Louisville, KY): Algebra I, Math 8, Math \\ 7 , Social Studies $7,8^{\text {th }}$ grade homeroom. \\ 1990-1992 Mathematics teacher, Altamont School (Birmingham, AL): Geometry. \\ 1977-1981 Mathematics teacher, Altamont School (Birmingham, AL): Calculus, Pre- \\ Calculus, Algebra 1, Algebra 2, Geometry, Math 8. \\ 1972-1973 Mathematics teacher, St. James School (Montgomery, AL): Algebra 1, Math 8.
}


$1970-1972$

Mathematics teacher, St. Anne's-Belfield School (Charlottesville, VA): Geometry, Algebra 1, Math 8.

\section{Academic Administration Experience}

1990-1997 Alumni Director and Director of Development, Altamont School (Birmingham,

$A L)$.

\section{Grants and Scholarships Received}

2003-2004 \$50,000 from the Kentucky Department of Education, for a summer teacher academy.

$2003 \$ 1,100$ (2 grants of $\$ 500$ and $\$ 600$ for research) from the College of Education and Human Development (CEHD), University of Louisville.

\section{Research Projects (and work on other grants)}

2002-2004 Researcher, Diagnostic Teacher Assessment of Mathematics and Science, a project of the Center for Research in Mathematics and Science Teacher Development (CRMSTD); Dr. William S. Bush, Director; University of Louisville.

2002- 2004 Researcher, Single-Sex Class Study, Southern Leadership Academy (Louisville, KY).

Spring 2004 Researcher, Kids Now Evaluation Project; University of Louisville.

Summer 2003 Consultant, Commonwealth Center for Instructional Technology and Learning Project (CCITL); University of Kentucky.

2001-2002 Researcher, Early Mathematics Project, a project of the Early Childhood Research Center (ECRC); Dr. Victoria Molfese, Director; University of Louisville.

\section{Papers I Presentations}

April $2006 \quad$ "All-Boy Mathematics Classes in Middle School" (proposal accepted) paper presented at the Research Pre-Session of the annual conference of the National Council for the Teachers of Mathematics. St. Louis, MO, April 23-26.

April $2006 \quad$ "Three Schools, Six Teachers, and One Intervention," (proposal accepted as part of a symposium on gender issues in education), paper presented at the annual meeting of American Educational Research Association, San Francisco, CA, April 7-11, 2006

October 2005 "What about the boys?" paper presented at the annual conference of the National Association of Single-Sex in Public Education, Cincinnati, OH, October 8-10, 2005.

Dec 2004 Davis, A. \& Brown, S. "Teaching Boys and Teaching Girls: Structures, Strategies, and Learning", presentation for teachers at Southern Leadership Academy, Louisville, KY.

Sept. 2004 Davis, A. \& Brown, S. "Teaching Boys: Structures, Strategies, and Learning", presentation for teachers at Clarksville Middle School, Clarksville, Indiana.

June 2004 Davis, A. "Teaching Single-Sex Mathematics Classes in Middle School," paper presented at the Ethnographic and Qualitative Research in Education conference, State University of New York, Albany.

April 2004 Davis, A.; Choi, N., Ronau, R., \& Muñoz, M. "Single-Sex Education and SelfEfficacy at an Urban Middle School", paper presented at the annual meeting of American Educational Research Association, San Diego, CA. 
April 2004 Davis, A. "Single-Sex Classes in an Urban Middle School: The Pilot Year," paper presented at the Spring Research Conference, University of Kentucky.

Oct. 2003 Davis, A. "Single-Sex Classes in an Urban Middle School: The Pilot Year," paper presented at the annual meeting of the Mid-Western Educational Research Association, Columbus, $\mathrm{OH}$.

Sept. 2003 Davis, A. "Single-Sex Classes at Southern Leadership Academy," presentation to school faculty about findings of my surveys, interviews and observations.

Sept. 2003 Davis, A. \& Bush, W. "The Case for Manipulatives and Rational Numbers," research report for ETA/Cuisenaire.

June 2003 Davis, A. "Effects of Single Gender Classes in an Urban Middle School," paper presented at Ethnographic and Qualitative Research in Education conference; Duquesne University, (Pittsburgh, PA).

April 2003 Davis, A. "Effects of Single Gender Classes in an Urban Middle School," paper presented at the Spring Research Conference, University of Louisville.

April 2002 Davis, A. Wright, W., \& Choi, N. "Self-Efficacy and Academic Self-Concept among Graduate Students", paper presented at the Spring Research Conference, University of Cincinnati.

March 2002 Davis, A. \& Brown, E. "The Calculator-Based Laboratory: Using the Light Probe and the Ranger," presentation to Gear-Up Program, University of Louisville.

\section{Professional Development}

May 2003 Hierarchical Linear Modeling seminar, University of Chicago.

2001- 2002 Future Professors Program, University of Louisville.

July 2000 Summer Institute, "The Art and Craft of Principalship," Harvard Graduate School of Education.

\section{Publications}

Spring 2004 Author of selected definitions, The Greenwood Dictionary of Education. (2003). John W. Collins, III \& Nancy P. O'Brien (Eds.). Westport, CT: Greenwood Press.

\section{Service}

2002-2004 Graduate Student Association of CEHD, University of Louisville; Teaching and Learning Representative, 2002-2003; Vice-President, 2003-2004.

Fall 2003 Author of unpublished booklet, "Teaching Boys and Teaching Girls," distributed to teachers and principals interested in single-sex education.

2002-2004 Research and Faculty Development Committee, CEHD, University of Louisville.

Spring 2002 Search Committee for Assistant Professor of Early Childhood Education, University of Louisville.

2001-2004 Peer tutoring, statistics and research methods.

2001-2002 Mathematics tutoring for the GED; Ahrens Adult Education Center, Jefferson County Public Schools, Louisville, KY. 


\section{References}

Dr. William S. Bush

Dr. Namok Choi

Dr. Louis Dale

Dr. Richard M. Davitt

Dr. Robert N. Ronau
Professor of Mathematics Education and Director of Center for Research in Mathematics and Science Teacher Development; College of

Education and Human Development; University of Louisville; Louisville, KY 40292:

502-852-0590; bill.bush@louisville.edu.

Associate Professor, Department of Leadership, Foundations, and Human Resource Education; College of Education and Human Development; University of Louisville; Louisville, KY 40292; 502-8524014; namok@louisville.edu.

Professor of Mathematics and Vice President for Equity and Diversity; University of Alabama at Birmingham; $15303^{\text {rd }}$ Ave. S, CH401;

Birmingham, AL 35294-1170; 205-934-8762;Idale@provost.uab.edu or Idale@uab.edu

Professor of Mathematics; Department of Mathematics; University of Louisville, Louisville, KY 40292; 502-852-6356; davitt@louisville.edu

Professor of Mathematics Education and Associate Dean for Research; College of Education and Human Development; University of Louisville; Louisville, KY; 40292; 502-852-0593; bob@louisville.edu 